UNIVERSIDADE DE SÃO PAULO

PROGRAMA DE PÓS-GRADUAÇÃO EM ENERGIA

CARLOS CEZAR DA SILVA

A ATRIBUIÇÃO DE CUSTOS EM SISTEMAS ENERGÉTICOS AGROPECUÁRIOS: UMA ANÁLISE EM EMERGIA, TERMOECONOMIA E ECONOMIA 
CARLOS CEZAR DA SILVA

\section{A ATRIBUIÇÃO DE CUSTOS EM SISTEMAS ENERGÉTICOS AGROPECUÁRIOS: UMA ANÁLISE EM EMERGIA, TERMOECONOMIA E ECONOMIA}

Tese apresentada ao Programa de PósGraduação em Energia da Universidade de São Paulo - USP. (Escola Politécnica / Faculdade de Economia e Administração / Instituto de Eletrotécnica e Energia / Instituto de Física) para a obtenção do título de Doutor em Energia.

Orientador: Prof. Dr. José Aquiles Baesso Grimoni. 
AUTORIZO A REPRODUÇÃO E DIVULGAÇÃO TOTAL OU PARCIAL DESTE TRABALHO, POR QUALQUER MEIO CONVENCIONAL OU ELETRÔNICO, PARA FINS DE ESTUDO E PESQUISA, DESDE QUE CITADA A FONTE.

FICHA CATALOGRÁFICA

Silva, Carlos Cezar da

A Atribuição de custos em sistemas energéticos agropecuários: uma Análise em emergia, termoeconomia e economia/ Carlos Cezar da Silva; orientador prof. Dr. José Aquiles Baesso Grimoni.-São Paulo, 2009.

156 p.: il.; $30 \mathrm{~cm}$.

Tese (Doutorado - Programa de Pós-Graduação em Energia)

EP / FEA / IEE / IF da Universidade de São Paulo.

1. Emergia 2. Termoeconomia 3. Análise

Econômica-financeira 4. Biossistemas 5. Energia. 


\section{DEDICATÓRIA}

Dedico este trabalho

Dedico este trabalho aos meus filhos, Cezar e Adrielle e a todas as grandes mentes de hoje e sempre, que através de seus estudos permitem que a humanidade se apóie em seus ombros, e desta forma, enxerguem um pouco mais além. 


\section{AGRADECIMENTOS}

À Deus pelo privilégio da Vida e por criar todos os Fenômenos da Natureza.

À minha mãe, Maria Aparecida Pavan, pelo exemplo, companheirismo e amor.

À minha esposa Geslaine, por me ouvir muito durante a elaboração deste estudo.

Ao Prof. Dr. José Aquiles Baesso Grimoni, pela grata oportunidade de tê-lo tido como orientador, pelo apoio e paciência no decorrer deste curso de doutorado.

À Prof ${ }^{a}$ Dra. Cecília M. V. B. de Almeida, que em sua imensa generosidade, competência e profissionalismo contribuiu com críticas, observações e incentivos além do esperado na elaboração deste trabalho. Orgulho-me por ter sido merecedor de tão grande confiança, apoio e amizade.

A Profa . Dra. Patrícia Helena Lara Santos Matai, pelas sugestões sempre pertinentes no aprimoramento deste trabalho.

Pelos grandes ensinamentos do mestre Prof. Dr. Biagio Fernando Giannetti, cujo trabalho motivou e forneceu bases sólidas para o desenvolvimento deste estudo.

Ao Prof. Dr. Gilberto Martins, por acreditar e me apoiar desde a graduação.

Ao Prof. Dr. Marcelo Modesto da Silva, por sua contribuição neste trabalho.

A Profa . Virgínia Parente, pela disponibilidade e acompanhamento nos cálculos de economia deste trabalho.

Ao Engenheiro Humberto de A. Pizza da Silva, pelo apoio e acompanhamento. À minha família, suporte maior, apoio, colaboração, amor e pelas horas de ausência e presença que souberam suportar.

Aos colegas de curso, que através de suas sugestões possibilitaram um aprendizado em conjunto.

Aos funcionários da biblioteca do IEE, pelo pronto atendimento durante minhas visitas, na busca de conhecimento em seu acervo.

Ao Instituto de Eletrotécnica e Energia, pela oportunidade da realização do curso.

A todas as instituições e pessoas que contribuíram direta ou indiretamente para a realização deste trabalho. 
"Lembre-se que da conduta de cada um depende 0 destino de todos."

Alexandre, o Grande 


\section{Sumário}

Lista de Tabelas .................................................................................. vii

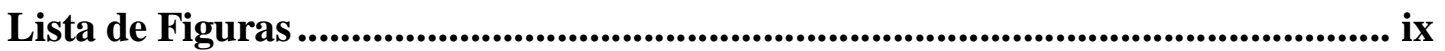

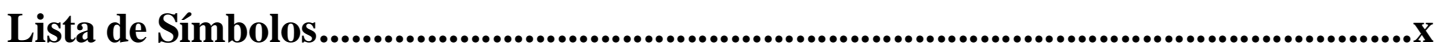

Lista de A breviações........................................................................... xiii

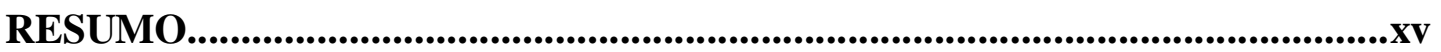

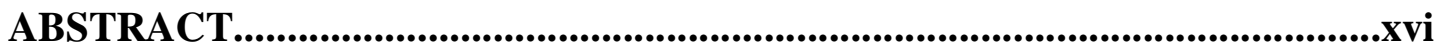

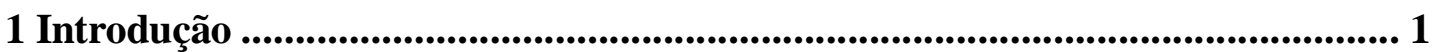

1.1. O uso da energia pelo homem............................................................. 1

1.2. A geração de eletricidade a partir de fontes renováveis ................................ 2

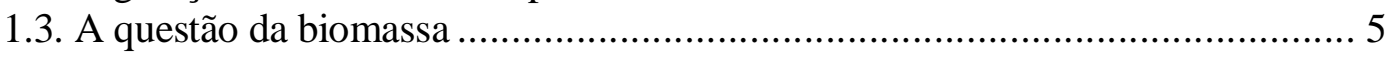

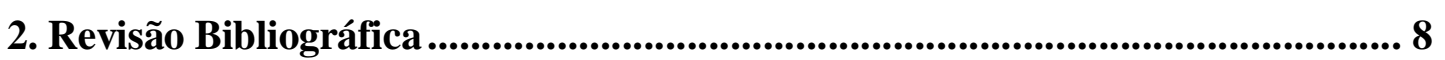

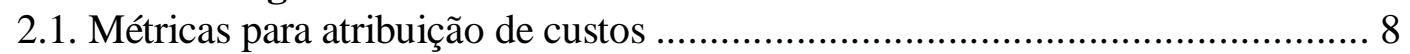

2.2. Sustentabilidade no meio rural................................................................... 9

2.3. A produção de eletricidade a partir da biomassa da cana-de-açúcar no Brasil ..10

2.4. A produção de eletricidade a partir da biomassa do gado ................................12

2.5. A produção de eletricidade a partir de biomassa suína ....................................14

2.6. Trabalhos da literatura relativos à avaliação de sistemas de cogeração com biomassa

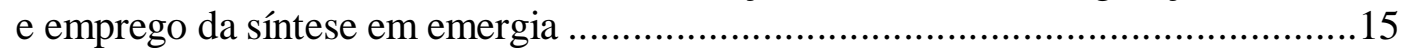

2.7. Trabalhos da literatura relativos à avaliação de sistemas de cogeração com biomassa

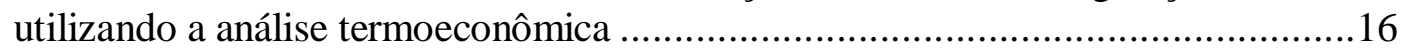

2.8. Trabalhos da literatura relativos à avaliação de sistemas de cogeração com biomassa

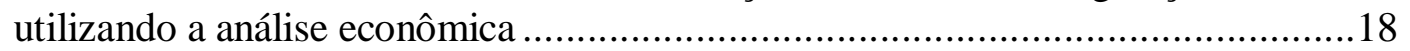

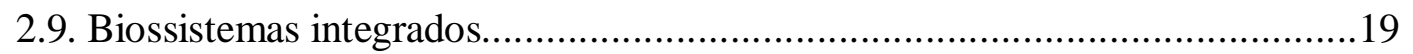

2.9.1. Definição de biossistemas integrados ................................................. 19

2.9.2. Modelos brasileiros de biossistemas integrados ...................................20

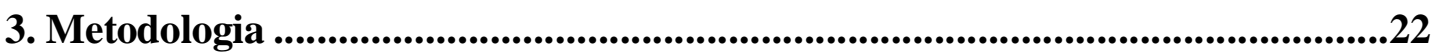

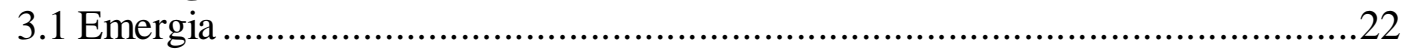

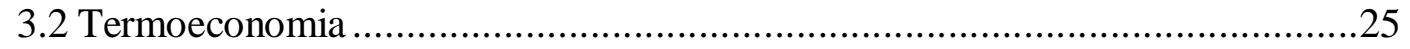

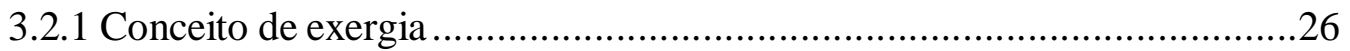

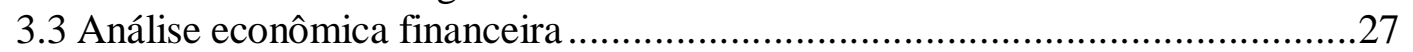

4. Descrição dos sistemas utilizados no estudo ...................................................28

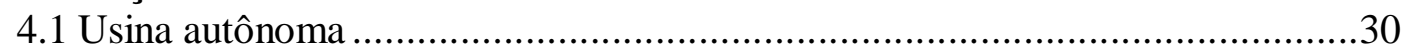

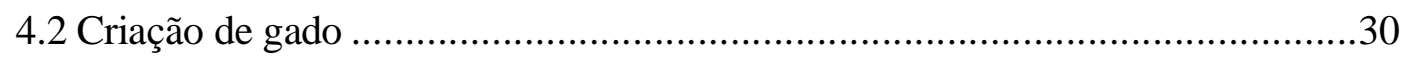

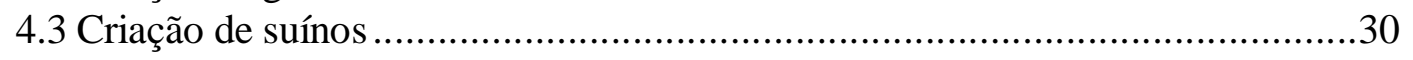

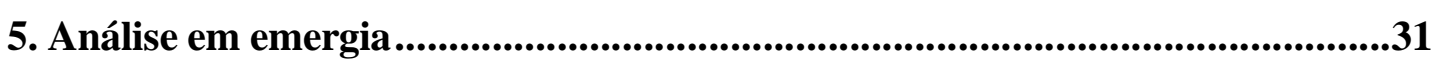

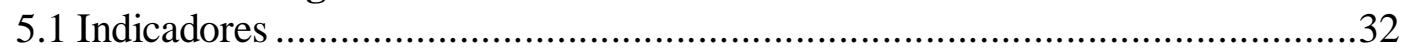

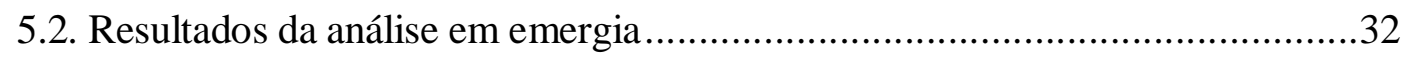

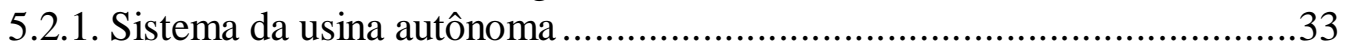

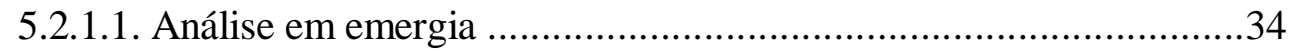

5.2.2. Biossistema da usina autônoma com criação de gado .............................35

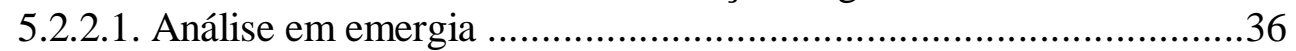

5.2.3. Biossistema da usina autônoma com criação de gado e suínos..................37 
5.2.3.1. Análise em emergia 38

5.2.4. Comparação entre as transformidades e custos dos biossistemas estudados39 5.3. Cálculo dos indicadores.. 40

6. A nálise em termoeconomia .................................................................4 43

6.1. Custo termoeconômico exergético ............................................................44

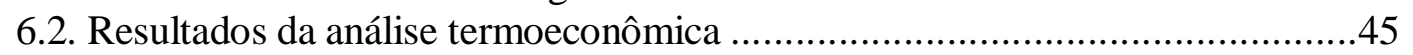

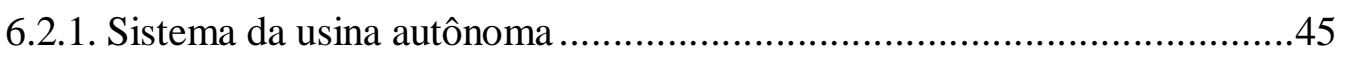

6.2.1.1 Volume de controle 1 (extração)...................................................48

6.2.1.2 Volume de controle 2 (destilaria)................................................49

6.2.1.3 Volume de controle 3 (biodigestão) ..............................................51

6.2.1.4 Volume de controle 4 (motor-gerador)........................................52

6.2.1.5 Volume de controle 5 (caldeira) .................................................53

6.2.1.6 Volume de controle 6 (turbinas) ................................................54

6.2.1.7 Custo ponderado da eletricide excedente do sistema de usina autônoma

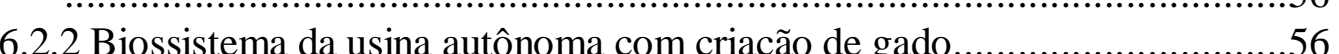

6.2.2.1 Volume de controle 7 (biodigestão) ...........................................57

6.2.2.2 Volume de controle 8 (motor-gerador).........................................58

6.2.2.3 Custo ponderado da eletricide excedente do biossistema da usina autônoma

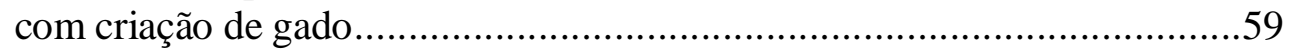

6.2.3 Biossistema da usina autônoma com criação de gado e suínos .................59

6.2.3.1 Volume de controle 8 (biodigestão de dejetos suínos) ....................60

6.2.3.2 Volume de controle 9 (motor-gerador).........................................60

6.2.3.3 Custo ponderado da eletricide excedente do biossistema da usina autônoma com criação de gado e suínos................................................................61

6.3. Comparação da análise termoeconômica para os biossistemas estudados ........61

7. A nálise em economia....................................................................................63

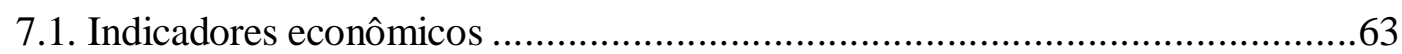

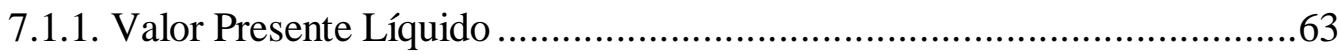

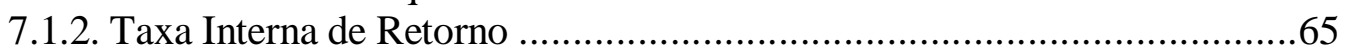

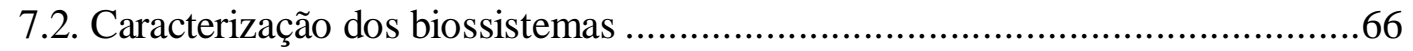

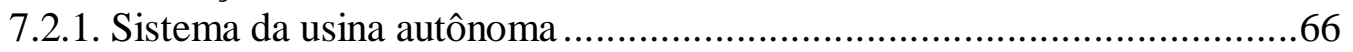

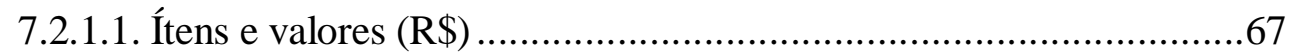

7.2.1.2. Custos anuais com matéria-prima, funcionários e manutenção........67

7.2.1.3. Faturamento anual com a venda de produtos..................................68

7.2.1.4. Lucro anual do sistema...........................................................68

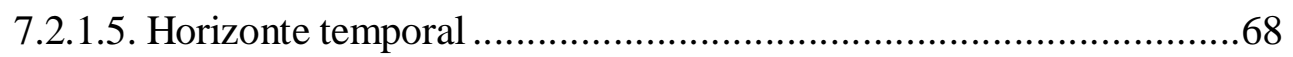

7.2.2 Biossistema da usina autônoma com dejetos de gado .............................68

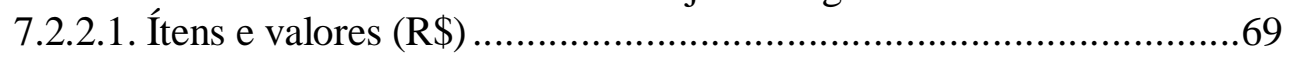

7.2.2.2. Custos anuais com matéria-prima, funcionários e manutenção........69

7.2.2.3. Faturamento anual com a venda de produtos................................69

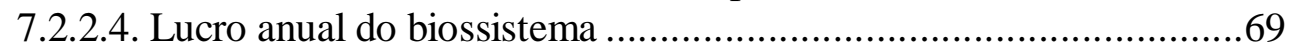

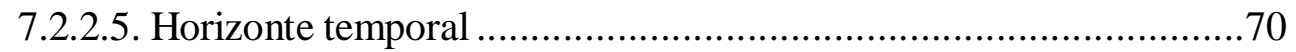

7.2.3. Biossistema da usina autônoma com dejetos de gado e suínos..................70

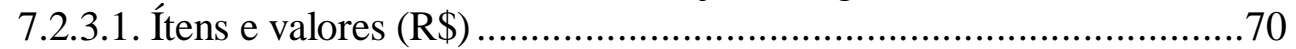

7.2.3.2. Custos anuais com matéria-prima, funcionários e manutenção.........70

7.2.3.3. Faturamento anual com a venda de produtos .................................70 


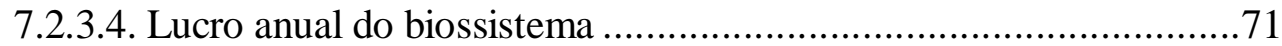

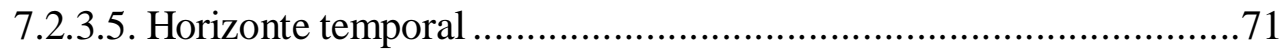

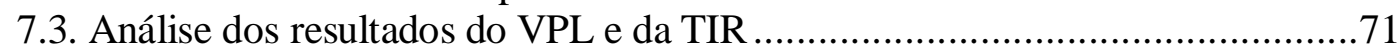

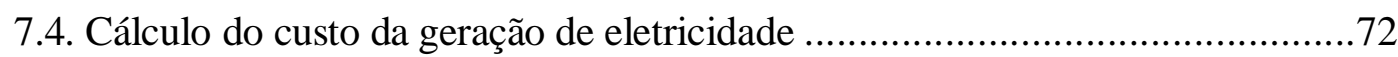

7.5. Análise do resultado de custo da geração de eletricidade .............................72

8. Conclusões................................................................................... 73

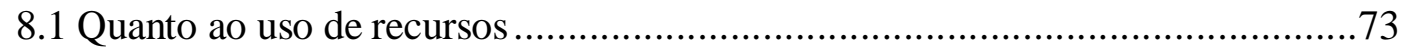

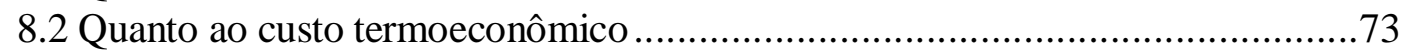

8.3 Quanto ao custo econômico financeiro......................................................74

8.4 Quanto à comparação entre as métricas........................................................74

9. Sugestões para trabalhos futuros..................................................... 76

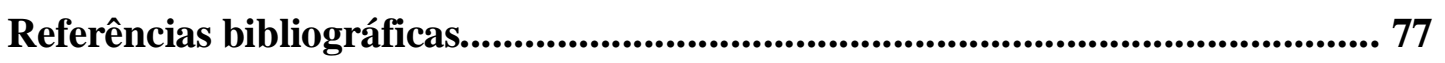

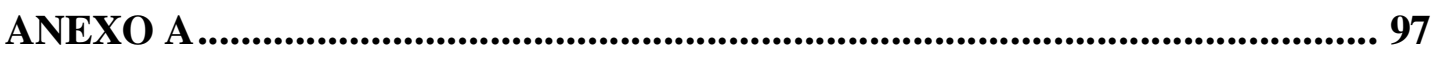

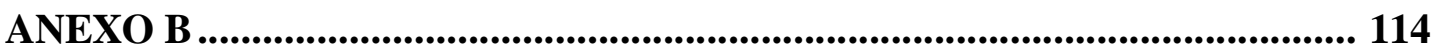

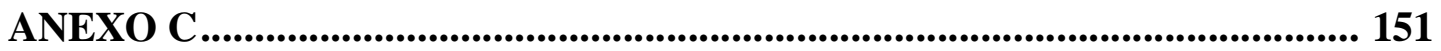




\section{Lista de Tabelas}

Tabela

Tabela 1. Comparação entre conceitos de energia e exergia 27

Tabela 2. Transformidade e emergias por unidade usadas nesse estudo 31

Tabela 3. Indicadores em emergia utilizados neste trabalho 32

Tabela 4. Avaliação da emergia do sistema da usina autônoma 34

Tabela 5. Avaliação da emergia do biossistema da usina autônoma com criação de gado

Tabela 6. Avaliação da emergia do biossistema da usina autônoma com criação de gado e suínos

Tabela 7. Comparação entre as transformidades e custos dos biossistemas 39

Tabela 8. Resumo dos índices em emergia 40

Tabela 9. Tabela de exergias específicas 43

Tabela 10. Custos dos fluxos de saída do volume de controle 1

Tabela 11. Custos dos fluxos de saída do volume de controle 2

Tabela 12. Custos dos fluxos de saída do volume de controle $3 \quad 52$

Tabela 13. Custos dos fluxos de saída do volume de controle $4 \quad 53$

Tabela 14. Custos dos fluxos de saída do volume de controle 5

Tabela 15. Custos dos fluxos de saída do volume de controle 6 com turbina de

$67 \mathrm{bar} / 480 \mathrm{C} \quad 56$

Tabela 16. Custos dos fluxos de saída do volume de controle 6 com turbina de

$21 \mathrm{bar} / 280 \mathrm{C} \quad 56$

Tabela 17. Custo ponderado da eletricidade excedente da usina autônoma 56

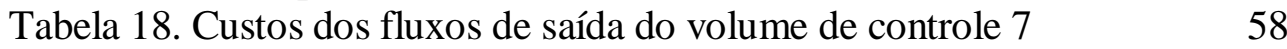

Tabela 19. Custos dos fluxos de saída do volume de controle 8 do gado 59

Tabela 20. Custo ponderado da eletricidade excedente da usina autônoma com criação de gado 59

Tabela 21. Custos dos fluxos de saída do volume de controle 8 do biodigestor dos suínos $\quad 60$

Tabela 22. Custos dos fluxos de saída do volume de controle 9

Tabela 23. Custo ponderado da eletricidade excedente do biossistema da usina autônoma com gado e suínos $\quad 61$

Tabela 24. Custo ponderado da eletricidade excedente dos biossistemas $\quad 62$

Tabela 25. Características da usina autônoma 66

Tabela 26. Investimentos monetários para implementação da usina autônoma

Tabela 27. Resultados do VPL e da TIR 71

Tabela 28. Custos de geração de eletricidade $\quad 72$

Tabela 29. Tabela dos indicadores utilizados neste estudo 75 


\section{Lista de Figuras}

Figura

Página

Figura 1. Principais processos de aproveitamento de biomassa na geração de energéticos

Figura 2. Potencial de geração de excedente de eletricidade no setor sucroalcooleiro

Figura 3. Biodigestor canadense $\quad 21$

Figura 4. Símbolos para utilização nos diagramas em emergias. $\quad 24$

Figura 5. Configuração da usina autônoma 28

Figura 6. Configuração da integração da usina autônoma com criação de gado

Figura 7. Configuração da integração da usina autônoma com criação de gado e suínos

Figura 8. Diagrama de energia do sistema da usina autônoma

Figura 9.Diagrama de energia do biossistema da usina autônoma com criação de gado

Figura 10. Diagrama de energia do biossistema da usina autônoma com criacão de gado e suínos

Figura 11. Diagrama ternário em emergia dos biossistemas estudados 42

Figura 12. Diagrama completo da usina autônoma 46

Figura 13. Volume de controle 1 da moenda 48

Figura 14. Volume de controle 2 da destilaria $\quad 50$

Figura 15. Volume de controle 3 do biodigestor $\quad 52$

Figura 16. Volume de controle 4 do motor-gerador 53

Figura 17. Volume de controle 5 da caldeira 54

Figura 18. Volume de controle 6 das turbinas de extração-condensação $\quad 55$

Figura 19. Volume de controle 7 do biodigestor do gado 58

Figura 20. Volume de controle 8 do motor-gerador do gado 58

Figura 21. Volume de controle 8 do biodigestor dos suínos 60

Figura 22. Volume de controle 9 do motor-gerador do gado e suínos 61 


\section{Lista de Símbolos}

$\% \mathrm{R}$ - percentual de recursos renováveis (Renovabilidade)

$\$$ - dólar americano (unidade monetária americana)

$\mathrm{R} \$$ - real (unidade monetária brasileira)

$\sum_{t=1}^{n}$ - somatória de $t=1$ até $t=n$

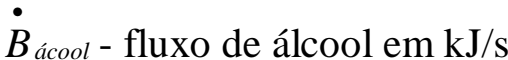

$\dot{\mathrm{B}}_{\text {bagaço - fluxo do bagaço em } \mathrm{kJ} / \mathrm{s}}$

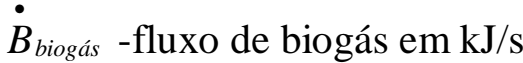

$\dot{\mathrm{B}}_{\text {caldo }}$ - fluxo do caldo em $\mathrm{kJ} / \mathrm{s}$

$\dot{\mathrm{B}}$ cana - fluxo da cana em $\mathrm{kJ} / \mathrm{s}$

$\dot{\mathrm{B}}$ condensado - fluxo de vapor condensado em $\mathrm{kJ} / \mathrm{s}$

$\dot{\mathrm{B}}_{\text {Torta }}$ - fluxo da torta de filtro em $\mathrm{kJ} / \mathrm{s}$

$\dot{B}_{v A(21)}$ - fluxo de vapor de 21 bar em kJ/s

$\dot{B}_{\text {va(67) }}$ - fluxo de vapor de $67 \mathrm{bar} \mathrm{em} \mathrm{kJ/s}$

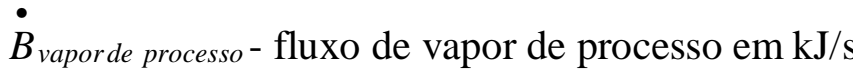

$\dot{\mathrm{B}}_{\text {vinhaça - fluxo da vinhaça em } \mathrm{kJ} / \mathrm{s}}$

${ }^{\circ} \mathrm{C}$ - graus celsius

$C_{\text {água }}$ - custo da água

Cálcool - custo do álcool

$\mathrm{C}_{\text {bagaço }}$ - custo do bagaço

$C_{\text {biogás - custo do biogás }}$

$\mathrm{C}_{\text {caldo }}$ - custo do caldo

$\mathrm{C}_{\text {cana }}$ - custo da cana

$\mathrm{C}_{\text {condensado }}$ - custo do vapor condensado

$\mathrm{C}_{\text {dejeto }}$ - custo do dejeto

$\mathrm{C}_{\text {ele }}$ - custo da eletricidade $\mathrm{C}_{\text {Torta }}$ - custo da torta de filtro

$\mathrm{C}_{\text {eleB }}$ - custo da eletricidade gerada pelo biogás

$\mathrm{C}_{\text {eleT }}$ - custo da médio ponderado da eletricidade gerada

$C_{\text {eleu }}$ - custo da eletricidade gerada pela usina

$\mathrm{C}_{\text {Torta }}$ - custo da torta de filtro

$\mathrm{C}_{\mathrm{VA}(21)}$ - custo do vapor de $21 \mathrm{bar}$

$C_{V A(67)}$ - custo do vapor de 67 bar 
$\mathrm{C}_{\text {vapor de processo }}$ - custo do vapor de processo

$\mathrm{C}_{\text {vinhaça }}$ - custo da vinhaça

$\mathrm{cm}^{2}$ - centímetro quadrado

$\mathrm{CO}_{2}$ - dióxido de carbono

consumo $_{\text {cana }}$ - consumo de cana em toneladas

Ex $x_{\text {condensado }}$ - exergia do vapor condensado

$E X_{V A(21)}$ - exergia do vapor de 21 bar

$E X_{V A(67)}$ - exergia do vapor de 67 bar

$E x_{\text {vapor de processo }}$ - exergia do vapor de processo

$E_{\text {vinhaça }}$ - exergia da vinhaça

I - investimento em R $\$$

i - fluxo de investimento em R $\$ / \mathrm{s}$

I o\&M - custo de operação e mão de obra em R \$

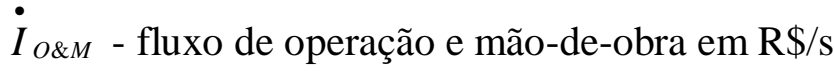

$\mathrm{II}_{0}$ - investimento inicial

mágua - fluxo da água em segundos

málcool - fluxo da água em segundos

$\dot{\mathrm{m}}_{\text {bagaço - fluxo do bagaço em segundos }}$

$\dot{\mathrm{m}}_{\text {biofertilizante - fluxo do biofertilizante em segundos }}$

$\bullet$

Mbiogás - fluxo do biogás em segundos

$\dot{\mathrm{m}}_{\text {caldo }}$ - fluxo do caldo em segundos

$\dot{\mathrm{m}}_{\text {cana }}$ - fluxo da cana em segundos

$\dot{\mathrm{m}}_{\text {condensado - fluxo do vapor condensado em segundos }}$

$\dot{\mathrm{m}}_{\text {dejeto }}$ - fluxo do dejeto em segundos

$\dot{\mathrm{m}}_{\text {Torta }}$ - fluxo da torta de filtro em segundos

$\dot{\mathrm{m}}_{\mathrm{V} \text { (21) }}$ - fluxo do vapor de 21 bar em segundos

$\dot{\mathrm{m}}_{\text {VA (67) }}$ - fluxo do vapor de 67 bar em segundos

$\dot{\mathrm{m}}_{\text {vaporde processo - fluxo do vapor de processo em segundos }}$

$\dot{\mathrm{m}}_{\text {vinhaça }}$ - fluxo da vinhaça em segundos

$m_{\text {água }}$ - massa da água

málcool - massa do álcool 
$m_{\text {bagaço }}$ - massa do bagaço

$m_{\text {biofertilizante }}$ - massa de biofertilizante

$m_{\text {biogás }}$ - massa do biogás

$m_{\text {caldo }}$ - massa do caldo

$m_{\text {cana }}$ - massa da cana

$m_{\text {condensado }}$ - massa de vapor condensado

$m_{\text {dejeto }}$ - massa do dejeto

$m_{\text {Torta }}$ - massa da torta de filtro

$m_{V A(21)}$ - massa de vapor de 21 bar

$m_{V A(67)}$ - massa de vapor de 67 bar

$m_{\text {vapor de processo - massa de vapor de processo }}$

$m_{\text {vinhaça }}$ - massa da vinhaça

produção $_{\text {ele }}=$ produção de eletricidade por TC

$P_{s}=$ segundos de atividade no ano

$r$ - taxa de desconto

á́lcool - densidade do álcool

$\rho_{\text {biogás }}-$ densidade do biogás

$\mathrm{s}$ - segundo

$\mathrm{t}$ - tonelada

$t$ - tempo

volume $_{\text {biogás }}=$ volume do biogás

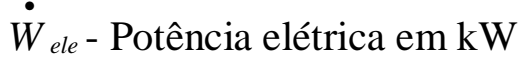

$\dot{W}_{\text {eleB - Potência elétrica em } \mathrm{kW}}$

W - trabalho em kJ 
ANEEL - Agência Nacional de Energia Elétrica

bar - unidade de medida de pressão do sistema c,g,s

cal - caloria

CENBIO - Centro Nacional de Referência em Biomassa

COPEL - Companhia Paranaense de Energia

CPEAR - Centro de Pesquisas em Energias Alternativas e Renováveis

$\mathrm{DBO}_{5}-$ Demanda Bioquímica de Oxigênio necessária para oxidar em 5 dias

EJ - hexa joule

ELR - índice de carga ambiental (enviromental loading Ratio)

EIR - investimento em emergia (E mergy Investment Ratio)

EMBRAPA - Empresa Brasileira de Pesquisa Agropecuária

ESI -índice de sustentabilidade (E nvironmental Sustainability index

EYR - Rendimento em Emergia(Emergy Yield Ratio)

F - Recurso Proveniente da Economia

$\mathrm{FC}$ - fator de capacidade

$\mathrm{FCt}-$ fluxo de caixa de $\mathrm{t}=0$ até $\mathrm{t}=\mathrm{n}$

FRC - fator de retorno de capital

FUN - funcionários

$\mathrm{g}$ - grama

GEE - Gases de Efeito Estufa

$\mathrm{h}$ - hora

ha - hectare

$\mathrm{J}$ - joule

kcal - quilocaloria

$\mathrm{kg}$ - quilograma

$\mathrm{kJ}$ - quilo-joule

$\mathrm{kW}$ - quilowatts

$\mathrm{kWh}$ - quilowatts-hora

L - litro

$\mathrm{m}^{2}-$ metros quadrados

$\mathrm{m}^{3}$ - metros cúbicos

MDL - Mecanismo de Desenvolvimento Limpo

MG - Minas Gerais

mm - milímetro

MME - Ministério da Minas e Energia

MW - Megawatts

MWh- Megawatts-hora

MUAI - Mini-Usina de Álcool Integrada

MPAB - Microposto de piscicultura acoplado a biodigestor

N - Recurso Não renovável

ONU - Organização das Nações Unidas

PIR - Planejamento Integrado de Recursos

$\mathrm{R}$ - Recurso Renovável

sej - solar emergy joules

SIN - Sistema Interligado Nacional 
TC - tonelada de cana

TIR - Taxa Interna de Retorno

TWh - Terawatts-hora

VLP- Valor Presente Líquido

un - unidade

UNICA - União da Indústria de cana-de-açúcar

UTE - Usina Termo Elétrica

WWTP - Sistema de Tratamento em Planta Convencional ( Waste Water Treatment Plant) Y - emergia total (saída do sistema)

\section{O bservação}

Os termos em línguas estrangeiras constantes neste estudo estão grafados em itálico, a não ser quando em referências bibliográficas. 


\begin{abstract}
Resumo
Este trabalho apresenta os resultados obtidos na comparação - através da contabilidade em emergia, em termoeconomia e em análise econômico financeira - de sistemas energéticos agropecuários. O objetivo deste estudo é o de reunir em um único trabalho três métricas distintas de atribuição de custos, considerando suas limitações e seus indicadores. Comparamse três configurações: o primeiro utiliza um sistema de geração de energia instalado em uma usina autônoma no Estado de São Paulo; o segundo um motorgerador alimentado com biogás produzido em um biodigestor de dejetos bovinos, integrado à usina, e o terceiro sistema um motorgerador alimentado com biogás produzido em um biodigestor de dejetos suínos que, para efeito do estudo também é integrado aos sistemas anteriores. Realiza-se a análise em emergia, termoeconomia e economia financeira, comparando-se as configurações com a finalidade de possibilitar uma visão multimétrica sobre as interações. Verifica-se que ao integrarmos os biossistemas, utilizando suas biomassas residuais como insumo de geração de eletricidade, o custo da eletricidade gerada é reduzido. A metologia empregada neste trabalho possibilita uma visão por três aspectos dos biossistemas: a visão ambiental por parte da emergia, a visão termodinâmica interna através dos rendimentos da primeira e segunda lei da termodinâmica por parte da termoeconomia e por fim a visão do investidor, que apresenta os resultados econômics financeiros da integração dos biossistemas.
\end{abstract}

Palavras chave: Emergia, Termoeconomia, Análise Econômica, Biossistemas, Energia. 


\begin{abstract}
A bstract
This work shows the results obtained when compairing the account in emergy, in Thermoeconomy and in an economic analysis of energy farming energy systems. The goal of this study is to assemble in an unique work three different ways of attributing costs, considering their restrictions and indexes. Three configurations are compaired: the first one uses an energy generation system installed in a sugar-ethanol plant in São Paulo. The second operates with a generator fed with biogas from a biodigestor of cattle manure that is integrated to the plant. The third system operates with a generator that receives pig slurry that is also integrated to the plant. The goal of quantifying the emergy on these systems, the thermoeconomic and the economic analysis in to make possible a wide view about the implications on these integrations.It is shown that when the biosystems are integrated, using their residual biomass as an input to electricity generation, the electricity cost is reduced. The methodology of this work makes possible seeing three aspects of the biosystems: the environmental sight by emergy, the inner thermodynamic sight given by the first and the second thermodinamic laws by the thermoeconomy and the investor sight that presents the economic financial results of the biosystems' integration.
\end{abstract}

Keywords: Emergy; Thermoeconomy; Economic Analisys; Biosystems; Energy. 
Capítulo 1 - Introdução

1. Introdução

A iminente necessidade de se diversificar a matriz energética agregada ao atual cenário brasileiro, favorece a elaboração de configurações diversas para aproveitamento dos resíduos gerados em nosso sistema agropecuário para geração de eletricidade.

Este estudo apresenta a interação entre três sistemas produtivos agropecuários que produzem resíduos passíveis de transformação em eletricidade.

Para situarmos o contexto histórico brasileiro, relacionamos nesta introdução a evolução do uso da energia, a sua utilização e os principais processos de transformação da biomassa residual em eletricidade empregadas pelo homem.

\subsection{O uso da energia pelo homem}

O homem primitivo, diante dos fenômenos naturais sentia temor e perplexidade, pelo fato de não poder explicá-los. Seu pensamento era sofreado por mitos e magias. Foi um processo longo até que o homem aprendesse a dominar o primeiro uso de energia: o fogo, que pôde lhe proporcionar luz, proteção, calor e outros usos finais.

Os ventos impulsionaram outro salto significativo na evolução do homem - o descobrimento de novos continentes. Porém, a coroação dos conhecimentos científicos (iniciados por volta de 1500, no período do Renascimento) aconteceu no século XVIII, com a Revolução Industrial, que além de impulsionar o desenvolvimento tecnológico através do carvão como principal fonte de energia, trouxe a concepção da natureza como fonte ilimitada de recursos à disposição do homem (HEMERY et al, 1993). A era do carvão foi marcada por um intenso crescimento industrial, associado a importantes descobertas, como exemplo, a máquina a vapor. Após a descoberta do petróleo, no final do século XIX, o carvão deixa de ser a principal fonte de energia.

No século XX, o uso intensificado do petróleo impulsionou ainda mais o processo de industrialização e os desenvolvimentos econômicos, ocasionando intensa modificação do espaço ocupado pelo homem (SANTOS, 1977). 
Já o do uso da geração de eletricidade impulsionou os avanços tecnológicos e criou uma forte dependência dos combustíveis fósseis para geração de energia, a exemplo do carvão mineral. (STRAPASSON, 2004).

Atualmente, contemplamos na primeira década do século XXI, o ritmo crescente no consumo de eletricidade, seja no setor residencial, comercial ou industrial em todo o mundo. Esse aumento na demanda energética pode apresentar crescimento com taxa superior ao aumento da oferta existente e, quando a demanda superar a oferta, instalar-se-á uma nova crise devido à escassez energética, a exemplo da ocorrida, em 2001, no Brasil.

De acordo com Goldemberg (2000), no aspecto global o consumo de energia cresce $2 \%$ ao ano e tem perspectivas de duplicar em 30 anos, caso prossigam as tendências atuais. Porém esse crescimento não é uniforme, dá-se em torno de $1 \%$ em países industrializados e 4\% em países não industrializados. Especificamente no Brasil isso significa a rápida exaustão de reservas de combustíveis fósseis.

Nesse contexto, projetos que dependam apenas de insumos renováveis para gerar energia representam uma melhor opção, pois se faz necessário a criação de uma estrutura que possa ser aprimorada para futuras situações estimando o aumento da demanda, bem como a escassez do petróleo.

\subsection{A geração de eletricidade a partir de fontes renováveis}

Neste estudo assume-se que as fontes renováveis são, segundo Braga et al (2002), os recursos naturais, que depois de utilizados ficam disponíveis novamente graças aos ciclos naturais, ou seja, sua taxa de uso é menor que a taxa de regeneração.

Os primeiros vetores energéticos utilizados pelo homem, como a força humana, a tração animal, a biomassa e a energia hidráulica eram provenientes de fontes renováveis.

Atualmente, o desenvolvimento sustentável é visto como uma necessidade global, para que as gerações vindouras tenham condições de sobrevivência (BRUNDTLAND, 1987). Através da criação do Protocolo de Kyoto, em 1992 (MRE, 1997) foi estabelecido que os países desenvolvidos devem reduzir 5\% as emissões dos gases do efeito estufa, no período de 2008 a 2012. Países em desenvolvimento a exemplo do Brasil, apesar de isentos desse compromisso, devem seguir o princípio de responsabilidade comum, pois o aquecimento global é uma questão de responsabilidade de todas as nações. 
O Planejamento Integrado de Recursos (PIR) é uma ferramenta que busca atingir as metas estabelecidas, cujo foco principal é a diminuição dos impactos ambientais provocados pela busca do desenvolvimento econômico. Portanto, a necessidade de utilização de fontes de energias renováveis é de fundamental importância, uma vez que contribuem para a mitigação das emissões de gases de efeito estufa (GEE) (UDAETA, 1997).

As primeiras usinas elétricas utilizavam o carvão mineral como combustível, sendo posteriormente substituído total ou parcialmente por outros combustíveis fósseis. Atualmente em alguns locais, o carvão vem sendo substituído por energia nuclear. Ainda hoje existem muitas usinas Termo Elétricas (UTE) alimentadas com gás natural e óleo combustível.

As usinas hidrelétricas, que obtém energia através do acionamento de turbinas pela queda d'água, sendo este um sistema de geração de longa vida útil e renovável, requerem grandes investimentos e acarretam conseqüências ao meio ambiente como, por exemplo, a perda da biodiversidade e de áreas de terra com a construção de reservatórios e barragens, que impedem o ciclo dos sedimentos, perdendo-se a fertilidade, o que acarreta na necessidade de aquisição de fertilizantes pelos agriculturos ribeirinhos ao corpos d'água. Ainda assim, devido à capacidade de gerar energia em larga escala, são uma opção atrativa, contabilizado os custos ambientais e sociais envolvidos. Em 2004, o Brasil gerou 87,2\% de sua energia através da hidroeletricidade (ROSA, 2007).

Na década de 1970 o setor elétrico entrou em uma nova fase em vários países, devido aos sucessivos choques do petróleo que aceleraram as reformas institucionais do setor. $\mathrm{Na}$ década de 1990, outras reformas que implantadas provocaram alterações na estrutura produtiva da indústria da eletricidade, ocasionadas pela crise financeira setorial e pelo crescimento da demanda em relação à oferta, dentre outros fatores (JANUZZI, 2008).

As reformas da década de 90, de caráter descentralizador, levaram ao aumento da cogeração $^{1}$ à produção elétrica em pequena escala, a utilização mais intensiva de fontes energéticas renováveis e à produção independente das concessionárias.

\footnotetext{
${ }^{1}$ Segundo a ANEEL:

Art 30 inciso I - Cogeração: processo operado numa instalação específica para fins da produção combinada das utilidades calor e energia mecânica, esta geralmente convertida total ou parcialmente em energia elétrica, a partir da energia disponibilizada por uma fonte primária. (ANEEL, 2006).
} 
Outras fontes renováveis de energia são utilizadas em menor escala a exemplo da energia eólica, obtida através da energia cinética do vento, as células de combustível, que combinam eletroquimicamente hidrogênio e oxigênio para produzir eletricidade, energia geotérmica, como também a conversão solar direta em eletricidade, através do sistema fotovoltaico.

O sistema fotovoltaico é constituído de um conjunto de painéis para captação de energia solar, no entanto para a fabricação das células fotovoltaicas como matéria prima são utilizados o silício, arseneto de gálio, sulfeto de cádmio dentre outros materiais. É uma fonte de energia com baixo impacto ambiental, no entanto o descarte de baterias e resíduos dos painéis solares que causam poluição ao meio ambiente.

No entanto a biomassa residual constitui-se em uma das fontes para produção de energia com maior potencial de crescimento, pois é considerada uma das principais alternativas para a diversificação da matriz energética, oferecendo eletricidade e biocombustíveis, a exemplo do biodiesel e etanol (ANEEL, 2009).

Segundo a ANEEL (2008), do ponto de vista energético, para fim de outorga de empreendimentos do setor elétrico, biomassa é todo recurso renovável oriundo de matéria orgânica (de origem animal ou vegetal) que pode ser utilizada na produção de energia.

De acordo com as estimativas de Hall (1991), a utilização de um terço dos resíduos disponíveis seria capaz de atender $10 \%$ do consumo elétrico mundial e com a implantação de um programa de plantio de 100 milhões de hectares de culturas especialmente para esta atividade, seria possível atender $30 \%$ do consumo.

Segundo estudo da Estatistical Review of World Energy, publicado em junho de 2008 pela Beyond Petroleum, a quantidade de biomassa residual existente no planeta é na ordem de 1,8 trilhões de toneladas. Este volume associado ao grau de eficiência das usinas em operação tem o potencial de geração de $11 \mathrm{mil} \mathrm{TWh} / \mathrm{ano}$, o que representa mais de $50 \%$ da eletricidade produzida no ano de 2007, que foi de 19,89 mil TWh.

Neste trabalho é apresentada a análise de sistemas de cogeração em usinas autônomas (produção de álcool a partir da cana-de-açúcar) de pequeno porte, associados à produção de eletricidade a partir do resíduo da biomassa no âmbito do setor elétrico, incluindo a geração de eletricidade com biogás produzido pela vinhaça e a integração de biogás de origem de dejetos bovinos e suínos. 


\subsection{A questão da biomassa}

O Brasil, por ter quase todo seu território localizado entre a linha do Equador e o Trópico de Capricórnio apresenta temperaturas e índices pluviométricos ideais para agricultura, constituindo excelentes condições para a produção e uso energético da biomassa em larga escala.

Segundo Ramage \& Scurlock (1996), a quantidade de biomassa no planeta é em torno de dois trilhões de toneladas, que em média representa 400 toneladas per capita, correspondendo aproximadamente a 3000 EJ por ano.

A biomassa proveniente da atividade agropecuária, através de dejetos animais, se manejada de maneira inadequada pode se transformar em contaminantes para o meio. Dessa forma, todo resíduo a ser descartado pode ser minimizado, mediante estudos e análises de suas características e potenciais para a reciclagem energética (GENEROSO, 2001).

Entretanto, muitos estudos promoveram o avanço tecnológico para o setor canavieiro, principalmente na produção de álcool e cogeração de eletricidade a partir do bagaço da canade-açúcar (Goldemberg, 2000). A alta produtividade dos canaviais disponibiliza grandes quantidades de matéria orgânica, sob a forma do bagaço. A sua transformação em energia, auxilia o abastecimento das regiões Sul e Sudeste do território brasileiro. A viabilidade tornase ainda mais vantajosa devido ao período de estiagem das principais bacias hidrográficas, coincidirem com a colheita da cana-de-açúcar (ANEEL, 2008).

A Figura 1 apresenta os principais processos de aproveitamento da biomassa através do diagrama.

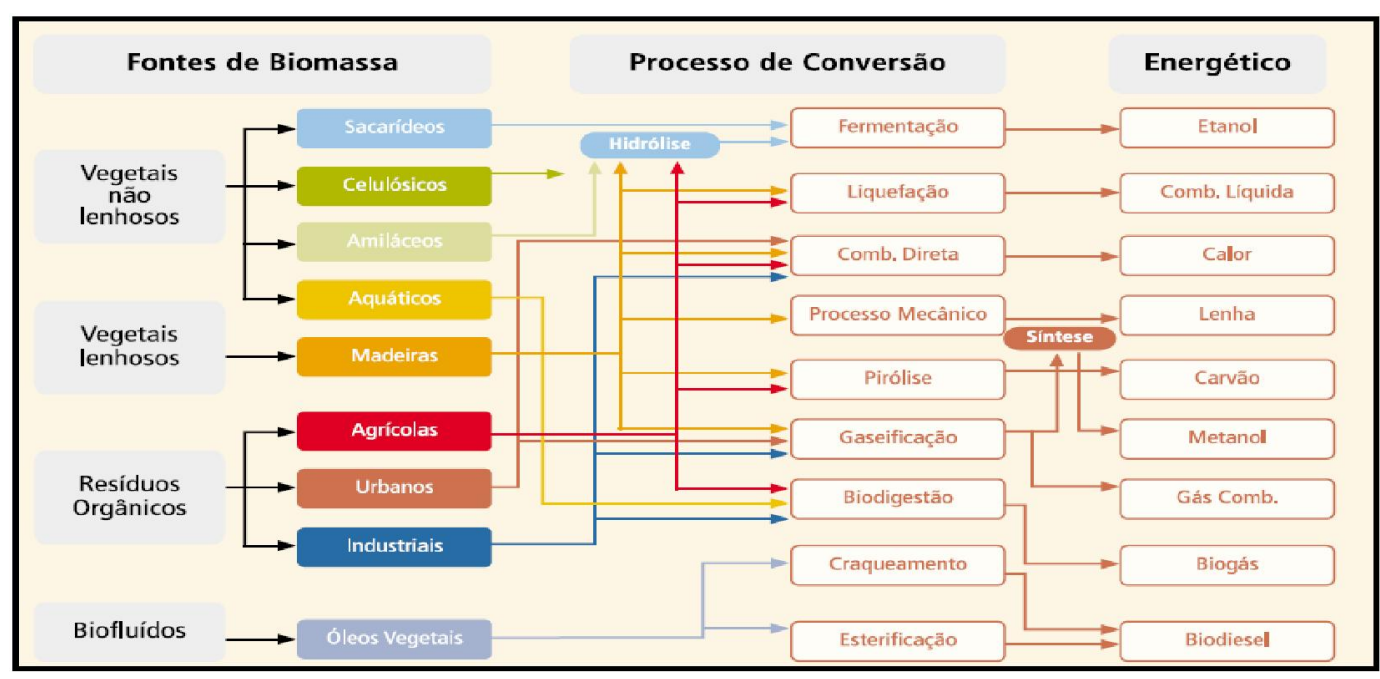

Figura 1 - Principais processos de aproveitamento de biomassa na geração de energéticos Fonte: ANEEL, 2008. 
Este trabalho objetiva apresentar a comparação de três configurações distintas para integração de biossistemas na geração de eletricidade, utilizando como métricas para atribuição de custos, as contabilidades em emergia, termoeconomia e econômico-financeira, além de:

- Analisar os custos de geração de energia em base de fluxos em emergia para as configurações propostas;

- Calcular os custos de geração de eletricidade em bases termoeconômicas;

- Analisar a viabilidade econômica para a integração dos sistemas de geração de eletricidade;

- Verificar o alcance dos indicadores na avaliação dos biossistemas estudados;

- Comparar as configurações dos biossistemas propostos quanto à sua contribuição ao meio ambiente e a economia;

- Calcular a área direta necessária para geração elétrica.

No Segundo capítulo desse estudo é feita a revisão bibliográfica, onde são apresentadas as formas de geração e potenciais de eletricidade dos sistemas abordados, e apresentados os estudos da literatura que têm utilizam as métricas presentes neste trabalho.

No terceiro capítulo são apresentadas as metodologias utilizadas neste estudo, possibilitando identificar quais fluxos são priorizados por cada métrica

No quarto capítulo são apresentados os biossistemas analisados neste estudo, com suas características e dimensões.

No quinto capítulo é realizada a análise em emergia dos biossistemas e da integração proposta neste estudo.

No sexto capítulo é realizada a análise termoeconômica dos biossistemas e da integração proposta neste estudo.

No sétimo capítulo é realizada a análise econômica financeira dos biossistemas e da integração proposta neste estudo.

No oitavo capítulo são apresentadas as conclusões deste estudo nas três métricas propostas. 
No nono capítulo são indicados novos estudos que podem ser realizados com a utilização da metologia propostas neste trabalho, além de indicar trabalhos que podem complementar este estudo 


\section{Revisão Bibliográfica}

Nesta revisão bilbiográfica, são apresentadas as abordagens atuais de atribuição de custos, artigos, teses, dissertações e livros revistos durante a elaboração desse estudo, utilizadas como base para a aplicação das métricas, assim como alguns processos de produção de eletricidade excedente com a utilização de biomassa residual de sistemas agropecuários.

\subsection{Métricas para atribuição de custos}

Desde o primeiro choque do petróleo (1973), começamos a nos conscientizar da necessidade de tornar compatíveis o crescimento econômico e a preservação dos recursos naturais. Desde então, os sistemas econômicos empregados são questionados. A colaboração da natureza, em qualquer processo produtivo, não era considerada. A partir deste momento, vários pesquisadores desenvolveram trabalhos relacionados com a degradação e escassez dos recursos naturais e sua influência nos limites do crescimento econômico.

Segundo Merico (1996), foram utilizadas várias abordagens que visavam a introdução das questões relacionadas aos recursos naturais nas estruturas e modelos de análise econômica. A primeira delas, utilizada nas décadas de 1960 e 1970 foi a Economia de Recursos Naturais, que tinha como objetivo determinar o uso ótimo dos recursos naturais renováveis e não renováveis. Esta abordagem não evitava a degradação ambiental, como também podia levar os recursos naturais à exaustão, se economicamente fosse viável. $\mathrm{Na}$ década de 1980, veio a Economia Ambiental que se apoiava na questão da poluição como uma externalidade do processo de produção e consumo. Na década de 1990, foi elaborada a Economia Ecológica que engloba o uso dos recursos naturais e das externalidades no processo produtivo, com ênfase no uso sustentável das funções ambientais e na capacidade dos ecossistemas em geral, de suportar a carga imposta pelo funcionamento econômico (MARTINEZ ALIER, 1998).

A Economia Ecológica baseia-se no uso dos recursos renováveis (taxa de formação maior do que de utilização), e no uso de recursos não-renováveis (taxa de formação em uma escala de tempo menor que seu uso).

A análise econômica financeira nessa vertente envolve elementos econômicos e biofísicos. Ela procura integrar as disciplinas de economia e ecologia possibilitando uma análise mais correta dos dois sistemas. 
Para migrarmos da economia do desperdício para uma Economia Ecológica, uma mudança estrutural se faz necessária, tanto no consumo como nas tecnologias utilizadas. $\mathrm{O}$ começo é fixar metas de redução de emissões danosas ao meio ambiente e seres vivos e fazer uso de recursos e imposições a exemplo de: proibições legais, multas, impostos, depósitos prévios, mercados de licenças de contaminação, entre outras sanções.

\subsection{Sustentabilidade no meio rural}

Segundo Altieri (1993), qualquer meio adotado com a finalidade de obter o desenvolvimento rural sustentável deve visar prioridades mais urgentes da região como a redução da miséria, o abastecimento adequado de alimentos e auto-suficiência, a conservação dos recursos naturais, a autonomia das comunidades locais e a participação efetiva das camadas de baixo poder aquisitivo das áreas rurais. Países como o Brasil, que tem sua economia baseada na agricultura, devem promover estratégias que enfatizem os métodos e procedimentos para se atingir o desenvolvimento sustentável social e ambiental, caracterizados pela satisfação das necessidades humanas, distribuição igualitária de terras, melhoria na qualidade de vida e aumento da autoconfiança regional.

Sempre que há desenvolvimento, surgem consequências para a sociedade e para o meio ambiente em todas as regiões do mundo, sejam boas ou não. Desenvolvimento econômico e meio ambiente mantém uma relação recíproca, nas quais atividades econômicas transformam o meio ambiente e, este por sua vez alterado, pode se tornar um limite para o desenvolvimento futuro. (ALTVATER, 1995).

Segundo Rapport et al (1998), a saúde do ecossistema é vital para que este possa suprir os bens e serviços necessários à nossa sobrevivência. $\mathrm{O}$ autor elenca três indicadores de saúde do ecossistema. O primeiro é o vigor, mensurado pela atividade do metabolismo ou a produção primária do sistema. O segundo, a organização, podendo ser avaliada com a biodiversidade e o número de interações entre os componentes do sistema. Já o terceiro, pela resistência, é a capacidade apresentada pelo sistema em manter sua estrutura e função mediante um stress.

Os países desenvolvidos, por não serem auto-suficientes, constituiem-se em sistemas abertos baseados em importações, ou seja, eles estão usando os recursos de outras sociedades e de outros ecossistemas (GIAMPIETRO et al, 1992). 
As análises de sustentabilidade, que são baseadas em considerações simplesmente contábeis, não são capazes de mensurar os custos impostos à natureza e ao rendimento ótimo dos sistemas industriais.

Nesse contexto, a análise em emergia, desenvolvida por Howard T. Odum (ODUM, 1996) tem como objetivo analisar os fluxos de energia e materiais nos sistemas dominados pelo homem para mostrar, por índices quantitativos, a dependência dos sistemas produtivos humanos das fontes de energia naturais, como também das derivadas da energia fóssil e descobrir as possibilidades de interação entre os sistemas da economia humana e os ecossistemas (ORTEGA, 1998).

A análise termoeconômica ou exergoconômica (TSATSARONIS, 1985), é uma metodologia em que todos os fluxos são expressos em base exergética com valoração financeira, independente de sua origem. Este valor é capaz de resumir o custo térmico total em bases financeiras do sistema estudado, possibilitando um estudo que visa à otimização do sistema.

2.3. A produção de eletricidade a partir da biomassa da cana-de-açúcar no Brasil

No Brasil, a colheita tradicional da cana-de-açúcar realizada manualmente, precedida pelas queimadas (queima da palha que produzem consideráveis emissões de dióxido de carbono $-\mathrm{CO}_{2}$ - na atmosfera), constitui um fator agravante para a saúde humana (ANEEL, 2008). As queimadas, realizadas nos canaviais, na maioria das vezes, são responsáveis por incêndios de grandes proporções em áreas adjacentes. Em vista ao aumento da produtividade da cana-de-açúcar, as usinas têm optado pela colheita mecânica, sendo desnecessárias as queimadas.

De forma direta, a utilização do bagaço na geração de eletricidade, praticamente anula a emissão do dióxido de carbono na atmosfera, pois as emissões que resultam são absorvidas e fixadas pela cana-de-açúcar durante seu crescimento (CHOFI, 2004).

Segundo a UNICA, 2007 na safra de 2006/07 foram produzidas 425 milhões de toneladas de cana pelo setor sucroalcooleiro, possibilitando a produção de 17,5 bilhões de litros de álcool e 29,5 milhões de toneladas de açúcar. As projeções para a safra de 2012/13 são de aproximadamente 700 milhões de toneladas de cana, que deverão produzir 36 bilhões de litros de álcool e 39 milhões de toneladas de açúcar, possiblitando, devido ao ciclo 
crescente, o aumento da oferta de bagaço.

O bagaço de cana-de-açúcar constitui-se atualmente no recurso de maior potencial para geração de eletricidade no país, disponibilizado enorme quantidade de matéria orgânica.

Um estudo realizado pelo CENBIO (Centro Nacional de Referência em Biomassa) em 2003 mostra o potencial de geração de excedente de eletricidade no setor sucroalcoleiro (Figura 2).

O resultado desse estudo traça o mapa da energia excedente em cada unidade da federação, indicando que nos Estados de São Paulo e Alagoas , o potencial é de 2244,33 MW, enquanto que para os Estados de Pernanbuco e Paraná é de 369,31 MW e menor de que 300 MW para as demais unidades federativas.

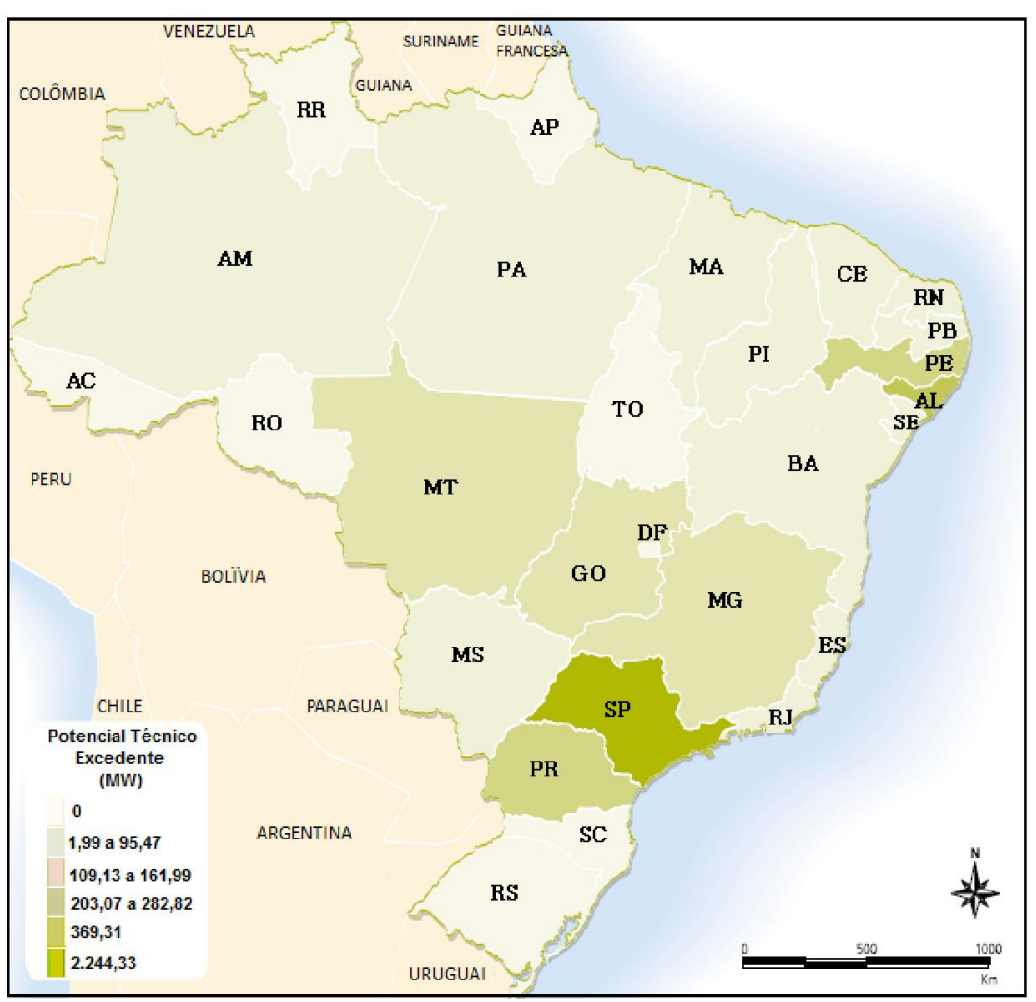

Figura 2. Potencial de geração de excedente de eletricidade no setor sucroalcoleiro.

Fonte: CENBIO, 2003.

De acordo com Brighenti (2003), existem algumas barreiras a serem vencidas para que todo o potencial da biomassa da cana-de-açúcar possa ser convertido em eletricidade, como o acesso à rede de distribuição, a falta de atratividade no preço ofertado para comercialização, a 
falta de interesse das concessionárias para contratos em longo prazo, além de financiamentos que ofereçam melhores condições que os atuais.

Para Nagaoka (2002), a reforma do setor elétrico brasileiro, teve o objetivo de permitir ao governo concentrar-se em suas funções de elaboração de políticas energéticas e de regulamentação do setor, transferindo ao setor privado as responsabilidades sobre a operação do sistema elétrico e de novos investimentos, propiciando a comercialização da eletricidade cogerada pelo setor sucroalcooleiro. Desta forma, o autor espera obtenção de maior participação da cogeração na matriz energética brasileira.

2.4. A produção de eletricidade a partir da biomassa do gado

A geração de eletricidade através da biomassa do gado se dá através do aproveitamento energético de dejetos orgânicos (esterco animal), realizados a partir do processo de digestão anaeróbia em biodigestores, cujo produto final é o biogás e o fertilizante gerado pelo efluente. Fatores como a umidade e o aquecimento contribuem para o processo. Geralmente o aquecimento é provocado pela ação de bactérias metanogênicas que produzem o biogás, cuja composição em sua grande parte, é de gás metano, com cerca de 50\% a 80\%, e dióxido de carbono (MATEUS, 2006).

Quando o bovino é explorado no regime extensivo (pastejo), os dejetos produzidos são dispersos no solo passando por um processo completo de decomposição, sem maiores problemas de poluição. Isto ocorre devido à pequena concentração de animais por área (GARCIA-VAQUERO,1981). Contudo, à medida que o animal permanece confinado, os dejetos produzidos ficam concentrados e necessitam serem tratados a fim de evitar poluição.

Segundo Coelho et al (2007), a expansão das plantações de cana-de-açúcar está ocasionando a redução das áreas de pastagem, de modo que a criação bovina tende ao estabulamento dos animais para manter ou aumentar a produção.

Outro fator que justifica o estabulamento é o crescimento populacional, pois cresce também o consumo de alimentos, fazendo com que, os produtores de carne adotem o sistema de confinamento, denominados "Sistemas Intensivos de Produção Animal" (CAMPOS, 1998).

Um dos maiores problemas destes sistemas é a grande quantidade de resíduos produzidos diariamente. Van Horn et al (1994), observaram que o gado elimina nos dejetos 
$33 \%$ da energia ingerida nos alimentos. Esta energia, somada aos constituintes minerais podem transformar-se em fonte de poluição ao meio ambiente, caso os dejetos não sejam manejados de maneira correta. Nesse sentido, o emprego de tecnologia da digestão anaeróbia para o tratamento dos dejetos é um dos mais promissores no campo da biotecnologia, uma vez que contribui para preservação do meio ambiente, promovendo com grande eficiência a degradação de resíduos orgânicos, viabilizando, desta forma, modernos sistemas de produção e otimizando a relação entre custo/benefício do empreendimento (LUCAS JUNIOR, 1987), pois, à medida que os sistemas de produção animal se intensificam e se modernizam, intensificam-se também as necessidades energéticas, bem como o tratamento dos resíduos.

No estudo realizado por Campos (1998), foi possível determinar o volume dos dejetos produzidos por 100 vacas confinadas em um sistema intensivo de produção de leite, do Centro de Pesquisa de Gado de Leite da EMBRAPA (Empresa Brasileira de Pesquisa Agropecuária) de Juiz de Fora - MG. Com base nesses estudos, Hardoim (1999), determinou o potencial de produção de metano dos dejetos, quando tratado por um biodigestor do tipo indiano. Foi verificado pelos próprios estudos de Hardoim et al (2000), que o sistema projetado pode suprir as necessidades de consumo energético do sistema, o que viabiliza a venda de excedentes de eletricidade. Esta tecnologia pode ser apropriada como estratégia de conservação e uso eficiente da energia, viabilizando os modernos sistemas de confinamento e reduzindo o custo da produção.

No âmbito internacional, a $8^{\circ}$ European Conference on Biomass for Energy, Environment, Agriculture and Industry (1994), abordou a biomassa como sendo um importante recurso energético, onde a larga escala de produção e utilização pode trazer grandes contribuições na diversificação de recursos energéticos (SILVA, 1998). Num sentido mais amplo, e com objetivo de reduzir a agressão causada pelo homem à natureza, no Rio de Janeiro, em 1992 aconteceu a II Conferência das Nações Unidas para o Meio Ambiente e desenvolvimento, que resultou num plano de ação denominado Agenda 21 (Plano de ação da Declaração do Rio-92), onde estabelece a substituição de $20 \%$ das fontes energéticas por renováveis até o ano 2000 e 50\% até o ano 2020 (CAVALCANTI et al, 1994).Resende et al (1998), afirmam que as dificuldades existentes para o rápido crescimento do uso da energia renovável dependem de alguns fatores, como o tempo requerido para estabilizar a tecnologia, 
produção industrial, recursos e análise financeira e econômica a fim de determinar a viabilidade do sistema, bem como aceitação pública.

Contudo, torna-se necessário o desenvolvimento de tecnologias apropriadas, em relação ao tratamento de resíduos, a fim de tornar mais eficiente o tratamento e sua utilização e desta maneira atender às determinações práticas e legais (LOURES, 1998).

2.5. A produção de eletricidade a partir de biomassa suína

No Brasil, segundo a EMBRAPA, em 2006, a suinocultura possui um rebanho de 35,2 milhões de animais. Os estados de Santa Catarina e Minas Gerais destacam-se na produção de suínos. Entretanto, a maior parte do rebanho concentra-se na Região Sul com 45,4\%. O estado do Paraná possui 12\% do rebanho nacional, constituindo 4,3 milhões de suínos, valor estimado em 2006, representando dessa forma, uma atividade de grande importância tanto do ponto de vista social como econômico. No entanto, a exemplo da pecuária bovina, há necessidade de melhorias no processo de manejo dos dejetos produzidos, a fim de minimizar os danos causados ao meio ambiente, uma vez que, comparado ao esgoto doméstico, os dejetos de suínos são 200 vezes mais poluentes, e pode ser medido pela $\mathrm{DBO}_{5}{ }^{2}$. $\mathrm{A} \mathrm{DBO}_{5}$ do esgoto doméstico é de $0,2 \mathrm{~g} / \mathrm{L}$, enquanto os dejetos de suínos apresentam valores entre 32 e 50 g/L (NISHIMURA et al, 2008).

De acordo com Tamminga e Vertegen (1992) há dificuldades de estimar os níveis de poluição da água, ar e solo, em virtude da falta de consenso sobre quais tecnologias são mais adequadas como também pela razão de existir diferentes tipos de composição química dos dejetos. A composição química dos dejetos varia conforme a categoria dos animais, tipo de alimentação, quantidade de água ingerida e tipo de manejo adotado. Portanto, deve-se atender às necessidades básicas dos animais, como a fome e a sede, sem causar deficiências nutricionais clínicas, e sem provocar intoxicações, de acordo com o Instituto de Tecnologia do Paraná.

\footnotetext{
${ }^{2}$ Demanda Bioquímica de Oxigênio - quantidade de oxigênio necessária para oxidar biologicamente a matéria orgânica por um período de cinco dias.
} 
Segundo Bartholomeu et al (2007), a instalação dos biodigestores para a captação de metano nas granjas suinícolas vem sendo considerada uma atividade para projetos de Mecanismo de Desenvolvimento Limpo (MDL). A redução de gases de efeito estufa pode ser revertida em receitas através da comercialização de créditos de carbono (CENAMO, 2005).

Os atuais projetos de MDL provenientes da suinocultura pretendem reduzir as emissões em cerca de 16,5 milhões de tCO2 ao longo de dez anos, resultando numa geração média anual de aproximadamente 0,9 tCO2 por animal (GEHLEN \& ANDRADE, 2008).

Tendo em vista que um suíno produz mensalmente cerca de $0,27 \mathrm{~m}^{3}$ de dejetos. Uma pequena propriedade com 2 mil suínos pode gerar energia suficiente para toda a sua propriedade e ainda produzir excedentes. O biodigestor apresenta vantagens à propriedade, a exemplo de agregar valor econômico dos dejetos devido à obtenção de sub-produtos, como biofertilizantes, biogás e eletricidade (PERDOMO et al, 2001).

Segundo Alkain (2007), a energia gerada através do biodigestor de um rebanho de mil suínos foi estipulada em 2,5 kWh, em média - o suficiente para atender à demanda de uma escola ou três casas, conforme estudos do Centro de Pesquisas em Energias Alternativas e Renováveis (CPEAR).

Neste sentido, as fontes agropecuárias energéticas apresentam-se como fonte alternativa de produção e geração de energia. Evidentemente, a quantidade de energia produzida atualmente comparada às hidrelétricas é muito menor, devido especialmente ao porte destas em relação ao número de biodigestores instalados. $\quad$ Em contrapartida, a produção de energia advinda de fontes agropecuárias apresenta baixo custo, reduzindo os impactos ambientais, levando-se em consideração todos os aspectos envolvidos.

2.6. Trabalhos da literatura relativos à avaliação de sistemas de geração de energia através do uso de biomassa, com o emprego da síntese em emergia.

Em virtude deste trabalho se restringir à geração de eletricidade através da utilização da biomassa residual, alguns dos artigos e teses que tratam do assunto e estão disponíveis na literatura foram pesquisados. Os estudos apontam uma grande quantidade de emergia associada ao fluxo de biomassa. Esse fato constitui-se em um motivo considerável para que este sistema seja manejado adequadamente. Outro fator importante a ser considerado é o impacto ambiental causado pela descarga de resíduos quando estes processos não dispõem de tratamentos adequados. 
Nesta perspectiva, a sociedade tem investido consideráveis recursos e tecnologia, com a finalidade de que o manejo se torne adequado.

Entre os trabalhos na literatura que utilizam a contabilidade em fluxos de emergia para avaliar os biossistemas capazes de gerar energia, podemos citar:

Björklund et al (2001), calcularam a transformidade da eletricidade gerada através do aproveitamento do biogás produzido por um biodigestor instalado na estação de tratamento de esgoto com sistema de tratamento convencional (WWTP, Waste Water Treatment Plant), na Suécia. Comparando o valor obtido com a transformidade da eletricidade utilizada no sistema, que é composta por uma parte de eletricidade de usina nuclear e outra parte proveniente de hidroelétrica, concluíram que se o sistema fosse utilizado para geração de eletricidade, seria ineficiente, pois a transformidade encontrada, $3,10.10^{5} \mathrm{sej} / \mathrm{J}$ foi maior do que as de outras fontes disponíveis em seu país, que para hidroeletricidade era de $8,0.10^{4}$ sej/J (solar emergy joule per joule).

Lei e Wang, 2008 realizaram cálculo da transformidade para geração de eletricidade a partir de resíduos municipais e encontraram o valor de $7,61.10^{6} \mathrm{sej} / \mathrm{J}$ para a energia gerada a partir de um incinerador.

Ometto et al, 2006 calculam em seu trabalho a transformidade para o álcool, a eletricidade e alimentos de uma MUAI - Mini-Usina de Álcool Integrada (CORSINI, 1992), obtendo a transformidade de eletricidade de $1,46.10^{5} \mathrm{sej} / \mathrm{J}$.

2.7. Trabalhos da literatura relativos à avaliação de sistemas de geração de energia através do uso de biomassa utilizando a análise termoeconômica.

Para a elaboração dos cálculos da análise termoeconômica desta tese foram necessários os conceitos desenvolvidos por: Orlando (1991), Kotas (1995), Bejan et al (1996), Horlock (1997), Khartchenko (1998) e Lora e Nascimento (2004).

Pellegrini (2008) utiliza a termoeconomia como base de cálculo em uma usina de cana-de-açúcar de médio porte, identificando os custos de Potência Elétrica e Calor, mostrando que a maximização da eficiência do sistema de cogeração leva à minimização dos custos em base exergética. Tal maximização corresponde à função de maior geração excedente de eletricidade. Utilizando o critério da igualdade para a análise termoeconômica, 
constatou que a maximização do lucro da usina está diretamente relacionada ao melhor uso da exergia disponível na cana, sobretudo com a otimização da planta de utilidades, que reduz os custos de produção da eletricidade e do vapor utilizados nos processos de produção, além de acrescentar uma receita com a venda do excedente de eletricidade.

Coelho (1999) propõe e discute mecanismos que viabilizam um programa amplo de excedentes de eletricidade a partir da biomassa, a exemplo das usinas de açúcar e álcool. $\mathrm{O}$ estudo realiza análise termoeconômica, com os critérios de igualdade e co-produto onde avalia os custos da eletricidade e do vapor do processo para diferentes configurações em usinas. Os estudos indicam que pode ocorrer viabilização da cogeração a partir da biomassa em larga escala, os custos de geração muitas vezes são superiores aos preços ofertados pelas concessionárias, na política atual das concessionárias só é viabilizado a venda de excedentes em escala reduzida, nesse âmbito, sugere propostas na legislação visando à inclusão de custos ambientais e taxação do carbono.

Velazquez (2006) realiza uma análise do setor elétrico brasileiro e debate perspectivas para a cogeração a partir da biomassa no setor industrial, revelando o setor de papel e celulose como um dos mais energointensivos e responsáveis pelo uso da biomassa, juntamente com o sucroalcooleiro, gerando parte da energia que consomem a partir de subprodutos do processso, a exemplo da lixívia. Entretanto não são auto-suficientes. Na perspectiva da indústria, o incentivo à auto-suficiência corre risco de interrupção no fornecimento, pois o custo de produção é superior aos custos de compra da eletricidade.

Silva (2004) analisou o sistema de geração de potência da Companhia Siderúrgica de Tubarão e formulou uma proposta de repotenciamento, utilizando a análise termoeconômica. A análise foi feita no atual sistema de geração composto por três configurações de Ciclo Rankine Regenerativo, supridas por gases siderúrgicos residuais do processo de fabricação do aço. Foram comparados os custos em condições de projeto e de operação do sistema.

A proposta de repotenciamento para este sistema foi baseada no ciclo combinado, considerando a disponibilidade de gases para geração e a demanda de energia para a usina siderúrgica. Três propostas de ciclos combinados foram formuladas, com caldeiras de recuperação com um, dois e três níveis de pressão de geração de vapor. Foi realizada uma análise dos diferentes parâmetros que influenciam no desempenho destas. As propostas de ciclo combinado foram avaliadas através da Teoria do Custo Exergético e da Análise Funcional Termoeconômica, determinando-se os custos exergético e monetário de produção 
de potência, sendo comparadas entre si e em relação ao sistema atual. Foi observado que a análise funcional, que utiliza o conceito de junção e distribuidores de exergia e neguentropia, possibilita uma distribuição mais realista entre os equipamentos consumidores de exergia do sistema, em relação a teoria do custo exergético. Foi observado, também, que o ciclo combinado de três níveis de pressão possui o menor custo exergético dentre os ciclos analisados.

2.8. Trabalhos da literatura relativos à avaliação de sistemas de geração de energia através do uso de biomassa utilizando a análise econômica

Para fundamentação dos cálculos em economia, foram pesquisadas as metodologias aplicadas nos trabalhos que utililizaram os conceitos econômicos presentes nesta tese.

Rodrigues (2005) apresenta análise econômica de diferentes configurações de sistemas cogeradores. Através da utilização de alguns conceitos econômicos (TIR - Taxa Interna de Retorno e VPL - Valor Presente Líquido), foram realizadas análises quantitativas e comparativas na geração de eletricidade e sua relação com o balanço térmico do processo.

Coreea Neto (2001) avalia a viabilidade técnica e econômica de geração termelétrica com ciclo combinado. A análise econômica conclui que a redução do investimento inicial relacionado ao gaseificador e seus sistemas auxiliares é significativa, se forem comparados os custos de instalação ao dos ciclos combinados. A redução da taxa de desconto do projeto do valor de referência reduz o custo da energia, porém a ausência de estudos e dados inviabilizou a análise econômica dos benefícios técnico-operacionais do processo de gaseificação e alimentação da turbina a gás. A eletricidade gerada pode ser competitiva com fontes tradicionais, principalmente se forem reduzidos os impostos federais a título de incentivo.

Barros Junior (2006) defende a implantação de mini-usinas na geração de eletricidade através de sistemas de cogeração. O estudo aplica conceitos de engenharia econômica e análise de viabilidades em centros educacionais e comerciais.

Pinhel (2000) avalia o impacto financeiro através de análise risco x retorno, visando o investimento em uma usina termelétrica a gás, considerando a complementaridade da geração térmica no sistema elétrico interligado, concluindo que estratégias de aumento da parcela flexível do gás devem ser priorizadas através de preços diferenciados, ou de arranjos operacionais. Riscos de falha penalizam fortemente a remuneração do investimento, devendo- 
se avaliar cuidadosamente as alternativas a fim de estabelecer um contrato de backup (calculado a partir da perda, ou redução no valor esperado do VPL).

Seabra (2008) em seu estudo afirma que usinas sucroalcoleiras, podem explorar a produção de outros produtos a exemplo dos aminoácidos e aditivos alimentares, através do baixo custo da cana e grande disponibilidade de energia. As tecnologias da hidrólise e da gaseificação, a médio e longo prazo permitirá maiores aproveitamentos, embora não constituam boas alternativas no aspecto econômico. $\mathrm{O}$ estudo da hidrólise apresentou-se economicamente mais interessante, de acordo com os critérios de aceitabilidade da TIR e do VPL, porém todas as tecnologias possuem potencial de exploração. Maiores desempenhos seriam obtidos através da integração com os processos da usina do autor aponta o setor como grande contribuinte para o desenvolvimento sustentável através do uso de biomassa.

\subsection{Biossistemas integrados}

O estudo da implantação de biossistemas integrados para tratamento de dejetos em pequenas e médias propriedades suinocultoras, bovinas e de usinas autônomas, presentes neste estudo visa mostrar a exeqüibilidade da implantação. Nada impede, contudo a implantação de tais biossistemas em grandes propriedades.

\subsubsection{Definição de biossistemas integrados}

A expressão biossistema integrado (TOLEDO, 2001) costuma ser aplicada ao desenvolvimento sistemático, de uma ou mais atividades rurais (produção de álcool, açúcar, criação de suínos, gado, caprinos, ovinos ou muares, entre outras) em uma mesma propriedade rural, de tal forma que uma atividade termine por complementar a outra, com aproveitamento total ou parcial das potencialidades de cada uma. O exemplo de biossistemas que utilizam dejetos da criação de suínos na alimentação de peixes e alevinos, reduzindo ou evitando completamente a compra de ração para estes (PILARSKI et al, 2004). Essa economia por parte da piscicultura pode ser revertida em favor da aquisição das rações e medicamentos requeridos pelos suínos. As algas criadas nos tanques de decantação, além de serem empregadas na alimentação de peixes, podem ser adicionadas às rações dos suínos, diminuindo ainda mais os custos da propriedade com tais insumos. 
Dessa forma, uma associação entre as atividades da suinocultura e da piscicultura resulta em um biossistema integrado, de grande significado para o desenvolvimento sustentável da propriedade rural.

\subsubsection{Modelos brasileiros de biosistemas integrados}

Inúmeros são os exemplos de projetos de biossistemas integrados desenvolvidos no Brasil. Apresentamos o projeto MPAB - Micro Posto de Piscicultura Acoplado a Biodigestor, desenvolvido pelo Instituto de Pesquisas Marinhas como um exemplo (TOLEDO, 2001). Este é um projeto típico de biossistema integrado, pois ocorre a integração entre os suínos e os vegetais, de maneira que os vegetais se beneficiam dos biofertilizantes produzido pelos suínos. Em troca, os vegetais podem integrar parte da alimentação dos animais, sob a forma de reforço dietético, ou participar como forragem das "camas" dos suínos.

O projeto foi parte do Programa de Desenvolvimento de Comunidades Rurais, no qual foi desenvolvido um biodigestor, envolvendo a criação extensiva ou intensiva de alevinos. $\mathrm{O}$ projeto visava, entre outras coisas, fornecer à comunidade rural carente um alimento de baixo custo e com alto valor nutritivo. O projeto priorizou, ainda, estender os benefícios do biogás e do biofertilizante à comunidade responsável pela manutenção e operação do microposto.

Uma das vantagens que o MPAB apresentou (em relação a outros projetos de Biosistemas que empregam biodigestores) é que o biodigestor indicado é aquele conhecido como biodigestor canadense (Figura 3). Neste sistema, o material a ser digerido é carregado continuamente. Nesse biodigestor todo tipo de material orgânico pode ser utilizado como biofertilizante, após ser biodigerido. 


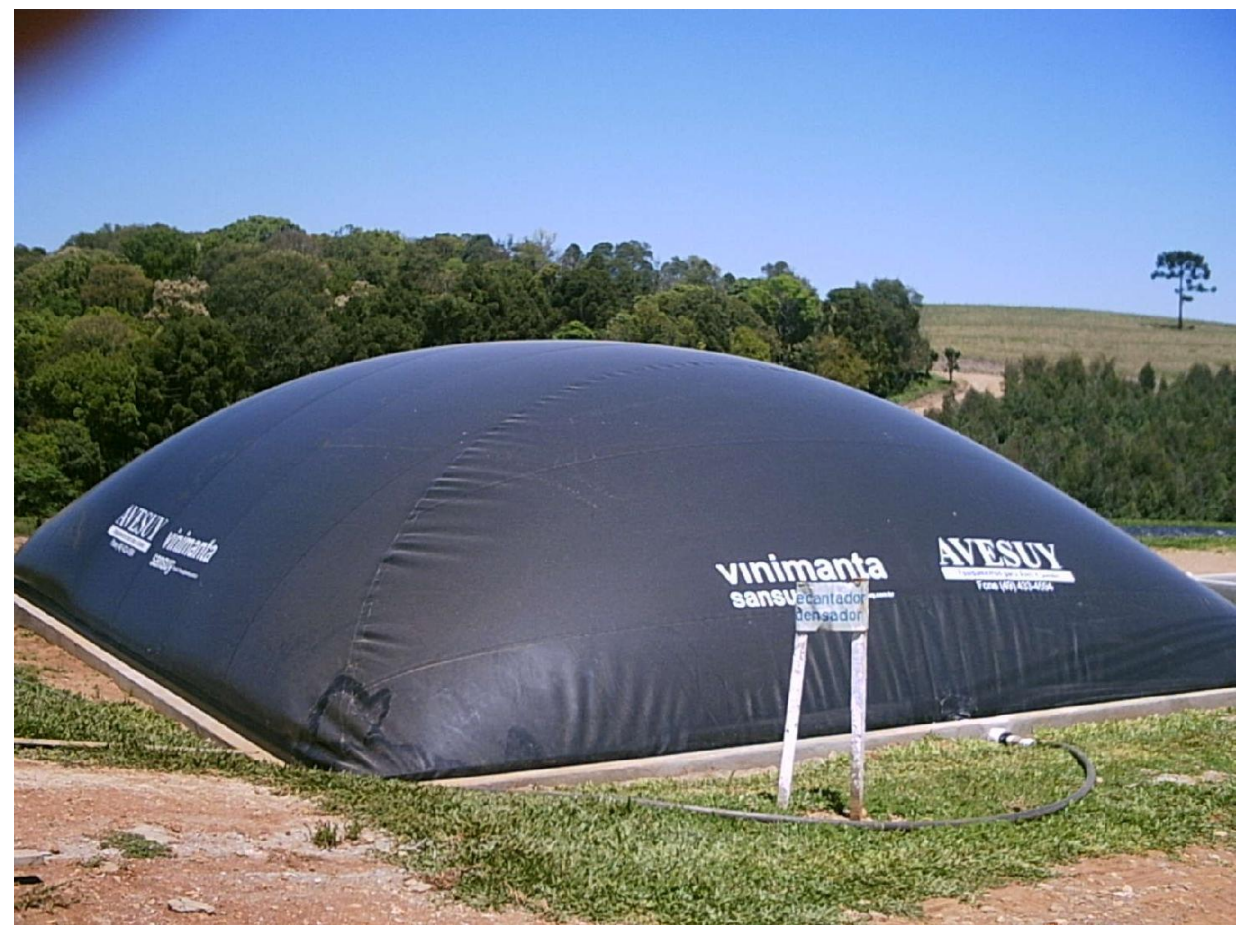

Figura 3 - Biodigestor canadense

Fonte: Oliveira, 2005.

O biodigestor canadense é, portanto, apropriado para utilização em biosistemas integrados, onde a interação entre animais, peixes, vegetais e humanos se dá de forma mais intensa.

Este estudo apresenta três configurações possíveis de interações de biosistemas. 


\section{Metodologia}

Este capítulo apresenta a metologia utilizada neste estudo, seus indicadores e conceitos, possibilitando o entendimento de cada métrica e seus objetos de estudo.

As métricas elencadas são utilizadas atualmete de forma isolada, no entanto a utilização das três métricas (emergia, termoconomia e economia-financeira) possibilitam uma visão mais ampla do sistema, por proporcionar a possibilidade de de mensuração das métricas em uma mesma unidade dimensional, cada uma com suas particularidades e limitações.

\subsection{Emergia}

A Emergia (memória energética) é utilizada como ferramenta do presente estudo com base nos conceitos apresentados por Odum (1996). O valor da emergia total incorpora todos os recursos e serviços utilizados para obtenção de um produto, processo ou serviço, sejam estes recursos provenientes do meio ambiente ou da economia. Para a análise, são construídos diagramas de energia para identificar todos os fluxos de material e energia que constituem o sistema. Esta metodologia utiliza uma álgebra própria, com a qual é possível calcular indicadores, a partir das relações entre as fontes de recursos que compõem o sistema estudado. As relações identificadas no diagrama de energia são construídas com os símbolos da Figura 4.

A unidade da emergia é o joule de emergia solar, que permite contabilizar os fluxos provenientes do meio ambiente e da economia com uma base comum, sej (solar emergy joules). A transformidade, sej/J, define a quantidade de emergia (sej) necessária para a obtenção de um joule de um produto, processo ou serviço, seja ele natural ou antropogênico. Uma vez determinada a transformidade de um produto, torna-se possível calcular a energia solar direta e indireta necessária para sua obtenção.

A contabilidade considera tanto os recursos utilizados para a implantação dos processos como aqueles empregados durante sua operação. Uma vez determinada a transformidade de certo número de produtos, torna-se possível calcular em cascata, a energia solar indireta necessária para se obter outro produto, processo ou serviço.

Brown e Mcclanahan (1996) sintetizaram de maneira prática e eficaz as etapas para observação e avaliação de um sistema produtivo com o uso da contabilidade em emergia. 
Identificando as entradas requeridas para a implantação e a operação de cada processo, mostraram como construir um diagrama de energia, as tabelas de emergia e como desenvolver a síntese em emergia. 


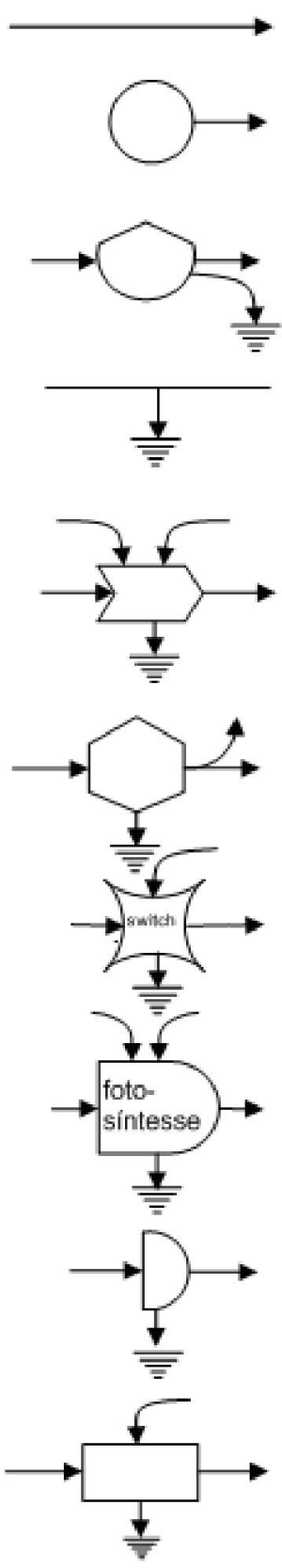

Fluxo de Energia: Um fluxo cuja vazão é proporcional ao volume do estoque ou à intensidade da fonte que o produz.

Fonte: Um recurso externo que fornece energia de acordo com um programa controlado externamente (função força).

Depósito: Uma reserva de energia dentro dos limites do sistema determinada pelo balanço de entradas e saídas.

Sumidouro de Energia: O sistema usa a energia potencial para produzir trabalho. O custo dessa transformação é a degradação da energia, que abandona o sistema como energia de baixa qualidade. Todos os processos de interação e os armazenamentos dispersam energia.

Inter ação: Interseção de no mínimo dois fluxos de energia para produzir uma saída (trabalho) que varia de acordo com certa função de energia. Exemplos: uma ação de controle de um fluxo sobre outro, presença de um fator limitante, uma válvula.

Consumidor: Unidade que usa e transforma a energia, a armazena como energia de maior qualidade e retro-alimenta energia (sistema auto-catalítico) para melhorar o fluxo de energia que recebe.

Interruptor: Um sistema de acionamento ou corte de um fluxo de energia de acordo com a ação de uma ou mais energias de controle.

Produtor: Unidade que coleta e transforma energia de baixa intensidade sob a ação de um ou mais fluxos de energia de alta qualidade.

Receptor de energia autolimitante: Uma unidade com saída autolimitada. Mesmo que de forças externas sejam altas, existe um círculo interno de energia que está controlado pela presença limitada de um material de alta qualidade.

Caixa: Símbolo de uso múltiplo que pode ser usado para representar uma unidade de consumo e produção dentro de um sistema maior. Representa um sub-sistema.

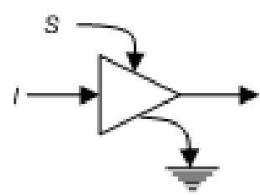

Amplificador de ganho constante: Uma unidade que fornece uma saída proporcional a uma entrada de energia, mas que pode ser modificada por um fator de ganho, contanto que a fonte de energia $S$ seja capaz de fornecer energia.

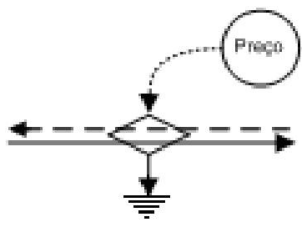

Transação: Um intercâmbio de recursos. Venda de bens ou serviços (linha contínua) em troca de um pagamento em dinheiro (linha tracejada). O preço é mostrado no símbolo como fonte de energia externa.

Figura 4. Símbolos para utilização nos diagramas em emergia (Odum,1996). 
Giannetti et al (2006) desenvolveram uma ferramenta gráfica que produz um diagrama triangular eqüilátero com três variáveis associadas a porcentagens, ao qual atribuem o nome de diagrama em emergia ternário.

Cada vértice do triângulo está associado a um fluxo renovável (R), não renovável (N) e proveniente da economia $(\mathrm{F})$ e os lados do triângulo representam combinações binárias. As combinações dos três fluxos são representadas por pontos no interior do triângulo e o valor percentual de cada fluxo é dado pela perpendicular que une o ponto e a lateral oposta ao vértice de interesse, onde é possível representar três variáveis em duas dimensões. Uma descrição completa da ferramenta gráfica é encontrada em (BARRELLA et al, 2005, ALMEIDA et al, 2005 e GIANNETTI et al, 2006).

$\mathrm{O}$ uso das propriedades dos triângulos eqüiláteros fornece informações adicionais sobre a dependência do sistema em estudo em um determinado tipo de fluxo ( $R, N$ ou F), sobre a (eco)eficiência do sistema, quanto ao uso de reservas e sobre a eficiência do suporte do ambiente, necessário à operação do sistema. A ferramenta gráfica permite comparar sistemas, produtos, processos e serviços, como também avaliar melhorias e acompanhar o desempenho do sistema ao longo do tempo. Com o auxílio dos diagramas, podem-se avaliar interações entre sistemas ou o desempenho de um setor industrial e as interações de sistemas ou do setor com o ambiente.

\subsection{Termoeconomia}

Para Tsatsaronis (1985) o termo "termoeconomia" pode ser entendido como uma combinação de uma análise termodinâmica baseada na primeira Lei da Termodinâmica, aliada a uma análise econômica convencional. Segundo o autor, o termo correto é exergoeconomia, cuja composição provém da combinação das palavras "ex" e "ergos", cuja última significa extração de trabalho, que melhor caracteriza as análises exergética e econômica.

Seu objetivo é encontrar valores referentes às variáveis do sistema (pressão, temperatura, composição química, eficiência dos equipamentos, entre outros) com a finalidade de minimizar custos de instalação, identificar a localização, magnitude e fontes de perdas termodinâmicas reais dentro do sistema, calcular separadamente os custos de cada produto que são gerados pelos sistemas que possuem mais de um produto final, como também compreender o processo de formação e fluxo de custos no sistema (TSATSARONIS, 1993 e BEJAN et al, 1996). 
Podemos entender Termoeconomia como um método de análise que fornece soluções para problemas em sistemas energéticos complexos.

Segundo Cruz (2004), é a métrica que atribui valores a insumos e produtos exergéticos.

A termoeconomia é uma ferramenta indispensável a sistemas energéticos complexos, pois alia conceitos de termodinâmica e economia, cujo objetivo é avaliar o desempenho e a eficiência de sistemas de cogeração de energia.

Para realizar uma análise termoeconômica é indispensável conhecer o conceito de exergia o qual apresentamos no próximo tópico.

\subsubsection{Conceito de exergia}

As bases que fundamentam o princípio de exergia começaram a surgir em 1824, quando o conceito de máquina proposto por Sadi Nicolas Lionard Carnot revela-se a alternativa mais eficiente no uso da energia sob a forma de calor para a realização de trabalho útil (HOJAS, 2007).

Segundo Kotas (1985), exergia é a máxima quantidade de trabalho obtida quando uma massa é trazida até um estado de equilíbrio termodinâmico com os componentes comuns do meio ambiente, através de processos reversíveis, envolvendo interação apenas com os componentes do meio ambiente.

Entende-se por valor termodinâmico real o custo da energia útil, e de acordo com Nogueira (2001) a energia sempre se conserva qualquer que seja o processo desenvolvido, entretanto sua realização de trabalho pode diminuir.

Para melhor entendimento utilizaremos os trabalhos de Szargut el al (1988), Wall e Gong (2001) e Dincer e Cengel (2001) onde os autores realizam uma comparação dos conceitos entre energia e exergia, conforme Tabela 1. 
Tabela 1. Comparação entre conceitos de energia e exergia.

\begin{tabular}{|l|l|}
\hline ENERGIA & EXERGIA \\
\hline $\begin{array}{l}\text { Depende somente de parâmetros dos fluxos de energia e matéria e } \\
\text { independe de parâmetros ambientais, onde "nada desaparece" }\end{array}$ & $\begin{array}{l}\text { Depende dos parâmetros ambientais, dos parâmetros de fluxos de } \\
\text { matéria e dos parâmetros dos fluxos de energia, onde "tudo se } \\
\text { dispersa" }\end{array}$ \\
\hline Está sujeita à lei de conservação & Não está sujeita à lei de conservação \\
\hline $\begin{array}{l}\text { Energia é conservada, isto é, em balanço energia nunca pode ser } \\
\text { produzida ou consumida. }\end{array}$ & $\begin{array}{l}\text { Exergia sempre se conserva em processos reversíveis e é consumida } \\
\text { em processos irreversíveis (processos reais), isto é, exergia nunca está } \\
\text { em balanço para processos reais }\end{array}$ \\
\hline É uma função do estado da matéria em consideração & $\begin{array}{l}\text { É uma função do estado da matéria em consideração e da matéria em } \\
\text { relação ao meio ambiente }\end{array}$ \\
\hline Energia é o movimento ou a capacidade de gerar movimento & \begin{tabular}{l} 
Exergia é trabalho ou a capacidade de produzir trabalho. \\
\hline No caso do gás ideal, não depende da pressão
\end{tabular} \\
\hline Energia tem valor diferente de zero & $\begin{array}{l}\text { Exempre depende da pressão } \\
\text { meio de referência }\end{array}$ \\
\hline "Tudo é energia" & "Contraste é exergia" \\
\hline Energia é uma medidade de quantidade & Exergia é uma medida de quantidade e de qualidade \\
\hline Para o vácuo ideal é igual a zero & Para o vácuo ideal é positiva \\
\hline
\end{tabular}

\subsection{Análise econômica financeira}

Segundo Friedman (1953), os objetivos da análise econômica finaceira incluem a formulação de teorias que sejam mais simples, mais frutíferas e mais confiáveis do que outras teorias ou nenhuma teoria. A análise pode começar com um simples modelo que propõe uma hipótese de uma variável a ser explicada por outra variável. Com frequência uma hipótese em economia é somente qualitativa, não quantitativa isto é, a hipótese implica a direção de uma mudança em uma variável, não a dimensão da mudança, para certa mudança de outra variável (QUIRK, 1987). Para clareza de exposição, a teoria qualitativa pode proceder com a suposição de ceteris paribus, isto é, mantendo constante outros termos explicatórios que não aquele em questão. No entanto, a teoria quantitativa da moeda prediz um aumento no valor nominal da produção a partir de um aumento da oferta de moeda.

A economia financeira, muitas vezes chamada simplesmente de finanças, está preocupada com a alocação dos recursos financeiros em um ambiente de risco (ou incerteza). Assim, seu foco está na operação dos mercados financeiros, na avaliação de preços de ativos financeiros, e na estrutura financeira das empresas (ROSS, 1987).

Em suma, a análise econômica apresenta resultados monetários que viabilizam ou não um empreendimento, de acordo com seus indicadores. 
4. Descrição dos sistemas utilizados no estudo

A priori, o desenvolvimento desta tese visa analisar e estudar os biossistemas de modo à visualisar suas interações. Foram desta forma, considerados dentro dos limites dos sistemas o aproveitamento de todos os resíduos para conversão em eletricidade, não avaliando os resultados de outros produtos do sistema. A representação gráfica das fronteiras dos sistemas é apresentada nas Figuras 5, 6 e 7.

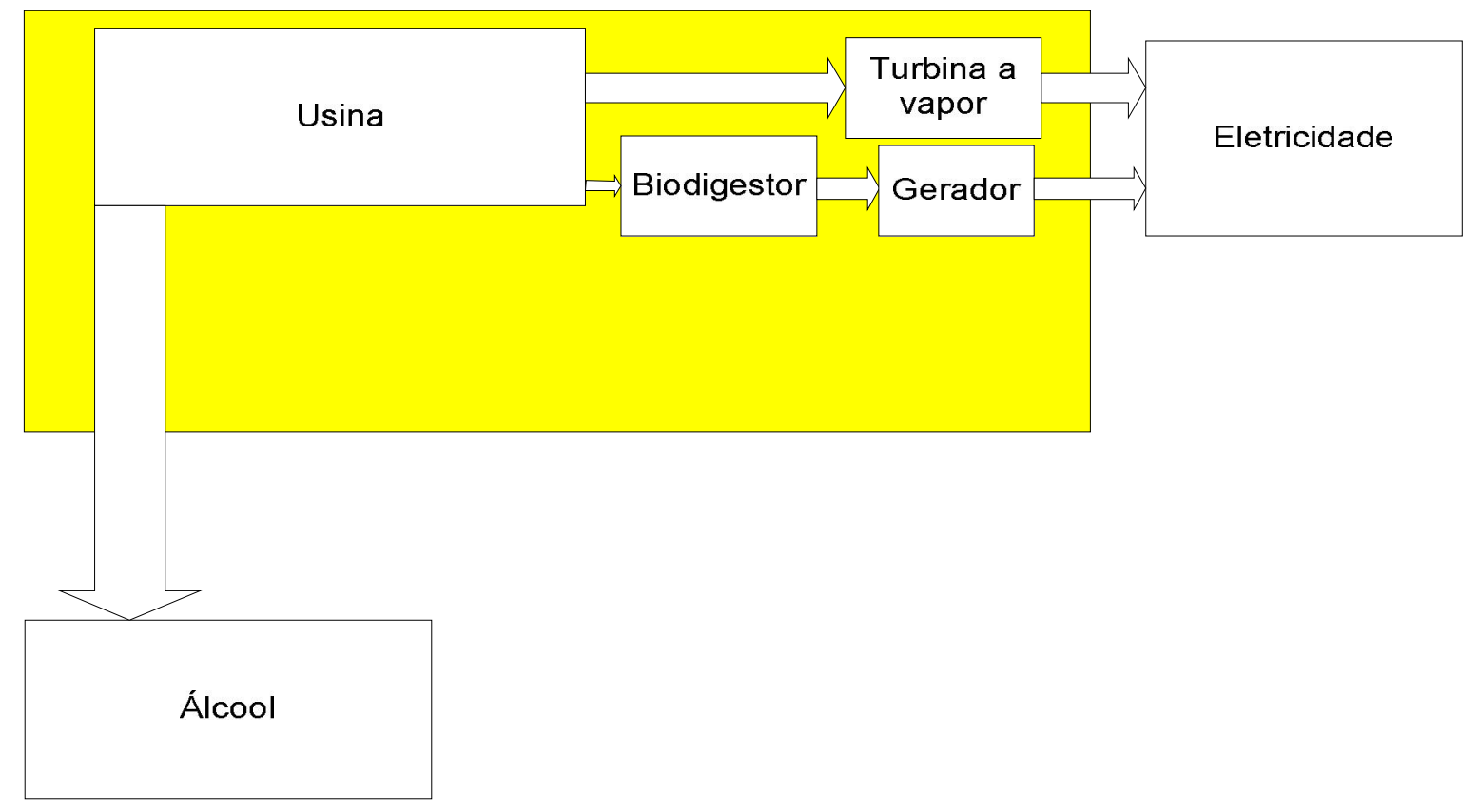

Figura 5 - Configuração da usina autônoma. 


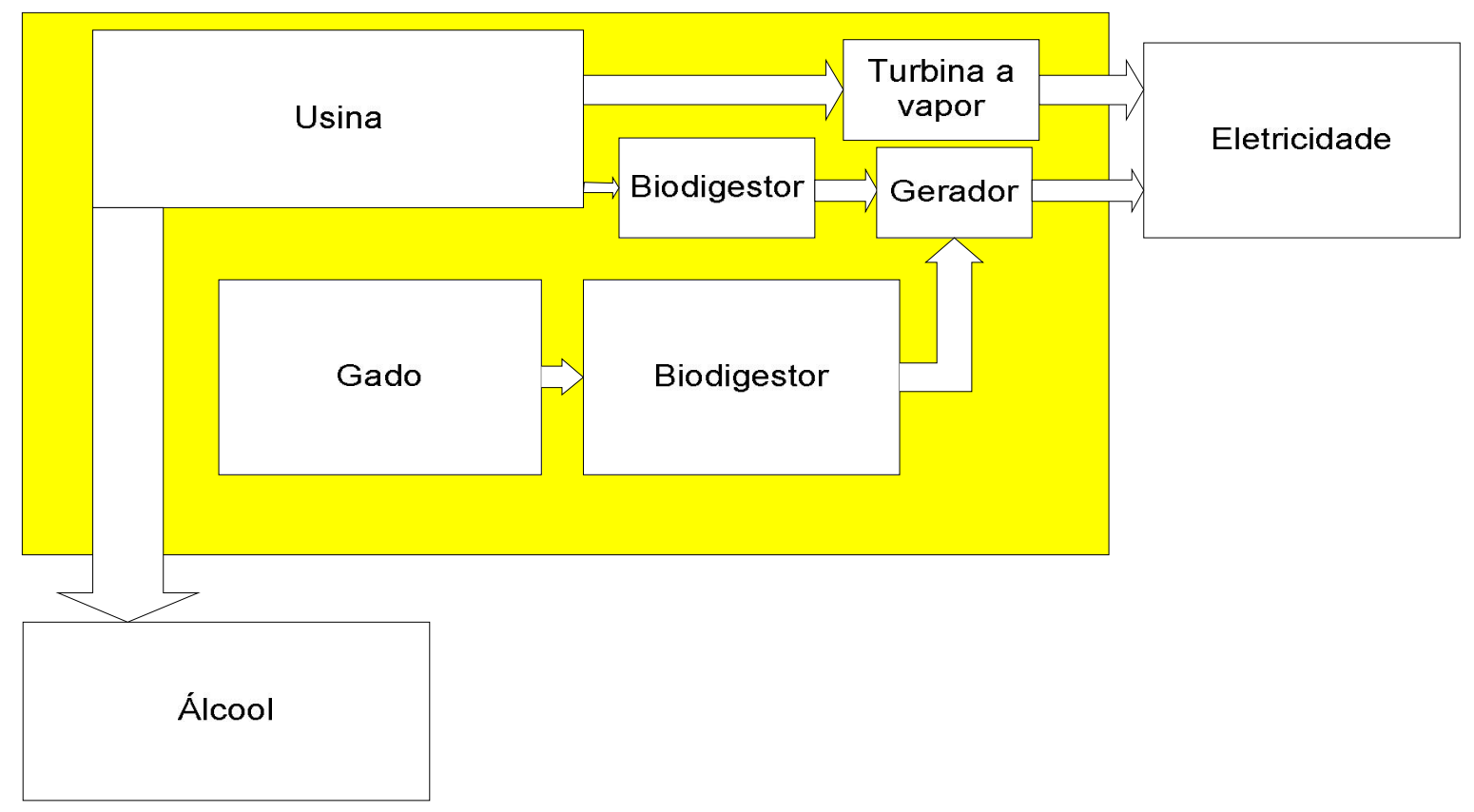

Figura 6 - Configuração da integração usina autônoma com criação de gado.

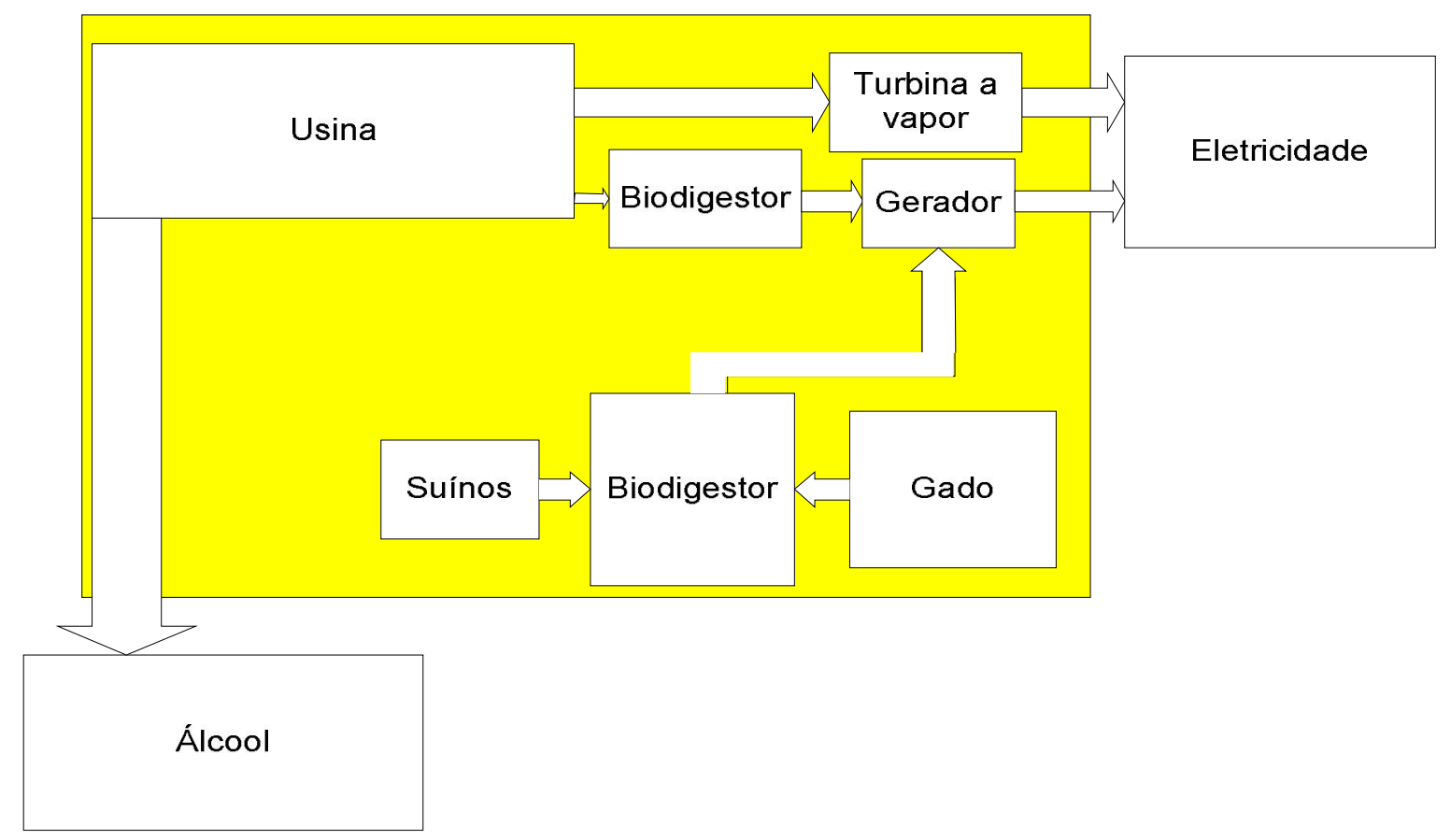

Figura 7 - Configuração de integração da usina autônoma com criação de gado e suínos 


\subsection{Usina autônoma}

O objeto de estudo desse trabalho foi à usina abordada por Ometto et al (2006), idealizada em uma área de 4360 ha, onde 1494 ha são utilizados para o plantio de cana, produzindo 40000 litros de álcool diários, e 27,1 kWh de eletricidade excedente por tonelada de cana utilizando uma caldeira de $67 \mathrm{bar} / 480^{\circ} \mathrm{C}$, operando durante 210 dias ao ano.

A usina em estudo se diferencia das usinas tradicionais por estar integrada à criação de gado em semiconfinamento para corte e leite.Para analisar esta usina, foi realizada a partição dos insumos utilizados para a operação da usina isoladamente, e em seguida um estudo de sua operação em conjunto com a criação de gado e outro com a criação de gado e suínos.

\subsection{Criação de gado}

O objeto de estudo desse trabalho foi o desenvolvido por Ometto et al (2006), idealizado em uma área de 4360 ha, onde 180 ha são utilizados somente para o gado em regime de confinamento. O rebanho é composto por 3438 animais que produzem 947 toneladas de carne, 5668 litros de leite e $1,18.10^{7} \mathrm{kWh}$ de eletricidade anuais .

\subsection{Criação de suínos}

O sistema utilizado para a análise da produção de suínos, deste estudo está baseado na simulação idealizada por Cavalett, 2004, adaptada para 5400 suínos, produzindo 378 toneladas de carne e $8,65.10^{6} \mathrm{kWh}$ de eletricidade anuais. Os valores dos recursos naturais foram estimados com base em valores médios para a região de Campinas.

O estudo de Ortega (2003) forneceu os dados referentes à transformidade do milho. O autor calcula os percentuais dos fluxos de R, N e F (Anexo A), os quais são utilizados neste estudo. 


\section{Análise em emergia}

A obtenção dos dados necessários para a contabilidade em emergia referentes à usina de álcool e criação de gado, foi extraída do artigo de Ometto et al, 2006, e para a criação de suínos os dados de Cavalett, 2004. As transformidades e as emergias por massa utilizada neste trabalho foram retiradas da literatura (Tabela 2).

Tabela 2. Transformidade e emergias por unidade usada neste estudo.

\begin{tabular}{|c|c|c|c|}
\hline Item & Emergia por unidade & Unidade & Referências \\
\hline Sol & 1,00 & $\mathrm{sej} / \mathrm{J}$ & Por definição \\
\hline Vento & $2,45.10^{3}$ & sej/J & Odum, 2000 \\
\hline Precipitação & $1,82.10^{4}$ & sej/J & apud Ometto et al, 2006 \\
\hline Chuva & $4,70.10^{4}$ & sej/J & Odum, 2000 \\
\hline Combustível & $5,50.10^{4}$ & sej/J & Bastianoni et al., 2001 \\
\hline Perda de solo & $7,38.10^{4}$ & sej/J & apud Ometto et al, 2006 \\
\hline Água de aquífero & $1,10.10^{5}$ & sej/J & apud Ometto et al, 2006 \\
\hline Água de poço & $1,76.10^{5}$ & sej/J & Odum, 2000 \\
\hline Suínos & $9,21.10^{5}$ & sej/J & Cavalett, 2004 \\
\hline Gado & $1,73.10^{6}$ & sej/J & apud Ometto et al, 2006 \\
\hline Mão de Obra & $4,30.10^{6}$ & sej/J & Silva, 2006 \\
\hline Milho & $9,25.10^{8}$ & sej/g & Ortega, 2003 \\
\hline Mudas & $1,47.10^{9}$ & sej/g & apud Ometto et al, 2006 \\
\hline Defensivo agrícola & $1,48.10^{9}$ & sej/g & apud Ometto et al, 2006 \\
\hline Nutrientes & $3,00.10^{9}$ & sej/g & apud Ometto et al, 2006 \\
\hline Nitrogênio & $4,61.10^{9}$ & sej/g & apud Ometto et al, 2006 \\
\hline Núcleo & $6,08.10^{9}$ & sej/g & apud Cavalett, 2004 \\
\hline Insumos & $3,80.10^{12}$ & sej/g & apud Ometto et al, 2006 \\
\hline Farelo & $3,26.10^{12}$ & sej/g & apud Cavalett, 2004 \\
\hline Dolar & $3,70.10^{12}$ & sej/\$ & Coelho et al, 2002 \\
\hline Insumos & $3,80.10^{12}$ & $\mathrm{sej} / \mathrm{g}$ & apud Ometto et al, 2006 \\
\hline Aço & $1,80.10^{15}$ & sej/g & apud Ometto et al, 2006 \\
\hline
\end{tabular}

Durante a pesquisa foram quantificados todos os materiais, equipamentos e mão-deobra para implantação e operação dos biossistemas.

Os fluxos de entrada de cada sistema de tratamento de efluente foram classificados em três categorias: R, N e F, mostrados separadamente nas tabelas considerando duas etapas: (i) fase de implantação e (ii) fase de operação. Por fim, foram utilizados os indicadores em emergia para a comparação entre os sistemas. 


\subsection{Indicadores}

Os indicadores utilizados foram desenvolvidos por Odum (1996). O rendimento em emergia (EYR), o investimento em emergia (EIR), o índice de carga ambiental (ELR). Além destes indicadores foi também calculado o índice de sustentabilidade (ESI). O ESI, proposto por Ulgiati e Brown (1998), apresenta a razão entre EYR e ELR. O percentual de emergia renovável (\%R) também é utilizado para comparar os sistemas de geração de energia. A Tabela 3 mostra as equações para o cálculo dos indicadores, assim como uma breve descrição de sua utilização.

Tabela 3. Indicadores em emergia utilizados neste estudo.

\begin{tabular}{|c|c|c|c|}
\hline Descrição & Indicador & Equação & \\
\hline $\begin{array}{l}\text { Rendimento em emergia é a relação entre a emergia total }(\mathrm{Y}) \text { e a emergia dos insumos } \\
\text { (F). É um indicador da emergia líquida que o sistema gera, pois fornece a habilidade do } \\
\text { processo para explorar recursos locais provenientes da natureza, sejam renováveis ou } \\
\text { não. O valor mínimo é a unidade, que ocorre quando a contribuição da natureza é nula } \\
(\mathrm{R}+\mathrm{N}=0) \text {. A diferença do valor unitário mede a contribuição do meio ambiente. }\end{array}$ & EYR & $\begin{array}{l}\mathrm{Y} /(\mathrm{F}) \\
\text { onde } \\
\mathrm{Y}=\mathrm{R}+\mathrm{N}+\mathrm{F}\end{array}$ & (1) \\
\hline $\begin{array}{l}\text { Investimento em emergia: mede o investimento da sociedade no sistema em relação à } \\
\text { contribuição da natureza; avalia se o processo usa adequadamente os recursos locais. Um } \\
\text { índice baixo indica que o ambiente provê mais recursos para o processo que a economia } \\
\text { (materiais e serviços). Pode medir o desenvolvimento econômico. ODUM (1996) } \\
\text { menciona que, em países desenvolvidos, o EIR tende a ser } 7 \text { ou maior. }\end{array}$ & EIR & $(\mathrm{F}) /(\mathrm{N}+\mathrm{R})$ & (2) \\
\hline $\begin{array}{l}\text { Índice de Carga Ambiental: Mede a proporção de recursos não renováveis em relação } \\
\text { aos renováveis para um dado processo produtivo; é um indicador da tensão que a } \\
\text { atividade produtiva analisada produz no ecossistema. }\end{array}$ & ELR & $(\mathrm{N}+\mathrm{F}) / \mathrm{R}$ & (3) \\
\hline $\begin{array}{l}\text { Índice de Sustentabilidade: Mede a taxa de sustentabilidade. Valores maiores indicam } \\
\text { sustentabilidade por períodos de tempo maior. Um sistema para ser considerado } \\
\text { sustentável por longo prazo deve ter uma baixa carga ambiental e alto rendimento em } \\
\text { emergia. }\end{array}$ & ESI & EYR/EIR & (4) \\
\hline $\begin{array}{l}\text { Percentual de recursos renováveis: Indica a porcentagem de energia que é derivada de } \\
\text { fontes renováveis. Os sistemas com alto valor deste índice são mais sustentáveis. }\end{array}$ & $\% \mathrm{R}$ & $100 *(\mathrm{R} / \mathrm{Y})$ & (5) \\
\hline
\end{tabular}

Com base nos valores dos fluxos ( $\mathrm{R}, \mathrm{N}$ e F) dos sistemas estudados, é possível aplicar o diagrama ternário (Barrella et al., 2005, Almeida et al., 2005 e Giannetti et al, 2006) para realizar a comparação entre as configurações propostas para os biossistemas de geração de eletricidade

\subsection{Resultados da análise em emergia}

A análise em emergia tem início com a construção de diagramas de energia utilizando os símbolos da Figura 4. A observação dos diagramas auxilia na identificação dos limites estabelecidos para os sistemas estudados, assim como na identificação de seus principais componentes e das interações entre eles. Nos diagramas são identificados todos os fluxos de 
material, energia e serviços necessários para a operação dos sistemas. Para a análise em emergia é atribuída uma linha que atravessa as fronteiras dos sistemas que representa um fluxo. Vale lembrar que as fronteiras foram estabelecidas, neste estudo de acordo com a operação de cada sistema. No biossistema da usina autônoma considerou-se a quantidade de insumos necessários para sua implantação e operação. Para os biossistemas integrados os insumos comuns (biodigestor, motogerador).

\subsubsection{Sistema da usina autônoma}

O diagrama de energia do sistema da usina autônoma é mostrado na Figura 8, onde podemos observar todos os fluxos de energia que circulam no sistema e as interações do sistema com o meio ambiente, esta figura foi adaptada do trabalho de Ometo et al, 2006, de onde foram retiradas as trocas financeiras com o mercado, os impostos e a criação de gado, e incluso um sistema de geração de eletricidade através de um motor do ciclo Otto.

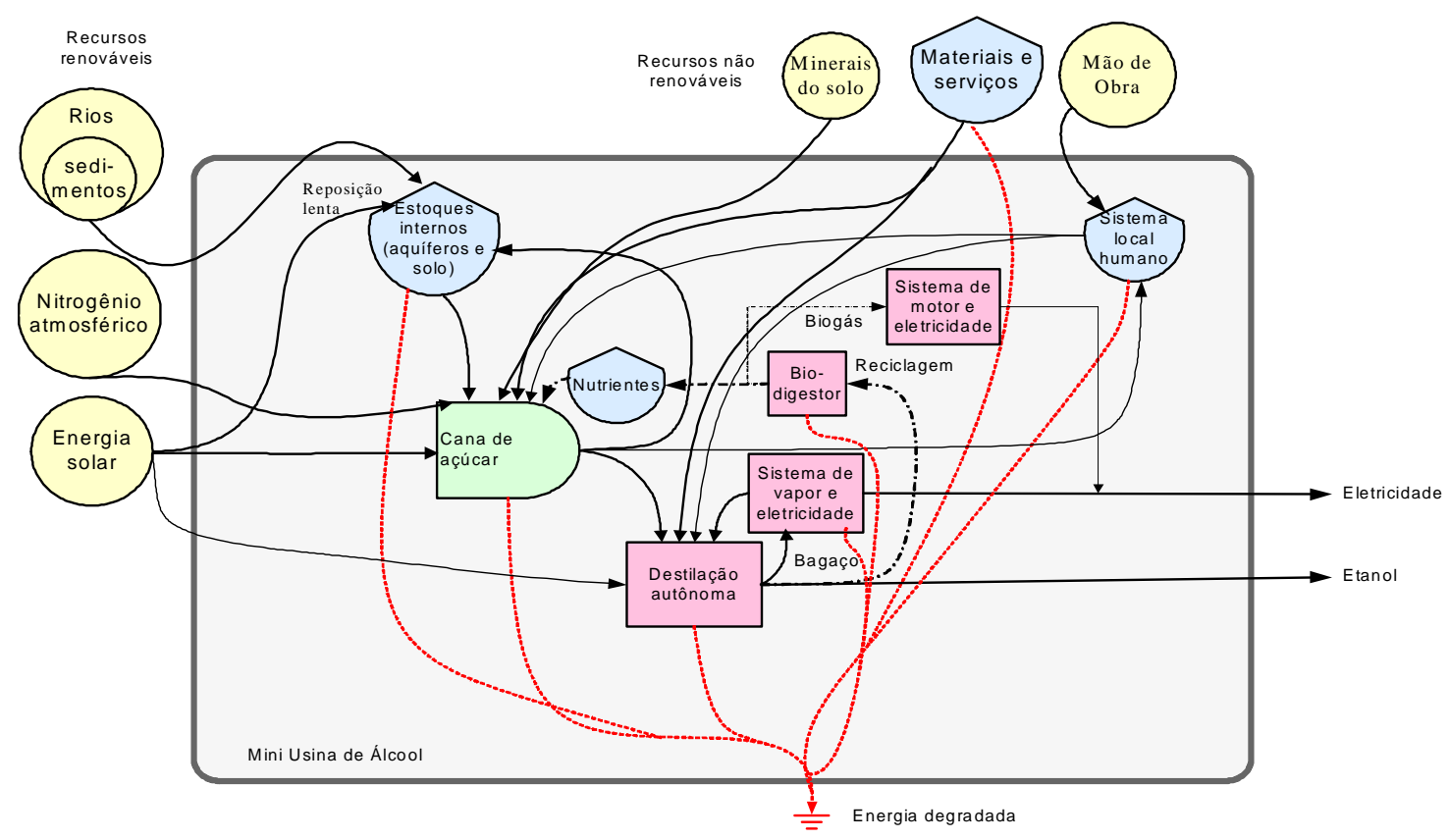

Figura 8. Diagrama de energia do sistema da usina autônoma. (adaptado de Ometto et al, 2006) 
A Tabela 4 apresenta os fluxos de material e energia que participam do sistema da usina autônoma.

Tabela 4. Avaliação da emergia do sistema da usina autônoma (*)

\begin{tabular}{|c|c|c|c|c|c|c|c|}
\hline Z & Descrição & 宽 & 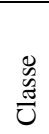 & /(un/ano) & $\begin{array}{l}\text { Emergia por } \\
\text { unidade } \\
\text { (sej/un) }\end{array}$ & $\begin{array}{l}\text { Emergia } \\
\text { /(sej/ano) }\end{array}$ & $/(\mathrm{sej} / \mathrm{sej})$ \\
\hline & Fase de I mplantação & & & & & & \\
\hline 1 & Mudas & g/ano & $\mathrm{R}$ & $4,30.10^{7}$ & $1,47.10^{9}$ & $6,32 \cdot 10^{16}$ & $1 \%$ \\
\hline 2 & Perda de solo & $\mathrm{J} /$ ano & $\mathrm{N}$ & $6,15 \cdot 10^{12}$ & $7,38.10^{4}$ & $4,54 \cdot 10^{17}$ & $8 \%$ \\
\hline 3 & Equip. e infraestrutura & \$/ano & $\mathrm{F}$ & $2,64.10^{5}$ & $3,70 \cdot 10^{12}$ & $9,76.10^{17}$ & $17 \%$ \\
\hline 4 & Aço para construção dos reatores e filtros UASB & g/ano & $\mathrm{F}$ & $9,43.10^{4}$ & $1,80.10^{9}$ & $1,70.10^{14}$ & $<1 \%$ \\
\hline 5 & $\begin{array}{l}\text { Mão de obra } \\
\text { Fase de O peração }\end{array}$ & J/ano & $\mathrm{F}$ & $9.63 .10^{10}$ & $4,30.10^{6}$ & $4,14 \cdot 10^{17}$ & $7,0 \%$ \\
\hline 6 & Precipitação & J/ano & $\mathrm{R}$ & $8,86 \cdot 10^{13}$ & $1,82.10^{4}$ & $1,61.10^{18}$ & $29 \%$ \\
\hline 7 & Nutritentes (rocha mãe) & g/ano & $\mathrm{R}$ & $2,69.10^{7}$ & $3,00.10^{9}$ & $8,07.10^{16}$ & $1 \%$ \\
\hline 8 & Nitrogênio (atm) & $\mathrm{J} /$ ano & $\mathrm{R}$ & $1,05.10^{7}$ & $4,61.10^{9}$ & $4,82 \cdot 10^{16}$ & $<1 \%$ \\
\hline 9 & Água de aquífero & J/ano & $\mathrm{R}$ & $3,69.10^{9}$ & $1,10.10^{5}$ & $4,06 \cdot 10^{14}$ & $<1 \%$ \\
\hline 10 & Insumos & g/ano & $\mathrm{F}$ & $4,88.10^{7}$ & $3,80.10^{9}$ & $1,86 \cdot 10^{17}$ & $3 \%$ \\
\hline 11 & Defensivos agrícolas & g/ano & $\mathrm{F}$ & $3,59 \cdot 10^{6}$ & $1,48.10^{9}$ & $5,31 \cdot 10^{15}$ & $<1 \%$ \\
\hline 12 & Mão de obra & $\mathrm{J} /$ ano & $\mathrm{F}$ & $3,66 \cdot 10^{11}$ & $4,30.10^{6}$ & $1,58.10^{18}$ & $28 \%$ \\
\hline 13 & Operações agrícolas & \$/ano & $\mathrm{F}$ & $1,10.10^{4}$ & $3,70 \cdot 10^{12}$ & $4,08 \cdot 10^{16}$ & $1 \%$ \\
\hline \multirow[t]{2}{*}{14} & Manutenção & \$/ano & $\mathrm{F}$ & $4,85.10^{4}$ & $3,70.10^{12}$ & $1,79.10^{17}$ & $3 \%$ \\
\hline & Emergia Total & & & & & $5,63.10^{18}$ & $100,0 \%$ \\
\hline
\end{tabular}

(*) Cálculos detalhados no Anexo A

\subsubsection{Análise em emergia}

A emergia total do sistema da usina autônoma tem valor de 5,63.10 ${ }^{18} \mathrm{sej} / \mathrm{ano}$. Aproximadamente $8 \%$ sej/sej de recursos não renováveis são utilizados, $32 \%$ sej/sej são de recursos renováveis e $60 \%$ sej/sej dos recursos da economia. O sistema utiliza aproximadamente $33,4 \%$ sej/sej de sua emergia total na implantação e 66,7\% sej/sej durante a sua operação.

A unidade funcional adotada foi $1 \mathrm{MWh}$ de eletricidade. A produção de eletricidade excedente anual da usina é de $7,17.10^{3} \mathrm{MWh}$, a emergia por unidade encontrada foi de $7,86 \times 10^{14}$ sej/MWh e transformidade de $2,12.10^{5} \mathrm{sej} / \mathrm{J}$. 
5.2.2. Biossistema de usina autônoma com criação de gado

O diagrama de energia do biossistema da usina autônoma integrada com a criação de gado é mostrado na Figura 9. No diagrama, podemos observar todos os fluxos de energia que circulam no sistema e as interações do sistema com o meio ambiente, esta figura foi adaptada do trabalho de Ometo et al, 2006, de onde foram retiradas as trocas financeiras com o mercado e os impostos, e incluso um sistema de geração de eletricidade através de um motor do ciclo Otto.

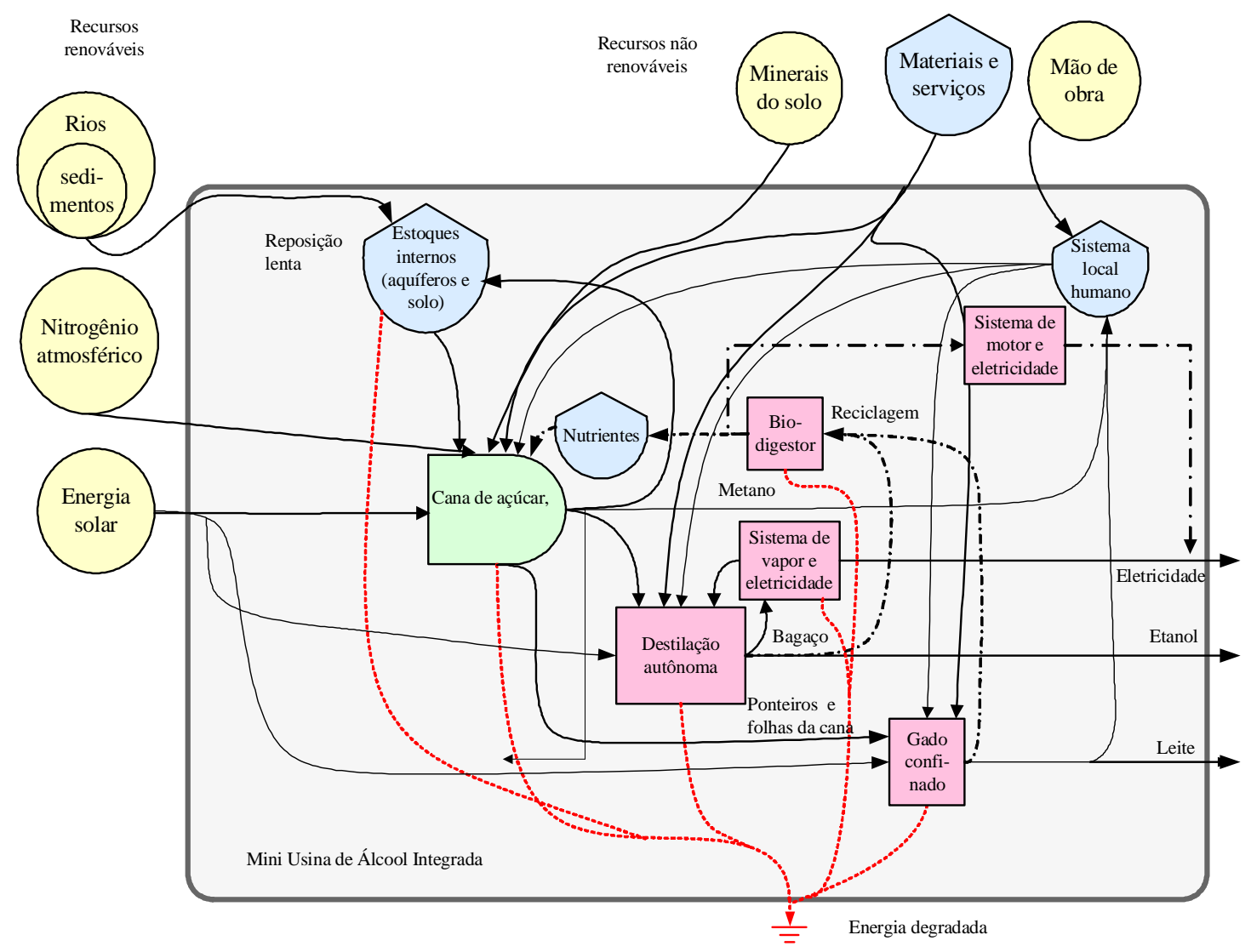

Figura 9. Diagrama de energia do biossistema da usina autônoma com criação de gado. (adaptado de Ometto et al, 2006). 
A Tabela 5 apresenta os fluxos de material e energia que participam do biossistema da usina autônoma com criação de gado.

Tabela 5. Avaliação da emergia do biossistema da usina autônoma com criação de gado (*)

\begin{tabular}{|c|c|c|c|c|c|c|c|}
\hline \multirow[b]{2}{*}{$\begin{array}{l}\text { đ̃ } \\
\text { Z }\end{array}$} & Descrição & \multirow[b]{2}{*}{ 葋 } & \multirow[b]{2}{*}{ 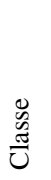 } & \multirow{2}{*}{$\begin{array}{l}\text { Valor } \\
\text { /(un/ano) }\end{array}$} & \multirow{2}{*}{$\begin{array}{l}\text { Emergia por } \\
\text { unidade } \\
\text { /(sej/un) }\end{array}$} & \multirow{2}{*}{$\begin{array}{l}\text { Emergia } \\
\text { /(sej/ano) }\end{array}$} & \multirow{2}{*}{$\begin{array}{l}\% \\
/(\text { sej/sej) }\end{array}$} \\
\hline & & & & & & & \\
\hline & \multicolumn{7}{|l|}{ Fase de I mplantação } \\
\hline 1 & Mudas & g/ano & $\mathrm{R}$ & $4,30 \cdot 10^{7}$ & $1,47.10^{9}$ & $6,32 \cdot 10^{16}$ & $1 \%$ \\
\hline 2 & Gado & $\mathrm{J} /$ ano & $\mathrm{R}$ & $6,39 \cdot 10^{10}$ & $1,73.10^{6}$ & $1,11.10^{17}$ & $2 \%$ \\
\hline 3 & Perda de solo & J/ano & $\mathrm{N}$ & $6,89 \cdot 10^{12}$ & $7,38.10^{4}$ & $5,08 \cdot 10^{17}$ & $7 \%$ \\
\hline 4 & Equip. e infraestrutura usina e gado & \$/ano & $\mathrm{F}$ & $2,71.10^{5}$ & $3,70 \cdot 10^{12}$ & $1,00 \cdot 10^{18}$ & $14 \%$ \\
\hline \multirow[t]{2}{*}{5} & Aço para construção dos reatores e filtros & & & & & & \\
\hline & UASB & g/ano & $\mathrm{F}$ & $9,43.10^{4}$ & $1,80.10^{9}$ & $1,70.10^{14}$ & $<1 \%$ \\
\hline 6 & Mão de obra & $\mathrm{J} /$ ano & $\mathrm{F}$ & $9,63 \cdot 10^{10}$ & $4,30.10^{6}$ & $4,14 \cdot 10^{17}$ & $6 \%$ \\
\hline 7 & Currais do gado & \$/ano & F & $2,92.10^{3}$ & $3,70.10^{12}$ & $1,08 \cdot 10^{16}$ & $<1 \%$ \\
\hline 8 & Valas de ração & \$/ano & $\mathrm{F}$ & $1,33 \cdot 10^{3}$ & $3,70.10^{12}$ & $4,93 \cdot 10^{15}$ & $<1 \%$ \\
\hline 9 & $\begin{array}{l}\text { Biodigestor } \\
\text { Fase de O peração }\end{array}$ & \$/ano & $\mathrm{F}$ & $1,00.10^{3}$ & $3,70.10^{12}$ & $3,70.10^{15}$ & $<1 \%$ \\
\hline 10 & Precipitação & $\mathrm{J} /$ ano & $\mathrm{R}$ & $9,92 \cdot 10^{13}$ & $1,82.10^{4}$ & $1,81 \cdot 10^{18}$ & $25 \%$ \\
\hline 11 & Nutrientes & g/ano & $\mathrm{R}$ & $3,01.10^{7}$ & $3,00.10^{9}$ & $9,04 \cdot 10^{16}$ & $1 \%$ \\
\hline 12 & Nitrogênio & $\mathrm{J} /$ ano & $\mathrm{R}$ & $1,17.10^{7}$ & $4,61.10^{9}$ & $5,40 \cdot 10^{16}$ & $1 \%$ \\
\hline 13 & Água de aquífero & $\mathrm{J} /$ ano & $\mathrm{R}$ & $4,13.10^{9}$ & $1,10.10^{5}$ & $4,55 \cdot 10^{14}$ & $<1 \%$ \\
\hline 14 & Mão de obra & $\mathrm{J} /$ ano & $\mathrm{F}$ & $4,57 \cdot 10^{11}$ & $4,30.10^{6}$ & $1,96 \cdot 10^{18}$ & $27 \%$ \\
\hline 15 & Trato do Gado ( $80 \%$ ) outros $20 \%$ pontas & \$/ano & $\mathrm{F}$ & $1,87.10^{5}$ & $3,70 \cdot 10^{12}$ & $6,93 \cdot 10^{17}$ & $10 \%$ \\
\hline 16 & Manutenção & \$/ano & $\mathrm{F}$ & $6,82.10^{4}$ & $3,70.10^{12}$ & $2,52 \cdot 10^{17}$ & $3 \%$ \\
\hline 17 & Insumos & g/ano & $\mathrm{F}$ & $4,88 \cdot 10^{7}$ & $3,80.10^{9}$ & $1,86.10^{17}$ & $3 \%$ \\
\hline 18 & Defensivos agrícolas & g/ano & $\mathrm{F}$ & $3,59 \cdot 10^{6}$ & $1,48.10^{9}$ & $5,31 \cdot 10^{15}$ & $<1 \%$ \\
\hline \multirow[t]{2}{*}{19} & Operações agrícolas & $\$$ /ano & $\mathrm{F}$ & $1,10.10^{4}$ & $3,70.10^{12}$ & $4,08 \cdot 10^{16}$ & $1 \%$ \\
\hline & Emergia Total & & & & & $7,21.10^{18}$ & $100,0 \%$ \\
\hline
\end{tabular}

(*) Cálculos detalhados no Anexo A

\subsubsection{Análise em emergia}

A emergia total do biossistema de usina autônoma com criação de gado tem valor de $7,21.10^{18}$ sej/ano. Aproximadamente $7 \%$ sej/sej de recursos não renováveis são utilizados, $29,5 \%$ sej/sej são de recursos renováveis e $63,5 \%$ sej/sej dos recursos da economia. O sistema utiliza aproximadamente 34\% sej/sej de sua emergia total na implantação e $66 \%$ sej/sej durante a sua operação.

A unidade funcional adotada foi $1 \mathrm{MWh}$ de eletricidade. A produção de eletricidade excedente anual da usina é de $1,90.10^{4} \mathrm{MWh}$, a emergia por unidade encontrada foi de $3,80.10^{14} \mathrm{sej} / \mathrm{MWh}$ e a transformidade de $1,05.10^{5} \mathrm{sej} / \mathrm{J}$. 
5.2.3. Biossistema da usina autônoma com criação de gado e suínos

O diagrama de energia do biossistema da usina autônoma com criação de gado e suínos é mostrado na Figura 10. No diagrama, podemos observar todos os fluxos de energia que circulam no sistema e as interações do sistema com o meio ambiente, esta figura foi adaptada do trabalho de Ometo et al, 2006, de onde foram retiradas as trocas financeiras com o mercado, os impostos, e inclusos a criação de suínos e o sistema de geração de eletricidade através de um motor do ciclo Otto.

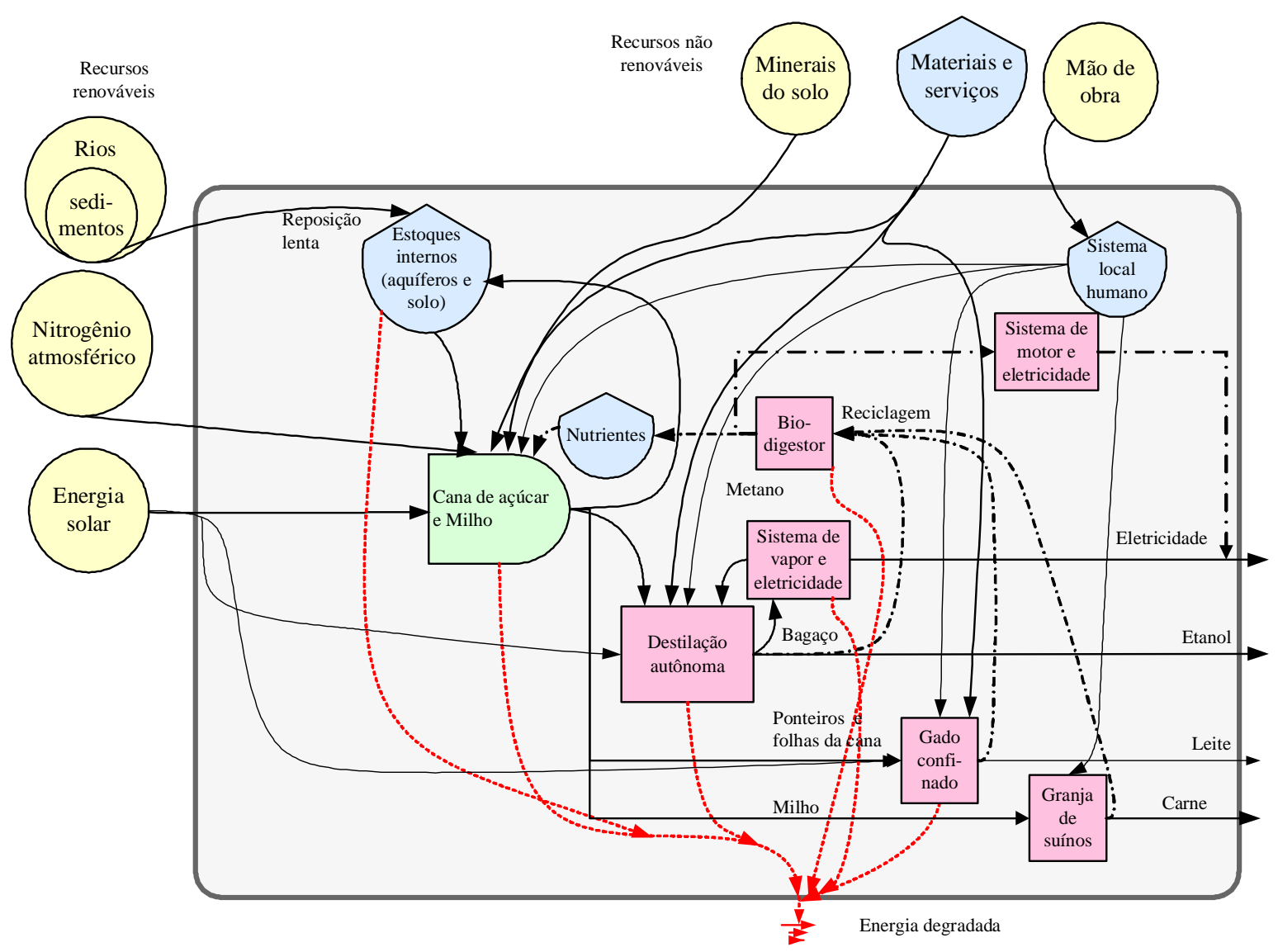

Figura 10. Diagrama de energia do biossistema da usina autônoma com criação de gado e suínos. (adaptado de Ometto et al, 2006) 
A Tabela 6 apresenta os fluxos de material e energia que participam do da usina autônoma com criação de gado e suínos.

Tabela 6. Avaliação da emergia do biossistema da usina autônoma com criação de gado e suínos (*)

\begin{tabular}{|c|c|c|c|c|c|c|c|}
\hline 苛 & Descrição & 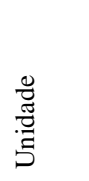 & $\begin{array}{l}0 \\
\tilde{D} \\
\tilde{\Xi} \\
\end{array}$ & /(un/ano) & $\begin{array}{l}\text { Emergia por } \\
\text { unidade }\end{array}$ & $\begin{array}{l}\text { Emergia } \\
\text { /(sej/ano) }\end{array}$ & $\begin{array}{l}\% \\
/(\text { sej/sej })\end{array}$ \\
\hline & Fase de I mplantação & & & & & & \\
\hline 1 & Mudas & g/ano & $\mathrm{R}$ & $4,30 \cdot 10^{7}$ & $1,47.10^{9}$ & $6,32 \cdot 10^{16}$ & $1 \%$ \\
\hline 2 & Gado & J/ano & $\mathrm{R}$ & $6,39 \cdot 10^{10}$ & $1,73.10^{6}$ & $1,11.10^{17}$ & $1 \%$ \\
\hline 3 & Suínos & $\mathrm{J} /$ ano & $\mathrm{R}$ & $8,14 \cdot 10^{10}$ & $2,51.10^{4}$ & $7,49.10^{16}$ & $1 \%$ \\
\hline 4 & Perda de solo & J/ano & $\mathrm{N}$ & $6,89 \cdot 10^{12}$ & $7,38.10^{4}$ & $5,08 \cdot 10^{17}$ & $5 \%$ \\
\hline 5 & Equip. e infraestrutura usina e gado & \$/ano & $\mathrm{F}$ & $2,71.10^{5}$ & $3,70.10^{12}$ & $1,00 \cdot 10^{18}$ & $10 \%$ \\
\hline 6 & Aço para construção dos reatores e filtros UASB & g/ano & $\mathrm{F}$ & $9,43 \cdot 10^{4}$ & $1,80.10^{9}$ & $1,70.10^{14}$ & $<1 \%$ \\
\hline 7 & Mão de obra & J/ano & $\mathrm{F}$ & $9,63 \cdot 10^{10}$ & $4,30.10^{6}$ & $4,14 \cdot 10^{16}$ & $4 \%$ \\
\hline 8 & Currais para o gado & \$/ano & $\mathrm{F}$ & $2,92.10^{3}$ & $3,70.10^{12}$ & $1,08 \cdot 10^{16}$ & $<1 \%$ \\
\hline 9 & Valas de ração para o gado & \$/ano & $\mathrm{F}$ & $1,33.10^{3}$ & $3,70.10^{12}$ & $4,93 \cdot 10^{15}$ & $<1 \%$ \\
\hline 10 & Granja para suínos & \$ano & $\mathrm{F}$ & $9,25.10^{3}$ & $3,70.10^{12}$ & $3,42.10^{16}$ & $<1 \%$ \\
\hline 11 & Equipamentos da granja de suínos & \$/ano & $\mathrm{F}$ & $3,60 \cdot 10^{2}$ & $3,70 \cdot 10^{12}$ & $1,33 \cdot 10^{15}$ & $<1 \%$ \\
\hline 12 & $\begin{array}{l}\text { Biodigestor } \\
\text { Fase de Operação }\end{array}$ & \$/ano & $\mathrm{F}$ & $1,00.10^{3}$ & $3,70.10^{12}$ & $3,70.10^{15}$ & $<1 \%$ \\
\hline 13 & Precipitação & J/ano & $\mathrm{R}$ & $9,92 \cdot 10^{13}$ & $1,82.10^{4}$ & $1,81 \cdot 10^{18}$ & $18 \%$ \\
\hline 14 & Nutritentes & g/ano & $\mathrm{R}$ & $3,01.10^{7}$ & $3,00.10^{9}$ & $9,04 \cdot 10^{16}$ & $1 \%$ \\
\hline 15 & Nitrogênio & $\mathrm{J} /$ ano & $\mathrm{R}$ & $1,17.10^{7}$ & $4,61.10^{9}$ & $5,40.10^{16}$ & $1 \%$ \\
\hline 16 & Água de aquífero & $\mathrm{J} /$ ano & $\mathrm{R}$ & $2,68 \cdot 10^{10}$ & $1,10.10^{5}$ & $2,95.10^{15}$ & $<1 \%$ \\
\hline 17 & Milho $12,1 \%$ (**) & g/ano & $\mathrm{R}$ & $1,26.10^{8}$ & $7,69 \cdot 10^{8}$ & $9,67 \cdot 10^{16}$ & $1 \%$ \\
\hline 18 & Milho 35,3\% (**) & g/ano & $\mathrm{N}$ & $3,29.10^{8}$ & $7,69 \cdot 10^{8}$ & $2,53 \cdot 10^{17}$ & $2 \%$ \\
\hline 19 & Milho $52,6 \%$ (**) & g/ano & $\mathrm{F}$ & $5,48.10^{8}$ & $7,69.10^{8}$ & $4,21.10^{17}$ & $4 \%$ \\
\hline 20 & Farelo De Soja & g/ano & $\mathrm{F}$ & $3,86.10^{8}$ & $3,26.10^{9}$ & $1,26.10^{18}$ & $12 \%$ \\
\hline 21 & Nucleo & g/ano & $\mathrm{F}$ & $5,94 \cdot 10^{7}$ & $6,08 \cdot 10^{9}$ & $3,61.10^{17}$ & $4 \%$ \\
\hline 22 & Combustivel & $\mathrm{J} /$ ano & $\mathrm{F}$ & $1,43.10^{9}$ & $5,50 \cdot 10^{4}$ & $7,87 \cdot 10^{13}$ & $<1 \%$ \\
\hline 23 & Mão de obra & $\mathrm{J} /$ ano & $\mathrm{F}$ & $5,9410^{11}$ & $4,30 \cdot 10^{6}$ & $2,56.10^{18}$ & $25 \%$ \\
\hline 24 & Trato do Gado ( $80 \%$ ) outros $20 \%$ pontas & \$/ano & $\mathrm{F}$ & $1,87.10^{5}$ & $3,70.10^{12}$ & $6,93 \cdot 10^{17}$ & $7 \%$ \\
\hline 25 & Manutenção & \$/ano & $\mathrm{F}$ & $6,83 \cdot 10^{4}$ & $3,70.10^{12}$ & $2,52 \cdot 10^{17}$ & $3 \%$ \\
\hline 26 & Insumos & g/ano & $\mathrm{F}$ & $4,88 \cdot 10^{7}$ & $3,80.10^{9}$ & $1,86.10^{17}$ & $2 \%$ \\
\hline 27 & Defensivos agrícolas & g/ano & $\mathrm{F}$ & $3,59.10^{6}$ & $1,48.10^{9}$ & $5,31 \cdot 10^{15}$ & $<1 \%$ \\
\hline 28 & Operações agrícolas & \$/ano & $\mathrm{F}$ & $1,10.10^{4}$ & $3,70.10^{12}$ & $4,08 \cdot 10^{16}$ & $\%$ \\
\hline & Emergia Total & & & & & $1,03.10^{19}$ & $100,0 \%$ \\
\hline
\end{tabular}

(*) Cálculos detalhados no Anexo A

(**) Cálculos dos percentuais na Tabela A-7 do Anexo A.

\subsubsection{Análise em emergia}

A emergia total do biossistema da usina autônoma com criação de gado e suínos tem valor de $1,03.10^{19}$ sej/ano. Aproximadamente 7,4\% sej/sej de recursos não renováveis são utilizados, 22,3\% sej/sej são de recursos renováveis e 70,3\% sej/sej dos recursos da economia. O sistema utiliza aproximadamente $21 \%$ sej/sej de sua emergia total na implantação e $79 \%$ sej/sej durante a sua operação.

A unidade funcional adotada foi $1 \mathrm{MWh}$ de eletricidade. A produção de eletricidade anual do biossistema é de $2,76.10^{4} \mathrm{MWh}$ e a emergia por unidade encontrada foi de $3,71.10^{14}$ sej/MWh e a transformidade de $1,03.10^{5} \mathrm{sej} / \mathrm{J}$. 
5.2.4. Comparação entre as transformidades e custos dos biossistemas estudados

A Tabela 7 apresenta a comparação entre as transformidades e custos dos biossistemas estudados.

Tabela 7. Comparação entre as transformidades e custos dos biossistemas

\begin{tabular}{ccccc}
\hline Biossistema & $\begin{array}{c}\text { Energia } \\
\text { Gerada } \\
\text { /MWh }\end{array}$ & $\begin{array}{c}\text { Emergia por } \\
\text { unidade } \\
\text { sej/MWh }\end{array}$ & $\begin{array}{c}\text { Transformidade } \\
\text { sej/J }\end{array}$ & $\begin{array}{c}\text { Valor em } \\
\mathrm{R} \$ / \mathrm{MWh}\end{array}$ \\
\hline Usina autônoma & $7,17.10^{3}$ & $7,86.10^{14}$ & $2,18.10^{5}$ & 212,00 \\
Autônoma/gado & $1,90.10^{4}$ & $3,80.10^{14}$ & $1,05.10^{5}$ & 103,00 \\
Autônoma/gado/suínos & $2,76.10^{4}$ & $3,71.10^{14}$ & $1,03.10^{5}$ & 100,00 \\
\hline
\end{tabular}

Os valores encontrados em emergia por unidade, transformidade e $\mathrm{R} \$ / \mathrm{MWh}$ apresentados na Tabela 7, indicam que o biossistema completo (usina autônoma com criação de gado e suínos) é o que possue menor transformidade e custo em $\mathrm{R} \$$. Em seguida, o biossistema da usina autônoma com criação de gado $3,1 \%$ maior e o sistema com a maior transformidade é o da usina autônoma isolada com percentual 113\% maior que a biossitema completo. $\mathrm{O}$ valor de transformidade é um indicador de eficiência, isso nos permite concluir que o biossistema completo é mais eficiente na geração de eletricidade, quando nos referimos ao uso de recursos.

Ainda observando os resultados da Tabela 7 para a transformidade da eletricidade gerada nestes biossistemas, verificamos que o valor do biossistema da usina autônoma é próximo ao valor determinado por Odum (1996) que é de 2,00.10 5 sej/J.

Essa análise não implica em afirmar que os biossistemas se comportam dessa mesma forma quando comparamos outros produtos, pois essa discussão trata somente da geração de eletricidade. 


\subsection{Cálculo dos indicadores}

Como podemos observar nas Tabelas 4,5 e 6 a emergia total é composta por três classes de recursos: R, N e F, a partir dos quais é possível calcular os indicadores em emergia (ODUM, 1996). Os indicadores obtidos no estudo do biossistema da usina autônoma foram comparados com aqueles obtidos pelos outros biossistemas, como mostra a Tabela 8.

De acordo com o índice EYR (Tabela 8), podemos verificar que o sistema da usina autônoma apresenta melhor rendimento em emergia, pois utiliza uma proporção maior de recursos locais renováveis e não renováveis $(\mathrm{R}+\mathrm{N})$ em relação ao investimento econômico.

O índice de EIR (Tabela 8) indica que o sistema da usina autônoma apresenta-se mais competitivo. O investimento de recursos da economia em relação aos recursos naturais utilizados na usina autônoma é menor.

Tabela 8. Resumo dos índices em emergia (*)

\begin{tabular}{llll}
\hline Índices em emergia & Usina autônoma & $\begin{array}{c}\text { Usina autônoma } \\
\text { com criação de gado }\end{array}$ & $\begin{array}{c}\text { Usina autônoma com } \\
\text { criação de gado e suínos }\end{array}$ \\
\hline Rendimento em emergia (EYR) & 1,67 & 1,58 & 1,42 \\
Investimento em emergia (EIR) & 1,50 & 1,74 & 2,37 \\
Carga ambiental (ELR) & 2,12 & 2,39 & 3,49 \\
Índice de sustentabilidade (ESI) & 0,79 & 0,66 & 0,41 \\
Percentual de Energia Renovável (\%R) & 32,02 & 29,46 & 22,29 \\
\hline
\end{tabular}

(*) Cálculos no Anexo A

O índice de carga ambiental ELR (Tabela 8), avalia o estresse ambiental, quanto menor o valor deste indicador, menor o estresse imposto ao ambiente (BROWN e ULGIATI, 2002). Verifica-se que o resultado obtido pelo sistema da usina autônoma $(2,12)$ representa que a energia solar dos recursos não renováveis e dos recursos advindos do sistema econômico é 2,12 vezes maior que a energia solar equivalente dos recursos renováveis utilizados, indicando uma baixa carga ambiental, sendo aproximadamente $13 \%$ menor do que o biossistema da usina autônoma com criação de gado e $70 \%$ menor que o biossistema completo, indicando ser o sistema que possui menor estresse ambiental.

O índice de sustentabilidade ESI (Tabela 8), determinado para os biossistemas, indica a necessidade de melhorias, a fim de aumentar a sustentabilidade dos ciclos. Ao compararmos 
esses valores, o índice do sistema da usina autônoma apresentou-se aproximadamente $20 \%$ maior do que o valor do sistema da usina autônoma com criação gado e, o dobro do índice do biossistema completo, indicando ser o sistema da usina autônoma sustentável por maior tempo.

O índice de emergia renovável \%R (Tabela 8) indica o percentual de energia renovável envolvida no processo. De acordo com o protocolo de Kyoto (MRE, 1997), que estabelece que até 2010 o uso de fontes de energia renovável deve alcançar 10\% da matriz energética (BRAGA et al, 2002), verifica-se nesse estudo que todos os biossistemas alcançam este índice, resaltando que o sistema da usina autônoma apresenta maior percentual, com índice de $32,02 \%$ de energia renovável de sua cadeia produtiva de seus fluxos em emergia.

A comparação dos valores dos indicadores encontrados para os biossistemas indica que a geração de eletricidade do sistema da usina autônoma oferece menor impacto ao ambiente do que os biossistemas comparados. Apesar de o biossistema completo utilizar menor quantidade de recursos (transformidade) para gerar a mesma quantidade de eletricidade, este sistema utiliza principalmente recursos provenientes da economia (Tabela 6). A distribuição dos fluxos no sistema de usina autônoma (Tabela 4), entre R, N e F mostra melhor aproveitamento dos recursos locais e gratuitos por este sistema, o que se reflete nos valores dos indicadores calculados.

Utilizando o diagrama ternário em emergia (BARRELLA et al, 2005, ALMEIDA et al, 2005 e GIANNETTI et al, 2006) para comparação entre os biossistemas estudados, observase (Figura 11) que o sistema de geração da usina autônoma está localizado próximo à linha de $\mathrm{ESI}=1$. 


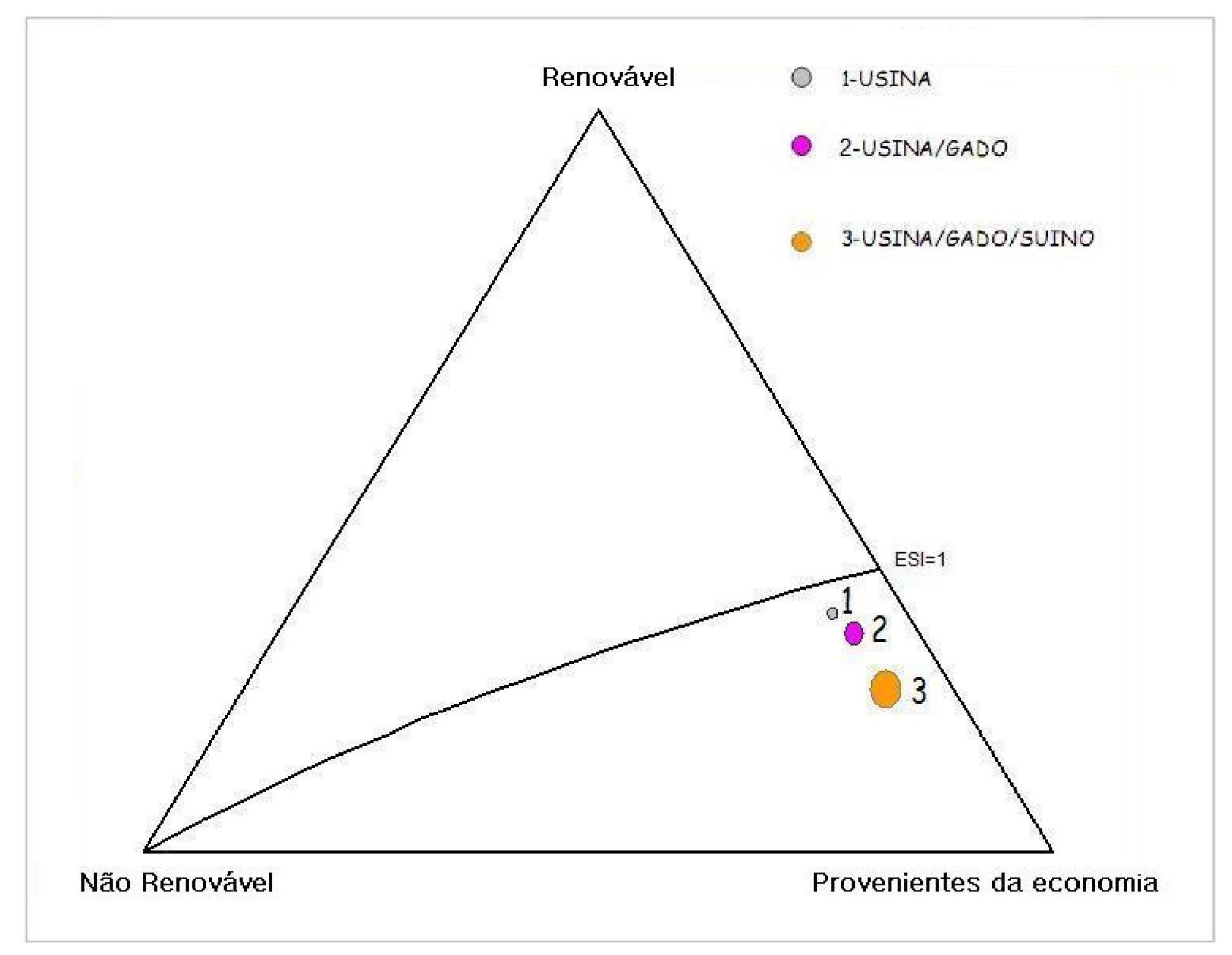

Figura 11. Diagrama ternário em emergia dos biossistemas estudados.

A representação do triângulo da Figura 11 tem o significado de que o sistema da usina autônoma apresenta maior índice de sustentabilidade.

As dimensões dos círculos que de cada configuração são proporcionais a quantidade de emergia total empregada. Observa-se que o sistema da usina autônoma com criação de gado e suínos utiliza maior fluxo em emergia que os sistemas comparados.

É possível ainda com a análise do diagrama ternário permite visualizar o uso de recursos dos sistemas, ou seja, quanto mais distante do vértice Renovável, menor é a quantidade de fluxos renováveis no sistema, o que corrobora com o resultado dos indicadores de sustentabilidade, mostrando que o sistema da usina autônoma utiliza maior percentual de fluxos renováveis comparando aos outros biossistemas. 


\section{Análise em termoeconomia}

Tsatsaronis (1993), afirma que para realizar uma análise termoeconômica completa de um sistema é necessário:

B Realizar a análise exergética detalhada do sistema;

B Realizar a análise economica detalhada dos equipamentos;

ß Obter o custo exergético;

B Realizar uma avaliação termoeconômica de cada equipamento do sistema;

Esta tese, porém não pretende realizar uma análise termoeconômica completa (SILVA, 2004 realiza uma análise termoeconômica completa), mas sim obter o custo energético de cada volume de controle e do sistema como um todo.

A obtenção dos dados refentes a análise em termoeconomia para a usina de álcool e criação de gado, foram extraídos do estudo de Ometto et al, 2006, e para a criação de suínos, foram utilizados os dados de Cavalett, 2004. As exergias utilizadas neste trabalho foram pesquisadas na literatura (Tabela 9), pois foi simulado um estudo em condições similares aos referenciados.

Tabela 9. Tabela de exergias específicas

\begin{tabular}{|c|c|c|c|c|}
\hline Fluxo & $\begin{array}{c}\text { Temperatura } \\
\left({ }^{\circ} \mathrm{C}\right)\end{array}$ & $\begin{array}{c}\text { Pressão } \\
\text { (bar) }\end{array}$ & $\begin{array}{l}\text { Exergia } \\
(\mathrm{kJ} / \mathrm{kg})\end{array}$ & Referência \\
\hline Cana-de-açúcar & 25 & 1,01 & 5614 & Pellegrini, 2008 \\
\hline Bagaço & 25 & 1,01 & 9892 & Pellegrini, 2008 \\
\hline Caldo & 35 & 1,01 & 3154 & Pellegrini, 2008 \\
\hline Álcool & 25 & 1,01 & 27224 & Pellegrini, 2008 \\
\hline Biogás & 25 & 1,01 & 18732 & Calculado $(*)$ \\
\hline Vapor de 67 bar & 480 & 67 & 1389 & Calculado (*) \\
\hline Vapor de 21 bar & 280 & 21 & 1034 & Calculado $(*)$ \\
\hline Vapor de processo & 130 & 2,50 & 609 & Calculado (*) \\
\hline Vapor condensado & 80 & 0,50 & 45 & Calculado $(*)$ \\
\hline
\end{tabular}

(*) Cálculo no Anexo B (Tabela B-24) 


\subsection{Custo termoeconômico exergético}

A termoeconomia atribui um custo a cada fluxo de energia ou componente existente no sistema, a somatória desses custos representa o custo total para a obtenção deste fluxo. Podemos expressar matematicamente o balanço de custos conforme Equação (1):

$$
\dot{I}+\dot{I}_{0} \& M+\dot{B}_{\text {entrada }} C_{\text {entrada }}=\sum \dot{B}_{\text {saída }} C_{\text {saída }}
$$

Sendo que para obtermos o fluxo $i$ que é dado com $\mathrm{R} \$ / \mathrm{s}$ é necessário multiplicar o custo dos equipamentos (em R\$) pelo FRC (equação (2)) e dividir pela quantidade em segundos que ele opera do período de um ano $\mathrm{P}_{\mathrm{s}}$ (equação(3)).

$$
F R C=\frac{r}{\left(1-(1+r)^{-t}\right)}
$$

Onde F RC é o fator de retorno do capital, $r$ é a taxa de juros e té o período em anos.

$$
P_{s}=24 \frac{\text { horas }}{\text { dia }} \times \text { dias de operação } \times \text { Fator de capacidade } \times 3600 \frac{\text { segundos }}{\text { hora }}
$$

O balanço representado pela Equação (1) pode ser aplicado para todos os componentes do sistema. Dessa forma, o sistema de equações formado pelas incógnitas são os custos médios por unidade de exergia de cada fluxo. Contudo, o número de equações é menor que o número de incógnitas. Na hipótese do sistema apresentar mais de um fluxo de saída, torna-se necessário o uso de equações auxiliares. Para determinar as equações a serem utilizadas, foram desenvolvidos diferentes critérios, dentre os quais se destacam os critérios de partição desenvolvidos por Reistad e Gaggioli (1980) e Wepfer (1980) apud Tsatsaronis (1993):

- Critério da Igualdade: todos os produtos têm o mesmo custo médio por unidade de exergia (equação (4)).

$$
\mathrm{C}_{\text {saída }(01)}=\mathrm{C}_{\text {saída (02) }}
$$

- Critério da extração: os custos dos equipamentos do volume de controle são descarregados num único fluxo, o fluxo do produto (equação (5)).

$$
\mathrm{C}_{\text {saída }}=\mathrm{C}_{\text {entrada }}+\mathrm{I}
$$

Onde I é o investimento total do sistema. 
- Critério do subproduto: define-se um custo para um dos produtos para eliminar uma das variáveis e calcula-se o outro produto.

A aplicação destes critérios implica em resultados diferentes, assim a opção por deles fica a critério do analista, pois envolve a definição da importância de cada produto do volume de controle.

Nesta tese foram utilizados os critérios de extração e de igualdade em todos os casos.

\subsection{Resultados da análise termoeconômica}

A análise em termoeconomia tem início com a definição de volumes de controle para a análise de fluxos de massa e energia. A observação dos diagramas auxilia na identificação dos fluxos de entrada e saída de massa e de energia, estabelecidos para os sistemas estudados, assim como na identificação de seus principais componentes. Nos diagramas são identificados todos os fluxos de material, energia e serviços necessários para a operação dos sistemas. É importante resaltar que as fronteiras foram estabelecidas, neste estudo, de acordo com a operação de cada sistema.

A usina autônoma estudada tem um custo de implantação de $\mathrm{R} \$ 11.956 .503,00$ (MELO, 2007) que são divididos entre seus volumes de controle e um custo de manutenção e operação de $\mathrm{R} \$ 1.360 .000,00$ anuais, os quais para efeito da análise termoeconômica foi dividido entre os volumes de controle pelo mesmo percentual que o volume de controle tem do montante do custo de implantação.

\subsubsection{Sistema da usina autônoma}

O sistema da usina autônoma (Figura 12) foi dividido em seis volumes de controle distintos que interagem entre si, com a finalidade de gerar álcool e energia como produtos finais, apesar de obtermos nesta análise os custos termoeconômicos de todos os produtos do sistema. Sendo assim, são comparados somente os custos da eletricidade gerada. 


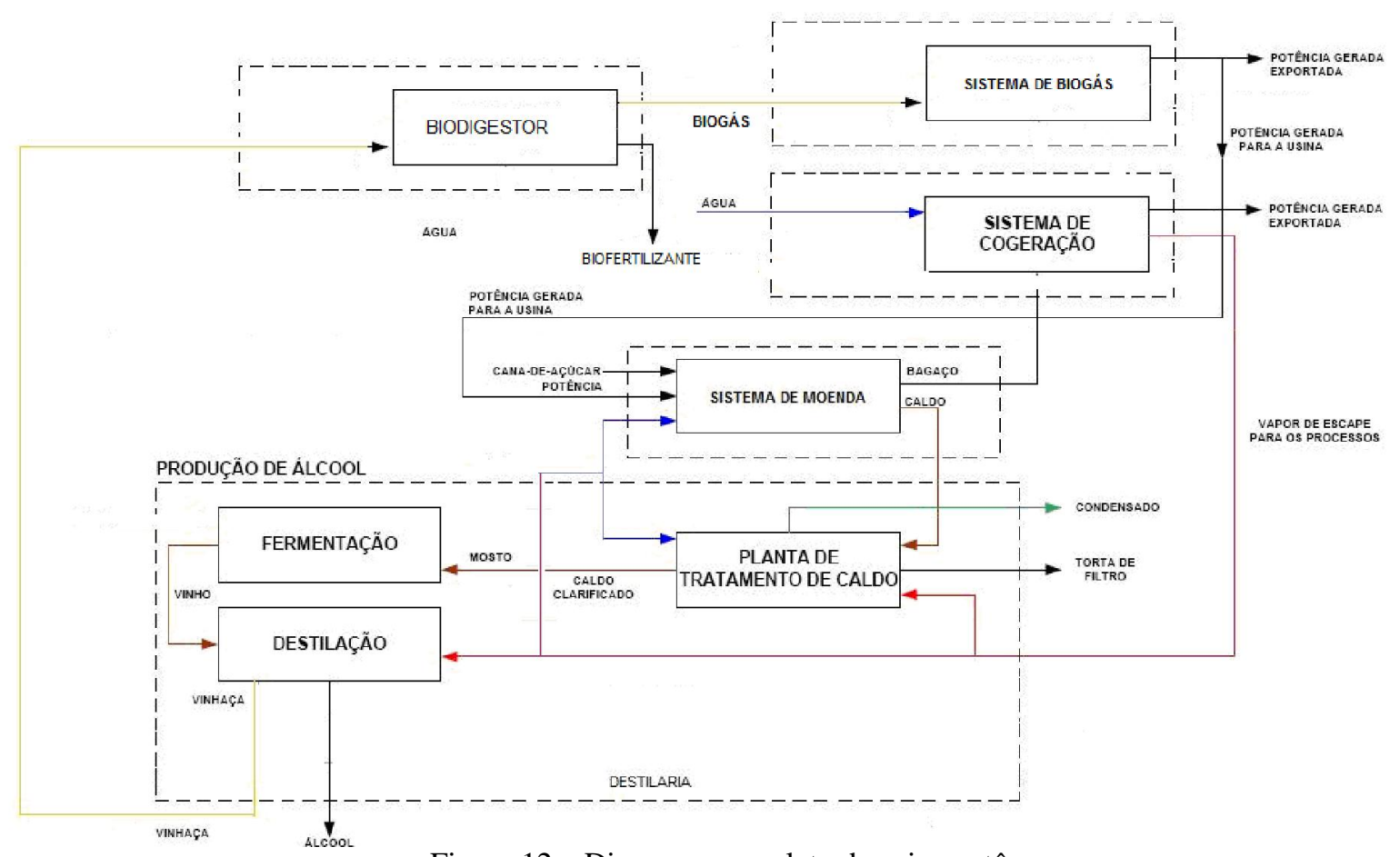

Figura 12 - Diagrama completo da usina autônoma

Para determinar os custos termoeconômicos de todos os fluxos de energia e exergia foram solucionadas as equações de 6 a 19 apresentadas abaixo, de acordo com o critério:

Critério de extração:

$$
\begin{aligned}
& \dot{\mathrm{I}}+\dot{\mathrm{I}}_{0} \& \mathrm{M}+\dot{\mathrm{m}}_{\text {água }} \cdot \mathrm{C}_{\text {água }}+\dot{\mathrm{m}}_{\text {cana }} \cdot \mathrm{C}_{\text {cana }}+\dot{\mathrm{W}}_{\text {ele }} \cdot \mathrm{C}_{\text {ele }}-\dot{\mathrm{m}}_{\text {bagaço }} \cdot \boldsymbol{C}_{\text {bagaço }} \\
& \dot{\mathrm{B}}_{\text {caldo }}=\mathrm{C}_{\text {caldo }} \\
& \dot{I}+\dot{I}_{0} \& \mathrm{M}+\dot{\mathrm{B}}_{\text {caldo }} \cdot \mathrm{C}_{\text {caldo }}+\dot{\mathrm{B}}_{\text {vapor de processo }} \cdot \mathrm{C}_{\text {vapor de processo }}-\dot{\mathrm{B}}_{\text {vinhaça }} \cdot \mathrm{C}_{\text {vinhaça }}-\dot{\mathrm{B}}_{\text {Torta }} \cdot \mathrm{C}_{\text {Torta }}
\end{aligned}
$$

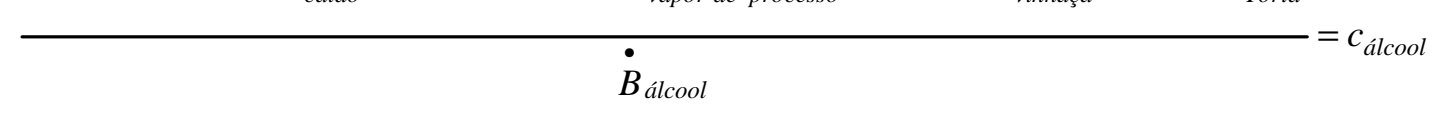

$$
\begin{aligned}
& \frac{\dot{I}+\dot{I} 0 \& M+\dot{m}_{\text {vinhaça }} \cdot C_{\text {vinhaça }-} \dot{m}_{\text {biofertilizante }} \cdot C_{\text {biofertilizante }}}{\dot{B}_{\text {biogás }}}=C_{\text {biogás }} \\
& \frac{\dot{I}+\dot{I}_{0 \text { \&M }}+\dot{B}_{\text {biogás }} \cdot C_{\text {biogás }}}{\dot{W}_{\text {eleB }}}=C_{\text {eleB }}
\end{aligned}
$$




$$
\frac{\dot{I}+\dot{I}_{0 \& M}+\dot{m}_{\text {bagaço } . c_{\text {bagaço }}}}{\dot{B}_{V A(67)}}=c_{V A(67)}
$$

$$
\begin{aligned}
& \frac{\dot{I}+\dot{I}_{0 \& M}+\dot{B}_{V A(67)} \cdot C_{V A(67)}-\dot{B}_{\text {vapor de processo } \cdot C_{\text {vapor de processo }}-\dot{B}_{V A(21)} \cdot C_{V A(21)}}}{\dot{W}_{\text {ele }} .}=C_{\text {eleUa }} \\
& \frac{\dot{I}+\dot{I}_{0 \& M}+\dot{B}_{V A(21)} \cdot C_{V A(21)}-\dot{B}_{\text {condensado _vapor_condensado }}}{\dot{W}_{\text {ele }}}=C_{\text {eleU b }}
\end{aligned}
$$

Critério de Igualdade:

$$
\begin{aligned}
& \frac{\dot{I}+\dot{I}_{0 \& M}+\dot{m}_{\text {água }} \cdot C_{\text {água }}+\dot{\mathrm{m}}_{\text {cana }} \cdot C_{\text {cana }}+\dot{W}_{\text {ele }} \cdot C_{\text {ele }}}{\dot{B}_{\text {caldo }}+\dot{B}_{\text {bagaço }}}=c_{\text {caldo }} \\
& \frac{\dot{I}_{+} \dot{I}_{0 \& M}+\dot{B}_{\text {caldo }} \cdot C_{\text {caldo }}+\dot{B}_{\text {vapor de processo }} \cdot C_{\text {vapor de processo }}}{\dot{B}_{\text {vinhaça }}+\dot{B}_{\text {Torta }}+\dot{B}_{\text {álcool }}}=C_{\text {álcool }} \\
& \frac{\dot{I}+\dot{I}_{0 \& M}+\dot{\mathrm{m}}_{\text {vinhaça }} \cdot C_{\text {vinhaça }}}{\dot{B}_{\text {biogás }}+\dot{\mathrm{B}}_{\text {biofertilizante }}}=c_{\text {biogás }} \\
& \frac{\dot{I}+\dot{I}_{0 \& M}+\dot{B}_{\text {biogás }} \cdot C_{\text {biogás }}}{\dot{W}_{\text {eleB }}}=C_{\text {eleB }} \\
& \frac{\dot{I}+\dot{I}_{0 \& M}+\dot{m}_{\text {bagaço }} \cdot c_{\text {bagaço }}}{\dot{B}_{V A(67)}}=c_{V A(67)} \\
& \frac{\dot{I}+\dot{I}_{0 \& M}+\dot{B}_{V A(67)} \cdot C_{V A(67)}}{\dot{W}_{\text {ele }}+\dot{B}_{\text {vapor de processo }}+\dot{B}_{V A(21)}}=C_{\text {eleVa }} \\
& \frac{\dot{I}_{+} \dot{I}_{0 \& M}+\dot{\mathrm{B}}_{V A(21)} \cdot C_{V A(21)}}{\dot{\mathrm{B}}_{\text {condensado }}+\dot{\mathrm{W}}_{\text {ele }}}=C_{\text {eleUb }}
\end{aligned}
$$




\subsubsection{Volume de controle 1 (extração)}

A extração é a de separação de materiais (PAYNE, 1989). O objetivo da extração é recuperar a máxima quantidade de caldo possível, como também produzir um bagaço com umidade em torno de $50 \%$, fator este admissível para ser queimado de maneira rápida e eficiente na caldeira.

A extração do caldo pode ser efetuada de duas maneiras: moagem ou difusão. A primeira é a mais comum em usinas brasileiras. Um tandem de moendas pode ser composto por quatro a sete ternos de moenda, sendo um terno constituído de três rolos de esmagamento. Esses são dispostos em triângulos de maneira que a fibra seja espremida duas vezes, na entrada e na saída do terno.

No primeiro terno é alcançada uma extração na faixa de $50 \%$ a $70 \%$, sendo o bagaço enviado para os ternos seguintes para completar a extração. Para aumentar a extração de sacarose, é realizada a embebição (água de embebição) no bagaço a fim de facilitar a recuperação da sacarose presente no próprio bagaço. Os valores normalmente praticados na embebição variam entre 250 e $300 \mathrm{~kg} / \mathrm{TC}$. A embebição é tradicionalmente realizada a temperatura ambiente.

A eficiência máxima de recuperação de sacarose na moagem é aproximadamente $96 \%$ (PAYNE, 1989, CAMARGO, 1990). A quantidade de energia mecânica necessária para o acionamento dos ternos é da ordem de 9,2 kWh/TC (PROCKNOR, 2001), sendo que o acionamento pode ser feito ou com turbinas a vapor ou com motores elétricos. O consumo total de eletricidade no sistema de extração, considerando o uso de moendas elétricas, é igual a $12,9 \mathrm{kWh} / \mathrm{TC}$.

A análise do volume de controle 1 tem início com a construção do diagrama do volume de controle apresentado na Figura 13.

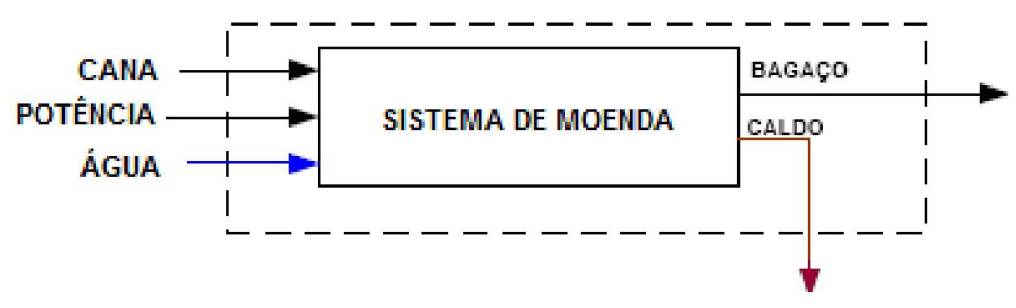

Figura 13 - Volume de controle 1 da moenda 
Em seguida são realizados os cálculos termoeconômicos (Anexo B) para cada volume de controle.

Para este estudo foram utilizados dois critérios de custos, a Tabela 10 apresenta os resultados para o volume de controle 1 com a utilização dos critérios de extração e de igualdade.

Tabela 10 - Custos dos fluxos de saída do volume de controle $1(*)$

\begin{tabular}{|c|c|c|}
\hline Fluxo & Extração & Igualdade \\
\hline caldo de cana $(\mathrm{R} \$ / \mathrm{kg})$ & $3,87.10^{-2}$ & $4,30.10^{-2}$ \\
\hline caldo de cana $(\mathrm{R} \$ / \mathrm{kJ})$ & $1,23.10^{-5}$ & $1,36.10^{-5}$ \\
\hline caldo de cana (R $\$ / L)$ & $4,18 \cdot 10^{-2}$ & $4,65 \cdot 10^{-2}$ \\
\hline Bagaço (R\$/kg) & $4,05 \cdot 10^{-2}$ & $1,35.10^{-1}$ \\
\hline Bagaço (R\$/kJ) & $4,10.10^{-6}$ & $1,36.10^{-5}$ \\
\hline
\end{tabular}

(*) cálculos detalhados no Anexo B

\subsubsection{Volume de controle 2 (destilaria)}

O processo de tratamento de caldo para a produção de álcool é o de fermentação em dornas.

No interior das dornas, os açúcares são transformados em etanol. Durante a reação, ocorre intensa liberação de dióxido de carbono, a solução aquece-se e ocorre a formação de alguns produtos secundários como: álcoois superiores, glicerol, aldeídos, entre outros. É necessário manter a temperatura da dorna entre $32^{\circ} \mathrm{C}$ e $35^{\circ} \mathrm{C}$, assim no interior das dornas são instaladas serpentinas com circulação de água.

Após a fermentação, o vinho é enviado às centrífugas para a recuperação do fermento. $\mathrm{O}$ concentrado do fermento recuperado, denominado leite de levedura, retorna às cubas para o tratamento. A fase leve da centrifugação, ou vinho "delevedurado", é enviada para as colunas de destilação. O teor alcoólico do vinho produzido é $9^{\circ} \mathrm{GL}$ e o rendimento estequiométrico da fermentação é aproximadamente 91\% (FINGUERUT, 2004).

O álcool diluído no vinho é recuperado através do processo de destilação, o qual utiliza os diferentes pontos de ebulição das substâncias voláteis para promover a separação. 
O vinho é enviado para a coluna de destilação, na qual a mistura água-etanol, chamada flegma (graduação alcoólica em tono de $50^{\circ} \mathrm{GL}$ ), é separada da vinhaça (produto de fundo) e do álcool de segunda (produto de topo). Essa coluna é separada em três partes: a coluna de epuração (onde o vinho é alimentado), responsável pela eliminação das impurezas; a coluna de concentração do álcool de segunda (considerado o produto de topo da coluna de destilação); e a coluna de esgotamento do vinho (parte inferior). A flegma segue para a coluna de retificação, onde a concentração da mistura atinge $96^{\circ} \mathrm{GL}$.

A energia necessária para operação dessas colunas é fornecida por vapor de baixa pressão através da troca direta (borbotagem) ou indireta (uso de refervedor).

As quantidades de vinhaça e flegma formada variam entre 9 e $15 \mathrm{~L} / \mathrm{L}$ de álcool, dependendo do tipo da troca realizada com o vapor.

A análise do volume de controle 2 tem início com a construção do diagrama do volume de controle apresentado na Figura 14.

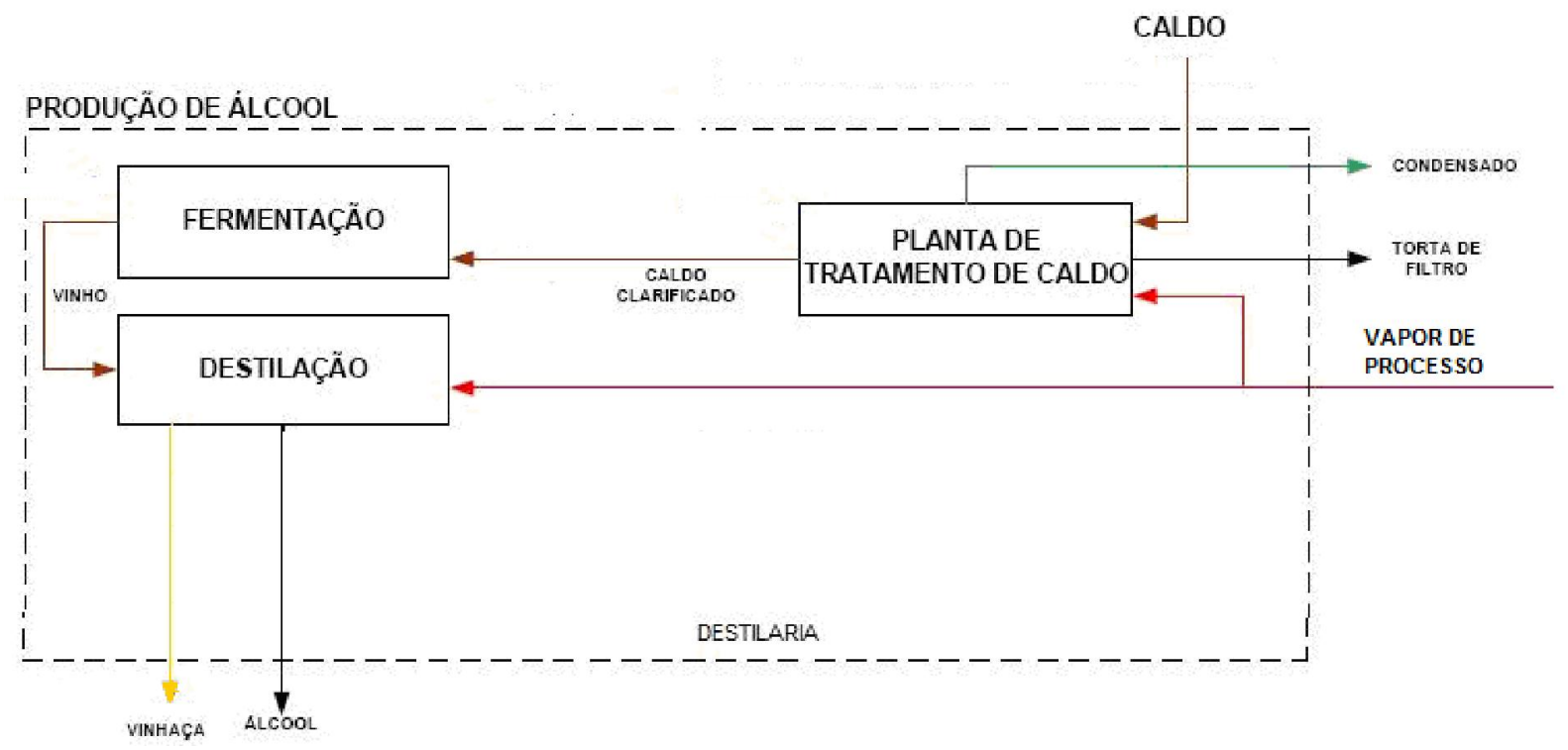

Figura 14 - Volume de controle 2 da destilaria

Para este estudo foram utilizados dois critérios de custos, a Tabela 11 apresenta os resultados para o volume de controle 2 com a utilização dos critérios de extração e de igualdade. 
Tabela 11 - Custos dos fluxos de saída do volume de controle 2 (*)

\begin{tabular}{|c|c|c|}
\hline Fluxo & Extração & Igualdade \\
\hline álcool (R \$/kg) & $3,87.10^{-1}$ & $9,05.10^{-1}$ \\
\hline álcool $(\mathrm{R} \$ / \mathrm{kJ})$ & $1,14.10^{-5}$ & $2,66.10^{-5}$ \\
\hline álcool $(\mathrm{R} \$ / \mathrm{L})$ & $3,09.10^{-1}$ & $7,24.10^{-1}$ \\
\hline vinhaça $(\mathrm{R} \$ / \mathrm{kg})$ & $1,03.10^{-3}$ & $2,24.10^{-3}$ \\
\hline vinhaça $(\mathrm{R} \$ \mathrm{~kJ})$ & $1,23.10^{-5}$ & $2,66.10^{-5}$ \\
\hline torta de filtro $(\mathrm{R} \$ / \mathrm{kg})$ & $5,65 \cdot 10^{-2}$ & $1,22.10^{-1}$ \\
\hline torta de filtro $(\mathrm{R} \$ / \mathrm{kJ})$ & $1,23.10^{-5}$ & $2,66.10^{-5}$ \\
\hline
\end{tabular}

(*) cálculos detalhados no Anexo B

\subsubsection{Volume de controle 3 (biodigestão)}

O processo de produção de biogás ocorre dentro de um biodigestor UASB (Upflow Anaerobic Sludge Blanket).

Esse modelo de biodigestor foi desenvolvido entre o final da década de 70 e o início da década de 80 por pesquisadores holandeses, que revolucionou o tratamento de efluentes líquidos através de sistemas anaeróbicos (ALMANÇA, 1994).

Através desse sistema a matéria orgânica a ser tratada é distribuída uniformemente no fundo do biodigestor, sendo então conduzida em fluxo ascendente para a parte superior do mesmo. Durante o trajeto, os resíduos entram em contato com um lodo saturado de microorganismos que, atuando na ausência de oxigênio, degradam o material introduzido.

Separadores instalados na parte superior do biodigestor se encarregam de selecionar os produtos resultantes do metabolismo anaeróbio onde, o biogás é coletado em câmaras específicas, o lodo retorna ao leito bacteriano sob ação da gravidade incorporando-se à população ativa, para dar continuidade ao processo biológico e o efluente tratado é conduzido às calhas coletoras, podendo ser utilizado como biofertilizante líquido diretamente sobre o solo (CHERNICHARRO, 1997).

A análise do volume de controle 3 tem início com a construção do diagrama de volume de controle apresentado na Figura 15. 


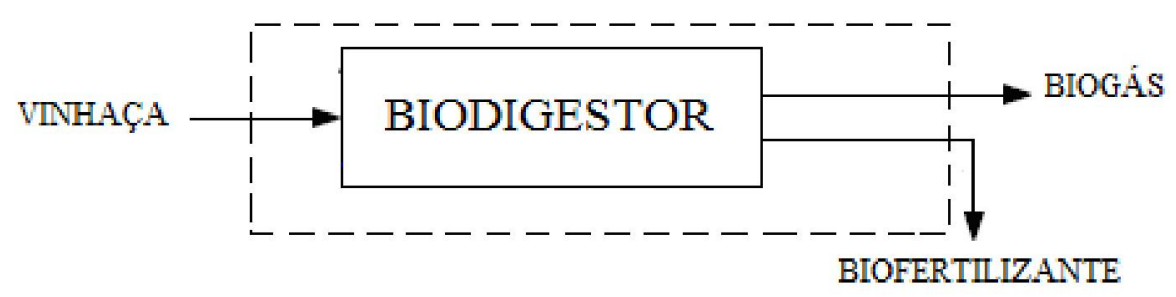

Figura 15 - Volume de controle 3 do biodigestor

Neste estudo foram utilizados dois critérios de custos. A Tabela 12 apresenta os resultados para o volume de controle 3 com a utilização dos critérios de extração e de igualdade.

Tabela 12 - Custos dos fluxos de saída do volume de controle 3 (*)

\begin{tabular}{|c|c|c|}
\hline Fluxo & Extração & Igualdade \\
\hline biogás $\left(\mathrm{R} \$ / \mathrm{m}^{3}\right)$ & $9,97.10^{-2}$ & $1,96.10^{-2}$ \\
\hline biogás $(\mathrm{R} \$ / \mathrm{kJ})$ & $6,70 \cdot 10^{-6}$ & $1,32.10^{-6}$ \\
\hline biogás $(\mathrm{R} \$ / \mathrm{kg})$ & $1,26.10^{-1}$ & $2,48.10^{-2}$ \\
\hline
\end{tabular}

(*) cálculos detalhados no Anexo B

\subsubsection{Volume de controle 4 (motor-gerador)}

O processo de produção de eletricidade com o biogás produzido nos biodigestores se dá em um motor de ciclo Otto adaptado.

Os motores a gás são máquinas térmicas que se constituem num sistema fechado ao qual se fornece calor de uma fonte externa, e que rejeita calor a um sumidouro externo, produzindo ma certa quantidade de trabalho, igual a diferença entre o calor recebido e o rejeitado. O sistema volta periodicamente ao seu estado inicial e, portanto, excluem-se as transformações exteriores ao sistema.

Nesse estudo um dos equipamentos para a geração de eletricidade, é um motor a gás oriundo de um cliclo Otto adaptado.

Neste tipo de motor, o gás utilizado como combustível não oferece nenhuma dificuldade operacional, pois reage facilmente com o ar na câmara de mistura.

$\mathrm{O}$ motor utilizado para esta análise tem potência líquida de $1475 \mathrm{~kW}_{\mathrm{e}}$ A análise do 
volume de controle 4 tem início com a construção do diagrama de volume de controle apresentado na Figura 16.

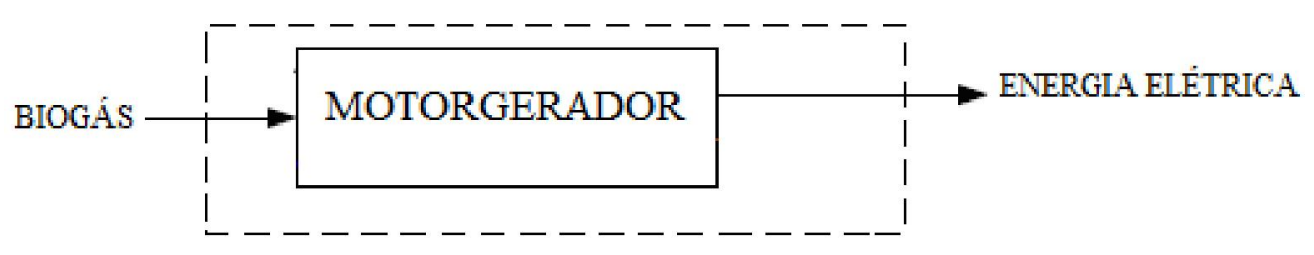

Figura 16 - Volume de controle 4 do motor-gerador

Neste estudo foram utilizados dois critérios de custos, a Tabela 13 apresenta os resultados para o volume de controle 4 com a utilização dos critérios de extração e de igualdade.

Tabela 13 - Custos dos fluxos de saída do volume de controle 4 (*)

\begin{tabular}{lcc}
\hline \multicolumn{1}{c}{ Fluxo } & Extração & Igualdade \\
\hline Eletricidade $(\mathrm{R} \$ / \mathrm{MWh})$ & 49,47 & 26,47 \\
Eletricidade $(\mathrm{R} \$ / \mathrm{kJ})$ & $1,37.10^{-5}$ & $7,35.10^{-6}$ \\
\hline
\end{tabular}

(*) cálculos detalhados no Anexo B

\subsubsection{Volume de controle 5 (caldeira)}

A produção de vapor de processo e de alta pressão para a turbina através da queima do bagaço é realizado em uma caldeira de 67 bar $/ 480^{\circ} \mathrm{C}$.

A caldeira analisada neste estudo recebe o bagaço proveniente do sistema de extração com 50\% de umidade e queima $100 \%$ da produção para gerar vapor a 67 bar com temperatura de $480^{\circ} \mathrm{C}$.

A análise do volume de controle 5 tem início com a construção do diagrama de volume de controle apresentado na Figura 17. 
BAGAÇO

CONDENSADO

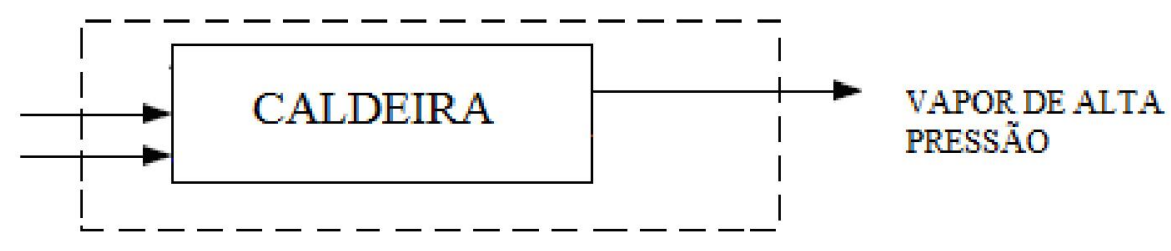

Figura 17 - Volume de controle 5 da caldeira

Neste este estudo foram utilizados dois critérios de custos, a Tabela 14 apresenta os resultados para o volume de controle 5 com a utilização dos critérios de extração e de igualdade.

Tabela 14- Custos dos fluxos de saída do volume de controle 5 (*)

\begin{tabular}{ccc}
\hline Fluxo & Extração & Igualdade \\
\hline vapor de $67 \mathrm{bar} / 480^{\circ} \mathrm{C}(\mathrm{R} \$ / \mathrm{kg})$ & $5,04.10^{-2}$ & $4,93.10^{-3}$ \\
vapor de $67 \mathrm{bar} / 480^{\circ} \mathrm{C}(\mathrm{R} \$ / \mathrm{kJ})$ & $3,63.10^{-5}$ & $3,55.10^{-6}$ \\
\hline
\end{tabular}

(*) cálculos detalhados no Anexo B

\subsubsection{Volume de controle 6 (turbinas)}

O processo de geração de eletricidade utilizando vapor de alta e baixa pressão é realizado em duas turbinas. A maioria das usinas brasileiras usa os sistemas com turbinas de contrapressão. Esses sistemas foram projetados para atender às demandas térmicas do processo, gerando quase toda ou toda a eletricidade necessária na usina. Nesses casos, a geração de eletricidade segue as variações da demanda de vapor no processo, sendo que a comercialização de excedentes é encarada como energia interruptível.

O uso de turbinas de condensação possibilita uma estabilização da geração de eletricidade excedente, porém a adequação da planta para comercialização de eletricidade excedente normalmente implica o uso de sistemas de extração-condensação (WALTER, 1994).

O sistema de turbinas analisado é de extração-condesação e tem uma geração de 40 $\mathrm{kWh}$ por tonelada de cana $(30 \mathrm{kWh}$ na turbina de contra pressão e $10 \mathrm{kWh}$ na turbina de condensação), resultando num excedende de $27,1 \mathrm{kWh} / \mathrm{TC}$ de energia pois $12,9 \mathrm{kWh} / \mathrm{TC}$ são consumidos pela usina durante o processo de extração. 
O uso de sistemas com turbinas de extração-condensação permite um aumento na geração de eletricidade excedente, já que todo o vapor pode ser produzido a pressões e temperaturas mais elevadas e ser parcialmente expandido nas turbinas até a pressão de admissão nos acionamentos, gerando um adicional de eletricidade. Além disso, o uso de sistemas mais avançados de cogeração requer uma redução do consumo de vapor no processo, para possibilitar a integração dessas tecnologias. Neste estudo o consumo de vapor de processo é de $340 \mathrm{~kg} / \mathrm{TC}$.

A análise do volume de controle 6 tem início com a construção do diagrama de volume de controle apresentado na Figura 18.

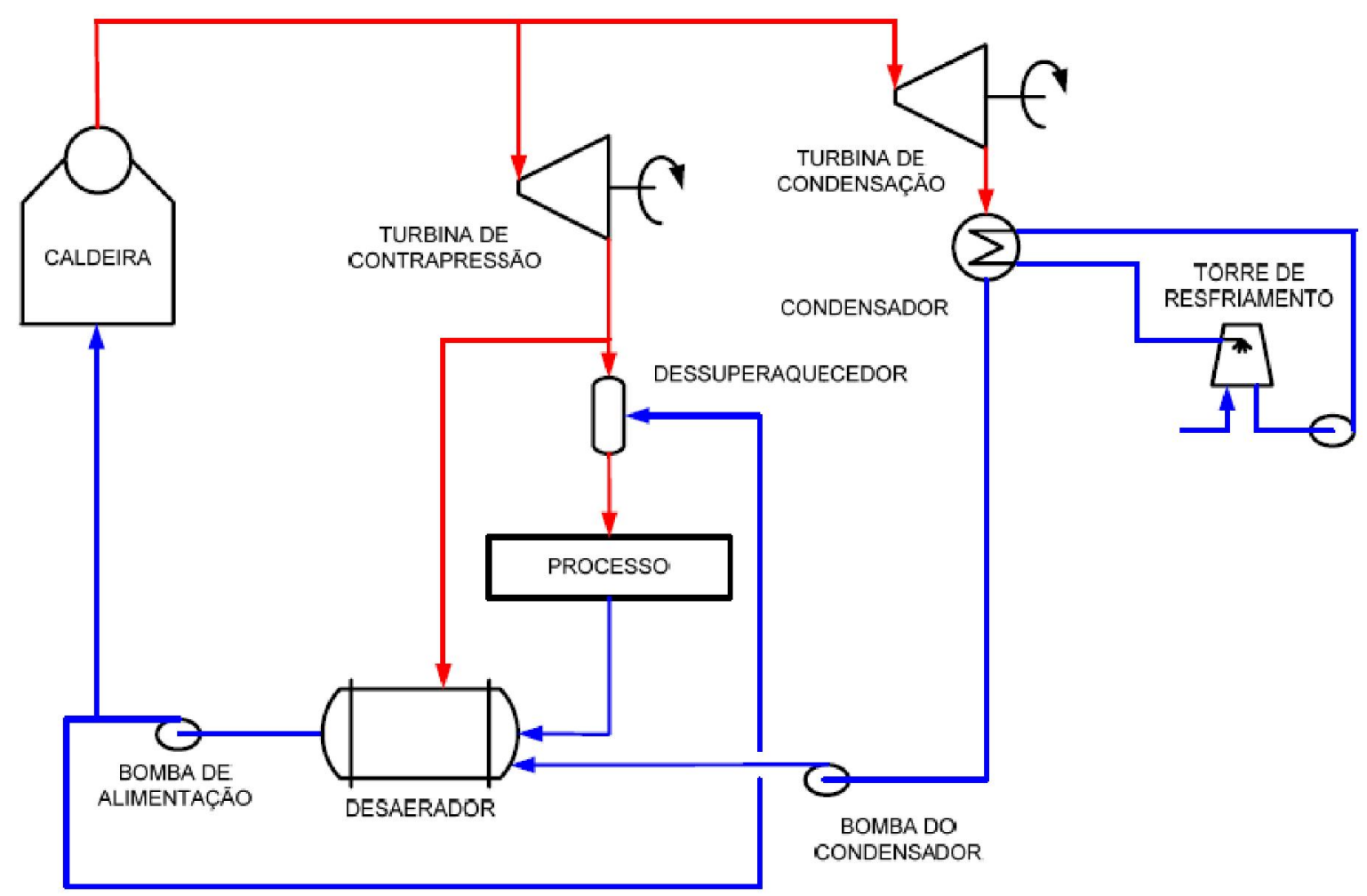

Figura 18 - Volume de controle 6 das turbinas extração-condensação

Neste estudo foram utilizados dois critérios de custos, as Tabelas 15 e 16 apresentam os resultados para o volume de controle 6 com a utilização dos critérios de extração e de igualdade. 
Tabela 15 - Custos dos fluxos de saída do volume de controle 6 com a turbina de 67 bar $/ 480^{\circ} \mathrm{C}(*)$

\begin{tabular}{llc}
\hline \multicolumn{1}{c}{ Fluxo } & Extração & Igualdade \\
\hline vapor de $2,5 \mathrm{bar} / 130^{\circ} \mathrm{C}(\mathrm{R} \$ / \mathrm{kg})$ & $2,21.10^{-2}$ & $6,72.10^{-3}$ \\
vapor de $2,5 \mathrm{bar} / 130^{\circ} \mathrm{C}(\mathrm{R} \$ / \mathrm{kJ})$ & $3,63.10^{-5}$ & $1,10.10^{-5}$ \\
vapor de $21 \mathrm{bar} / 280^{\circ} \mathrm{C}(\mathrm{R} \$ \mathrm{~kg})$ & $3,75.10^{-2}$ & $1,14.10^{-2}$ \\
vapor de $21 \mathrm{bar} / 280^{\circ} \mathrm{C}(\mathrm{R} \$ / \mathrm{kJ})$ & $3,62.10^{-5}$ & 39,70 \\
Eletricidade $(\mathrm{R} \$ / \mathrm{kJ})$ & $1,35.10^{-4}$ & $1,10.10^{-5}$ \\
Eletricidade $(\mathrm{R} \$ / \mathrm{MWh})$ & 484,00 & 39,70 \\
\hline
\end{tabular}

(*) cálculos detalhados no Anexo B

Tabela 16 - Custos dos fluxos de saída do volume de controle 6 com a turbina de $21 \mathrm{bar} / 280^{\circ} \mathrm{C}\left({ }^{*}\right)$

\begin{tabular}{lll}
\hline \multicolumn{1}{c}{ Fluxo } & Extração & Igualdade \\
\hline Condensado a $80^{\circ} \mathrm{C}(\mathrm{R} \$ / \mathrm{kg})$ & $1,63.10^{-3}$ & $3,12.10^{-3}$ \\
Condensado a $80^{\circ} \mathrm{C}(\mathrm{R} \$ / \mathrm{kJ})$ & $3,63.10^{-5}$ & $6,94.10^{-5}$ \\
Eletricidade $(\mathrm{R} \$ / \mathrm{kJ})$ & $1,92.10^{-4}$ & $6,94.10^{-5}$ \\
Eletricidade $(\mathrm{R} \$ / \mathrm{kJ})$ & 691,00 & 250,00 \\
\end{tabular}

(*) cálculos detalhados no Anexo B

6.2.1.7 Custo ponderado da eletricidade excedente do sistema de usina autônoma

A análise termoeconômica resulta em dois custos distintos de eletricidade, a energia do sistema motor-gerador e do sistema de cogeração.

A Tabela 17 apresenta o custo ponderado da eletricidade utilizando os dois critérios, extração e igualdade.

Tabela 17 - Custo ponderado da eletricidade excedente da usina autônoma (*)

\begin{tabular}{lccc}
\hline \multicolumn{1}{c}{ Fluxo } & Extração & Igualdade & Unidade \\
\hline Eletricidade & 335,00 & 65,00 & $\mathrm{R} \$ / \mathrm{MWh}$
\end{tabular}

(*) cálculos detalhados no Anexo B

6.2.2. Biossistema da usina autônoma com criação de gado

O biossistema da usina autônoma com a criação de gado foi dividido em 8 volumes de controle distintos que interagem entre si com a finalidade de gerar álcool e eletricidade como 
produtos finais, apesar de obtermos, nesta análise, os custos termoeconômicos de todos os produtos do sistema, vamos comparar somente os custos da eletricidade gerada.

Considerando que a diferença entre o sistema de usina autônoma isolada e do biossistema da usina autônoma com criação de gado é tão somente o incremento de um biodigestor e um motor-gerador, suprime-se a apresentação dos 6 volumes de controle da usina autônoma por serem idênticos ao caso anterior.

\subsubsection{Volume de controle 7 (biodigestão)}

O processo de produção de biogás ocorre em biodigestor modelo canadense. Esse modelo de biodigestor é uma variante dos modelos indiano e chinês. Foi projetado para zonas mais frias que as tropicais. Assim sendo, sua construção deve ser feita totalmente sob o solo. (Almança, 1994).

O biodigestor modelo canadense é próprio para o uso rural. Utiliza como substrato dejetos de animais e resíduos agrícolas. A transformação da matéria orgânica em gás é possível devido à fermentação anaeróbia (sem a presença do ar).

Este processo pode ser dividido em três estágios com três distintos grupos de microrganismos. O primeiro estágio envolve bactérias fermentativas, compreendendo microrganismos anaeróbios e facultativos. Neste estágio, materiais orgânicos complexos (carboidratos, proteínas e lipídios) são hidrolizados e fermentados em ácidos graxos, álcool, dióxido de carbono, hidrogênio, amônia e sulfetos.

As bactérias acetogênicas participam do segundo estágio, consumindo os produtos primários e produzindo hidrogênio, dióxido de carbono e ácido acético. Dois grupos distintos de bactérias metanogênicas participam do terceiro estágio, o primeiro grupo reduz o dióxido de carbono a metano e o segundo descarboxiliza o ácido acético produzindo metano e dióxido de carbono.

Apesar de parecer complexo, este processo de fermentação ocorre naturalmente e continuamente dentro do biodigestor (CHERNICHARRO, 1997).

A análise do volume de controle 7 tem início com a construção do diagrama de volume de controle apresentado na Figura 19. 


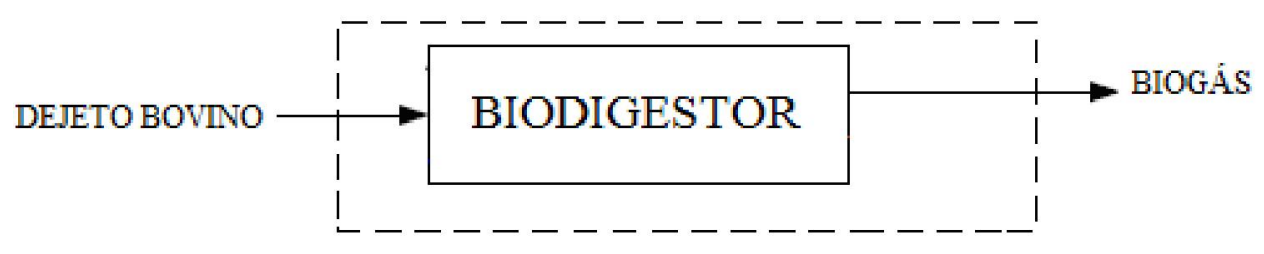

Figura 19 - Volume de controle 7 do biodigestor do gado

Neste estudo foram utilizados dois critérios de custos, a Tabela 18 apresenta os resultados para o volume de controle 7 com a utilização dos critérios de extração e de igualdade.

Tabela 18 - Custos dos fluxos de saída do volume de controle 7 (*)

\begin{tabular}{llcc}
\hline & Fluxo & Extração & Igualdade \\
\hline Biogás $\left(\mathrm{R} \$ / \mathrm{m}^{3}\right)$ & $5,38.10^{-3}$ & $5,38.10^{-3}$ \\
Biogás $(\mathrm{R} \$ / \mathrm{kJ})$ & $3,62.10^{-7}$ & $3,62.10^{-7}$ \\
\hline
\end{tabular}

(*) cálculos detalhados no Anexo B

\subsubsection{Volume de controle 8 (motor-gerador)}

O processo de produção de eletricidade com o biogás produzido nos biodigestores se dá em um motor de ciclo Otto adaptado.

O motor utilizado neste etudo é idêntico ao da usina autônoma.

A análise do volume de controle 8 tem início com a construção do diagrama de volume de controle apresentado na Figura 20.

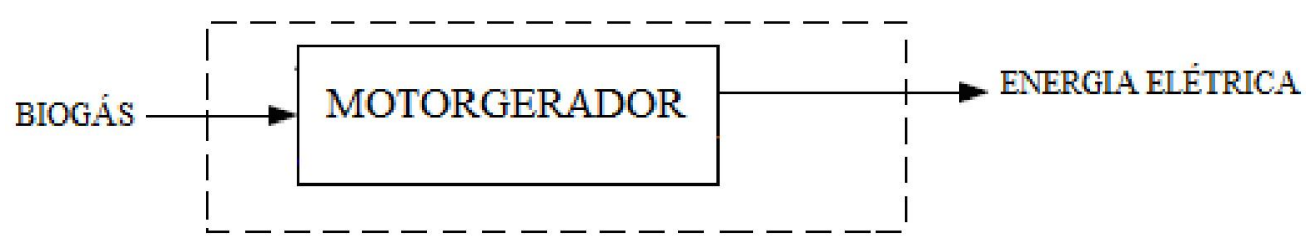

Figura 20 - Volume de controle 8 do motor-gerador do gado

Neste estudo foram utilizados dois critérios de custos, a Tabela 19 apresenta os resultados para o volume de controle 8 com a utilização dos critérios de extração e de igualdade. 
Tabela 19 - Custos dos fluxos de saída do volume de controle 8 (*)

\begin{tabular}{lcc}
\hline \multicolumn{1}{c}{ Fluxo } & Extração & Igualdade \\
\hline Eletricidade $(\mathrm{R} \$ \mathrm{MWh})$ & 30,80 & 30,80 \\
Eletricidade $(\mathrm{R} \$ / \mathrm{kJ})$ & $8,56.10^{-6}$ & $8,56.10^{-6}$ \\
\hline *) cálculos detalhados no Anexo B & &
\end{tabular}

6.2.2.3 Custo ponderado da eletricidade excedente do biossistema da usina autônoma com criação de gado.

A análise termoeconômica resulta em dois custos distintos de eletricidade, a energia do sistema motor-gerador e do sistema de cogeração.

A Tabela 20 apresenta o custo ponderado da eletricidade do biossistema, utilizando os dois critérios, extração e igualdade.

Tabela 20 - Custo ponderado da eletricidade excedente da usina autônoma com criação de gado $\left(^{*}\right)$

\begin{tabular}{lcc}
\hline \multicolumn{1}{c}{ Fluxo } & Extração & Igualdade \\
\hline Eletricidade (R\$MWh) & 146,00 & 43,70 \\
\hline *) cálculos detalhados no Anexo B & & \\
\hline
\end{tabular}

\subsubsection{Biossistema usina autônoma com criações de gado e suínos}

O biossistema da usina autônoma integrado com as criações de gado e suínos foi separado em 9 volumes de controle distintos que interagem entre si com a finalidade de gerar álcool e eletricidade como produtos finais, apesar de obtermos os custos termoeconômicos de todos os produtos do sistema, foram comparados somente os custos da eletricidade gerada.

Considerando que a diferença entre o biossistema de usina autônoma com criação de gado e do biossistema da usina autônoma com criação de gado e suínos é tão somente o incremento de dejetos no biodigestor pré-existente, suprime-se a apresentação dos 7 volumes de controle da usina autônoma por serem idênticos ao caso anterior, acrescenta-se o volume de controle 8 (biodigestão somente de dejetos suínos) e o volume de controle 9 (motorgerador). 
6.2.3.1 Volume de controle 8 (biodigestão de dejetos suínos)

O processo de produção de biogás ocorre dentro do mesmo biodigestor do biossistema da usina autônoma com criação de gado.

A análise do volume de controle 8 tem início com a construção do diagrama de volume de controle apresentado na Figura 21.

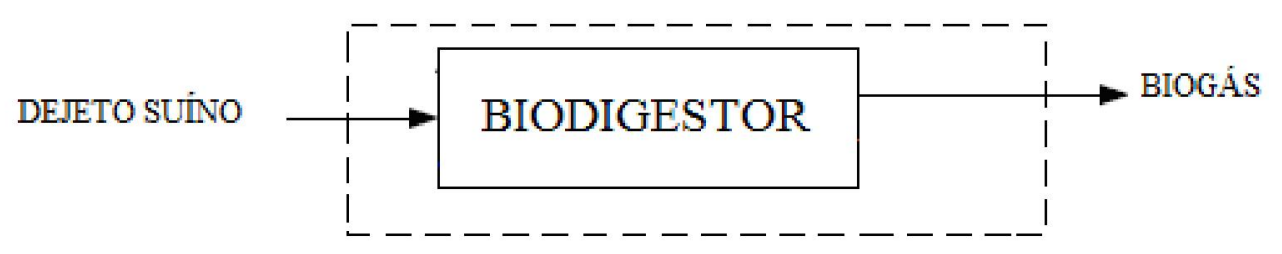

Figura 21 - Volume de controle 8 do biodigestor dos suínos

Neste estudo foram utilizados dois critérios de custos, a Tabela 21 apresenta os resultados para o volume de controle 3 com a utilização dos critérios de extração e de igualdade.

Tabela 21 - Custos dos fluxos de saída do volume de controle 8 do biodiestor dos suínos (*)

\begin{tabular}{lccc}
\hline & Fluxo & Extração & Igualdade \\
\hline Biogás $\left(\mathrm{R} \$ / \mathrm{m}^{3}\right)$ & $1,33.10^{-1}$ & $1,33.10^{-1}$ \\
Biogás $(\mathrm{R} \$ / \mathrm{kJ})$ & $8,97.10^{-6}$ & $8,97.10^{-6}$ \\
\hline
\end{tabular}

(*) cálculos detalhados no Anexo B

\subsubsection{Volume de controle 9 (motor-gerador)}

O processo de produção de eletricidade com o biogás produzido no biodigestor se dá em um motor de ciclo Otto adaptado.

O motor utilizado neste etudo é idêntico ao da usina autônoma.

A análise do volume de controle 9 tem início com a construção do diagrama de volume de controle apresentado na Figura 22, onde o fluxo de entrada é a somatória do biogás dos dejetos da criação de gado e da criação de suínos. 


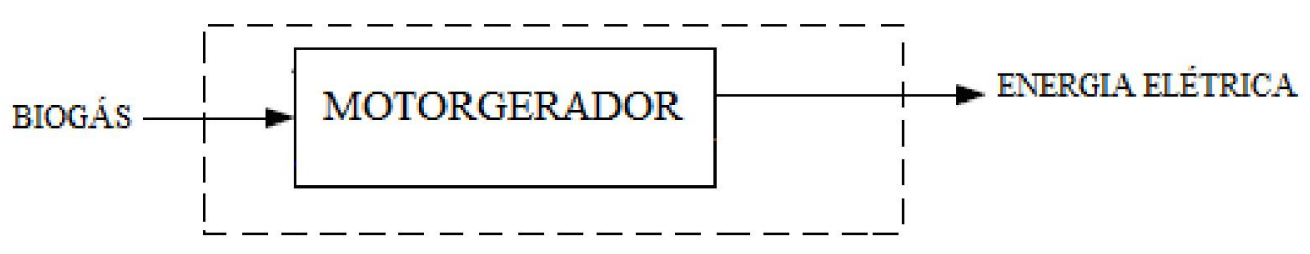

Figura 22 - Volume de controle 9 do motor-gerador do gado e suínos

Neste estudo foram utilizados dois critérios de custos, a Tabela 22 apresenta os resultados para o volume de controle 9 com a utilização dos critérios de extração e de igualdade.

Tabela 22 - Custos dos fluxos de saída do volume de controle 9 (*)

\begin{tabular}{|c|c|c|}
\hline Fluxo & Extração & Igualdade \\
\hline Eletricidade (R \$/MWh) & 34,00 & 34,00 \\
\hline Eletricidade $(\mathrm{R} \$ / \mathrm{kJ})$ & $9,44 \cdot 10^{-6}$ & $9,44 \cdot 10^{-6}$ \\
\hline
\end{tabular}

(*) cálculos detalhados no Anexo B

6.2.3.3. Custo ponderado da eletricidade excedente do biossistema da usina autônoma com criação de gado e suínos

A análise termoeconômica resulta em dois custos distintos de eletricidade, a energia do sistema motor-gerador e do sistema de cogeração.

A Tabela 23 apresenta o custo ponderado da eletricidade do biossistema utilizando os dois critérios, extração e igualdade.

Tabela 23 - Custo ponderado da eletricidade excedente do biossistema da usina autônoma com gado e suínos (*)

\begin{tabular}{lcc}
\hline \multicolumn{1}{c}{ Fluxo } & Extração & Igualdade \\
\hline Eletricidade $(\mathrm{R} \$ \mathrm{MWh})$ & 112,00 & 42,00 \\
\hline *) cálculos detalhados no Anexo B & & \\
\hline
\end{tabular}

6.3. Comparação da análise termoeconômica para os biossistemas estudados

A Tabela 24 apresenta a comparação entre os custos termoeconômicos da geração de eletricidade dos biossistemas estudados. 
Tabela 24 - Custo ponderado da eletricidade excedente dos biossistemas (*)

\begin{tabular}{lr}
\hline \multicolumn{1}{c}{ Biossistema } & Extração \\
\hline Usina autônoma $(\mathrm{R} \$ / \mathrm{MWh})$ & 335,00 \\
Usina autônoma com criação de gado $(\mathrm{R} \$ / \mathrm{MWh})$ & 146,00 \\
Usina autônoma com criações de gado e suínos $(\mathrm{R} \$ / \mathrm{MWh})$ & 43,70 \\
\end{tabular}

(*) cálculos detalhados no Anexo B

Os resultados apresentados na Tabela 24 e mostrados no Gráfico 1 indicam que em se tratando de geração de eletricidade, o biossistema completo representa o menor custo em $\mathrm{R} \$ / \mathrm{MWh}$ tanto utilizando o critério de extração, como o critério da igualdade a medida que se inserem novas unidades ao biosistema.

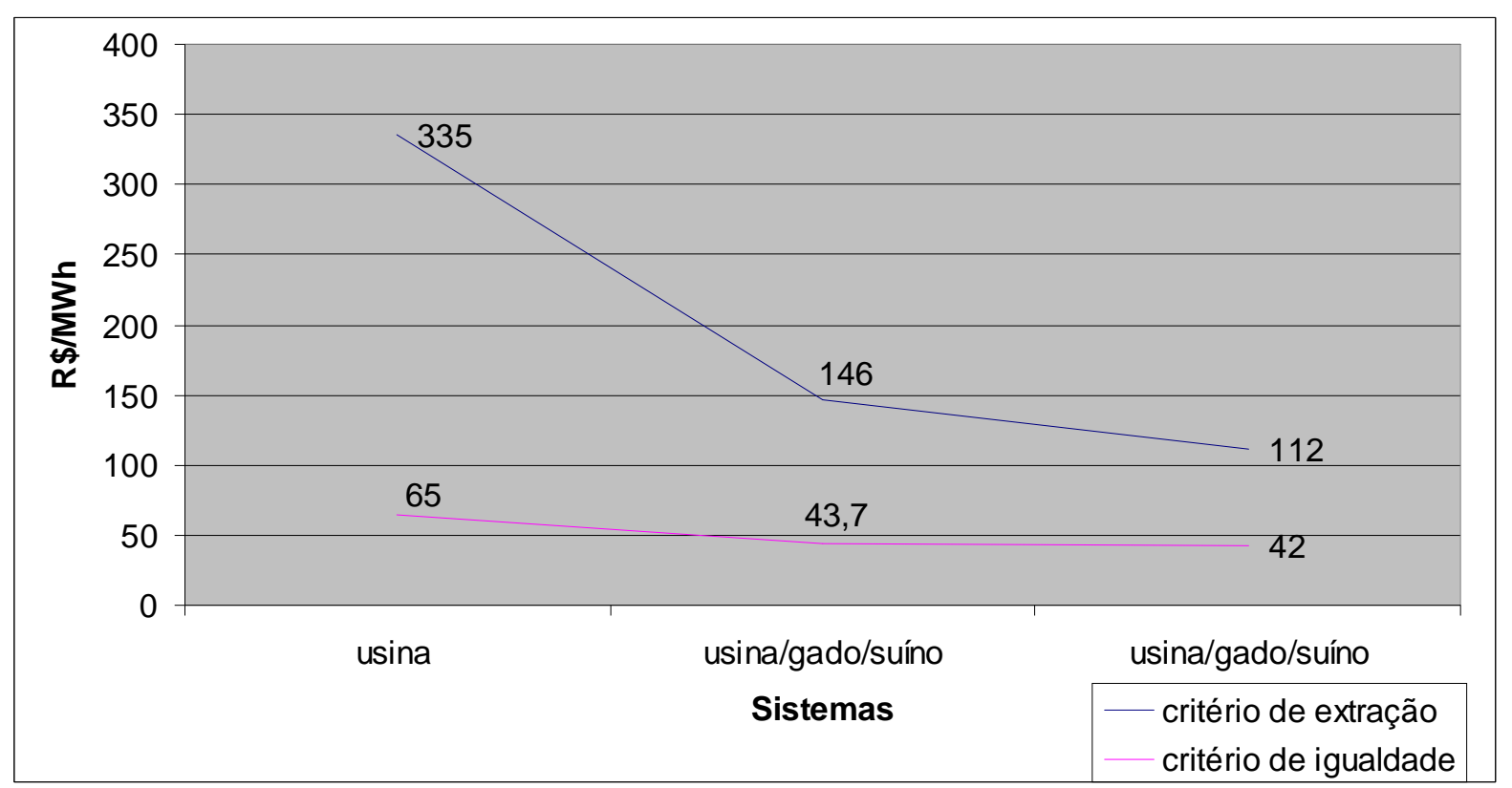

Gráfico 1 - Evolução dos custos com a integração dos sistemas 


\section{Análise econômica-financeira}

Os dados utilizados na análise econômica para a o sistema da usina autônoma, foram extraídos do estudo desenvolvido por Ometto et al, 2006, com a valoração financeira apresentada por Melo, 2007. Para a criação de gado, foram utilizados os custos de equipamentos apresentados por Ometto et al., 2006, e o custo da mão de obra de Macedo, 2005 e para a criação de suínos, foram utilizados os dados de Cavalett, 2004.

\subsection{Métodos de Avaliação}

Para avaliarmos a viabilidade de um investimento existem índices a exemplo do Valor Presente Líquido (VPL) e da Taxa Interna de Retorno (TIR), que utilizam o método do fluxo de caixa descontado, baseados no conceito do valor do dinheiro no tempo.

Tanto o VPL quanto a TIR são utilizados como parâmetros para a tomada de decisão entre aplicar ou não determinada quantia em um projeto. Podem ser consideradas em conjunto ou de maneira isolada, como fizeram Brealey et al (2006), a fim de obter a melhor avaliação sobre rendimentos aplicados em um determinado investimento financeiro. Eles mostraram que ao considerar somente o valor da TIR para estabelecer a viabilidade de um investimento, pode levar a uma decisão equivocada. Assim, a utilização de duas ferramentas torna-se mais pertinente.

\subsubsection{Valor Presente Líquido}

O VPL é a técnica mais conhecida para avaliar investimentos de capital (GITMAN, 1997), trata-se da equivalência monetária atual da soma dos fluxos de caixas que acontecerão no futuro, durante um período pré-determinado e dado uma taxa de desconto.

Por considerar explicitamente o valor do dinheiro no tempo, o valor presente líquido é considerado uma técnica sofisticada de análise de investimentos. Este tipo de técnica desconta os fluxos de caixa da empresa a uma taxa de juros específica. Essa taxa, freqüentemente chamada de taxa de desconto, custo de oportunidade ou custo de capital, além de taxa de juros, refere-se ao retorno mínimo que deve ser obtido por um projeto, de forma a manter inalterado o valor de mercado da empresa (GITMAN, 1997). 
O valor presente líquido, de acordo com a Equação (20), é obtido subtraindo-se o investimento inicial do valor presente das entradas de caixa, descontadas a uma taxa igual ao custo de capital do investimento, para um determinado tempo ou número de períodos.

$$
\mathrm{VPL}=\sum_{\mathrm{t}=1}^{\mathrm{n}} \frac{F \mathrm{C}_{t}}{(1+r)^{t}}-I_{0}
$$

onde,

$\mathrm{FCt}=$ Fluxo de Caixa de $\mathrm{t}=0$ até $\mathrm{t}=\mathrm{n}$

$\mathrm{t}=$ tempo, em anos

$\mathrm{r}=$ taxa de desconto

$\mathrm{II}_{0}=$ Investimento inicial

Utilizando o VPL, tanto as entradas como as saídas de caixa são convertidas para valores monetários atuais. Uma vez que o fluxo de caixa resultante dos modelos trata de um investimento convencional, o investimento inicial está automaticamente expresso em termos monetários atuais.

O critério clássico de decisão quando se utiliza o VPL é do tipo "aceitar ou rejeitar".

Há três situações possíveis para o valor do VPL:

- VPL < 0: investimento não é economicamente atrativo porque o valor das rendas obtidas é menor do que o valor do investimento inicial.

- $\mathrm{VPL}=0: \mathrm{O}$ investimento é indiferente, pois o retorno financeiro é igual ao investimento inicial efetuado.

- VPL > 0: O investimento é economicamente atrativo, dado que a somatória das rendas obtidas é maior do que o investimento inicial.

Se o VPL for maior que zero o projeto é aceito, caso contrário, o projeto será rejeitado. Se o VPL for maior que zero, o investidor estará obtendo um retorno maior que o custo de capital, desta forma, estaria aumentando o valor de mercado da sua infra-estrutura (GITMAN, 1997). 
As parcelas do fluxo de caixa podem ser variáveis, pois, de acordo com Veiga (2006), elas dependem da evolução da oferta e da demanda no futuro, da composição do parque gerador futuro, da disponibilidade de insumos e também da política operativa, a exemplo de custo de déficit e curvas de aversão a riscos. Todavia, elas podem ser consideradas constantes, caso a produção seja invariável e vendida por meio de contratos com preços fixos durante todo o período considerado.

Deve-se considerar uma taxa de desconto do capital, pois no VPL um dólar hoje vale mais do que um dólar em um tempo futuro já que - investido no presente - esse mesmo dólar renderá juros e terá maior valor no futuro.

\subsubsection{Taxa Interna de Retorno}

Uma vez calculado o VPL da aplicação pode-se obter também a TIR. Esta taxa é um valor que depende apenas dos fluxos de caixa esperados do projeto.

A TIR, apesar de ser consideravelmente mais difícil de calcular de modo manual que o VPL, é possivelmente a técnica sofisticada mais utilizada para a avaliação de alternativas de investimentos (GITMAN, 1997). A TIR, em outras palavras, é a taxa de desconto que faz com que o VPL de uma oportunidade de investimento iguale-se a zero (já que o valor presente das entradas de caixa é igual ao investimento inicial). Matematicamente, a TIR é obtida resolvendo-se a Equação (21) para o valor de k que torne o VPL igual a zero.

$$
0=\sum_{t=1}^{n} \frac{F C_{t}}{(1+T I R)^{t}}-I_{0}
$$

onde,

$\mathrm{FCt}=$ Fluxo de Caixa de $\mathrm{t}=0$ até $\mathrm{t}=\mathrm{n}$

$\mathrm{t}=$ tempo, em anos

TIR= Taxa Interna de Retorno

$\mathrm{II}_{0}=$ Investimento inicial

O critério de decisão, quando a TIR é usada para optar entre "aceitar ou rejeitar", é: se a TIR for maior que o custo de capital (taxa de juros), se aceita o projeto, caso contrário, o projeto deverá ser rejeitado. 
Esse critério garante que a empresa esteja obtendo pelo menos, sua taxa requerida de retorno. Tal resultado deveria aumentar o valor de mercado da infra-estrutura. No caso deste estudo o projeto que obtiver a maior TIR, será o mais atraente do ponto-de-vista financeiro para o investidor.

De acordo com Carvalho (2008), a TIR utilizada na quantificação da receita deve ser estabelecida por meio de negociações entre o poder concedente e o investidor, nas quais entram critérios subjetivos tais como "atratividade" para o investidor e "razoabilidade" para os consumidores dos produtos gerados pela usina. Para o investidor interessa que a TIR seja a mais alta possível, para que o retorno de seu investimento seja rentável.

Quando se observa a discordância entre os métodos de VPL e TIR, deve-se priorizar o projeto com maior VPL e assumir que o objetivo é maximizar o valor presente do investimento.

\subsection{Caracterização dos biossistemas}

A caracterização dos biossistemas é feita com base em trabalhos pesquisados na literatura, que produzem eletricidade excedente.

\subsubsection{Sistema da usina autônoma}

As características do sistema da usina autônoma deste estudo são apresentadas na Tabela 25.

Tabela 25 - Características da usina autônoma

\begin{tabular}{ll}
\hline Descrição & Dimensão \\
\hline Moagem/dia & 500 TC \\
Rendimento estimado & 80 litros de álcool/TC \\
Geração de vapor na caldeira & 15 toneladas vapor/h \\
Moenda & 4 ternos $18 \times 24$ polegadas \\
Pressão de trabalho & 67 bar \\
Produção de bagaço & $250 \mathrm{~kg} / \mathrm{TC}$ \\
\hline
\end{tabular}


7.2.1.1 Ítens e valores (R\$) da usina autônoma

Os investimentos monetários para implantação da usina autônoma são relacionados na Tabela 26.

Tabela 26 Investimentos monetários para implantação da usina autônoma

\begin{tabular}{lr}
\hline Descrição & Valor (R\$) \\
\hline Recepção e estocagem & $853.498,00$ \\
Preparação e alimentação da cana & $647.467,00$ \\
Moagem & $1.904 .525,00$ \\
Tratamento do caldo & $104.572,00$ \\
Fermentação & $693.543,00$ \\
Destilação & $1.576 .408,00$ \\
Armazenamento da produção & $317.827,00$ \\
Água, tratamento e alimentação da fábrica & $250.510,00$ \\
Resfriamento da água & $80.010,00$ \\
Geração de Vapor & $932.510,00$ \\
Geração de energia (turbina 1) & $450.510,00$ \\
Geração de energia (turbina 2) & $450.510,00$ \\
Parte elétrica e automação & $560.000,00$ \\
Laboratório industrial & $94.500,00$ \\
Laboratório ATR & $375.000,00$ \\
Construção civil & $1.146 .961,00$ \\
Informatização & $99.698,00$ \\
Complementos diversos & $1.008 .754,00$ \\
Biodigestor $\quad$ (UASB) & $80.000,00$ \\
Motor-gerador (biogás) & $329.700,00$ \\
\hline CUSTO TOTAL DE IMPLANTAÇÃO & $11.956 .503,00$ \\
\hline
\end{tabular}

7.2.1.2. Custos anuais com matéria-prima, funcionários e manutenção

A usina autônoma consome $1,05.10^{5}$ toneladas de cana anuais, a um custo de $\mathrm{R} \$ 23,00$ a tonelada. São necessários 68 funcionários de mão-de-obra não especializada com custo mensal individual, inclusos os impostos de R \$ 850,00 (Macedo, 2005). São necessários 11 funcionários de mão-de-obra especializada com custo mensal individual, incluso os impostos de R\$ 3.500,00 (Macedo, 2005). Custo de Manutenção de R \$ 109.000,00 anuais (OMETTO et al. 2006). 
Os custos de instalação, operação e manutenção a pesar de representarem valores em anos distintos, são utilizados em conjunto, a inflação no Brasil neste período não foi significativa, o custo total anual da usina é então de $\mathrm{R} \$ 3.775 .900,00$, considerando-se o pagamento de 13 salários aos funcionários somando-se ao custo da cana e da manutenção.

\subsubsection{Faturamento anual com a venda de produtos}

A usina comercializa anualmente $8,4.10^{6}$ litros de álcool a um valor médio de $\mathrm{R} \$ 0,6821$ o litro (UNICA, 2008) e 7,17.10 3 MWh de energia a um valor médio de $\mathrm{R} \$ 138,85$ o MWh (EPE, 2007).

O faturamento anual da usina considerando a venda de álcool e eletricidade é no valor de $\mathrm{R} \$$ 6.725.194,50, pressuposto neste estudo como fluxo livre.

\subsubsection{Lucro anual da usina}

Considerando um faturamento de $\mathrm{R} \$ \mathbf{6 . 7 2 5 . 1 9 4 , 5 0}$ e um custo de produção de $\mathrm{R} \$ 3.775 .900,00$, a usina tem um lucro anual no valor de $\mathrm{R} \$ 2.949 .295,50$.

\subsubsection{Horizonte temporal}

O horizonte temporal considerado foi de 20 anos, prazo determinado para duração de uma usina, em função da vida útil dos equipamentos (THOMSON, 2004).

Como critério de decisão foi utilizado o Valor Presente Líquido (VPL) e a Taxa Interna de Retorno (TIR).

7.2.2. Biossistema da usina autônoma com dejeto de gado.

As características do sistema anexam ao sistema anterior, agregando os ítens a seguir:

Sistema da usina autônoma

Biodigestor canadense com volume de $5000 \mathrm{~m}^{3}$

Grupo Motor-gerador 


\subsubsection{Itens e Valores}

Os investimentos monetários para implantação da usina autônoma integrada com dejetos de gado são relacionados abaixo:

Sistema da usina autônoma

Biodigestor

Motor-gerador

Total
$\mathrm{R} \$ 11.956 .503,00$

$\mathrm{R} \$ 45.000,00$

$\mathrm{R} \$ 329.700,00$

$\mathrm{R} \$ 12.331 .203,00$

7.2.2.2 Custos anuais com matéria-prima, funcionários e manutenção

Aos custos do sistema da usina autônoma ( $\mathrm{R} \$ 3.775 .900,00)$, acrescentam:

São necessários mais dois funcionários de mão-de-obra não especializada com custo mensal individual, inclusos os impostos de $\mathrm{R} \$ 850,00$ (Macedo, 2005). Custo de Manutenção de $\mathrm{R} \$ 4.500,00$ anuais (Ometto et al, 2006). Totalizando um custo anual de R \$ 3.802.500,00, considerando-se o pagamento de 13 salários aos funcionários.

7.2.2.3. Faturamento anual com a venda de produtos

O biossistema comercializa anualmente $8,4.10^{6}$ litros de álcool a um valor médio de $\mathrm{R} \$ 0,6821$ o litro (UNICA, 2008) e 1,90.10 $\mathrm{MWh}$ de energia a um valor médio de $\mathrm{R} \$ 138,85$ o MWh (EPE, 2007). O faturamento anual do biossistema da usina autônoma com dejetos de gado é no valor de $\mathrm{R} \$ 8.367 .790,00$.

7.2.2.4. Lucro anual do biossistema da usina autônoma com dejetos de gado

Considerando um faturamento de $\mathrm{R} \$ 8.367 .790,00$ e um custo de produção de $\mathrm{R} \$$ 3.802.500,00, a usina tem um lucro anual no valor de $\mathrm{R} \$ 4.565 .290,00$. 


\subsubsection{Horizonte temporal}

O horizonte temporal considerado foi de 20 anos, prazo determinado para duração de uma usina, em função da vida útil dos equipamentos, biodigestor e motor-gerador (THOMSON, 2004). Como critério de decisão foi utilizado o Valor Presente Líquido (VPL) e a Taxa Interna de Retorno (TIR).

7.2.3. Biossistema da usina autônoma com dejetos de gado e suínos.

As características deste sistema são as mesmas do sistema anterior.

\subsubsection{Itens e Valores}

Os investimentos monetários para implantação da usina autônoma com dejetos de gado e suínos é o mesmo que da usina autônoma com dejetos de gado.

Biossistema da usina autônoma com dejetos de gado

$\mathrm{R} \$ 12.331 .203,00$

7.2.3.2 Custos anuais com matéria-prima, funcionários e manutenção

Aos custos do biossistema da usina autônoma com dejetos de gado ( $\mathrm{R} \$ 3.802 .500,00$ ), acrescentam:

São necessários mais trinta funcionários de mão-de-obra não especializada com custo mensal individual, inclusos os impostos de R\$ 850,00 (MACEDO, 2005).

Totalizando um custo anual de $\mathrm{R} \$ 4.134 .000,00$, considerando-se o pagamento de 13 salários aos funcionários.

7.2.3.3. Faturamento anual com a venda de produtos

O biossistema comercializa anualmente $8,4 \cdot 10^{6}$ litros de álcool a um valor médio de R\$ 0,6821 o litro (UNICA, 2008) e 2,76.10 $\mathrm{MWh}$ de energia a um valor médio de $\mathrm{R} \$ 138,85$ o MWh (EPE, 2007). O faturamento anual do biossistema é no valor de $\mathrm{R} \$ 9.561 .900,00$. 
7.2.3.4. Lucro anual do biossistema da usina autônoma com dejetos de gado e suínos

Considerando um faturamento de $\mathrm{R} \$ 9.561 .900,00 \mathrm{e}$ um custo de produção de $\mathrm{R} \$$ 4.134.000,00, o biossistema tem um lucro anual no valor de $\mathrm{R} \$ 5.427 .900,00$.

\subsubsection{Horizonte temporal}

O horizonte temporal considerado foi de 20 anos, prazo determinado para duração de uma usina, em função da vida útil dos equipamentos, biodigestor e motor-gerador (Thomson, 2004).

Como critério de decisão foi utilizado o Valor Presente Líquido (VPL) e a Taxa Interna de Retorno (TIR).

\subsection{Análise dos resultados do VPL e da TIR}

Para o cálculo do VPL foi utilizada a taxa de desconto de 15\% (taxa média de juros bancários para investimento comercial em abril de 2009) e os resultados da análise do VPL e da TIR são apresentados na Tabela 27:

Tabela 27 - Resultados do VPL e da TIR (*)

\begin{tabular}{lrr}
\hline Biossistema & VPL (R\$) & \multicolumn{1}{c}{ TIR (\%) } \\
\hline Autônoma & $5.655 .746,86$ & $24,4 \%$ \\
Autônoma + gado & $14.125 .617,72$ & $36,95 \%$ \\
Autônoma + gado + suínos & $18.820 .715,05$ & $43,99 \%$ \\
\hline
\end{tabular}

(*) cálculos no Anexo C

Os cálculos foram realizados em planilha eletrônica (Excel 2003) e estão descriminados no Anexo C.

Os resultados apresentados na Tabela 25 indicam que os três sistemas apresentam valores de VPL maiores de que zero, indicando que são opções viáveis de investimento, mas segundo o critério adotado nesta tese, o biossistema usina autônoma com dejetos de gado e suínos é o mais rentável, pois seu VPL é maior que os biossistema da usina autônoma com dejetos de gado e que o sistema da usina autônoma isolado. 
A análise pelo critério da TIR apresenta resultado similar, indicando que novamente o biossistema usina autônoma com dejetos de gado e suínos com uma TIR de 43,99\%, indicando que o retorno do investimento se dá em pouco mais de dois anos.

Logo, considerando-se a análise econômica, verifica-se que o biossistemamda usina autônoma com dejetos de gado e suínos é o mais viável economicamente.

\subsection{Cálculo do custo de geração de eletricidade}

O resultado apresentado no item anterior leva em consideração a venda do álcool em seu faturamento anual.

Para que possamos calcular o custo do MWh de energia gerado nos sistemas em análise, é necessário realizar um inventário dos componentes que efetivamente participam da geração de eletricidade.

A planilha com o memorial dos cálculos está no Anexo C. Os custos relativos a esta atividade são apresentados na Tabela 28.

Tabela 28 - Custos de geração de eletricidade

\begin{tabular}{lr}
\hline & CUSTO DO M Wh gerado (R \$/M Wh) \\
\hline Biossistema & Custo \\
Usina autônoma & 74,41 \\
Usina autônoma + dejetos do gado & 33,21 \\
Usina autônoma + dejetos do gado e suínos & 30,87 \\
\hline cálculos no Anexo C
\end{tabular}

7.5. Análise do resultado de custo de geração de eletricidade

A Tabela 28 apresenta os custos de geração de eletricidade para cada um dos biossistemas apresentados, mostrando que a integração dos biossistemas conduz a redução de custos do MWh de energia gerado, ou seja, quando se anexa à usina autônoma o aproveitamento de dejetos do gado, temos um custo menor em reais (R\$) por MWh e quando anexamos os dejetos suínos e bovinos, a redução é ainda maior, pois o custo do biossistema de usina autônoma com dejetos de gado e suíno resultou em um custo de 30,87 R \$/MWh de eletricidade, enquanto o biossistema de usina autônoma com dejetos de gado resultou em 33,21 R\$/MWh e o sistema da Usina autônoma teve um custo de 74,41 R\$/MWh. 


\section{Conclusões}

As conclusões deste estudo foram separadas quanto ao uso de recursos (emergia), quanto à termoeconomia e quanto a economia financeira, em seguida apresentamos a comparação entre as métricas.

\subsection{Quanto ao uso de recursos}

O capítulo 5 deste estudo apresenta o cálculo dos indicadores em emergia, e de acordo com os resultados, verificamos que apresentam índices similares em sua maioria, o que não permite uma definição do biossistema com melhor desempenho.

Por meio da representação gráfica no diagrama ternário em emergia (Figura 10), a interpretação dos resultados dos índices em emergia se torna mais rápida, por ser esta uma ferramenta visual. Nota-se que a posição ocupada pelo ponto que representa o sistema da usina autônoma, apresenta melhor desempenho ambiental que os demais, por estar mais próxima da linha de ESI =1, contudo os sistemas comparados se encontram na mesma região, não sendo conclusivo.

A análise em emergia permite ainda a comparação da transformidade (intensidade dos fluxos). Os biossistemas analisados apresentam transformidades da mesma ordem de grandeza para a geração de eletricidade, sendo que a transformidade para a o sistema de usina autônoma é aproximadamente $106 \%$ sej/sej maior que o biossistema da usina com criação de gado, isso se deve ao fato de que o sistema da usina autônoma emprega recursos também para a geração de álcool, e $112 \%$ sej/sej maior que o biossistema integrado completo.

Analisando a transformidade, o biossistema com melhor desempenho é o da usina autônoma com criação de gado e suínos.

\subsection{Quanto ao custo termoeconômico}

O capítulo 6 apresenta a análise termoeconômica, que permite atribuir custos a cada fluxo do sistema energético, baseando-se somente em conceitos termodinâmicos e econômicos dos biossistemas.

Os resultados mostram uma redução de custos (Tabela 24 e Gráfico 1) ao passo que se integram os biossistemas propostos, indicando que o biossistema da usina autônoma com 
criação de gado e suínos apresenta melhor desempenho nesta métrica que os demais.

A escolha do critério de partição (extração ou igualdade) tem grande influência na determinação de custos dos biossistemas, e é nesse ponto que centra as maiores discussões na área de termoeconomia atualmente, contudo a utilização dos dois critérios, apesar de apresentarem valores distintos, resulta na indicação de que o biossistema da usina autônoma com criação de gado e suínos tem menores custos para a eletricidade.

\subsection{Quanto ao custo econômico financeiro}

O capítulo 7 apresenta a análise econômica financeira. Os biossistemas analisados quanto à geração de eletricidade, resultam em um menor custo (Tabela 26) para o biossistema de usina autônoma com criação de gado e suínos.

O que indica que a integração de biossistemas é viável economicamente no que tange à geração de eletricidade.

\subsection{Quanto à comparação entre as métricas}

Durante a elaboração deste estudo procuramos identificar as limitações de cada métrica utilizada, e conclui-se:

Emergia: esta métrica valora os custos dos produtos dos biossistemas através do uso de recursos ambientais, se preocupando com a origem de cada fluxo para compor seus indicadores, ou seja, uma visão ambiental da carga oferecida pelo biossistema, que podemos entender como se a biosfera estivesse olhando para o biossistema, sem se importar com quem compra ou vende os produtos deste.

Termoeconomia: esta métrica valora os custos dos produtos dos biossistemas através de alocação de custos financeiros de acordo com os conceitos termodinâmicos, ou seja, uma visão interna do sistema e de seu rendimento, focando a qualidade e a quantidade de energia que entra e sai do sistema agregada a cada produto, sendo portanto uma métrica que valora a quantidade de energia dos produtos.

Economia financeira: esta métrica valora os produtos dos biossistemas através do custo financeiro necessário para operá-lo, ou seja, uma visão do empresário e do mercado financeiro 
em aplicar ou não se capital em um investimento, realizando desta forma uma análise sob o ponto de vista do vendedor ou investidor do biossistema.

A Tabela 29 mostra um resumo dos resultados obtidos em todas as métricas.

Tabela 29. Tabela dos indicadores utilizados neste estudo

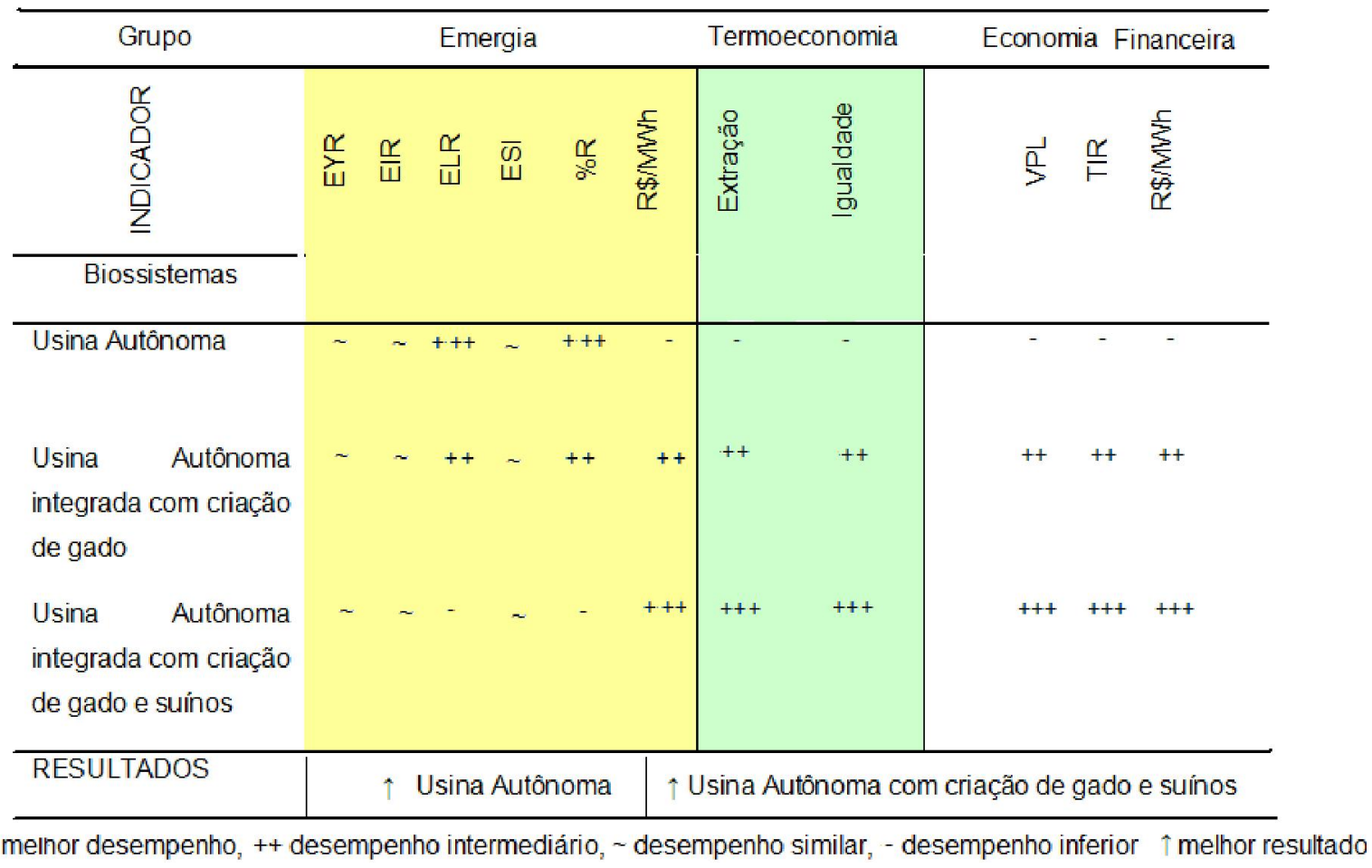

Verifica-se que para os indicadores em emergia o biossistema da usina autônoma apresenta melhor desempenho, não sendo conclusivo pela proximiadade dos índices, contudo quando se analisa a transformidade o biossistema com melhor desempenho é o mesmo que para os custos termoeconômicos e econômicos financeiros, o biossistema da usina autônoma com criação de gado e suínos apresenta menor custo.

Conclui-se que a escolha do biossistema a ser implantado, cuja intenção seja gerar eletricidade, neste estudo de caso é o da usina autônoma com criação de gado e suínos.

Os resultados desse estudo demonstram que a redução de custos foi maior quando foi realizada a integração da criação de gado. A inclusão da criação de suínos também apresentou redução de custos em todas as métricas utilizadas, contudo o percentual de redução foi menor. 
9. Sugestões para trabalhos futuros

Este trabalho teve a pretenção de esgotar o tema proposto. Os conhecimentos obtidos através do desenvolvimento desta Tese podem ser consideravelmente ampliados através de trabalhos em escalas e sistemas diferenciados.

As hipóteses levantadas neste trabalho podem ser substituídas por dados coletados para um estudo de caso com valores reais, uma vez que não foi possível realizar esta coleta devido ao fato da não identificação de projetos que se assemelhem ao estudo proposto.

Seguem algumas sugestões para trabalhos futuros, utilizando a metodologia proposta com a possibilidade de incluir novas métricas ou parâmetros que possibilitem o melhor aproveitamento energético:

- Realizar a análise da geração e cogeração de eletricidade na integração da Indústria de papel e celulose com os biossistemas de seu entorno;

- Desenvolver e analisar biossistemas de geração e cogeração de eletricidade que perdure durante todo o ano, com o uso de gás natural na entresafra da cana-deaçúcar;

- Realizar o cálculo das eficiências exergéticas de cada volume de controle dos biossistemas estudados;

- Realizar simulações em biossistemas de grandes propriedades, com a finalidade de apontar a sinergia ótima para o conjunto;

- Incluir a análise da energia evitada em próximos trabalhos;

- Incluir ganhos com crédito de carbono na análise elaborada. 
Referências bibliográficas

AGUIAR, C. L., MENEZES, T. J., - Conversão enzimática do bagaço de cana-de-açúcar. R evista Biotecnologia Ciência \& Desenvolvimento, n.26, p.52-56, maio/jun., 2002.

ALKAIM, J. L., - Aquecimento Global e as Energias Renováveis e Alternativas. In: II JORNADA UNISUL DE INICIAÇÃO CIENTÍFICA - JUNIC. SEMINÁRIO DE PESQUISA, 2.,2007, Santa Catarina. A nais. Palhoça, 2007.

ALMANÇA, R. A., - Avaliação do uso da vinhaça da cana-de-açucar na geração de eletricidade : estudo de caso. .1994. 132p. Dissertação(Mestrado em Energia) - Programa Interunidades de Pós-graduação em Energia, Universidade de São Paulo, São Paulo, 1994.

ALMEIDA, C.M.V.B.; BARRELLA, F.A.; GIANNETTI, B.F. Emergetic ternary diagrams: five examples for application in environmental accounting for decision-making. J ournal of Cleaner Production, v 15, n. 1, .p. 63-74, 2007

ALTIERI, M.A. Biodiversity and pest management in agroecosystems. New York: Food Products, 1993, 185p.

ALTVATER, E. O preço da riqueza. Unesp, São Paulo, 1995.

AGÊNCIA NACIONAL DE ELETRICIDADE. 2006. Disponível em :

<http://www.aneel.gov.br/NXT/gateway.dll/

libraryaneel/tematica/politicaenergetica/bren2006235.xml?f=templates $\$ \mathrm{fn}=$ documentframe.htm $\$ 3.0 \$ q=\$ u q=\$ x=\$ u p=1>$ Acesso em : 04 maio 2008.

.Usinas UTE em operação no Brasil, 2008. Disponível em:

<http://www.aneel.gov.br/aplicações/capacidadebrasil.asp>. Acesso em 04 maio 2008. 
.Biomassa. Disponível em: <http://www.aneel.gov.br/aplicacoes/atlas/pdf/05Biomassa(2).pdf>. Acesso em: 30.mar.2009.

ANUÁRIO da Pecuária Brasileira. São Paulo: Editora Argos, 2001. 359 p.

BARRELLA, F.A.; ALMEIDA, C.M.V.B.; GIANNETTI, B.F. - Ferramenta para tomada de decisão considerando a interação dos sistemas de produção e meio ambiente. Revista Produção, v 15, n.1, p. 87-101, 2005.

BARROS JUNIOR, A. F. Estudo da viabilidade técnica e econômica em sistemas de cogeração com a instalação de chiller de absorção em grupos motores geradores para a produção de energia térmica, 2006.

BARTHOLOMEU, D.B.; BARTHOLOMEU, M.B.; RANIERO, L.M.; MIRANDA, S.H.G. O Mercado de Carbono e a Atividade Suinícola. Revista Agroanalysis, São Paulo, p.46, 2007.

BASTIANONI S.; MARCHETTINI N.; PANZIERI M.; TIEZZI E. - Sustainability assessment of a farm in the Chianti area (Italy), J ournal of Cleaner Production. v.9, p.365373, 2001.

BEJAN, A., TSATSARONIS, G. \& MORAN, M., Thermal Design \& Optimization. New York: John Wiley \& Sons, 1996, 542p.

BJÖRKLUND, J,; GEBER, U.; RYDEBERG, T. - Emergy Analysis of Municipal Wastewater treatment and generation of electricity by digestion of sewage sludge. R esources, Conservation and Recycling, 31, p.293-316, 2001. 
BRAGA, B.; HESPANHOL, I.; CONEJO, J. G. L; BARROS, M. T. L; SPENCER, M.; PORTO M.; NUCCI, N.; JULIANO, N.; EIGER, S. - Introdução à Engenharia A mbiental. São Paulo, Prendtice Hall, 2002.

BRASIL. Lei n. ${ }^{\circ} 24.043$ de 12 de setembro de 2003. - Regulamenta o capítulo IV, da Lei Complementar n. ${ }^{\circ}$ 264, de 14 de dezembro de 1999, que dispõe sobre as taxas de Vigilância Sanitária do Distrito Federal e dá outras providências, 2003.

BRASIL. Lei n. ${ }^{\circ} 9.605$ de 12 de fevereiro de 1998. - Dispõe sobre as sanções penais e administrativas derivadas de condutas e atividades lesivas ao meio ambiente, e dá outras providências que Regulamenta o capítulo IV, da Lei Complementar n. ${ }^{\circ}$ 264, de 14 de dezembro de 1999, que dispõe sobre as taxas de Vigilância Sanitária do Distrito Federal e dá outras providências, 1998.

BREALEY, R. A.; MYERS, S. C.; ALLEN, F.,- Principles of Corporate Finance. $8^{\text {th }}$.ed. New York: McGraw-Hill/Irwin, , 2006. 1028 p.

BRIGHENTI, C. R. F., Integração do Cogerador de Energia do Setor Autônoma com 0 Sistema Elétrico. 2003. 169p. Dissertação (Mestrado em Energia) - Instituto de Eletrotécnica e Energia, Universidade de São Paulo. São Paulo, 2003.

BROWN, M.T.; ARDING J. - Transformities. Working Paper, Center for W etlands. Gainesville :University of Florida, 1991.

BROWN, MT.; ULGIATI, S.- Emergy Measures of Carrying Capacity to Evaluate Economic Investments, Population and Environment. A J ournal of I nterdisciplinary Studies, v. 22, n. $5,2001$. 
BROWN, M.T.; BURANAKARN, V. - Emergy indices and ratios for sustainable material cycles options, R esources Conservation and Recycling, 38 p.1-22, 2003.

BROWN, M. T.; McCLANAHAN, T.R. - Emergy analysis perspectives of Thailand and Mekong River dam proposals, Ecological M odeling, 91,p.105-130, 1996.

BROWN, M.T..; ULGIATI, S.- Emergy evaluations and environmental loading of electricity production systems, J ournal of Cleaner Production, v. 10, p.321-334, 2002.

BRUNDTLAND, G. H. - Our common future: World Commission on Environment and Development. Oxford: Oxford University Press, 1987.

CAMARGO, A. C. (Coord.) Conservação de energia na indústria do açúcar e do álcool. São Paulo: Instituto de Pesquisas Tecnológicas ,1990. 796 p.

CAMPOS, A T., Manejo de dejetos de bovinos. In: ENCONTRO NACIONAL DE TÉCNICOS, PESQUISADORES E EDUCADORES DE CONSTRUÇÕES RURAIS, 3. CONGRESSO BRASILEIRO DE ENGENHARIA AGRÍCOLA, 27.,1998, Lavras. Anais. Lavras: UFLA, 1998. p.233-79.

CARVALHO, J. F. Prioridades para investimentos em usinas Elétricas, 2008.

CASAROTTO FILHO, N., KOPITTKE, B. H., - Análise de investimentos. 10. ed. São Paulo: Atlas, 2007.

CAVALCANTI, C. et al. II Desenvolvimento e natureza: estudos para uma sociedade sustentável. Recife: INPSO/FUNDAJ, 1994. p. 262. 
CAVALETT, O., A nálise emergética da piscicultura integrada a criação de suínos e de pesques pagues. Dissertação ( Mestrado)-Universidade de Campinas, Campinas, 2004.

CENAMO, M.C., O Mercado de carbono e as oportunidades para o agronegócio brasileiro. Piracicaba: CEPEA/DEAS/ESALQ/USP, 2005.

CENTRO NACIONAL DE REFERÊNCIA EM BIOMASSA. Panorama do potencial de biomassa no Brasil. Brasília: ANEEL, 2003.

Projeto Expansão de Cana no Estado de São Paulo. São Paulo: Secretaria de Meio ambiente. 2006.

CHERNICHARO, C.A.L. R eatores A naeróbios. Minas Gerais: DESA/UFMG, 1997.

CHOHFI, M. F. Balanço de Emissão e Seqüestro de $\mathrm{CO}_{2}$ na Produção de Eletricidade Excedente no Setor Sucro-A Icooleiro. Itajubá: Universidade Federal de Itajubá, 2004.

COELHO, O., ORTEGA, E., COMAR, V. Balanço de emergia do Brasil. Campinas: UNICAMP, 2002.

COELHO, S. T.- M ecanismos para a implementação da cogeração de eletricidade a partir de biomassa. Um modelo para o estado de São Paulo. 1999.200p. Tese (Doutorado em Energia) - Instituto de Eletrotécnica e Energia, Universidade de São Paulo, São Paulo.

COELHO, S. T., LORA, B. A., MONTEIRO, M. B. C.A. A expansão da cultura canavieira no estado de são paulo.In: CONGRESSO IBEROAMERICANO DE ENGENHARIA MECANICA, 8.,2007, México. A nais. 
CORREA NETO, V. Análise de viabilidade da cogeração de eletricidade em ciclo combinado com gaseificação de biomassa de cana-de açúcar e gás natural. Rio de Janeiro: Universidade Federal do Rio de Janeiro, 2001.

CORSINI R. - M ini usinas integradas. exposição comparativa. Brasil. Monografia, 1992, $22 \mathrm{p}$.

CRUZ, R. W. - A. A nálise da I ntrodução de Cogeração no Sistema I solado no I nterior do Estado do Amazonas. Tese (Doutorado).- Campinas: Faculdade de Engenharia Mecânica Unicamp, 2004.

DINCER. I. , CENGEL, Y.A. - "Energy, Entropy and Exergy Concepts and Their Roles in Thermal Engineering”. Entropy, vol.3, p. 116-149, 2001. ISSN 1099-4300.

EMPRESA DE PESQUISA ENERGÉTICA. Boletim trimestral, 2007 Disponível em <http://www.epe.gov.br/BoletimTrimestral/Forms/EPEBoletimMercado.aspx> Acesso em : 20.mar.09.

ERLACH, B., SERRA, L., VALERO, A. "Structural Theory as Standard for Thermoeconomics", Energy Conversion and M anagement, v. 40, p. 1627-1649. , 1999.

FINGUERUT, J. Produção de alcool: pesquisa e desenvolvimento. In: Curso Internacional Energia na indústria de açúcar e alcool. Núcleo de Estudos em Sistemas Térmicos, Universidade Federal de Itajubá, 2004.

FRIEDMAN, M. A M etodologia da economia Positiva: ensaios sobre economia positiva, Chicago: University of Chicago Press, 1953, p. 10, 14-15. 
GEBER, U.; BJÖRKLUND, J. The relationship between ecosystem services and purchased input in Swedish wastewater treatment system: a case study. Ecological Engineering, v.18, p.39-59, 2001.

GENEROSO, F. B., Quantificação e caracterização de dejetos produzidos em propriedade com exploração leiteira para uso em biodigestores e reciclagem de nutrientes. 2001. 66 f. Monografia (Trabalho de Graduação em Agronomia) - Faculdade de Ciências Agrárias e Veterinárias, Universidade Estadual Paulista, Jaboticabal, 2001.

GAGGIOLI, R. A. Efficiency and Costing. 1983. p.3 (ACS Symposium Series, 235)

GARCIA-VAQUERO, E. Projeto e construção de alojamento para animais. 2.ed. Lisboa: Litexta Portugal, 1981. 237 p.

GIAMPIETRO. M., CERRETELLI, G., PIMENTEL, D. Energy analysis of agricultural ecosystem management: human return and sustainability, Agriculture, Ecoystems and Environment, v. 38, 219-244, 1992.

GIANNETTI, B. F.; BARRELlA, F. A.; ALMEIDA, C. M. V. B. - A combined tool for environmental scientists and decision makers: ternary diagrams and emergy accounting, J ournal of cleaner production, 14, p.201-210, 2006.

GITMAN, L.J., Princípios de administração financeira. 7. ed., São Paulo: Harbra, 1997.

GITMAN, L. J. Administração Financeira : uma abordagem gerencial. São Paulo: Pearson, 2003. 
GOLDEMBERG, J. Energia, meio ambiente e desenvolvimento. São Paulo: Edusp, 1998.

GOLDEMBERG, J. Pesquisa e desenvolvimento na área de energia . São Paulo, São Paulo em Per spectiva, v.14, n.3, p.91-97, 2000.

GOLDEMBERG, L. ; LUCON, O. Energia e Meio ambiente no Brasil. Estudos A vançados, v. 21, n. 59, p. 21-38, 2007.

HALL, D.O. Biomass Energy. Energy Policy, v. 19, n. 8, p. 711-737, Oct. 1991.

HARDOIM, P.C. E feito da temperatura de operação e da agitação mecânica na eficiência da biodigestão anaeróbia de dej etos de bovinos. 1999.88p. Tese (Doutorado em Zootecina) Faculdade de Ciências Agrárias e Veterinárias da Universidade Estadual Paulista "Júlio de Mesquita Filho, Jaboticabal, 1999.

HARDOIM, P. C., GONCALVES, A. D. M. A. Avaliação do potencial do emprego do biogás nos equipamentos utilizados em sistemas de produção de leite. In: ENCONTRO DE ENERGIA NO MEIO RURAL, 3., 2000, Campinas.A nais.

HEMERY, D.; DEBEIR, J.; DELÉAGE, J. Uma história da energia. Brasília: Editora da Universidade de Brasília, 1986.

HESS, G. et al. Engenharia econômica. Rio de Janeiro: Editora Bertrand Brasil. 17. ed., 1984. $80 \mathrm{p}$.

HOJAS, P.S. A nálise exergética, termoeconômica e ambiental de um sistema de geração de energia. estudo de caso: Usina Termoelétrica UTE - Rio Madeira., Brasília: Universidade de Brasília, 2007. 176p. Publicação DM-109 
HORLOCK, J.H. Combined power plants. Oxford: Pergamon Press, 1992. 288p.

HORLOCK, J.H. Cogeneration -combined heat and power (CHP): thermodynamics and economics. Florida: Krieger Publishing, 1997. 226p.

INSTITUTO NACIONAL DE EFICIÊNCIA ENERGÉTICA Co-geradores querem setor regulado. Rio de Janeiro : INEE, 2001.

IZIDORO, C. Análise econômico-financeira de projetos. Disponível em: <http://www.duplipensar.net/artigos/2008-texto/analise-economico-financeira-de-projetos.html>. Acesso em: 08 mar. 2008.

JANNUZZI, G. M. Planejando a crise energética. Newslatter Ambiente Brasil 2008.

Disponível em: http://www.fem.unicamp.br/ jannuzzi/documents/planejandoacrisedeenergia.htm Acesso em: 28 maio 2008.

KHARTCHENKO, N.V. Advanced energy systems. Washington: Taylor \& Francis , 1998. 285p.

KOTAS, T.J. The Exergy method of thermal plant analysis. London: Butterworks, 1985.

LAGANIS, L.; DEBELJAK, M. Sensitivity analysis of the emergy flows at the solar salt production process in Slovenia, E cological M odeling, v. 194, p.287-295, 2006.

LAMO, PAULO DE. Sistema produtor de gás metano através de tratamento de E fluentes industriais. Piracicaba: METHAX/BIOPAQ - CODISTIL -, 1991.

LAZZARETTO, A.; TSATSARONIS, G. - A general process-based methodology for exergy 
costing. In: A.B. Duncan, J. Fiszdon, D. O’Neal and K. Den Braven, Editors, Proceedings of Advanced Energy Systems Division AES vol. 36, p. 413-428,1996

LEI, K., WANG, Z. - Municipal wastes and their solar transformities: An emergy synthesis for Macao, W aste M anagement v.28 - 2522-2531, 2008.

LORA, E. e NASCIMENTO, M.A. (Coord.) G eração termelétrica: planejamento, projeto e operação. Rio de Janeiro: Interciência, 2004, 1296 p.

LOURES, E.G. Manejo de dejetos de suínos. In: Encontro nacional de técnicos, pesquisadores e educadores de construções rurais, 3. Congresso Brasileiro de Engenharia Agrícola, 27, 1998., Lavras.A nais. : UFLA, 1998.

LOZANO, M.A., VALERO, A. Theory of exergy cost. Energy. v.18 n.9,p. 939-960, Sep.1993.

LUCAS JÚNIOR, J. - O esterco de suínos como substrato de biodigestor contínuo: observações quanto ao início da operação. In: CONGRESSO BRASILEIRO DE ENGENHARIA AGRÍCOLA, 16, 1987.Jundiaí. A nais. Jundiaí: SBEA.,1987. p.658.

MACEDO, I. C. O Ciclo da cana-de-açúcar e reduções adicionais nas emissões de CO2 através do uso como combustível da palha da Cana. Piracicaba: Centro de Tecnologia Copersucar, 2000.

MACEDO, I. C.; LEAL, M. R. L. V.; SILVA, J. E. A. R. B alanço das emissões de gases do efeito estufa na produção e no uso do etanol no Brasil. São Paulo: Secretaria do Meio Ambiente, 2004.

MACEDO, I.C. A ENERGIA DA CANA-DE-AÇUCAR: doze estudos sobre a agroindustria da cana-de-açucar n Brasil e a sua sustentabilidade. São Paulo: Berlandis \& Vertecchia, 2005, $237 \mathrm{p}$. 
MANUAL de gestão ambiental na suinocultura:. projeto de controle da contaminação ambiental decorrente da suinocultura no Estado do Paraná. Curitiba: SEMA, 2004. p. 6.

MARTINEZ ALIER, J. Da E conomia E cológica ao E cologismo Popular. Blumenau: Ed. da FURB, 1998. 402p

MARTINS, E. Contabilidade de Custos. 9.ed. São Paulo: Atlas, 2003.

MATEUS, T. A Suinicultura e a fermentação anaeróbica: o potencial energético do biogás através de efluentes da agro-pecuária. Biomassa e Biocombustíveis. Dissertação (Mestrado em Energias Renováveis) -Faculdade de Engenharia da Universidade do Porto, 2006.

MELO, F.A.D. SEMINÁRIO DE TECNOLOGIA PARA PEQUENA PRODUÇÃO DE ÁLCOOL, 2007, Pernambuco. Anais eletrônicos. Disponível em: <http://www.cna.org.br/tecppa/Apresenta/UFRPE.Francisco\%20Dutra.pdf> Acesso em: 20 jan. 2009.

MERICO, L.F.K. I ntrodução à E conomia E cológica. Blumenau: Ed. da FURB, 1996. 160p.

MINISTÉRIO DA AGRICULTURA - PECUÁRIA E ABASTECIMENTO Cana de A çúcar, 2008. Disponível em: 〈http://www.agricultura.gov.br>. Acesso em: 14 jul. 2008.

MINISTÉRIO DE MINAS E ENERGIA. Caminho limpo para o desenvolvimento. Brasília, 2004. Disponível em: <http://www.mme.gov.br/programas_display. do?prg=5>. Acesso em: 06 maio 2008. 
.Balanço Energético Nacional 2002: Ano Base 2001. Brasília: MME, .2002. 183p.

MINISTÉRIO DAS RELAÇÕES EXTERIORES. Protocolo de Quioto à convenção sobre mudança do clima. Traduzido pelo Ministério da Ciência e Tecnologia, 1997.

NAGAOKA, M. P. T. A. Comercialização da eletricidade cogerada pelo setor autônoma em regiões do Estado de São Paulo. 2002. 82p. Dissertação (Mestrado em Agronomia) Faculdade de Ciências Agronômicas, Universidade Estadual Paulista "Julio de Mesquita Filho", Botucatu, 2002.

NASCIMENTO, C., GARCIA, J. P., MARQUES, P. Reflexões sobre a contribuição de Carnot à primeira lei termodinâmica. Q uímica Nova, São Paulo, v. 27, p. 513-515, 2003.

NISHIMURA, R.; KOLTERMANN, IP.; SOUZA, K.G.C.; ORTEGA, J.M. Balanço energético em suinocultura com geração de energia elétrica a partir do biogás, 2008.

NOGUEIRA, A.H.L. Energia: conceitos e fundamentos. In: CONSERVAÇÃO DE ENERGIA: EFICIÊNCIA ENERGÉTICA DE INSTALAÇÕES E EQUIPAMENTOS. Itajubá: FUPAI, 2001.

NOGUEIRA, L. A. H., WALTER, C. S. Experiências de geração de eletricidade a partir de biomassa no Brasil: aspectos técnicos e econômicos. Itajubá: Escola Federal de Engenharía de, 1996.

ODUM, H.T. Environmental accounting : emergy and environmental decision making. New York: John Wiley \& Songs ,1996. p.370.

ODUM, H.T. Emergy evaluation of an OTEC electrical power system. Energy v.25, p.39893993, 2000. 
OLIVEIRA P. A. V. Projeto de biodigestor para produção de biogás em sistema de produção de suínos. Santa Catarina, 2005. Disponível em <http://www.cnpsa.embrapa.br/down.php?tipo=artigos\&cod_artigo=263.> Acesso em: 23 mar. 2009.

OMETTO, A. R. et. al. M ini-usinas de álcool integradas :avaliação emergética. Campinas:, Faculdade de Engenharia de Alimentos, Universidade Estadual de Campinas ,2006.

ORGANIZAÇÃO DAS NAÇÕES UNIDAS Protocolo de Quioto à convenção-quadro das nações unidas sobre mudança do clima. Disponível em: <http://www.onubrasil.org.br/doc_quioto.php>. Acesso em: 10.dez. 2008.

ORLANDO, J.A. Cogeneration Planer's Handbook. USA: Fairmont Press, 1991.

ORTEGA, E. - Análise emergética: uma ferramenta para quantificar a sustentabilidade nos Agroecossistemas.. In: WORKSHOP SOBRE AGROECOLOGIA E DESENVOLVIMENTO SUSTENTÁVEL, 1,1998, Campinas. Resumo, Campinas: Unicamp, 1998.

ORTEGA, E. Balanço emergético da produção de milho agroquímico, 2003. Disponível em : http:// <www.unicamp.br/fea/ortega/plan-disc/milho-quimico-complexa.xls>.Acesso em: 23.nov.2008.

PALETTA, C. E. M. A s implicações dos aspectos legais, econômicos e financeiros na implementação de projetos de geração de energia a partir de biomassa no Brasil: um estudo de viabilidade. 2004. 163p. Dissertação (Mestrado em Energia) - Instituto de Eletrotécnica e Energia, Universidade de São Paulo.

PAYNE, J. H. Operações unitárias na produção de açúcar de cana. São Paulo: Nobel , 1989. 
PELLEGRINI, L. F. Análise e otimização termo-econômica-ambiental aplicada à produção combinada de açúcar, álcool e eletricidade .2008. 350p. Tese (Doutorado ) Escola Politécnica, Universidae de São Paulo. 2008.

PERDOMO, C. C. - Alternativas para o manejo e tratamento de dejetos suínos. Suinocultura Industrial, Porto Feliz, n. 152, p. 16-26, jun./jul. 2001.

PILARSKI, F. et al. Consórcio Suíno-Peixe: Aspectos Ambientais e Qualidade do Pescado. R evista Brasil Zootecnia, v.33, n.2, p.267-276, 2004.

PINHEL, A. Simulação de uma usina térmica a gás no novo contexto do setor elétrico brasileiro: uma análise risco x retorno. 2000. Dissertação (Mestrado) - Programas de pósgraduação de engenharia da Universidade Federal do Rio de Janeiro, Rio de Janeiro, 2000.

PINTO, P. C. Tecnologia da digestão anaeróbia da vinhaça e desenvolvimento sustentável. Campinas, 1999. Dissertação (Mestrado em planejamento de sistemas energéticos)- Faculdade de Engenharia Mecânica , Universidade estadual de Campinas. 1999.

PROCKNOR, C Cogeração de Eletricidade. R evista Stab, Jul, 2001.

QUIRK, J. Qualitative economics the new palgrave: a dictionary of economics 1987, v. 4. p. 1-3.

RAMAGE, J.; SCURLOCK, J. Biomass. In: BOYLE, G. (Ed.). R enewable energy: power for a sustainable future. Oxford: Oxford University Press, 1996. cap. 4, p. 137-182

RAPPORT, D.J.; CONSTANZA R.; MCMICHAEL, A.J. Assessing ecosystem health. Tree, v.3, n.10, oct., 1998 . 
REES, W.E.; WACKERNAGEL, M.- Ecological footprints and appropriated carrying capacity: measuring the natural capital requirements of the human economy. In: JANSSON, A.-M., HAMMER, M., FOLKE, C.; COSTANZA, R. (Eds.). Investing in Natural Capital. Washington: Island Press, 1994. p. 362-390.

REISTAD, G. M., GAGGIOLI, R. A. Thermodynamics: Second Law Analysis.1980. p.143. (ACS Series, 122)

RESENDE, A.P.S. A energia renovável e o meio ambiente. In: ENERGIA, AUTOMAÇÃO E INSTRUMENTAÇÃO. CONGRESSO BRASILEIRO DE ENGENHARIA AGRÍCOLA, 28, 1998.A nais. Lavras: UFLA. 1998.p 16.

RIPOLLI, M. L. C. Mapeamento do palhiço enfardado de cana-de-açúcar (Saccharum spp.) e do seu potencial energético. 2002, 91p. Dissertação (Mestrado em Agronomia). Escola Superior de Agricultura Luiz de Queiroz, Universidade de São Paulo, Piracicaba, 2002.

RIPOLLI, T. C. C.; MOLINA W. F.; RIPOLI, M. L. C. O. Bagaço e o palhiço na produção de eletricidade. In Mudanças Climáticas Globais e a Agropecuária Brasileira: memória do Workshop. Embrapa Meio Ambiente. Jaguariúna - ISSN 1516-4691, 1999.

RIPOLLI, T. C. C.; RIPOLI, M. L. C. - Biomassa de cana-de-açúcar: colheita, energia e ambiente. Universidade de São Paulo. Escola Superior de Agricultura Luiz de Queiroz. Piracicaba - ISBN 85-904440-5, 2004.

RIPOLLI, T. C. C. E a mão de obra. R evista I dea News. n. 59, Ribeirão Preto, set 2005.

RODRIGUES, L.G.S. - ANÁLISE ENERGÉTICA DE DIFERENTES SISTEMAS DE COGERAÇÃO COM BAGAÇO DE CANA-DE-AÇÚCAR, Dissertação apresentada à Faculdade de Engenharia de Ilha Solteira da Universidade Estadual Paulista, 2005. 
ROSA, L., TOLMASQUIM, M., Pires, J.C.L. A reforma do setor elétrico no Brasil e no mundo: uma visão crítica. Rio de Janeiro: Ed.Relume Dumará, 1998.

ROSA, V.H.S. Energia elétrica renovável em pequenas comunidades no Brasil: Em busca de um modelo sustentável. 2007.440 p. Tese (Doutorado) - Universidade de Brasília, 2007.

ROSS, S. A. finance.In: EATWELL, John ; MILGATE,Murray ; NEWMAN , Peter The New palgrave: a dictionary of economics, 1987. v. 2, p. 322-26.

SANTOS, M. Técnica, espaço, tempo: globalização e meio técnico-científico informacional. 3.ed. São Paulo: Hucitec., 1977. 190p.

SEABRA, J. E. A. Avaliação técnico-econômica de opções para o aproveitamento integral da biomassa no Brasil. 2008. Tese (Doutorado) -Universidade Estadual de Campinas, Campinas, 2008.

SGANZERLA, E. Biodigestores: uma solução. Porto Alegre: Livraria e Editora Agropecuária, 1983.

SILVA, C. C. Estudo de caso de sistemas de tratamento de efluentes domésticos com o uso de indicadores ambientais., 2006, Dissertação (mestrado) - Programa de Pós-Graduação em Engenharia. Universidade Paulista ,São Paulo, 2006.

SILVA, F.M. Utilização do biogás como combustível. In: Energia, Automação e Instrumentação. Congresso Brasileiro de Engenharia Agrícola, 28, 1998,Lavras. Anais. Lavras: UFLA, 1998. p 97 
SILVA, M. M. Repotenciamento em sistemas de geração de potência na indústria siderúrgica utilizando análise termoeconômica ,2004. 245p. Tese (Doutorado) -, Departamento de Energia, Faculdade de Engenharia Mecânica, Universidade Estadual de Campinas, Campinas, 2004.

SONTAG, R. E., BORGNAKKE, C., VAN WYLEN, G. J. Fundamentos da termodinâmica.6.ed. São Paulo: Edgard Blücher, 2003. Tradução de: Euryale de Jesus Zerbini

SOUZA, Z. J. Geração de eletricidade excedente no setor autônoma: entraves estruturais e custos de transação. 2003. 278p. Tese (Doutorado em Engenharia de Produção) - Centro de Ciências Exatas e de Tecnologia, Universidade Federal de São Carlos, São Carlos, 2003.

STRAPASSON, Alexandre Betinardi A energia térmica e o paradoxo da eficiência energética-desafios para um novo modelo de planejamento energético. 2004. 134p.

Dissertação (Mestrado em Energia ) - Programa Interunidades de Pós-Graduação em Energia. São Paulo, 2004.

SZARGUT, J. MORRIS, D. R. STEWARD, F. R. Exergy analysis of themal, chemical, and metallurgical processes. New York :Hemisphere, 1988.

TAMMINGA, S., VERSTEGEN, M. W. A. Implications of nutrition of animals on environmental pollution. Oxford: Butterworth-Heinemann ,1992.

TSATSARONIS, G. thermoeconomic analysis and optimization of energy systems, progress Energy and Combustion Science v.19, p. 227-257, 1993.

TIEZZI, E.; BASTIANONI. S.; MARCHETTINI, N. Environmental cost and steady: the problem of adiabaticity in the emergy value. E cological M odeling, v.90, p. 33-37, 1995. 
THOMSON. Taxas de depreciação de bens do ativo imobilizado, Anuário. São Paulo: Ed. Thomson, 2004. 235p.

TOLEDO, L. R. Na cama o dia todo: criação de suínos em galpões com piso recoberto de serragem ou maravalha elimina a necessidade de esterqueiras e de lagoas de tratamento de dejetos. Globo Rural, n. 194, 2001.

TSATSARONIS, G.; WINHOLD, M. Exergoeconomic analysis and evaluation of energyconversion plants - I. A New General Methodology, II. Analysis of a Coal-fired Steam Power Plant. Energy, v. 10, n. 1, p. 69-94, 1985.

TSATSARONIS, G. Thermoeconomic analysis and optimization of energy systems. Progress in Energy and Combustion Science, v. 19, p. 227-257, 1993.

TSATSARONIS, G, PISA, J. exergoeconomic evaluation and optimization of energy systems: application to the cgam problem. Energy, v. 19, p. 287-321,1994.

UDAETA, M.E.M. Planejamento integrado de recursos energéticos -PIR para o setor elétrico (pensando o desenvolvimento sustentável). 1997. 347p.Tese (Doutorado)- Escola Politécnica da Universidade de São Paulo, São Paulo, 1997.

ULGIATI, S.; BROWN, M.T. Monitoring patterns of sustainability in natural and man-made ecosystems. E cological M odeling,v.108, p.23-36; 1998.

ULGIATI, S.; BROWN, M.T. Quantifying the environmental support for dilution and abatement of process emissions : The case of electricity production. J ournal. Cleaner Production, v.10, p.335-348, 2002.

ULGIATI, S.; ODUM, H.T.; BATIANONI, S. Emergy use environmental loading and sustainability an emergy analysis of Italy. Ecological M odeling, v.73, p.215-268, 1994. 
UNIÃO DA INDÚSTRIA DE CANA-DE-AÇÚCAR. Ranking de Produção de Cana, A çúcar e Álcool - R egião Centro-Sul - Safra 2006/2007. São Paulo, 2007. Disponível em: <http://www.portalunica.com.br/files/estatisticas/ranking06/07.xls> Acesso em: 02 maio 2008.

VAN HORN, H.H., WILKIE, A C., POWERS, W.J., NORDSTEDT, R.A. - Components of dairy manure management systems. J ournal Dairy Science, v.77, n.7, p.2008-30, 1994.

VEIGA, M. Planejamento energético: oportunidades e desafios .Rio de Janeiro: Sociedade Brasileira de Planejamento Energético, 2006

VELAZQUEZ, S. G. A. Cogeração de energia no segmento de papel e celulose: contribuição à matriz energética brasileira. 2000. 190p. (Dissertação de Mestrado) Programa Interunidades de Pós-Graduação em Energia, Universidade de São Paulo, São Paulo, 2000

VELAZQUEZ, S. G. A. Perspectivas para geração de excedente de eletricidade no Segmento de Papel e Celulose com a utilização de sistemas de gaseificação/turbina a gás. 2006. 261p. (Tese de Doutorado) Programa Interunidades de Pós-Graduação em Energia, Universidade de São Paulo. São Paulo.

VIEIRA, L. S. R. Modelo exergoeconômico iterativo para melhoria de sistemas complexos integrado a um simulador de processos profissional, 2003. Tese (Doutorado) Universidade Federal do Rio de Janeiro, Rio de Janeiro, 2003.

VIEIRA, L. S. R., DONATELLI, J. L., CRUZ, M. E. Integration of an Iterative Methodology 
for Exergoeconomic Improvement of Thermal Systems with a Process Simulator. Energy Conversion and M anagement, v. 45, p. 2495-2523, 2004.

WEPFER, W. J. Thermodynamics: Second Law Analysis. 1980.p161.( ACS Series, 122)

ZYLBERSZTAJN, D.; COELHO, S. T. Potencial de geração de energia elétrica nas usinas de açúcar e álcool brasileira, através de gaseificação da cana e emprego de turbinas a gás. Revista Brasileira de Energia, Rio de Janeiro, v.2, n. 2, 1992. 


\section{ANEXO A}

Cálculos detalhados da Usina de álcool

Tabela A-1. Avaliação da emergia da usina autônoma, da Tabela 4

\section{Nota Implantação}

$1 \quad$ M udas

Total Área $\quad=1,49 \times 10^{7} \mathrm{~m}^{2}$

Massa de muda por $\mathrm{m}^{2}=2,88 \mathrm{~g} / \mathrm{m}^{2} \mathrm{ano}$

Energia total $=\left(\right.$ área m$\left.^{2}\right) \times\left(g\right.$ de muda/ $\left.\mathrm{m}^{2} a n o\right)$

Energia total $=\left(1,49 \times 10^{7} \mathrm{~m}^{2}\right) \times\left(2,88 \times 10^{-2} \mathrm{~kg} / \mathrm{m}^{2}\right.$ ano $)$ $=4,30 \times 10^{7} \mathrm{~g} / \mathrm{ano}$

2 Perda de solo

Total Área $\quad=149 \times 10^{7} \mathrm{~m}^{2}$

Perda de matéria orgânica $=1,82 \times 10^{1} \mathrm{~g} / \mathrm{m}^{2}$

Energia total $=\left(\right.$ área $\left.\mathrm{m}^{2}\right) \times\left(\mathrm{g}\right.$ de matéria orgânica/ $\left.\mathrm{m}^{2}\right) \times(\mathrm{kcal} / \mathrm{g}) \mathrm{x}(\mathrm{J} / \mathrm{kcal})$

Energia total $=\left(1,49 \times 10^{7} \mathrm{~m}^{2}\right) \times\left(1,82 \times 10^{-2} \mathrm{~kg} / \mathrm{m}^{2} \times\right.$ ano $) \times(5400 \mathrm{kcal} / \mathrm{kg}) \times(4186 \mathrm{~J} / \mathrm{kcal})$

$$
=6,15 \times 10^{12} \mathrm{~J} / \mathrm{ano}
$$

3 E quipamentos e I nfraestrutura (Depreciação em 20 anos (vida útil) - Thomson, 2004)

Valor em R $\$ 11.876 .203,00$

Valor normalizado $=(11876203 \mathrm{R} \$) /(2,25 \mathrm{R} \$ / \$) /(20$ anos $)($ cotação de 19/03/2009)

$$
=2,64 \times 10^{5} \$ \text { ano }
$$

4 A ço para reator es UASB (Depreciação em 10 anos (vida útil) - Thomson, 2004)

Massa $\quad=9,43 \times 10^{5} \mathrm{~g}$

Massa normalizada $=\left(9,43 \times 10^{5} \mathrm{~g}\right) /(10$ anos $)$

$$
=9,43 \times 10^{4} \mathrm{~g} / \mathrm{ano}
$$

$5 \quad$ M ão de obra

Total homem-dias $\quad=21$ homens

Necessidade diária do metabolismo humano

$=3,00 \times 10^{3} \mathrm{kcal} / \mathrm{dia}$ por homem

Ent. total de energia $=\left[(265\right.$ dias $\left./ \mathrm{ano}) \times\left(3,00 \times 10^{3} \mathrm{kcal} / \mathrm{dia}\right) \times(4186 \mathrm{~J} / \mathrm{kcal}) \times(21 \mathrm{homens})\right]+\left[\begin{array}{ll}(100 & \text { dias }) \times\left(3,00 \times 10^{3}\right.\end{array}\right.$ $\mathrm{kcal} / \mathrm{dia}) \mathrm{x}(4186 \mathrm{~J} / \mathrm{kcal}) \mathrm{x}(21$ homens $)]$

$$
=9,63 \times 10^{10} \mathrm{~J} / \mathrm{ano}
$$




\section{Operação}

6 Precipitação

Área da lavoura $\quad=1,49 \times 10^{7} \mathrm{~m}^{2}$

Precipitação média $=1200 \mathrm{~mm} / \mathrm{ano}$

Energia livre de Gibbs $=4,94 \mathrm{~J} / \mathrm{g}$

Energia Total $=\left(1,49 \times 10^{7} \mathrm{~m}^{2}\right) \times(1200 \mathrm{~mm} / \mathrm{ano}) \times\left(1 \times 10^{-3} \mathrm{~m} / \mathrm{mm}\right) \times\left(1 \times 10^{6} \mathrm{~g} / \mathrm{m}^{3}\right) \times(4,94 \mathrm{~J} / \mathrm{g})$

$$
=8.86 \times 10^{13} \mathrm{~J} / \mathrm{ano}
$$

$7 \quad$ Nutrientes

Total Área $\quad=1,49 \times 10^{7} \mathrm{~m}^{2}$

Nutrientes por $\mathrm{m}^{2} \quad=1,8 \mathrm{~g} / \mathrm{m}^{2}$

Energia total $=\left(\right.$ área $\left.\mathrm{m}^{2}\right) \times\left(\mathrm{g}\right.$ de nutrientes $\left./ \mathrm{m}^{2}\right) \times(\mathrm{kcal} / \mathrm{g}) \times(\mathrm{J} / \mathrm{kcal})$

Energia total $=\left(1,49 \times 10^{7} \mathrm{~m}^{2}\right) \times\left(1,8 \mathrm{~g} / \mathrm{m}^{2} \times\right.$ ano $)$

$$
=2,69 \times 10^{7} \mathrm{~g} / \text { ano }
$$

$8 \quad$ Nitrogênio

Total Área $\quad=1,49 \times 10^{7} \mathrm{~m}^{2}$

Nitrogênio por $\mathrm{m}^{2} \quad=7 \times 10^{-1} \mathrm{~g} / \mathrm{m}^{2}$

Energia total $=\left(\right.$ área $\left.\mathrm{m}^{2}\right) \times\left(\mathrm{g}\right.$ de nitrogênio/ $\left.\mathrm{m}^{2}\right)$

Energia total $=\left(1,49 \times 10^{7} \mathrm{~m}^{2}\right) \times\left(7 \times 10^{-1} \mathrm{~g} / \mathrm{m}^{2} \times\right.$ ano $)$

$$
=1,05 \times 10^{7} \mathrm{~g} / \mathrm{ano}
$$

9 Água de aquífero

Total Área $\quad=1,49 \times 10^{7} \mathrm{~m}^{2}$

$\mathrm{m}^{3}$ de água por $\mathrm{m}^{2}=5 \times 10^{-5} \mathrm{~m}^{3} / \mathrm{m}^{2}$

Energia da água $\quad=4,94 \times 10^{6} \mathrm{~J} / \mathrm{m}^{3}$

Energia total $=\left(\right.$ área $\left.\mathrm{m}^{2}\right) \mathrm{x}\left(\mathrm{m}^{3}\right.$ de água/ $\left.\mathrm{m}^{2}\right) \mathrm{x}\left(\mathrm{J} / \mathrm{m}^{3}\right)$

Energia total $=\left(1,49 \times 10^{7} \mathrm{~m}^{2}\right) \times\left(5 \times 10^{-5} \mathrm{~m}^{3} / \mathrm{m}^{2} \times\right.$ ano $) \times\left(4,94 \times 10^{6} \mathrm{~J} / \mathrm{m}^{3}\right)$

$$
=3,69 \times 10^{9} \mathrm{~J} / \mathrm{ano}
$$

10 Insumos

Total Área

$$
=1,49 \times 10^{7} \mathrm{~m}^{2}
$$

Litros de insumo por $\mathrm{m}^{2}=4,09 \times 10^{-3} \mathrm{~L} / \mathrm{m}^{2}$

Densidade do insumo $=8 \times 10^{2} \mathrm{~g} / \mathrm{L}$

Massa total =(área $\left.\mathrm{m}^{2}\right) \mathrm{x}\left(\mathrm{L}\right.$ de insumo $\left./ \mathrm{m}^{2}\right) \mathrm{x}($ densidade $)$

Energia total $=\left(1,49 \times 10^{7} \mathrm{~m}^{2}\right) \times\left(4,09 \times 10^{-3} \mathrm{~L} / \mathrm{m}^{2} \times\right.$ ano $) \times\left(8 \times 10^{2} \mathrm{~g} / \mathrm{L}\right)$

$$
=4,88 \times 10^{7} \mathrm{~g} / \mathrm{ano}
$$


11 Defensivos agrícolas

Total Área $\quad=1,49 \times 10^{7} \mathrm{~m}^{2}$

Litros por $\mathrm{m}^{2}=3 \times 10^{-4} \mathrm{~L} / \mathrm{m}^{2}$

Densidade $\quad=8 \times 10^{2} \mathrm{~g} / \mathrm{L}$

Energia total $=\left(\right.$ área $\left.\mathrm{m}^{2}\right) \mathrm{x}\left(\mathrm{L}\right.$ de defensivo/ $\left.\mathrm{m}^{2}\right) \mathrm{x}($ densidade $)$

Energia total $=\left(1,49 \times 10^{7} \mathrm{~m}^{2}\right) \times\left(3 \times 10^{-4} \mathrm{~L} / \mathrm{m}^{2} \times\right.$ ano $) \times\left(8 \times 10^{2} \mathrm{~g} / \mathrm{L}\right)$

$=3,59 \times 10^{6} \mathrm{~g} / \mathrm{ano}$

12 M ão de obra

Total homem-dias $=81$ homens

Necessidade diária do metabolismo humano

$=3,00 \times 10^{3} \mathrm{kcal} / \mathrm{dia}$ por homem

Ent. total de energia $=\left[(265\right.$ dias/ano $\left.) \times\left(3,00 \times 10^{3} \quad \mathrm{kcal} / \mathrm{dia}\right) \times(4186 \mathrm{~J} / \mathrm{kcal}) \times(81 \mathrm{homens})\right]+\left[(100 \mathrm{dias}) \times\left(3,00 \times 10^{3}\right.\right.$ $\mathrm{kcal} / \mathrm{dia}) \mathrm{x}(4186 \mathrm{~J} / \mathrm{kcal}) \mathrm{x}(81$ homens $)$ ] $=3,66 \times 10^{11} \mathrm{~J} / \mathrm{ano}$

13 Operações agrícolas

Valor em U\$ 11.029,18/ano

Valor normalizado $=(11029,18 \mathrm{U} \$ /$ ano $)$

$=1,10 \times 10^{4} \$ /$ ano

14 M anutenção

Área Total $\quad=\left(1,49 \times 10^{7} \mathrm{~m}^{2}\right)$

Custo anual por $\mathrm{m}^{2}=\left(3,24 \times 10^{-3} \$ / \mathrm{m}^{2}\right)$

Custo anual = =(área em $\left.\mathrm{m}^{2}\right) \times\left(\right.$ custo anual $\left.\mathrm{em} \$ / \mathrm{m}^{2}\right)$

Custo anual $\quad=\left(1,49 \times 10^{7} \mathrm{~m}^{2}\right) \times\left(3,24 \times 10^{-3} \$ / \mathrm{m}^{2}\right)$

$=4,85 \times 10^{4} \$ / \mathrm{ano}$ 
Tabela A-2. Avaliação da emergia do biossistema da usina autônoma com criação de gado Tabela 5.

\section{Nota I mplantação}

1 M udas

$$
\text { Total Área } \quad=1,49 \times 10^{7} \mathrm{~m}^{2}
$$

Massa de muda por $\mathrm{m}^{2}=2,88 \mathrm{~g} / \mathrm{m}^{2} \mathrm{ano}$

Energia total $=\left(a^{\prime}\right.$ ea $\left.\mathrm{m}^{2}\right) \times\left(\mathrm{g}\right.$ de muda/ $\left.\mathrm{m}^{2} a n o\right)$

Energia total $=\left(1,49 \times 10^{7} \mathrm{~m}^{2}\right) \times\left(2,88 \times 10^{-2} \mathrm{~kg} / \mathrm{m}^{2}\right.$ ano $)$

$$
=4,30 \times 10^{7} \mathrm{~g} / \mathrm{ano}
$$

2 Gado

Total de animais $\quad=3438$

Massa do bezerro $=75 \mathrm{~kg}$

Expectativa de vida $=30$ anos

Energia de calor equivalente $=7438596,49 \mathrm{~J} / \mathrm{kg}$

Energia total $=(3438$ animais $)(75 \mathrm{~kg} / \mathrm{animal}) \mathrm{X}(7438596,49 \mathrm{~J} / \mathrm{kg}) /(30$ anos $)$

$$
=6,39 \times 10^{10} \mathrm{~J} / \mathrm{ano}
$$

3 Perda de solo

$$
\text { Total Área } \quad=1,67 \times 10^{7} \mathrm{~m}^{2}
$$

Perda de matéria orgânica $=1,82 \times 10^{1} \mathrm{~g} / \mathrm{m}^{2}$

Energia total $=\left(\right.$ área $\left.\mathrm{m}^{2}\right) \times\left(\mathrm{g}\right.$ de matéria orgânica/ $\left.\mathrm{m}^{2}\right) \times(\mathrm{kcal} / \mathrm{g}) \times(\mathrm{J} / \mathrm{kcal})$

Energia total $=\left(1,67 \times 10^{7} \mathrm{~m}^{2}\right) \times\left(1,82 \times 10^{-2} \mathrm{~kg} / \mathrm{m}^{2} \times\right.$ ano $) \times(5400 \mathrm{kcal} / \mathrm{kg}) \times(4186 \mathrm{~J} / \mathrm{kcal})$

$$
=6,89 \times 10^{12} \mathrm{~J} / \mathrm{ano}
$$

4 Equipamentos e I nfraestrutura usina e gado (Depreciação em 20 anos (vida útil) - Thomson, 2004) Valor em $\mathrm{R} \$ 12.205 .603,00$

Valor normalizado $=(12205603 \mathrm{R} \$) /(2,25 \mathrm{R} \$ / \$) /(20$ anos $)($ cotação de 19/03/2009)

$$
=2,71 \times 10^{5} \$ / \text { ano }
$$

5 A ço para reator es UASB (Depreciação em 10 anos (vida útil) - Thomson, 2004)

$$
\text { Massa } \quad=9,43 \times 10^{5} \mathrm{~g}
$$

Massa normalizada $=\left(9,43 \times 10^{5} \mathrm{~g}\right) /(10$ anos $)$

$$
=9,43 \times 10^{4} \mathrm{~g} / \mathrm{ano}
$$


6 M ão de obra

Total homem-dias $=21$ homens

Necessidade diária do metabolismo humano

$=3,00 \times 10^{3} \mathrm{kcal} / \mathrm{dia}$ por homem

Ent. total de energia $=\left[(265\right.$ dias/ano $\left.) \times\left(3,00 \times 10^{3} \mathrm{kcal} / \mathrm{dia}\right) \times(4186 \mathrm{~J} / \mathrm{kcal}) \times(21 \mathrm{homens})\right]+\left[\begin{array}{ll}(100 & \text { dias }) \times\left(3,00 \times 10^{3}\right.\end{array}\right.$ $\mathrm{kcal} / \mathrm{dia}) \times(4186 \mathrm{~J} / \mathrm{kcal}) \mathrm{x}(21$ homens $)]$

$$
=9,63 \times 10^{10} \mathrm{~J} / \mathrm{ano}
$$

$7 \quad$ Currais

Investimento $=87587 \$$

Vida útil

$=30$ anos

Total

$=($ investimento)$) /($ vida útil $)$

Total

$=(87587 \$) /(30$ anos $)$

$=2,92 \times 10^{3} \$ /$ ano

8 Valas de ração

Investimento $=40000 \$$

Vida útil

$=30$ anos

Total

$=($ investimento $) /($ vida útil $)$

Total

$=(40000 \$) /(30$ anos $)$

$=1,33 \times 10^{3} \$$ ano

9 Biodigestor

Investimento $=20000 \$$

Vida útil

$=20$ anos

Total

$=($ investimento $) /($ vida útil $)$

Total

$=(20000 \$) /(20 \mathrm{anos})$

$=1,00 \times 10^{3} \$ /$ ano 


\section{Operação}

10 Precipitação

Área da lavoura $\quad=1,67 \times 10^{7} \mathrm{~m}^{2}$

Precipitação média $=1200 \mathrm{~mm} / \mathrm{ano}$

Energia livre de Gibbs $=4,94 \mathrm{~J} / \mathrm{g}$

Energia Total $=\left(1,67 \times 10^{7} \mathrm{~m}^{2}\right) \times(1200 \mathrm{~mm} / \mathrm{ano}) \times\left(1 \times 10^{-3} \mathrm{~m} / \mathrm{mm}\right) \times\left(1 \times 10^{6} \mathrm{~g} / \mathrm{m}^{3}\right) \times(4,94 \mathrm{~J} / \mathrm{g})$

$$
=9,92 \times 10^{13} \mathrm{~J} / \mathrm{ano}
$$

$11 \quad$ Nutrientes

Total Área $\quad=1,67 \times 10^{7} \mathrm{~m}^{2}$

Nutrientes por $\mathrm{m}^{2} \quad=1,8 \mathrm{~g} / \mathrm{m}^{2}$

Energia total $=\left(\right.$ área $\left.\mathrm{m}^{2}\right) \times\left(\mathrm{g}\right.$ de nutrientes $\left./ \mathrm{m}^{2}\right) \times(\mathrm{kcal} / \mathrm{g}) \times(\mathrm{J} / \mathrm{kcal})$

Energia total $=\left(1,67 \times 10^{7} \mathrm{~m}^{2}\right) \times\left(1,8 \mathrm{~g} / \mathrm{m}^{2} \times\right.$ ano $)$

$$
=3,01 \times 10^{7} \mathrm{~g} / \mathrm{ano}
$$

12 Nitrogênio

Total Área $\quad=1,67 \times 10^{7} \mathrm{~m}^{2}$

Nitrogênio por $\mathrm{m}^{2} \quad=7 \times 10^{-1} \mathrm{~g} / \mathrm{m}^{2}$

Energia total $=\left(\right.$ área $\left.\mathrm{m}^{2}\right) \times\left(\mathrm{g}\right.$ de nitrogênio/ $\left.\mathrm{m}^{2}\right)$

Energia total $=\left(1,67 \times 10^{7} \mathrm{~m}^{2}\right) \times\left(7 \times 10^{-1} \mathrm{~g} / \mathrm{m}^{2} \times\right.$ ano $)$

$$
=1,17 \times 10^{7} \mathrm{~g} / \mathrm{ano}
$$

13 Água de aquífero

Total Área $\quad=1,67 \times 10^{7} \mathrm{~m}^{2}$

$\mathrm{m}^{3}$ de água por $\mathrm{m}^{2}=5 \times 10^{-5} \mathrm{~m}^{3} / \mathrm{m}^{2}$

Energia da água $\quad=4,94 \times 10^{6} \mathrm{~J} / \mathrm{m}^{3}$

Energia total $=\left(\right.$ área $\left.\mathrm{m}^{2}\right) \mathrm{x}\left(\mathrm{m}^{3}\right.$ de água/ $\left.\mathrm{m}^{2}\right) \mathrm{x}\left(\mathrm{J} / \mathrm{m}^{3}\right)$

Energia total $=\left(1,67 \times 10^{7} \mathrm{~m}^{2}\right) \times\left(5 \times 10^{-5} \mathrm{~m}^{3} / \mathrm{m}^{2} \times\right.$ ano $) \times\left(4,94 \times 10^{6} \mathrm{~J} / \mathrm{m}^{3}\right)$

$$
=4,13 \times 10^{9} \mathrm{~J} / \mathrm{ano}
$$

14 M ão de obra

Total homem-dias $=101$ homens

Necessidade diária do metabolismo humano

$$
=3,00 \times 10^{3} \mathrm{kcal} / \mathrm{dia} \text { por homem }
$$

Ent. total de energia $=\left[(265\right.$ dias/ano $\left.) \times\left(3,00 \times 10^{3} \mathrm{kcal} / \mathrm{dia}\right) \times(4186 \mathrm{~J} / \mathrm{kcal}) \times(101 \mathrm{homens})\right]+\left[(100 \mathrm{dias}) \times\left(3,00 \times 10^{3}\right.\right.$ $\mathrm{kcal} / \mathrm{dia}) \mathrm{x}(4186 \mathrm{~J} / \mathrm{kcal}) \mathrm{x}(101$ homens $)$ ]

$$
=4,57 \times 10^{11} \mathrm{~J} / \mathrm{ano}
$$


15 Trato do Gado

Despesa anual $\quad=187344,40 \$$

Total $\quad=1,87 \times 10^{5} \$$

16 M anutenção

Despesa anual $=19752,00 \$$ gado $+48456 \$$ cana

Total $=6,82 \times 10^{4} \$$

17 Insumos

Total Área $\quad=1,49 \times 10^{7} \mathrm{~m}^{2}$

Litros de insumo por $\mathrm{m}^{2}=4,09 \times 10^{-3} \mathrm{~L} / \mathrm{m}^{2}$

Densidade do insumo $=8 \times 10^{2} \mathrm{~g} / \mathrm{L}$

Massa total $=\left(\right.$ área $\left.\mathrm{m}^{2}\right) \times\left(\mathrm{L}\right.$ de insumo $\left.\mathrm{m}^{2}\right) \times($ densidade $)$

Energia total $=\left(1,49 \times 10^{7} \mathrm{~m}^{2}\right) \times\left(4,09 \times 10^{-3} \mathrm{~L} / \mathrm{m}^{2} \times\right.$ ano $) \times\left(8 \times 10^{2} \mathrm{~g} / \mathrm{L}\right)$

$=4,88 \times 10^{7} \mathrm{~g} / \mathrm{ano}$

18 Defensivos agrícolas

Total Área $\quad=1,49 \times 10^{7} \mathrm{~m}^{2}$

Litros por $\mathrm{m}^{2}=3 \times 10^{-4} \mathrm{~L} / \mathrm{m}^{2}$

Densidade $\quad=8 \times 10^{2} \mathrm{~g} / \mathrm{L}$

Energia total $=\left(\right.$ área $\left.\mathrm{m}^{2}\right) \times\left(\mathrm{L}\right.$ de defensivo/ $\left.\mathrm{m}^{2}\right) \times($ densidade $)$

Energia total $=\left(1,49 \times 10^{7} \mathrm{~m}^{2}\right) \times\left(3 \times 10^{-4} \mathrm{~L} / \mathrm{m}^{2} \times\right.$ ano $) \times\left(8 \times 10^{2} \mathrm{~g} / \mathrm{L}\right)$

$=3,59 \times 10^{6} \mathrm{~g} / \mathrm{ano}$

19 Operações agrícolas

Valor em U\$ 11.029,18 ano

Valor normalizado $=(11029,18 \mathrm{U} \$ / \mathrm{ano})$

$=3,23 \times 10^{4} \$ /$ ano 
Tabela A-3. Avaliação da Emergia do biossistema da usina autônoma com criação de gado e suínos da Tabela 6.

Nota I mplantação

1 Mudas

Total Área $\quad=1,49 \times 10^{7} \mathrm{~m}^{2}$

Massa de muda por $\mathrm{m}^{2}=2,88 \mathrm{~g} / \mathrm{m}^{2} \mathrm{ano}$

Energia total $=\left(\right.$ área $\left.\mathrm{m}^{2}\right) \times\left(\mathrm{g}\right.$ de muda/ $\left.\mathrm{m}^{2} a n o\right)$

Energia total $=\left(1,49 \times 10^{7} \mathrm{~m}^{2}\right) \times\left(2,88 \times 10^{-2} \mathrm{~kg} / \mathrm{m}^{2}\right.$ ano $)$

$=4,30 \times 10^{7} \mathrm{~g} / \mathrm{ano}$

2 Compra de gado

Total de animais $\quad=3438$

Massa do bezerro $=75 \mathrm{~kg}$

Expectativa de vida $=30$ anos

Energia de calor equivalente $=7438596,49 \mathrm{~J} / \mathrm{kg}$

Energia total $=(3438$ animais $)(75 \mathrm{~kg} / \mathrm{animal}) \mathrm{X}(7438596,49 \mathrm{~J} / \mathrm{kg}) /(30$ anos $)$

$$
=6,39 \times 10^{10} \mathrm{~J} / \mathrm{ano}
$$

3 Compra de suínos

Total de animais $\quad=5400$

Massa do leitão desmamado $=6 \mathrm{~kg}$

Expectativa de vida $=10$ anos

Energia de calor equivalente $=25116000 \mathrm{~J} / \mathrm{kg}$

Energia total $=(5400$ animais $)(6 \mathrm{~kg} /$ animal $) \mathrm{X}(25116000 \mathrm{~J} / \mathrm{kg}) /(10$ anos $)$

$$
=8,14 \times 10^{10} \mathrm{~J} / \mathrm{ano}
$$

$4 \quad$ Perda de solo

Total Área $\quad=1,67 \times 10^{7} \mathrm{~m}^{2}$

Perda de matéria orgânica $=1,82 \times 10^{1} \mathrm{~g} / \mathrm{m}^{2}$

Energia total $=\left(\right.$ área $\left.\mathrm{m}^{2}\right) \times\left(\mathrm{g}\right.$ de matéria orgânica/ $\left.\mathrm{m}^{2}\right) \times(\mathrm{kcal} / \mathrm{g}) \mathrm{x}(\mathrm{J} / \mathrm{kcal})$

Energia total $=\left(1,67 \times 10^{7} \mathrm{~m}^{2}\right) \times\left(1,82 \times 10^{-2} \mathrm{~kg} / \mathrm{m}^{2} \times\right.$ ano $) \times(5400 \mathrm{kcal} / \mathrm{kg}) \times(4186 \mathrm{~J} / \mathrm{kcal})$

$=6,89 \times 10^{12} \mathrm{~J} / \mathrm{ano}$ 
5 Equipamentos e Infraestrutura usina e gado (Depreciação em 20 anos (vida útil) - Thomson, 2004) Valor em R $\$ 12.205 .603,00$

Valor normalizado $=(12205603 \mathrm{R} \$) /(2,25 \mathrm{R} \$ / \$) /(20$ anos $)($ cotação de 19/03/2009)

$$
=2,71 \times 10^{5} \$ \text { ano }
$$

6 A ço para reator es UASB (Depreciação em 10 anos (vida útil) - Thomson, 2004)

Massa $\quad=9,43 \times 10^{5} \mathrm{~g}$

Massa normalizada $=\left(9,43 \times 10^{5} \mathrm{~g}\right) /(10$ anos $)$

$$
=9,43 \times 10^{4} \mathrm{~g} / \mathrm{ano}
$$

$7 \quad$ Mão de obra

Total homem-dias $=21$ homens

Necessidade diária do metabolismo humano

$$
=3,00 \times 10^{3} \mathrm{kcal} / \mathrm{dia} \text { por homem }
$$

Ent. total de energia $=\left[(265\right.$ dias/ano $\left.) \times\left(3,00 \times 10^{3} \mathrm{kcal} / \mathrm{dia}\right) \times(4186 \mathrm{~J} / \mathrm{kcal}) \times(21 \mathrm{homens})\right]+\left[\left(\begin{array}{ll}100 & \text { dias }) \times\left(3,00 \times 10^{3}\right.\end{array}\right.\right.$ $\mathrm{kcal} / \mathrm{dia}) \times(4186 \mathrm{~J} / \mathrm{kcal}) \times(21$ homens $)$ ]

$$
=9,63 \times 10^{10} \mathrm{~J} / \mathrm{ano}
$$

8 Currais para o gado

Investimento $=87587 \$$

Vida útil

$$
=30 \text { anos }
$$

Total

$$
=(\text { investimento)/(vida útil) }
$$

Total

$$
=(87587 \$) /(30 \text { anos })
$$

$$
=2,92 \times 10^{3} \$ / \text { ano }
$$

9 Valas de ração para o gado

Investimento $=40000 \$$

Vida útil

$$
=30 \text { anos }
$$

Total

$$
\text { =(investimento)/(vida útil) }
$$

Total

$$
=(40000 \$) /(30 \text { anos })
$$

$$
=1,33 \times 10^{3} \$ / \text { ano }
$$

10 Granja para suínos

Investimento $=183840 \$$

Vida útil

Total

Total
$=20$ anos

$=($ investimento $) /($ vida útil $)$

$=(183840 \$) /(20$ anos $)$

$=9,25 \times 10^{3} \$$ ano 
11 Equipamentos da granja de suínos

Investimento $=7200 \$$

Vida útil

$=20$ anos

Total

$=($ investimento $) /($ vida útil $)$

Total

$=(7200 \$) /(20$ anos $)$

$=3,6 \times 10^{2} \$$ ano

12 Biodigestor

Investimento $=20000 \$$

Vida útil

$=20$ anos

Total

$=($ investimento $) /($ vida útil $)$

Total

$=(20000 \$) /(20$ anos $)$

$=1,00 \times 10^{3} \$$ ano

Operação

13 Precipitação

Área da lavoura $\quad=1,67 \times 10^{7} \mathrm{~m}^{2}$

Precipitação média=1200 mm/ano

Energia livre de Gibbs=4,94 J/g

Energia Total $=\left(1,67 \times 10^{7} \mathrm{~m}^{2}\right) \times(1200 \mathrm{~mm} / \mathrm{ano}) \times\left(1 \times 10^{-3} \mathrm{~m} / \mathrm{mm}\right) \times\left(1 \times 10^{6} \mathrm{~g} / \mathrm{m}^{3}\right) \times(4,94 \mathrm{~J} / \mathrm{g})$

$=9,92 \times 10^{13} \mathrm{~J} / \mathrm{ano}$

$14 \quad$ Nutrientes

Total Área $\quad=1,67 \times 10^{7} \mathrm{~m}^{2}$

Nutrientes por $\mathrm{m}^{2} \quad=1,8 \mathrm{~g} / \mathrm{m}^{2}$

Energia total $=\left(\right.$ área $\left.\mathrm{m}^{2}\right) \times\left(\mathrm{g}\right.$ de nutrientes $\left./ \mathrm{m}^{2}\right) \times(\mathrm{kcal} / \mathrm{g}) \times(\mathrm{J} / \mathrm{kcal})$

Energia total $=\left(1,67 \times 10^{7} \mathrm{~m}^{2}\right) \times\left(1,8 \mathrm{~g} / \mathrm{m}^{2} \times\right.$ ano $)$

$=3,01 \times 10^{7} \mathrm{~g} / \mathrm{ano}$

15 Nitrogênio

Total Área $\quad=1,67 \times 10^{7} \mathrm{~m}^{2}$

Nitrogênio por $\mathrm{m}^{2} \quad=7 \times 10^{-1} \mathrm{~g} / \mathrm{m}^{2}$

Energia total $=\left(\right.$ área $\left.\mathrm{m}^{2}\right) \mathrm{x}\left(\mathrm{g}\right.$ de nitrogênio/ $\left.\mathrm{m}^{2}\right)$

Energia total $=\left(1,67 \times 10^{7} \mathrm{~m}^{2}\right) \times\left(7 \times 10^{-1} \mathrm{~g} / \mathrm{m}^{2} \times\right.$ ano $)$

$=1,17 \times 10^{7} \mathrm{~g} / \mathrm{ano}$ 
16 Água de aquífero

Total Área $\quad=1,67 \times 10^{7} \mathrm{~m}^{2}$

$\mathrm{m}^{3}$ de água por $\mathrm{m}^{2}=5 \times 10^{-5} \mathrm{~m}^{3} / \mathrm{m}^{2}$

Consumo dos suínos=4590 $\mathrm{m}^{3} / \mathrm{ano}$

Energia da água $\quad=4,94 \times 10^{6} \mathrm{~J} / \mathrm{m}^{3}$

Energia total $=\left[\left(\right.\right.$ área $\left.^{2}\right) \times\left(\mathrm{m}^{3} \mathrm{de}\right.$ água/ $\left.\mathrm{m}^{2}\right)+$ consumo dos suínos $\left.)\right] \mathrm{x}\left(\mathrm{J} / \mathrm{m}^{3}\right)$

Energia total $=\left[\left(1,67 \times 10^{7} \mathrm{~m}^{2}\right) \times\left(5 \times 10^{-5} \mathrm{~m}^{3} / \mathrm{m}^{2} \times\right.\right.$ ano $\left.)+4590 \mathrm{~m}^{3} / \mathrm{ano}\right] \times\left(4,94 \times 10^{6} \mathrm{~J} / \mathrm{m}^{3}\right)$

$$
=2,68 \times 10^{10} \mathrm{~J} / \mathrm{ano}
$$

17 M ilho (renovável)

Total do consumo $\quad=1490000000 \mathrm{~g} / \mathrm{ano}$

Percentual renovável=12,1 \% (ORTEGA, 2003)

Consumo anual =(consumo) $\mathrm{x}$ (percentual)

Consumo anual $=1,49 \times 10^{9} \mathrm{~g} / \mathrm{ano} \times 12,1 \%$

Consumo anual $\quad=1,26.10^{6} \mathrm{~g} / \mathrm{ano}$

18 M ilho (não renovável)

Total do consumo $\quad=1490000000 \mathrm{~g} / \mathrm{ano}$

Percentual renovável=35,3\% (ORTEGA, 2003)

Consumo anual =(consumo) $\mathrm{x}$ (percentual)

Consumo anual $=1,04 \mathrm{X} 10^{9} \mathrm{~g} / \mathrm{ano} \times 35,3 \%$

$=3,29 \times 10^{8} \mathrm{~g} / \mathrm{ano}$

19 M ilho (F ontes Pagas)

Total do consumo $\quad=1040000000 \mathrm{~g} / \mathrm{ano}$

Percentual renovável=52,6 \% (ORTEGA, 2003)

Consumo anual =(consumo) $\mathrm{x}$ (percentual)

Consumo anual $=1,04 \mathrm{X} 10^{9} \mathrm{~g} / \mathrm{ano} \times 52,5 \%$

$=5,48 \times 10^{8} \mathrm{~g} / \mathrm{ano}$

20 Farelo de Soja

$$
\begin{aligned}
\text { Total do consumo } & =386100000 \mathrm{~g} / \mathrm{ano} \\
& =3,86 \times 10^{8} \mathrm{~g} / \mathrm{ano}
\end{aligned}
$$

$21 \quad$ Núcleo

Total do consumo $=59400000 \mathrm{~g} / \mathrm{ano}$

$$
=5,94 \times 10^{7} \mathrm{~g} / \mathrm{ano}
$$


22 Combustível

Consumo anual =30 litros

Energia do combustível $=1,14 \times 10^{4} \mathrm{kcal} / \mathrm{L}$

Energia total $=($ consumo $) \times($ energia $) \times(J /$ kcal $)$

Energia total $\quad=(30 \mathrm{~L}) \times\left(1,14 \times 10^{4} \mathrm{kcal} / \mathrm{L}\right) \times(4186 \mathrm{~J} / \mathrm{kcal})$

$=1,43 \times 10^{9}$

23 M ão de obra qualificada

Total homem-dias $=131$ homens

Necessidade diária do metabolismo humano

$=3,00 \times 10^{3} \mathrm{kcal} / \mathrm{dia}$ por homem

Ent. total de energia=[(265 dias/ano $\left.) \times\left(3,00 \times 10^{3} \mathrm{kcal} / \mathrm{dia}\right) \times(4186 \mathrm{~J} / \mathrm{kcal}) \times(131 \mathrm{homens})\right]+\left[(100\right.$ dias $) \times\left(3,00 \times 10^{3}\right.$ $\mathrm{kcal} / \mathrm{dia}) \mathrm{x}(4186 \mathrm{~J} / \mathrm{kcal}) \mathrm{x}(131$ homens $)$

$$
=5,94 \times 10^{11} \mathrm{~J} / \mathrm{ano}
$$

24 Trato do Gado

Despesa anual $\quad=187344,40 \$$

Total $=1,87 \times 10^{5} \$$

25 M anutenção

Despesa anual $\quad=19752,00 \$$ gado $+48456 \$$ cana

Total $=6,83 \times 10^{4} \$$

26 Insumos

Total Área $\quad=1,49 \times 10^{7} \mathrm{~m}^{2}$

Litros de insumo por $\mathrm{m}^{2}=4,09 \times 10^{-3} \mathrm{~L} / \mathrm{m}^{2}$

Densidade do insumo $=8 \times 10^{2} \mathrm{~g} / \mathrm{L}$

Massa total $=\left(\right.$ área $\left.\mathrm{m}^{2}\right) \times\left(\mathrm{L}\right.$ de insumo/ $\left.\mathrm{m}^{2}\right) \times($ densidade $)$

Energia total $=\left(1,49 \times 10^{7} \mathrm{~m}^{2}\right) \times\left(4,09 \times 10^{-3} \mathrm{~L} / \mathrm{m}^{2} \times\right.$ ano $) \times\left(8 \times 10^{2} \mathrm{~g} / \mathrm{L}\right)$

$$
=4,88 \times 10^{7} \mathrm{~g} / \mathrm{ano}
$$

27 Defensivos agrícolas

Total Área $\quad=1,49 \times 10^{7} \mathrm{~m}^{2}$

Litros por $\mathrm{m}^{2}=3 \times 10^{-4} \mathrm{~L} / \mathrm{m}^{2}$

Densidade $\quad=8 \times 10^{2} \mathrm{~g} / \mathrm{L}$

Energia total $=\left(\right.$ área $\left.\mathrm{m}^{2}\right) \mathrm{x}\left(\mathrm{L}\right.$ de defensivo $\left./ \mathrm{m}^{2}\right) \mathrm{x}($ densidade $)$

Energia total $=\left(1,49 \times 10^{7} \mathrm{~m}^{2}\right) \times\left(3 \times 10^{-4} \mathrm{~L} / \mathrm{m}^{2} \times\right.$ ano $) \times\left(8 \times 10^{2} \mathrm{~g} / \mathrm{L}\right)$

$=3,59 \times 10^{6} \mathrm{~g} / \mathrm{ano}$ 
28 Operações agrícolas

Valor em U\$ 11.029,18 ano

Valor normalizado $=(11029,18 \mathrm{U} \$ /$ ano $)$

$=1,10 \times 10^{4} \$ / \mathrm{ano}$ 
Tabela A-4. Índices em emergia do sistema usina autônoma da Tabela 8.

$$
\begin{aligned}
& \mathrm{F}=3,38 \times 10^{18} \mathrm{sej} \\
& \mathrm{N}=4,54 \times 10^{17} \mathrm{sej} \\
& \mathrm{R}=1,80 \times 10^{18} \mathrm{sej}
\end{aligned}
$$

$$
E Y R=\frac{Y}{F}=\frac{N+R+F}{F}
$$

$\mathrm{EYR}=\underline{4,54 \times 10^{17}+1,80 \times 10^{18}+3,38 \times 10^{18}}$

$$
3,398 \times 10^{18}
$$

$\mathrm{EYR}=1,67$

$$
\begin{aligned}
& \mathrm{EIR}=\frac{\mathrm{F}}{\mathrm{N}+\mathrm{R}}=\frac{3,38 \times 10^{18}}{4,54 \times 10^{17}+1,80 \times 10^{18}}=1,50 \\
& \mathrm{ELR}=\frac{\mathrm{N}+\mathrm{F}}{\mathrm{R}}=\frac{4,54 \times 10^{17}+3,38 \times 10^{18}}{1,80 \times 10^{18}}=2,12
\end{aligned}
$$

$$
\mathrm{ESI}=\frac{\mathrm{EYR}}{\mathrm{ELR}}=\frac{1,67}{2,12}=0,79
$$

$$
\% \mathrm{R}=\frac{\mathrm{R}}{\mathrm{Y}}=\frac{1,80 \times 10^{18}}{5,63 \times 10^{18}}=0,3202 \times 100 \%=32,02 \% \mathrm{sej} / \mathrm{sej}
$$


Tabela A-5. Índices em emergia do biossistema da usina autônoma com criação de gado da Tabela 8.

$$
\begin{aligned}
& F=4,58 \times 10^{18} \mathrm{sej} \\
& \mathrm{N}=5,08 \times 10^{17} \mathrm{sej} \\
& \mathrm{R}=2,12 \times 10^{18} \mathrm{sej}
\end{aligned}
$$

$$
\begin{aligned}
& \mathrm{EYR}=\frac{Y}{F}=\frac{N+R+F}{F} \\
& E Y R=\frac{5,08 \times 10^{17}+2,12 \times 10^{18}+4,58 \times 10^{18}}{4,58 \times 10^{18}}
\end{aligned}
$$

$\mathrm{EYR}=1,58$

$$
\mathrm{EIR}=\frac{\mathrm{F}}{\mathrm{N}+\mathrm{R}}=\frac{4,58 \times 10^{18}}{5,08 \times 10^{17}+2,12 \times 10^{18}}=1,74
$$

$$
\mathrm{ELR}=\frac{\mathrm{N}+\mathrm{F}}{\mathrm{R}}=\frac{5,08 \times 10^{17}+4,58 \times 10^{18}}{2,12 \cdot 10^{18}}=2,39
$$

$$
\mathrm{ESI}=\frac{\mathrm{EYR}}{\mathrm{ELR}}=\frac{1,58}{2,39}=0,66
$$

$$
\% \mathrm{R}=\frac{\mathrm{R}}{\mathrm{Y}}=\frac{2,12 \times 10^{18}}{7,21 \times 10^{18}}=0,2946 \times 100 \%=29,46 \%
$$


Tabela A-6. Índices em emergia do biossistema da usina autônoma com criação de gado e suínos da Tabela 8.

$\mathrm{F}=7,25 \times 10^{18} \mathrm{sej}$

$\mathrm{N}=7,61 \times 10^{17}$ sej

$\mathrm{R}=2,30 \times 10^{18}$ sej

$$
\begin{aligned}
& E Y R=\frac{Y}{F}=\frac{N+R+F}{F} \\
& E Y R=\frac{7,61 \times 10^{17}+2,30 \times 10^{18}+7,25 \times 10^{18}}{7,25 \times 10^{18}}
\end{aligned}
$$

$\mathrm{EYR}=1,42$

$$
\mathrm{EIR}=\frac{\mathrm{F}}{\mathrm{N}+\mathrm{R}}=\frac{7,25 \times 10^{18}}{7,61 \times 10^{17}+2,30 \times 10^{18}}=2,37
$$

$$
\mathrm{ELR}=\frac{\mathrm{N}+\mathrm{F}}{\mathrm{R}}=\frac{7,61 \times 10^{17}+7,25 \times 10^{18}}{2,30.10^{18}}=3,49
$$

$$
\mathrm{ESI}=\frac{\mathrm{EYR}}{\mathrm{ELR}}=\frac{1,42}{3,49}=0,41
$$

$$
\% \mathrm{R}=\frac{\mathrm{R}}{\mathrm{Y}}=\frac{2,30 \times 10^{18}}{1,03 \times 10^{19}}=0,2229 \times 100 \%=22,29 \%
$$


Tabela A-7. Tabela de cálculo da produção de milho em base de emergia.

Balanço emergético da produção de M I LHO AG ROQUí M ICO Dados: 1999-2003

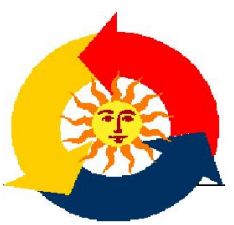

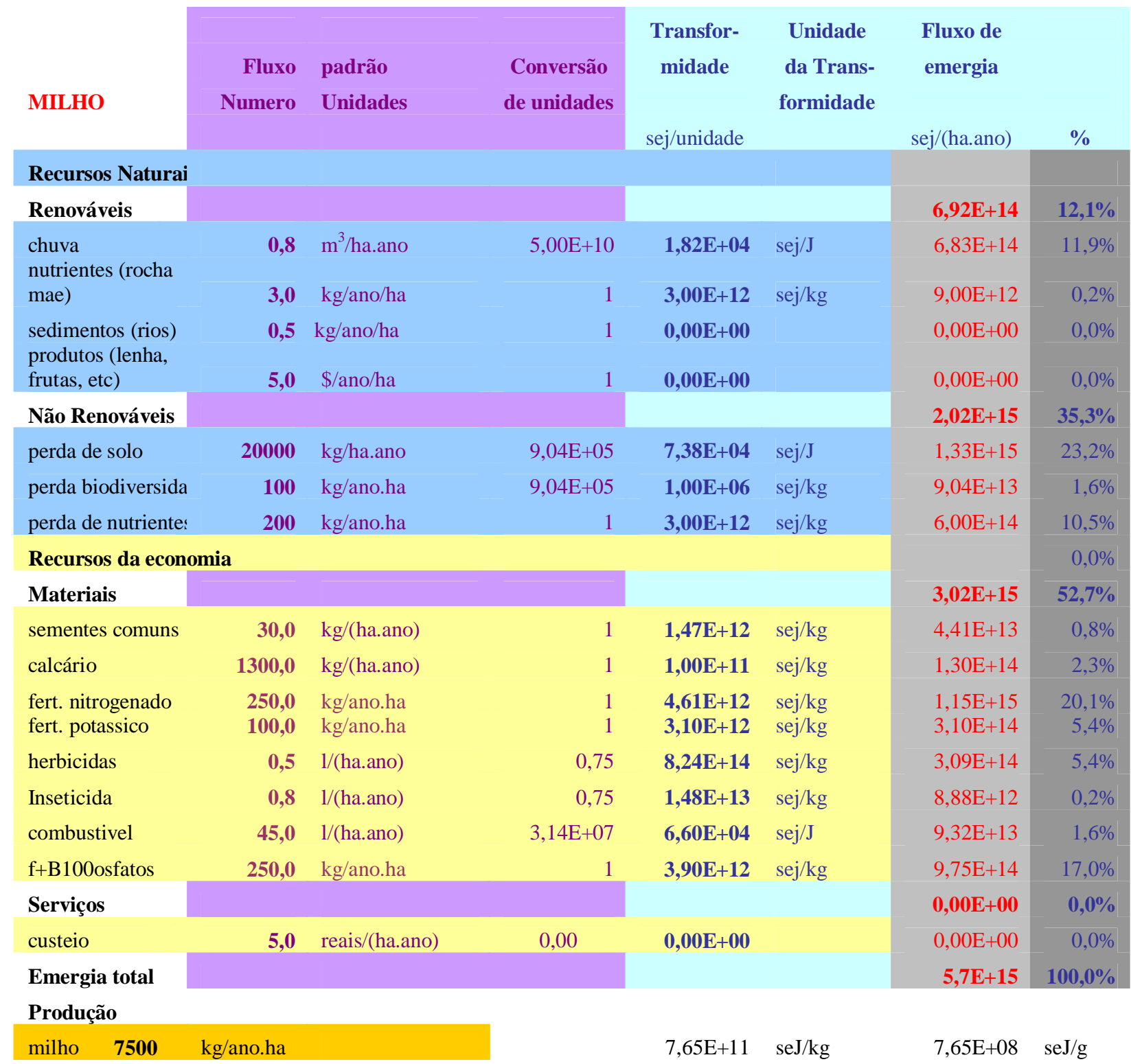

Planilha de cálculo da emergia do milho, com os percentuais (R, N e F)

Fonte:

Ortega,

2003. 


\section{ANEXO B}

Memorial descritivo dos cálculos de termoeconomia

Tabela B-1. Cálculos da análise termoeconômica da Moenda pelo critério da extração, da Tabela 10.

$\mathrm{I}=$ Custo do sistema de moenda $=\mathrm{R} \$ 3.405 .490,00$

$i=$ I.FRC $/ P_{s}$

$\mathrm{I}_{0 \& \mathrm{M}}=28,482 \%$ do total $=387000 \mathrm{R} \$ / \mathrm{ano}$

$i_{0 \& M}=$ fluxo de R $\$ /$ s ou seja (custo de $O \& M$ ) $/ \mathrm{P}_{\mathrm{s}}$

$\mathrm{FC}=$ fator de capacidade $=0,90$

$\mathrm{FRC}=$ fator de retorno do capital

$\mathrm{C}_{\text {cana }}=\mathrm{R} \$ 23,00$ a tonelada de cana

$C_{\text {bagaço }}=C_{\text {cana }}=\frac{2,3 \cdot 10^{-2} \frac{\mathrm{R} \$}{\mathrm{~kg}}}{5164 \frac{\mathrm{kJ}}{\mathrm{kg}}}=4,10 \cdot 10^{-6} \frac{\mathrm{R} \$}{\mathrm{~kJ}}$

$\dot{\mathrm{m}}_{\text {cana }}=\mathrm{m}_{\text {cana }} / \mathrm{P}_{\mathrm{s}}$

$\mathrm{m}_{\text {cana }}=1,05 \cdot 10^{5}$ Toneladas de Cana

$\dot{\mathrm{W}}_{\text {ele }}=12,9 \mathrm{kWh} * \mathrm{~m}_{\text {cana }} / \mathrm{P}_{\mathrm{s}}$

$P_{s}=$ segundos de atividade no ano

$\mathrm{C}_{\text {ele }}=4,95 \cdot 10^{-2} \mathrm{R} \$ / \mathrm{kWh}$

$\dot{\mathrm{B}}_{\text {caldo }}=(0,875+0,135) \times \mathrm{m}_{\text {cana }} \times \mathrm{b}_{\text {cana }} / \mathrm{P}_{\mathrm{s}}$

$\dot{\mathrm{m}}_{\text {bagaço }}=0,25 \times \mathrm{m}_{\text {cana }} / \mathrm{P}_{\mathrm{s}}$

$\dot{\mathrm{m}}_{\text {água }}=260(\mathrm{~L} / \mathrm{TC}) \times \mathrm{m}_{\text {cana }} / \mathrm{P}_{\mathrm{s}}$

$\mathrm{C}_{\text {água }}=5,84 \cdot 10^{-3} \mathrm{R} \$ / \mathrm{L}$

$r=15 \%$

$\mathrm{t}=20$ anos

$$
\begin{aligned}
& F R C=\frac{r}{\left(1-(1+r)^{-t}\right)} \\
& F R C=\frac{0,15}{\left(1-(1+0,15)^{-20}\right)}=0,1597615 \\
& P_{s}=24 \frac{\text { horas }}{\text { dia }} \times 210 \text { dias } \times F C \times 3600 \frac{\text { segundos }}{\text { hora }}=16.329 .600 \text { segundos }
\end{aligned}
$$




$$
\begin{aligned}
& i=\frac{R \$ 3.405 .490,00 \times 0,1597615}{16.329 .600 \text { segundos }}=3,33.10^{-2} \frac{R \$}{S} \\
& i_{O \& M}=\frac{38700 \frac{\mathrm{R} \$}{\mathrm{ano}}}{16.329 .600 \frac{\text { segundos }}{\text { ano }}}=2,37.10^{-2} \frac{\mathrm{R} \$}{\mathrm{~s}} \\
& \dot{\mathrm{m}}_{\text {água . Cágua }}=\frac{260 \frac{\mathrm{L}}{\mathrm{TC}} \times 1,05 \cdot 10^{5} \mathrm{TC}}{16329600 \text { segundos }} \times 5,84.10^{-3} \frac{\mathrm{R} \$}{\mathrm{~L}}=9,76.10^{-3} \frac{\mathrm{R} \$}{\mathrm{~S}} \\
& \dot{\mathrm{m}}_{\text {cana }} \cdot C_{\text {cana }}=\frac{1,05 \cdot 10^{5} \mathrm{TC}}{16329600 \text { segundos }} \times 23,00 \frac{\mathrm{R} \$}{\mathrm{TC}}=1,48 \cdot 10^{-1} \frac{\mathrm{R} \$}{\mathrm{~s}} \\
& \dot{\mathrm{W}}_{\text {ele }} \cdot \mathrm{C}_{\text {ele }}=\frac{12,9 \frac{\mathrm{kWh}}{\mathrm{TC}} \times 1,05 \cdot 10^{5} \mathrm{TC}}{16329600 \text { segundos }} \times 4,95 \cdot 10^{-2} \frac{\mathrm{R} \$}{\mathrm{kWh}}=4,10 \cdot 10^{-3} \frac{\mathrm{R} \$}{\mathrm{~s}} \\
& \dot{\mathrm{B}}_{\text {caldo }}=\frac{(0,875+0,135) \times \frac{\mathrm{T} \text { caldo }}{\mathrm{TC}} \times 1,05 \cdot 10^{5} \mathrm{TC}}{16329600 \text { segundos }} 1000 \frac{\mathrm{kg}}{\text { Tcaldo }}=6,49 \frac{\mathrm{kg}}{\mathrm{s}} \times 3154 \frac{\mathrm{kJ}}{\mathrm{kg}}=20483,15 \frac{\mathrm{kJ}}{\mathrm{s}} \\
& \dot{\mathrm{m}}_{\text {bagaço }} \times \mathrm{C}_{\text {bagaço }}=\frac{125 \times \frac{\mathrm{kg} \mathrm{bagaço}}{\mathrm{TC}} \times 1,05.10^{5} \mathrm{TC} \times 4,05 \frac{\mathrm{R} \$}{\mathrm{~kg}_{\text {bagaço }}}+125 \mathrm{~L}_{\text {água }} \times 5,84.10^{-3} \frac{\mathrm{R} \$}{\mathrm{~L}} \times 1 \frac{\mathrm{L}}{\mathrm{kg}}}{16329600 \text { segundos }}=3,26.10^{-2} \frac{\mathrm{R} \$}{\mathrm{~s}}
\end{aligned}
$$

Analisando que o produto da moenda é o caldo, este deve arcar com os custos, então:

$$
\mathrm{C}_{\text {cana }}=\mathrm{C}_{\text {bagaço }}
$$

Logo,

$$
\begin{aligned}
& \dot{I}+\dot{I}_{0 \& M}+\dot{\mathrm{m}}_{\text {água }} \cdot C_{\text {água }}+\dot{\mathrm{m}}_{\text {cana }} \cdot C_{\text {cana }}+\dot{\mathrm{W}}_{\text {ele }} \cdot C_{\text {ele }}=\dot{\mathrm{B}}_{\text {caldo }} \cdot C_{\text {caldo }}+\dot{\mathrm{m}}_{\text {bagaço }} \cdot C_{\text {bagaço }} \\
& \dot{\mathrm{I}}+\dot{\mathrm{I}}_{0 \& M}+\dot{\mathrm{m}}_{\text {água }} \cdot C_{\text {água }}+\dot{\mathrm{m}}_{\text {cana }} \cdot C_{\text {cana }}+\dot{\mathrm{W}}_{\text {ele }} \cdot C_{\text {ele }}-\dot{\mathrm{m}}_{\text {bagaço }} \cdot C_{\text {bagaço }}=\dot{\mathrm{B}}_{\text {caldo }} \cdot C_{\text {caldo }} \\
& \frac{\dot{\mathrm{I}}+\dot{\mathrm{I}}_{0 \& \mathrm{M} M}+\dot{\mathrm{m}}_{\text {água }} \cdot C_{\text {água }}+\dot{\mathrm{m}}_{\text {cana }} \cdot C_{\text {cana }}+\dot{\mathrm{W}}_{\text {ele }} \cdot C_{\text {ele }}-\dot{\mathrm{m}}_{\text {bagaço }} \cdot C_{\text {bagaço }}}{\dot{\mathrm{B}}_{\text {caldo }}}=C_{\text {caldo }}
\end{aligned}
$$$$
C_{\text {caldo }}=\frac{3,33 \cdot 10^{-2} \frac{R \$}{\mathrm{~s}}+2,37 \cdot 10^{-2} \frac{R \$}{\mathrm{~s}}+9,76 \cdot 10^{-3} \frac{R \$}{\mathrm{~s}}+1,48 \cdot 10^{-1} \frac{R \$}{\mathrm{~s}}+4,10 \cdot 10^{-3} \frac{\mathrm{R} \$}{\mathrm{~s}}-3,26 \cdot 10^{-2} \frac{\mathrm{R} \$}{\mathrm{~s}}}{20483,15 \frac{\mathrm{kJ}}{\mathrm{s}}}=1,23 \cdot 10^{-5} \frac{\mathrm{R} \$}{\mathrm{~kJ}}
$$ 


$$
\begin{aligned}
& C_{\text {caldo }}=1,23 \cdot 10^{-5} \frac{\mathrm{R} \$}{\mathrm{~kJ}} \times 3154 \frac{\mathrm{kJ}}{\mathrm{kg}}=3,87.10^{-2} \frac{\mathrm{R} \$}{\mathrm{~kg}} \\
& \mathrm{C}_{\text {caldo }}=1,23 \cdot 10^{-5} \frac{\mathrm{R} \$}{\mathrm{~kJ}} \times 3154 \frac{\mathrm{kJ}}{\mathrm{kg}} \times 1,08 \frac{\mathrm{kg}}{\mathrm{L}}=4,18 \cdot 10^{-2} \frac{\mathrm{R} \$}{\mathrm{~L}} \\
& \mathrm{C}_{\text {bagaço }}=4,10.10^{-6} \frac{\mathrm{R} \$}{\mathrm{~kJ}} \times 9892 \frac{\mathrm{kJ}}{\mathrm{kg}}=4,05.10^{-2} \frac{\mathrm{R} \$}{\mathrm{~kg}}
\end{aligned}
$$


Tabela B-2. Cálculos da análise termoeconômica da Moenda pelo critério da igualdade, da Tabela 10

$\mathrm{I}=$ Custo do sistema de moenda $=\mathrm{R} \$ 3.405 .490,00$

$i$ = fluxo de R $\$ /$ s ou seja (custo do sistema).FRC/P

$\mathrm{I}_{0 \& \mathrm{M}}=$ Custo de $\mathrm{O} \& \mathrm{M}$ da usina $=28,482 \%$ do total $=387000 \mathrm{R} \$ / \mathrm{ano}$

$i_{0 \& M}=$ fluxo de $\mathrm{R} \$ / \mathrm{s}$ ou seja (custo de $\mathrm{O \& M}$ ) $/ \mathrm{P}_{\mathrm{S}}$

$\mathrm{FC}=$ fator de capacidade $=0,90$

$\mathrm{FRC}=$ fator de retorno do capital

$\mathrm{C}_{\text {cana }}=\mathrm{R} \$ 23,00$ a tonelada de cana

-

$\mathrm{m}_{\text {cana }}=\mathrm{m}_{\text {cana }} / \mathrm{P}_{\mathrm{s}}$

$\mathrm{m}_{\text {vinhaça }}=1,05 \cdot 10^{5}$ Toneladas de Cana

$\dot{\mathrm{W}}_{\text {ele }}=\left(\right.$ consumo $\left._{\text {cana }} * \mathrm{~m}_{\text {cana }}\right) / \mathrm{P}_{\mathrm{s}}$

$\mathrm{P}_{\mathrm{s}}=$ segundos de atividade no ano

consumo $_{\text {cana }}=12,9 \mathrm{kWh} / \mathrm{TC}$

$\mathrm{C}_{\text {ele }}=$ custo da eletricidade do motor a biogás $=2,65 \cdot 10^{-2} \mathrm{R} \$ / \mathrm{kWh}$

$\dot{\mathrm{B}}_{\text {caldo }}=(0,875+0,135) \times \mathrm{m}_{\text {cana }} \times$ exergia ${ }_{\text {cana }} / \mathrm{P}_{\mathrm{s}}$

$\dot{\mathrm{m}}_{\text {bagaço }}=0,25^{*} \mathrm{~m}_{\text {cana }} /$ tempo

$\dot{\mathrm{m}}_{\text {água }}=260(\mathrm{~L} / \mathrm{TC})^{*} \mathrm{~m}_{\text {cana }} /$ tempo

$\mathrm{C}_{\text {água }}=5,84 \cdot 10^{-3} \mathrm{R} \$ / \mathrm{L}$

$r=15 \%$

$\mathrm{t}=20$ anos

$F R C=\frac{r}{\left(1-(1+r)^{-t}\right)}$
$F R C=\frac{0,15}{\left(1-(1+0,15)^{-20}\right)}=0,1597615$

$\mathrm{P}_{\mathrm{s}}=24 \frac{\text { horas }}{\text { dia }} \times 2$ 210dias $\times \mathrm{FC} \times 3600 \frac{\text { segundos }}{\text { hora }}=16.329 .600$ segundos

$i=\frac{R \$ 3.405 .490,00 \times 0,1597615}{16.329 .600 \text { segundos }}=3,33.10^{-2} \frac{R \$}{S}$

$i_{0 \& M}=\frac{38700 \frac{\mathrm{R} \$}{\mathrm{ano}}}{16.329 .600 \frac{\text { segundos }}{\text { ano }}}=2,37.10^{-2} \frac{\mathrm{R} \$}{\mathrm{~s}}$ 


$$
\begin{aligned}
& \dot{\mathrm{m}}_{\text {água }} \cdot C_{\text {água }}=\frac{260 \frac{\mathrm{L}}{\mathrm{TC}} \times 1,05 \cdot 10^{5} \mathrm{TC}}{16329600 \text { segundos }} \times 5,84 \cdot 10^{-3} \frac{\mathrm{R} \$}{\mathrm{~L}}=9,76 \cdot 10^{-3} \frac{\mathrm{R} \$}{\mathrm{~s}} \\
& \dot{\mathrm{m}}_{\text {cana }} \cdot C_{\text {cana }}=\frac{1,05 \cdot 10^{5} \mathrm{TC}}{16329600 \text { segundos }} \times 23,00 \frac{\mathrm{R} \$}{\mathrm{TC}}=1,48 \cdot 10^{-1} \frac{\mathrm{R} \$}{\mathrm{~s}} \\
& \dot{W}_{\text {ele }} \cdot C_{\text {ele }}=\frac{12,9 \frac{\mathrm{kWh}}{\mathrm{TC}} \times 1,05 \cdot 10^{5} \mathrm{TC}}{16329600 \text { segundos }} \times 2,65 \cdot 10^{-2} \frac{\mathrm{R} \$}{\mathrm{kWh}}=2,20 \cdot 10^{-3} \frac{\mathrm{R} \$}{\mathrm{~s}} \\
& \dot{\mathrm{B}}_{\text {caldo }}=\frac{(0,875+0,135) \times \frac{\mathrm{Tcaldo}}{\mathrm{TC}} \times 1,05 \cdot 10^{5} \mathrm{TC}}{16329600 \text { segundos }} 1000 \frac{\mathrm{kg}}{\text { Tcaldo }}=6,49 \frac{\mathrm{kg}}{\mathrm{s}} \times 3154 \frac{\mathrm{kJ}}{\mathrm{kg}}=20483,15 \frac{\mathrm{kJ}}{\mathrm{s}} \\
& \dot{B}_{\text {bagaço }}=\frac{0,25 \times \frac{\text { Tbagaço }}{\mathrm{TC}} \times 1,05 \cdot 10^{5} \mathrm{TC}}{16329600 \text { segundos }} \times 9892 \frac{\mathrm{kJ}}{\mathrm{kg}} \times 1000 \frac{\mathrm{kg}}{\text { Tbagaço }}=15901,49 \frac{\mathrm{kJ}}{\mathrm{s}}
\end{aligned}
$$

Utilizando o método da igualdade os fluxos de saída têm o mesmo custo:

$$
\mathrm{C}_{\text {caldo }}=\mathrm{C}_{\text {bagaço }}
$$

Logo,

$$
\begin{aligned}
& \dot{I}+\dot{I}_{0 \& M}+\dot{m}_{\text {água }} \cdot C_{\text {água }}+\dot{\mathrm{m}}_{\text {cana }} \cdot C_{\text {cana }}+\dot{W}_{\text {ele }} \cdot C_{\text {ele }}=\dot{B}_{\text {caldo }} \cdot C_{\text {caldo }}+\dot{B}_{\text {bagaço }} \cdot C_{\text {bagaço }} \\
& \dot{\mathrm{I}}+\dot{\mathrm{I}}_{\text {o\&M }}+\dot{\mathrm{m}}_{\text {água }} \cdot \mathrm{C}_{\text {água }}+\dot{\mathrm{m}}_{\text {cana }} \cdot \mathrm{C}_{\text {cana }}+\dot{\mathrm{W}}_{\text {ele }} \cdot \mathrm{C}_{\text {ele }}=\mathrm{C}_{\text {caldo }} \cdot\left(\dot{\mathrm{B}}_{\text {caldo }}+\dot{\mathrm{B}}_{\text {bagaço }}\right) \\
& \frac{\dot{I}+\dot{I}_{0 \& M}+\dot{m}_{\text {água }} \cdot C_{\text {água }}+\dot{\mathrm{m}}_{\text {cana }} \cdot C_{\text {cana }}+\dot{W}_{\text {ele }} \cdot C_{\text {ele }}}{}=C_{\text {caldo }} \\
& C_{\text {caldo }}=\frac{3,33 \cdot 10^{-2} \frac{R \$}{\mathrm{~s}}+2,37 \cdot 10^{-2} \frac{R \$}{\mathrm{~s}}+9,76 \cdot 10^{-3} \frac{\mathrm{R} \$}{\mathrm{~s}}+1,48 \cdot 10^{-1} \frac{\mathrm{R} \$}{\mathrm{~s}}+2,20.10^{-3}}{20483,15 \frac{\mathrm{kJ}}{\mathrm{s}}+15901,49 \frac{\mathrm{kJ}}{\mathrm{s}}}=1,36 \cdot 10^{-5} \frac{\mathrm{R} \$}{\mathrm{~kJ}} \\
& \mathrm{C}_{\text {caldo }}=1,36.10^{-5} \frac{\mathrm{R} \$}{\mathrm{~kJ}} \times 3154 \frac{\mathrm{kJ}}{\mathrm{kg}}=4,30 \cdot 10^{-2} \frac{\mathrm{R} \$}{\mathrm{~kg}} \\
& \mathrm{C}_{\text {caldo }}=1,36.10^{-5} \frac{\mathrm{R} \$}{\mathrm{~kJ}} \times 3154 \frac{\mathrm{kJ}}{\mathrm{kg}} \times 1,08 \frac{\mathrm{kg}}{\mathrm{L}}=4,65.10^{-2} \frac{\mathrm{R} \$}{\mathrm{~L}} \\
& \mathrm{C}_{\text {bagaço }}=1,36.10^{-5} \frac{\mathrm{R} \$}{\mathrm{~kJ}}
\end{aligned}
$$




$$
\mathrm{C}_{\text {bagaço }}=1,36.10^{-5} \frac{\mathrm{R} \$}{\mathrm{~kJ}} \times 9892 \frac{\mathrm{kJ}}{\mathrm{kg}}=1,35.10^{-1} \frac{\mathrm{R} \$}{\mathrm{~kg}}
$$

Tabela B-3. Cálculos da análise termoeconômica da Destilaria pelo critério da extração, da Tabela 11.

$\mathrm{I}=$ Custo do sistema de destilaria $=\mathrm{R} \$ 5.667 .773,00$

$i$ = fluxo de $\mathrm{R} \$ /$ s ou seja (custo do sistema).FRC/P $\mathrm{P}_{\mathrm{s}}$

$\mathrm{I}_{\mathrm{O} \& \mathrm{M}}=644.684,43 \mathrm{R} \$$

$\mathrm{FC}=$ fator de capacidade $=0,90$

$F R C=$ fator de retorno do capital

$\mathrm{C}_{\text {caldo }}=1,23 \cdot 10^{-5} \mathrm{R} \$ / \mathrm{kJ}$ ou $3,87 \cdot 10^{-2} \mathrm{R} \$ / \mathrm{kg}$

$\mathrm{C}_{\text {vinhaça }}=1,23 \cdot 10^{-5} \mathrm{R} \$ / \mathrm{kJ}$

$\mathrm{E}_{\text {vinhaça }}=$ Exergia da vinhaça $=83,99 \mathrm{~kJ} / \mathrm{kg}$

$\mathrm{m}_{\text {caldo }}=(0,875+0,135) \times \mathrm{m}_{\text {cana }}$

$\mathrm{m}_{\text {cana }}=1,05 \cdot 10^{5} \mathrm{TC}$

$\mathrm{P}_{\mathrm{s}}=$ segundos de atividade no ano

$\dot{\mathrm{B}}_{\text {caldo }}=(0,875+0,135) * \mathrm{~m}_{\text {cana }} / \mathrm{P}_{\mathrm{s}}$

$\mathrm{m}_{\text {vapor de processo }}=340 \mathrm{~kg} / \mathrm{TC}$

$\dot{\mathrm{B}}_{\text {vapor de processo }}=E \mathrm{x}_{\text {vapor de processo }} / \mathrm{P}_{\mathrm{S}}$

$\mathrm{C}_{\text {vapor de processo }}=$ custo calculado na cogeração $\mathrm{A}=3,63.10^{-5} \mathrm{R} \$ / \mathrm{kJ}$

$\dot{\mathrm{B}}$

$\dot{\mathrm{B}}_{\text {álcool }}=\left[\left(\right.\right.$ fluxóálcool $\left.\left.* \mathrm{~m}_{\text {cana }}\right) / \mathrm{P}_{\mathrm{s}}\right] \times \rho_{\text {álcool }}$

$\rho_{\text {álcool }}=0,8 \mathrm{~kg} / \mathrm{L}$

$r=15 \%$

$\mathrm{t}=20$ anos

$\mathrm{FRC}=\frac{\mathrm{r}}{\left(1-(1+r)^{-\mathrm{t}}\right)}$

$\mathrm{FRC}=\frac{0,15}{\left(1-(1+0,15)^{-20}\right)}=0,1597615$

$P_{s}=24 \frac{\text { horas }}{\text { dia }} \times 2$ 210dias $\times F C \times 3600 \frac{\text { segundos }}{\text { hora }}=16.329 .600$ segundos

$i=\frac{R \$ 5667773,00 \times 0,1597615}{16329600 \text { segundos }}=5,55.10^{-2} \frac{R \$}{\mathrm{~s}}$

$\dot{I}_{0 \& M}=\frac{644684,43 R \$}{16329600 \text { segundos }}=3,95.10^{-2} \frac{R \$}{S}$ 
$\dot{\mathrm{m}}_{\text {caldo }} \cdot C_{\text {caldo }}=\frac{\frac{1,01 T \text { caldo }}{\mathrm{TC}} \times 1,05 \cdot 10^{5} \mathrm{TC}}{16329600 \text { segundos }} \times 1000 \frac{\mathrm{kg}}{\text { Tcaldo }} \times 3,87 \cdot 10^{-2} \frac{\mathrm{R} \$}{\mathrm{~kg}}=2,51.10^{-1} \frac{\mathrm{R} \$}{\mathrm{~s}}$

$\dot{B} . C_{\text {vapor de processo }}=\frac{340 \frac{\mathrm{kg}}{\mathrm{TC}} \times 1,05.10^{5} \mathrm{TC}}{16329600 \text { segundos }} \times 609 \frac{\mathrm{kJ}}{\mathrm{kg}} \times 3,63.10^{-5} \frac{\mathrm{R} \$}{\mathrm{~kJ}}=4,83.10^{-2} \frac{\mathrm{R} \$}{\mathrm{~s}}$

$\dot{\mathrm{m}}_{\text {vinhaça }} \cdot$ cvinhaça $=\frac{1,06 \cdot 10^{8} \mathrm{~kg}_{\text {caldo }}-8,40.10^{6} \mathrm{~L}_{\text {álcool }} \times 0,8 \frac{\mathrm{kg}}{\mathrm{L}_{\text {álcool }}}-4,2.10^{5} \mathrm{~kg}_{\text {torta }}}{16329600 \text { égundos }} \times 1000 \frac{\mathrm{kg}}{\mathrm{Tcaldo}} \times 1,23.10^{-5} \frac{\mathrm{R} \$}{\mathrm{~kJ}} \times 83,99 \frac{\mathrm{kJ}}{\mathrm{kg}}=2,34.10^{-1} \frac{\mathrm{R} \$}{\mathrm{~s}}$

$\dot{\mathrm{m}}_{\text {Torta }} \cdot C_{\text {Torta }}=\frac{\frac{4 \mathrm{~kg}}{\mathrm{TC}} \times 1,05 \cdot 10^{5} \mathrm{TC}}{16329600 \text { segundos }} \times 1,23 \cdot 10^{-5} \frac{\mathrm{R} \$}{\mathrm{~kJ}} \times 4600 \frac{\mathrm{kJ}}{\mathrm{kg}}=9,96.10^{-4} \frac{\mathrm{R} \$}{\mathrm{~s}}$

$\dot{B}_{\text {álcool }}=\frac{80 \frac{\mathrm{L}}{\mathrm{TC}} \times 1,05 \cdot 10^{5} \mathrm{TC}}{16329600 \text { segundos }}=0,5144 \frac{\mathrm{L}}{\mathrm{s}} \times 0,80 \frac{\mathrm{kg}}{\mathrm{L}} \times 34030 \frac{\mathrm{kJ}}{\mathrm{kg}}=14004,12 \frac{\mathrm{kJ}}{\mathrm{s}}$

Analisando que o produto da destilaria é o álcool, este deve arcar com os custos, então:

$\mathrm{C}_{\text {caldo }}=\mathrm{C}_{\text {vinhaça }}=\mathrm{C}_{\text {Torta }}$

Logo,

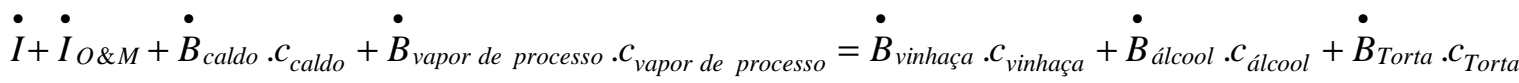

$\dot{I}+\dot{I}_{0 \& M}+\dot{B}_{\text {caldo }} \cdot C_{\text {caldo }}+\dot{B}_{\text {vapor de processo }} \cdot C_{\text {vapor de processo }}-\dot{B}_{\text {vinhaça }} . C_{\text {vinhaça }}-\dot{B}_{\text {Torta }} . C_{\text {Torta }}$

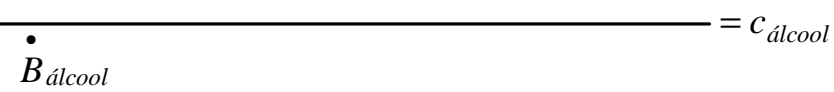

$C_{\text {álcool }}=\frac{5,55 \cdot 10^{-2} \frac{R \$}{\mathrm{~s}}+3,95 \cdot 10^{-2} \frac{R \$}{\mathrm{~s}}+2,51 \cdot 10^{-1} \frac{\mathrm{R} \$}{\mathrm{~s}}+4,83 \cdot 10^{-2} \frac{\mathrm{R} \$}{\mathrm{~s}}-2,34 \cdot 10^{-1} \frac{\mathrm{R} \$}{\mathrm{~s}}-9,39 \cdot 10^{-4} \frac{\mathrm{R} \$}{\mathrm{~s}}}{14040,12 \frac{\mathrm{kJ}}{\mathrm{s}}}=1,14 \cdot 10^{-5} \frac{\mathrm{R} \$}{\mathrm{~kJ}}$

$\mathrm{C}_{\text {álcool }}=1.14 \cdot 10^{-5} \frac{\mathrm{R} \$}{\mathrm{~kJ}} \times 34030 \frac{\mathrm{kJ}}{\mathrm{kg}}=3,87 \cdot 10^{-1} \frac{\mathrm{R} \$}{\mathrm{~kg}}$

$\mathrm{C}_{\text {álcool }}=3,87 \cdot 10^{-1} \frac{\mathrm{R} \$}{\mathrm{~kg}} \times 0,8 \frac{\mathrm{kg}}{\mathrm{L}}=3,09 \cdot 10^{-1} \frac{\mathrm{R} \$}{\mathrm{~L}}$

$\mathrm{C}_{\text {vinhaça }}=1,23 \cdot 10^{-5} \frac{\mathrm{R} \$}{\mathrm{~kJ}}$

$C_{\text {vinhaça }}=1,23 \cdot 10^{-5} \frac{\mathrm{R} \$}{\mathrm{~kJ}} \times 83,99 \frac{\mathrm{kJ}}{\mathrm{kg}}=1,03 \cdot 10^{-3} \frac{\mathrm{R} \$}{\mathrm{~kg}}$

$\mathrm{C}_{\text {Torta }}=1,23.10^{-5} \frac{\mathrm{R} \$}{\mathrm{~kJ}}$

$C_{\text {Torta }}=1,23 \cdot 10^{-5} \frac{\mathrm{R} \$}{\mathrm{~kJ}} \times 4600 \frac{\mathrm{kJ}}{\mathrm{kg}}=5,65 \cdot 10^{-2} \frac{\mathrm{R} \$}{\mathrm{~kg}}$ 
Tabela B-4. Cálculos da análise termoeconômica da Destilaria pelo critério da igualdade, da Tabela 11.

$\mathrm{I}=$ Custo do sistema de destilaria $=\mathrm{R} \$ 5.667 .773,00$

$i$ = fluxo de $\mathrm{R} \$ /$ s ou seja (custo do sistema).FRC/P $\mathrm{P}_{\mathrm{s}}$

$I_{\text {O\&M }}=644.684,43 \mathrm{R} \$$

$\mathrm{FC}=$ fator de capacidade $=0,90$

$\mathrm{FRC}=$ fator de retorno do capital

$\mathrm{C}_{\text {aldo }}=1,36.10^{-5} \mathrm{R} \$ / \mathrm{kJ}$ ou $4,30.10^{-2} \mathrm{R} \$ / \mathrm{kg}$

$\mathrm{m}_{\text {caldo }}=(0,875+0,135) \times \mathrm{m}_{\text {cana }}$

$\mathrm{m}_{\text {cana }}=1,05 \cdot 10^{5} \mathrm{TC}$

$\mathrm{P}_{\mathrm{s}}=$ segundos de atividade no ano

$\dot{\mathrm{B}}_{\text {caldo }}=(0,875+0,135) * \mathrm{~m}_{\text {cana }} / \mathrm{P}_{\mathrm{s}}$

$\mathrm{m}_{\text {vapor }}=340 \mathrm{~kg} / \mathrm{TC}$

$\dot{\mathrm{B}}_{\text {vapor }}=$ b. $\mathrm{m}_{\text {vapor }} / \mathrm{P}_{\mathrm{s}}$

$\mathrm{C}_{\text {vapor }}=$ custo calculado na cogeração $=1 \cdot 10.10^{-5} \mathrm{R} \$ / \mathrm{kJ}$

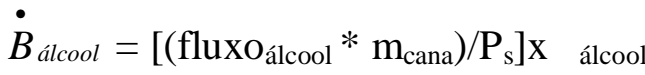

$\rho_{\text {álcool }}=0,8 \mathrm{~kg} / \mathrm{L}$

$r=15 \%$

$\mathrm{t}=20$ anos

$F R C=\frac{r}{\left(1-(1+r)^{-t}\right)}$

$F R C=\frac{0,15}{\left(1-(1+0,15)^{-20}\right)}=0,1597615$

$P_{s}=24 \frac{\text { horas }}{\text { dia }} \times 210$ dias $\times$ FC $\times 3600 \frac{\text { segundos }}{\text { hora }}=16.329 .600$ segundos

$i=\frac{R \$ 5667773,00 \times 0,1597615}{16329600 \text { segundos }}=5,55.10^{-2} \frac{R \$}{S}$

$\dot{I}_{0 \& M}=\frac{644684,43 R \$}{16329600 \text { segundos }}=3,95.10^{-2} \frac{R \$}{S}$ 
$\dot{\mathrm{m}}_{\text {caldo }} \cdot C_{\text {caldo }}=\frac{\frac{1,01 T \text { caldo }}{\mathrm{TC}} \times 1,05.10^{5} \mathrm{TC}}{16329600 \text { segundos }} \times 1000 \frac{\mathrm{kg}}{\mathrm{Tcaldo}} \times 4,30.10^{-2} \frac{\mathrm{R} \$}{\mathrm{~kg}}=2,79.10^{-1} \frac{\mathrm{R} \$}{\mathrm{~s}}$

$\dot{B} . C_{\text {vapor de processo }}=\frac{340 \frac{\mathrm{kg}}{\mathrm{TC}} \times 1,05.10^{5} \mathrm{TC}}{16329600 \text { segundos }} \times 609 \frac{\mathrm{kJ}}{\mathrm{kg}} \times 1,10.10^{-5} \frac{\mathrm{R} \$}{\mathrm{~kJ}}=1,47.10^{-2} \frac{\mathrm{R} \$}{\mathrm{~s}}$

$\dot{\mathrm{B}}_{\text {vinhaça }}=\frac{1,06.10^{8} \mathrm{~kg}_{\text {caldo }}-8,40.10^{6} \mathrm{~L}_{\text {álcool }} \times 0,8 \frac{\mathrm{kg}}{\mathrm{L}_{\text {álcool }}}-4,2.10^{5} \mathrm{~kg}_{\text {Torta }}}{1632960 \text { şegundos }} \times 84,18 \frac{\mathrm{kJ}}{\mathrm{kg}}=509,88 \frac{\mathrm{kJ}}{\mathrm{s}}$

$\dot{B}_{\text {Torta }}=\frac{\frac{4 \mathrm{~kg}}{\mathrm{TC}} \times 1,05.10^{5} \mathrm{TC}}{16329600 \text { segundos }} \times 4600 \frac{\mathrm{kJ}}{\mathrm{kg}}=118,31 \frac{\mathrm{kJ}}{\mathrm{s}}$

$\dot{B}_{\text {álcool }}=\frac{80 \frac{\mathrm{L}}{\mathrm{TC}} \times 1,05.10^{5} \mathrm{TC}}{16329600 \text { segundos }} \times 34030 \frac{\mathrm{kJ}}{\mathrm{kg}} \times 0,80 \frac{\mathrm{kg}}{\mathrm{L}}=14004,12 \frac{\mathrm{kJ}}{\mathrm{s}}$

Analisando pelo método da igualdade:

$\mathrm{C}_{\text {álcool }}=\mathrm{C}_{\text {vinhaça }}=\mathrm{C}_{\text {Torta }}$

Logo,

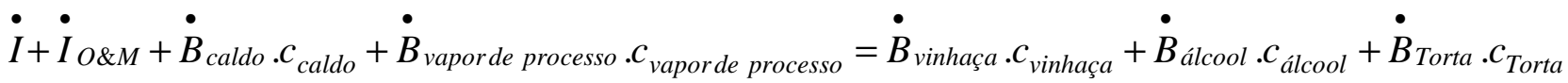

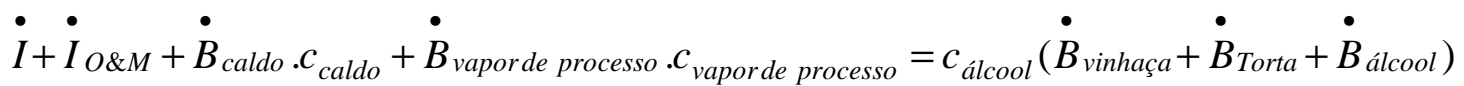

$\frac{\dot{I}+\dot{I}_{0 \& M}+\dot{B}_{\text {caldo }} \cdot C_{\text {caldo }}+\dot{B}_{\text {vapor de processo }} \cdot C_{\text {vapor de processo }}}{\dot{B}_{\text {vinhaça }}+\dot{B}_{\text {Torta }}+\dot{B}_{\text {álcool }}}=c_{\text {álcool }}$

$C_{\text {álcool }}=\frac{5,55 \cdot 10^{-2} \frac{R \$}{\mathrm{~s}}+3,95 \cdot 10^{-2} \frac{\mathrm{R} \$}{\mathrm{~s}}+2,79 \cdot 10^{-2} \frac{\mathrm{R} \$}{\mathrm{~s}}+1,47 \cdot 10^{-2} \frac{\mathrm{R} \$}{\mathrm{~s}}}{509,88 \frac{\mathrm{kJ}}{\mathrm{s}}+118,31 \frac{\mathrm{kJ}}{\mathrm{s}}+14004,12 \frac{\mathrm{kJ}}{\mathrm{s}}}=2,66 \cdot 10^{-5} \frac{\mathrm{R} \$}{\mathrm{~kJ}}$

$C_{\text {álcool }}=2,66.10^{-5} \frac{\mathrm{R} \$}{\mathrm{~kJ}} \times 34030 \frac{\mathrm{kJ}}{\mathrm{kg}}=9,05 \cdot 10^{-1} \frac{\mathrm{R} \$}{\mathrm{~kg}}$

$C_{\text {álcool }}=2,66.10^{=5} \frac{\mathrm{R} \$}{\mathrm{~kJ}} \times 34030 \frac{\mathrm{kJ}}{\mathrm{kg}} \times 0,8 \frac{\mathrm{kg}}{\mathrm{L}}=7,24.10^{-1} \frac{\mathrm{R} \$}{\mathrm{~L}}$

$C_{\text {vinhaça }}=2,66.10^{-5} \frac{\mathrm{R} \$}{\mathrm{~kJ}} \times 84,18 \frac{\mathrm{kJ}}{\mathrm{kg}}=2,24 \cdot 10^{-3} \frac{\mathrm{R} \$}{\mathrm{~kg}}$ 


$$
\mathrm{C}_{\text {Torta }}=2,66.10^{-5} \frac{\mathrm{R} \$}{\mathrm{~kJ}} \times 4600 \frac{\mathrm{kJ}}{\mathrm{kg}}=1,22.10^{-1} \frac{\mathrm{R} \$}{\mathrm{~kg}}
$$

Tabela B-5. Cálculos da análise termoeconômica do biodigestor pelo critério da extração, da Tabela 12.

$$
\begin{aligned}
& \mathrm{I}=\text { Custo do Biodigestor }=80000 \mathrm{R} \$ \\
& \mathrm{I}_{0 \& \mathrm{M}}=\text { Custo da O\&M }=9099,65 \mathrm{R} \$ \\
& \mathrm{C}_{\text {vinhaça }}=\text { Custo da vinhaça }=1,03 \cdot 10^{-3} \mathrm{R} \$ / \mathrm{kg} \\
& \mathrm{m}_{\text {vinhaça }}=\text { Massa da vinhaça }=9,89.10^{7} \mathrm{~kg} \\
& \rho_{\text {biogás }}=0,79 \mathrm{~kg} / \mathrm{m}^{3} \\
& \text { fluxo }_{\text {biogás }}=11,83 \mathrm{~m}^{3} / \mathrm{TC} \\
& \mathrm{C}_{\text {biofertilizante }}=\text { Custo do biofertilizante }=1,16 \cdot 10^{-5} \mathrm{R} \$ / \mathrm{kJ} \\
& \mathrm{m}_{\text {biofertilizante }}=9,79 \cdot 10^{7} \mathrm{~kg} \\
& \dot{\mathrm{m}}_{\text {biofertilizante }}=5,71 \cdot 10^{-5} \mathrm{~kg} / \mathrm{s}
\end{aligned}
$$

saída $=1,24.10^{6} \mathrm{~m}^{3}$ de biogás e $9,79.10^{7} \mathrm{~kg}$ de biofertilizante

$$
\frac{\dot{I}+\dot{I}_{0 \& M}+\dot{m}_{\text {vinhaça }} \cdot C_{\text {vinhaça- }} \dot{m}_{\text {biofertilizante }} \cdot C_{\text {biofertilizante }}}{\dot{B}_{\text {biogás }}}=c_{\text {biogás }}
$$

$$
\begin{aligned}
& i=\frac{80000 R \$ \times 0,1597615}{16329600 \text { segundos }}=7,84 \cdot 10^{-4} \frac{R \$}{\mathrm{~s}} \\
& \dot{I}_{0 \& M}=\frac{9099,65 R \$}{16329600 \text { segundos }}=5,57.10^{-4} \frac{R \$}{\mathrm{~s}} \\
& \dot{\mathrm{m}}_{\text {vinhaça }} C_{\text {vinhaça }}=\frac{1,06 \cdot 10^{8} \mathrm{~kg}_{\text {caldo }}-8,40.10^{6} \mathrm{~L}_{\text {álcool }} \times 0,8 \frac{\mathrm{kg}}{\mathrm{L}_{\text {álcool }}}-3,68 \cdot 10^{4} \mathrm{~kg}_{\text {Torta }}}{1632960 \text { \& } \operatorname{eg} \text { undos }} \times 1,03 \cdot 10^{-3} \frac{\mathrm{R} \$}{\mathrm{~kg}}=6,23.10^{-3} \frac{\mathrm{R} \$}{\mathrm{~s}}
\end{aligned}
$$




$$
\begin{aligned}
& \dot{\mathrm{B}}_{\text {biogás }}=\frac{1,24 \cdot 10^{6} \mathrm{~m}^{3}}{16329600 \text { segundos }} \times 14873 \frac{\mathrm{kJ}}{\mathrm{m}^{3}}=1131,37 \frac{\mathrm{kJ}}{\mathrm{s}} \\
& 7,83 \cdot 10^{-4} \frac{\mathrm{R} \$}{\mathrm{~s}}+5,57 \cdot 10^{-4} \frac{\mathrm{R} \$}{\mathrm{~s}}+6,79 \cdot 10^{-3} \frac{\mathrm{R} \$}{\mathrm{~s}}=1131,37 \cdot \frac{\mathrm{kJ}}{\mathrm{s}} \mathrm{C}_{\text {biogás }} \\
& C_{\text {biogás }}=\frac{7,83 \cdot 10^{-4} \frac{\mathrm{R} \$}{\mathrm{~s}}+5,57 \cdot 10^{-4} \frac{\mathrm{R} \$}{\mathrm{~s}}+6,23 \cdot 10^{-3} \frac{\mathrm{R} \$}{\mathrm{~s}}}{1131,37 \cdot \frac{\mathrm{kJ}}{\mathrm{s}}} \\
& C_{\text {biogás }}=6,70 \cdot 10^{-6} \frac{\mathrm{R} \$}{\mathrm{~kJ}} \\
& C_{\text {biogás }}=6,70 \cdot 10^{-6} \frac{\mathrm{R} \$}{\mathrm{~kJ}} \times 14873 \frac{\mathrm{kJ}}{\mathrm{m}^{3}}=9,97 \cdot 10^{-2} \frac{\mathrm{R} \$}{\mathrm{~m}^{3}} \\
& C_{\text {biogás }}=\frac{9,97 \cdot 10^{-2} \frac{\mathrm{R} \$}{\mathrm{~m}^{3}}}{0,79 \frac{\mathrm{kg}}{\mathrm{m}^{3}}}=1,26 \cdot 10^{-1} \frac{\mathrm{R} \$}{\mathrm{~kg}}
\end{aligned}
$$


Tabela B-6. Cálculos da análise termoeconômica do biodigestor pelo critério da igualdade, da Tabela 12.

$$
\begin{aligned}
& \mathrm{I}=\text { Custo do Biodigestor }=80000 \mathrm{R} \$ \\
& \mathrm{I}_{0 \& \mathrm{M}}=\text { Custo da O\&M }=9099,65 \mathrm{R} \$ \\
& \mathrm{C}_{\text {vinhaça }}=\text { Custo da vinhaça }=2,24 \cdot 10^{-3} \mathrm{R} \$ / \mathrm{kg} \\
& \mathrm{m}_{\text {vinhaça }}=\text { Massa da vinhaça }=9,89.10^{7} \mathrm{~kg} \\
& \mathrm{P}_{\text {biogás }}=0,79 \mathrm{~kg} / \mathrm{m}^{3} \\
& \text { volume }_{\text {biogás }}=11,83 \mathrm{~m}^{3} / \mathrm{TC}(\mathrm{LAMO}, 1991)
\end{aligned}
$$

saída

$1,24.10^{6} \mathrm{~m}^{3}$ de biogás e $9,79.10^{7} \mathrm{~kg}$ de biofertilizante

$\dot{\mathrm{m}}_{\text {biofertilizante }}=5,71 \cdot 10^{-5} \mathrm{~kg} / \mathrm{s}$

Analisando pelo método da igualdade:

$$
C_{\text {biofertilizante }}=C_{\text {biogás }}
$$

Logo,

$$
\begin{aligned}
& \dot{I}+\dot{I}_{0 \& M}+\dot{m}_{\text {vinhaça }} \cdot C_{\text {vinhaça }}=\dot{B}_{\text {biogás }} \cdot C_{\text {biogás }}+\dot{B}_{\text {biofertilizante }} \cdot C_{\text {biofertilizante }} \\
& \frac{\dot{I}+\dot{I}_{0 \& M}+\dot{m}_{\text {vinhaça }} \cdot C_{\text {vinhaça }}}{\dot{B}_{\text {biogás }}+\dot{B}_{\text {biofertilizante }}}=c_{\text {biogás }} \\
& \dot{i}=\frac{80000 R \$ \times 0,1597615}{16329600 \text { segundos }}=7,83 \cdot 10^{-4} \frac{R \$}{S} \\
& \dot{I}_{0 \& M}=\frac{9099,65 R \$}{16329600 \text { segundos }}=5,57.10^{-4} \frac{R \$}{S} \\
& \dot{\mathrm{m}}_{\text {vinhaça }} \cdot C_{\text {vinhaça }}=\frac{1,06 \cdot 10^{8} \mathrm{~kg}_{\text {caldo }}-8,40 \cdot 10^{6} \mathrm{~L}_{\text {álcool }} \times 0,8 \frac{\mathrm{kg}}{\mathrm{L}_{\text {álcool }}}-3,68 \cdot 10^{4} \mathrm{~kg}_{\text {Torta }}}{16329600 \text { segundos }} \times 2,24 \cdot 10^{-3} \frac{\mathrm{R} \$}{\mathrm{~kg}}=1,36 \cdot 10^{-2} \frac{\mathrm{R} \$}{\mathrm{~s}} \\
& \dot{\mathrm{B}}_{\text {biogás }}=\frac{1,24 \cdot 10^{6} \mathrm{~m}^{3}}{16329600 \text { segundos }} \times 14873 \frac{\mathrm{kJ}}{\mathrm{m}^{3}}=11313,71 \frac{\mathrm{kJ}}{\mathrm{s}} \\
& \dot{\mathrm{B}}_{\text {biofertilizante }}=\frac{9,79.10^{7} \mathrm{~kg}}{16329600 \text { segundos }} \times 50 \frac{\mathrm{kJ}}{\mathrm{kg}}=2998,50 \frac{\mathrm{kJ}}{\mathrm{s}}
\end{aligned}
$$


$C_{\text {biogás }}=\frac{7,83 \cdot 10^{-4} \frac{R \$}{\mathrm{~s}}+5,57 \cdot 10^{-4} \frac{\mathrm{R} \$}{\mathrm{~s}}+1,36 \cdot 10^{-2} \frac{\mathrm{R} \$}{\mathrm{~s}}}{11313,71 \cdot \frac{\mathrm{kJ}}{\mathrm{s}}+2998,50 \cdot \frac{\mathrm{kJ}}{\mathrm{s}}}$

$C_{\text {biogás }}=1,32 \cdot 10^{-6} \frac{\mathrm{R} \$}{\mathrm{~kJ}}$

$C_{\text {biogás }}=1,32.10^{-6} \frac{\mathrm{R} \$}{\mathrm{~kJ}} \times 14873 \frac{\mathrm{kJ}}{\mathrm{m}^{3}}=1,96.10^{-2} \frac{\mathrm{R} \$}{\mathrm{~m}^{3}}$

$C_{\text {biogás }}=\frac{1,96 \cdot 10^{-2} \frac{\mathrm{R} \$}{\mathrm{~m}^{3}}}{0,79 \frac{\mathrm{kg}}{\mathrm{m}^{3}}}=2,48 \cdot 10^{-2} \frac{\mathrm{R} \$}{\mathrm{~kg}}$ 
Tabela B-7. Cálculos da análise termoeconômica do motor-gerador pelo critério da extração, da Tabela 13.

$\mathrm{I}=$ Custo do sistema (motor) $=\mathrm{R} \$ 329.700,00$

$i$ = fluxo de $\mathrm{R} \$ /$ s ou seja (custo do sistema).FRC/P $\mathrm{P}_{\mathrm{S}}$

$i_{0 \& M}=$ fluxo de R $\$ /$ s ou seja (custo de $\left.O \& M\right) / P_{\mathrm{s}}$

$\mathrm{I}_{0 \& M}=37501,94 \mathrm{R} \$$

$\mathrm{FC}=$ fator de capacidade $=0,90$

$F R C=$ fator de retorno do capital

$\mathrm{C}_{\text {biogás }}=9,97.10^{-2} \mathrm{R} \$ / \mathrm{m}^{3}$

$\dot{\mathrm{B}}_{\text {biogás }}=\left[\left(\right.\right.$ fluxo $\left.\left._{\text {biogás }} * \mathrm{~m}_{\text {cana }}\right) / \mathrm{P}_{\mathrm{s}}\right]$

fluxo $_{\text {biogás }}=11,83 \mathrm{~m}^{3} / \mathrm{TC}(\mathrm{LAMO}, 1991)$

$\mathrm{m}_{\text {cana }}=1,05 \cdot 10^{5} \mathrm{TC}$

$\dot{\mathrm{W}}_{\text {eleB }}=\left(\right.$ consumo $\left._{\text {biogás }} * \mathrm{~m}_{\text {biogás }}\right) / \mathrm{Ps}$

$\mathrm{P}_{\mathrm{s}}=$ segundos de atividade no ano

$r=15 \%$

$\mathrm{t}=20$ anos

$F R C=\frac{r}{\left(1-(1+r)^{-t}\right)}$

$\mathrm{FRC}=\frac{0,15}{\left(1-(1+0,15)^{-20}\right)}=0,1597615$

$P_{s}=24 \frac{\text { horas }}{\text { dia }} \times 210$ dias $\times$ FC $\times 3600 \frac{\text { segundos }}{\text { hora }}=16.329 .600$ segundos

$i=\frac{R \$ 329700,00 \times 0,1597615}{16.329 .600 \text { segundos }}=3,23.10^{-3} \frac{R \$}{\mathrm{~s}}$

$\dot{I}_{0 \& M}=\frac{R \$ 37501,94}{16.329 .600 \text { segundos }}=2,30.10^{-3} \frac{R \$}{\mathrm{~s}}$ 
$\dot{B}_{\text {biogás }} C_{\text {biogás }}=\frac{11,83 \frac{\mathrm{m}^{3}}{\mathrm{TC}} \times 1,05 \cdot 10^{5} \mathrm{TC}}{16329600 \text { segundos }} \times 9,97 \cdot 10^{-2} \frac{\mathrm{R} \$}{\mathrm{~m}^{3}}=7,58 \cdot 10^{-3} \frac{\mathrm{R} \$}{\mathrm{~s}}$

$\dot{W}_{\text {ele }}=\frac{\frac{m^{3}}{T C}(\text { biogás }) \times T C\left(m_{\text {cana }}\right) \times k W(\text { potência })}{\frac{m^{3}}{h}(\text { consumo }) \times \operatorname{segundos}\left(P_{s}\right)}=\frac{k W h}{s}($ fluxo de energia $)$

$\dot{\mathrm{W}}_{\text {ele }}=\frac{11,83 \frac{\mathrm{m}^{3}}{\mathrm{TC}} \times 1,05 \cdot 10^{5} \mathrm{TC} \times 1475 \mathrm{~kW}}{423,5 \frac{\mathrm{m}^{3}}{\mathrm{~h}}} \cdot \frac{3600}{16329600 \text { segundos }} \frac{\mathrm{kJ}}{\mathrm{kWh}}=954 \frac{\mathrm{kJ}}{\mathrm{s}}$

Logo,

$$
\begin{aligned}
& \frac{\dot{I}+\dot{I}_{0 \& M}+\dot{B}_{\text {biogás } . C_{\text {biogás }}}}{\dot{W}_{\text {eleB }}}=C_{\text {eleB }} \\
& C_{\text {eleB }}=\frac{3,23 \cdot 10^{-3} \frac{R \$}{\mathrm{~s}}+2,30 \cdot 10^{-3} \frac{\mathrm{R} \$}{\mathrm{~s}}+7,58 \cdot 10^{-3} \frac{\mathrm{R} \$}{\mathrm{~s}}}{954 \frac{\mathrm{kJ}}{\mathrm{s}}}=1,37.10^{-5} \frac{\mathrm{R} \$}{\mathrm{~kJ}} \\
& C_{\text {eleB }}=1,37.10^{-5} \frac{\mathrm{R} \$}{\mathrm{~kJ}} \times 3600 \frac{\mathrm{kJ}}{\mathrm{kWh}}=4,95.10^{-2} \frac{\mathrm{R} \$}{\mathrm{kWh}} \times 1000 \frac{\mathrm{kWh}}{\mathrm{MWh}}=49,47 \frac{\mathrm{R} \$}{\mathrm{MWh}}
\end{aligned}
$$


Tabela B-8. Cálculos da análise termoeconômica do motor-gerador pelo critério da igualdade, da Tabela 13.

$\mathrm{I}=$ Custo do sistema (motor) $=\mathrm{R} \$ 329.700,00$

$i$ = fluxo de R $\$ /$ s ou seja (custo do sistema).FRC/P $\mathrm{P}_{\mathrm{s}}$

$i_{0 \& M}=$ fluxo de $\mathrm{R} \$ / \mathrm{s}$ ou seja (custo de $\left.\mathrm{O \& M}\right) / \mathrm{P}_{\mathrm{s}}$

I $0 \& M=37501,94 \mathrm{R} \$$

$F C=$ fator de capacidade $=0,90$

$\mathrm{FRC}=$ fator de retorno do capital

$\mathrm{C}_{\text {biogás }}=1,96.10^{-2} \mathrm{R} \$ / \mathrm{m}^{3}$

$\dot{\mathrm{B}}_{\text {biogás }}=\left[\left(\right.\right.$ fluxo $\left.\left._{\text {biogás }} * \mathrm{~m}_{\text {cana }}\right) / \mathrm{P}_{\mathrm{s}}\right]$

volume $_{\text {biogás }}=11,83 \mathrm{~m}^{3} / \mathrm{TC}(\mathrm{LAMO}, 1991)$

$\mathrm{m}_{\text {cana }}=1,05 \cdot 10^{5} \mathrm{TC}$

$\dot{\mathrm{W}}_{\text {ele }}=\left(\right.$ consumo $\left._{\text {biogás }} * \mathrm{~m}_{\text {biogás }}\right) / \mathrm{P}_{\mathrm{s}}$

$\mathrm{P}_{\mathrm{s}}=$ segundos de atividade no ano

$r=15 \%$

$\mathrm{t}=20$ anos

$\mathrm{FRC}=\frac{\mathrm{r}}{\left(1-(1+r)^{-\mathrm{t}}\right)}$

$F R C=\frac{0,15}{\left(1-(1+0,15)^{-20}\right)}=0,1597615$

$P_{s}=24 \frac{\text { horas }}{\text { dia }} \times 2$ 210dias $\times$ FC $\times 3600 \frac{\text { segundos }}{\text { hora }}=16.329 .600$ segundos

$i=\frac{R \$ 329700,00 \times 0,1597615}{16.329 .600 \text { segundos }}=3,23.10^{-3} \frac{R \$}{S}$

$\dot{I}_{0 \& M}=\frac{R \$ 37501,94}{16.329 .600 \text { segundos }}=2,30.10^{-3} \frac{R \$}{\mathrm{~s}}$ 
$\dot{B}_{\text {biogás }} C_{\text {biogás }}=\frac{11,83 \frac{\mathrm{m}^{3}}{\mathrm{TC}} \times 1,05.10^{5} \mathrm{TC}}{16329600 \text { segundos }} \times 1,96.10^{-2} \frac{\mathrm{R} \$}{\mathrm{~m}^{3}}=1,49.10^{-3} \frac{\mathrm{R} \$}{\mathrm{~s}}$

$\dot{W}_{\text {ele }}=\frac{\frac{\mathrm{m}^{3}}{\mathrm{TC}}(\text { biogás }) \times \mathrm{TC}\left(\mathrm{m}_{\text {cana }}\right) \times \mathrm{kW}(\text { potência })}{\frac{\mathrm{m}^{3}}{\mathrm{~h}}(\text { consumo })} \times \frac{3600}{\mathrm{P}_{\mathrm{s}}} \frac{\mathrm{kJ}}{\mathrm{kWh}}=\mathrm{kWh}($ fluxo de energia $)$

$\dot{\mathrm{W}}_{\text {ele }}=\frac{11,83 \frac{\mathrm{m}^{3}}{\mathrm{TC}} \times 1,05 \cdot 10^{5} \mathrm{TC} \times 1475 \mathrm{~kW}}{423,5 \frac{\mathrm{m}^{3}}{\mathrm{~h}}} \cdot \frac{3600}{16329600 \text { segundos }} \frac{\mathrm{kJ}}{\mathrm{kWh}}=954 \frac{\mathrm{kJ}}{\mathrm{s}}$

Logo,

$$
\begin{aligned}
& \frac{\dot{I}+\dot{I}_{0 \& M}+\dot{B}_{\text {biogás }} \cdot C_{\text {biogás }}}{\dot{W}_{\text {eleB }}}=C_{\text {eleB }} \\
& C_{\text {eleB }}=\frac{3,23 \cdot 10^{-3} \frac{R \$}{\mathrm{~s}}+.2,30.10^{-2} \frac{R \$}{\mathrm{~s}}+1,49 \cdot 10^{-3} \frac{\mathrm{R} \$}{\mathrm{~s}}}{954 \frac{\mathrm{kJ}}{\mathrm{s}}}=7,35 \cdot 10^{-6} \frac{\mathrm{R} \$}{\mathrm{~kJ}} \\
& C_{\text {eleB }}=7,35 \cdot 10^{-6} \frac{\mathrm{R} \$}{\mathrm{~kJ}} \times 3600 \frac{\mathrm{kJ}}{\mathrm{kWh}}=2,65 \cdot 10^{-2} \frac{\mathrm{R} \$}{\mathrm{kWh}} \times 1000 \frac{\mathrm{kWh}}{\mathrm{MWh}}=26,47 \frac{\mathrm{R} \$}{\mathrm{MWh}}
\end{aligned}
$$


Tabela B-9. Cálculos da análise termoeconômica da caldeira pelo critério da extração, da Tabela 14.

$\mathrm{I}=$ Custo da Caldeira $=932510 \mathrm{R} \$$

$\mathrm{I}_{0 \& \mathrm{M}}=$ Custo da O\&M = 106068,90 R\$

$\mathrm{C}_{\text {bagaço }}=$ Custo do bagaço $=4,05 \cdot 10^{-2} \mathrm{R} \$ / \mathrm{kg}$

$m_{\text {bagaço }}=$ Massa do bagaço $=2,63 \cdot 10^{4} \mathrm{~kg}$

$\mathrm{Ex}_{\text {vapor de processo }}=$ Exergia do vapor de processo $(2,5 \mathrm{bar} / 130 \mathrm{C})=609 \mathrm{~kJ} / \mathrm{kg}$

$E x_{V A(21)}=$ Exergia do vapor de alta $(21 \mathrm{bar} / 280 \mathrm{C})=1034 \mathrm{~kJ} / \mathrm{kg}$

$\mathrm{EX}_{\mathrm{VA}(67)}$ Exergia do vapor de alta $(67 \mathrm{bar} / 480 \mathrm{C})=1389 \mathrm{~kJ} / \mathrm{kg}$

saída $=5,25 \cdot 10^{7} \mathrm{~kg}$ de vapor de $67 \mathrm{bar}$

$$
\begin{aligned}
& \frac{\dot{I}+\dot{I}_{0 \& M}+\dot{m}_{\text {bagaço }} \cdot C_{\text {bagaço }}}{\dot{B}_{V A(67)}}=C_{V A(67)} \\
& i=\frac{932510 R \$ \times 0,1597615}{16329600 \text { segundos }}=9,12 \cdot 10^{-3} \frac{R \$}{\mathrm{~s}} \\
& \dot{I}_{0 \& M}=\frac{106068,90 R \$}{16329600 \text { segundos }}=6,50 \cdot 10^{-3} \frac{R \$}{S} \\
& \dot{\mathrm{m}}_{\text {bagaço. }} \mathrm{C}_{\text {bagaço }}=\frac{2,63 \cdot 10^{4} \mathrm{~kg}_{\text {bagaço }} \times 4,05 \cdot 10^{-2} \frac{\mathrm{R} \$}{\mathrm{~kg}}}{16329600 \text { segundos }}=6,50 \cdot 10^{-5} \frac{\mathrm{R} \$}{\mathrm{~s}} \\
& \dot{\mathrm{B}}_{\mathrm{AA}_{(67)}}=3,22 \frac{\mathrm{kg}}{\mathrm{s}} \times 1389 \frac{\mathrm{kJ}}{\mathrm{kg}}=4,47.10^{3} \frac{\mathrm{kJ}}{\mathrm{s}} \\
& C_{V A(67)}=\frac{9,12 \cdot 10^{-3} \frac{R \$}{s}+6,50 \cdot 10^{-3} \frac{R \$}{s}+6,50 \cdot 10^{-5} \frac{R \$}{s}}{4,47 \cdot 10^{3} \frac{\mathrm{kJ}}{\mathrm{s}}}=3,63 \cdot 10^{-5} \frac{\mathrm{R} \$}{\mathrm{~kJ}} \\
& C_{\text {VA(67) }}=3,63 \cdot 10^{-5} \frac{\mathrm{R} \$}{\mathrm{~kJ}} \times 1389 \frac{\mathrm{kJ}}{\mathrm{kg}}=5,04 \cdot 10^{-2} \frac{\mathrm{R} \$}{\mathrm{~kg}}
\end{aligned}
$$


Tabela B-10. Cálculos da análise termoeconômica da caldeira pelo critério da igualdade, da Tabela 14.

$$
\begin{aligned}
& \mathrm{I}=\text { Custo da Caldeira }=932510 \mathrm{R} \$ \\
& \mathrm{I}_{0 \& \mathrm{M}}=\text { Custo da O\&M }=106068,90 \mathrm{R} \$ \\
& \mathrm{C}_{\text {bagaço }}=\text { Custo do bagaço }=1,35.10^{-1} \mathrm{R} \$ / \mathrm{kg} \\
& \mathrm{m}_{\text {bagaço }}=\text { Massa do bagaço }=2,63 \cdot 10^{4} \mathrm{~kg} \\
& E x_{\text {vapor de processo }}=\text { Exergia do vapor de processo }(2,5 \mathrm{bar} / 130 \mathrm{C})=609 \mathrm{~kJ} / \mathrm{kg} \\
& E x_{\mathrm{VA}(67)}=\text { Exergia do vapor de alta }(67 \mathrm{bar} / 480 \mathrm{C})=1389 \mathrm{~kJ} / \mathrm{kg} \\
& \text { saída }=5,25.10^{7} \mathrm{~kg} \text { de vapor }
\end{aligned}
$$$$
\frac{\dot{I}+\dot{I}_{0 \& M}+\dot{m}_{\text {bagaço }} \cdot C_{\text {bagaço }}}{\dot{B}_{V A(67)}}=C_{V A(67)}
$$

$$
\begin{aligned}
& \dot{I}=\frac{932510 R \$ \times 0,1597615}{16329600 \text { segundos }}=9,12 \cdot 10^{-3} \frac{R \$}{\mathrm{~S}} \\
& \dot{I}_{0 \& M}=\frac{106068,90 R \$}{16329600 \text { segundos }}=6,50 \cdot 10^{-3} \frac{R \$}{\mathrm{~s}}
\end{aligned}
$$

$$
\begin{aligned}
& \dot{\mathrm{m}}_{\text {bagaço }} \cdot \mathrm{c}_{\text {bagaço }}=\frac{2,63 \cdot 10^{4} \mathrm{~kg}_{\text {bagaço }} \times 1,35 \cdot 10^{-1} \frac{\mathrm{R} \$}{\mathrm{~kg}}}{16329600 \text { segundos }}=2,17 \cdot 10^{-4} \frac{\mathrm{R} \$}{\mathrm{~s}} \\
& \dot{\mathrm{B}}_{V A(67)}=3,22 \frac{\mathrm{kg}}{\mathrm{s}} \times 1389 \frac{\mathrm{kJ}}{\mathrm{kg}}=4,47.10^{3} \frac{\mathrm{kJ}}{\mathrm{s}}
\end{aligned}
$$$$
C_{V A(67)}=\frac{9,12 \cdot 10^{-3} \frac{R \$}{S}+6,50 \cdot 10^{-3} \frac{R \$}{s}+2,17 \cdot 10^{-4} \frac{R \$}{s}}{4,47 \cdot 10^{3} \frac{k J}{s}}
$$$$
C_{V A(67)}=3,55.10^{-6} \frac{R \$}{k J}
$$$$
C_{\mathrm{VA}(67)}=3,55 \cdot 10^{-6} \frac{\mathrm{R} \$}{\mathrm{~kJ}} \times 1389 \frac{\mathrm{kJ}}{\mathrm{kg}}=4,93 \cdot 10^{-3} \frac{\mathrm{R} \$}{\mathrm{~kg}}
$$ 
Tabela B-11. Cálculos da análise termoeconômica da Cogeração A 67 bar pelo critério da extração, da Tabela 15.

$\mathrm{I}=$ Custo do sistema da Cogen $=\mathrm{R} \$ 1.090 .520,00$

$i$ = fluxo de $\mathrm{R} \$ / \mathrm{s}$ ou seja (custo do sistema).FRC/P $\mathrm{P}_{\mathrm{s}}$

$\mathrm{FC}=$ fator de capacidade $=0,90$

$F R C$ = fator de retorno do capital

$m_{\text {bagaço }}=0,25 * m_{\text {cana }}$

$\mathrm{m}_{\text {cana }}=1,05 \cdot 10^{5}$ Toneladas de Cana

$\mathrm{P}_{\mathrm{s}}=$ segundos de atividade no ano

$\dot{\mathrm{B}}_{\mathrm{VA}(67)}=\mathrm{m}_{\mathrm{VA}(67)} / \mathrm{P}_{\mathrm{S}}$

$\mathrm{W}_{\text {ele }}=$ produção $0_{\text {ele }} * \mathrm{~m}_{\text {cana }}$

produção $_{\text {ele }}=30 \mathrm{kWh} / \mathrm{TC}$ ou $108000 \mathrm{~kJ} / \mathrm{TC}$

$r=15 \%$

$\mathrm{t}=20$ anos

$F R C=\frac{r}{\left(1-(1+r)^{-t}\right)}$
$F R C=\frac{0,15}{\left(1-(1+0,15)^{-20}\right)}=0,1597615$

$P_{s}=24 \frac{\text { horas }}{\text { dia }} \times 210$ dias $\times$ Fc $\times 3600 \frac{\text { segundos }}{\text { hora }}=16.329 .600$ segundos

$i=\frac{R \$ 1541030,00 \times 0,1597615}{16329600 \text { segundos }}=1,07.10^{-2} \frac{R \$}{S}$

$\dot{I}_{0 \& M}=\frac{R \$ 175285,43}{16329600 \text { segundos }}=7,60.10^{-3} \frac{R \$}{\mathrm{~s}}$

$$
\begin{aligned}
& \dot{\mathrm{B}}_{V A(67)} \cdot C_{V A(67)}=\frac{1389 \frac{\mathrm{kJ}}{\mathrm{kg}} \times 5,25 \cdot 10^{7} \mathrm{~kg} \times 3,62.10^{-5} \frac{\mathrm{R} \$}{\mathrm{~kJ}}}{16329600 \text { segundos }}=1,62.10^{-1} \frac{\mathrm{R} \$}{\mathrm{~s}} \\
& \dot{\mathrm{B}}_{V A(21) \cdot C_{V A(21)}}=\frac{1034 \frac{\mathrm{kJ}}{\mathrm{kg}} \times 1,68.10^{-7} \mathrm{~kg} \times 3,62.10^{-5} \frac{\mathrm{R} \$}{\mathrm{~kJ}}}{16329600 \text { segundos }}=3,85.10^{-2} \frac{\mathrm{R} \$}{\mathrm{~s}}
\end{aligned}
$$


$\dot{B}_{\text {vapor de processo }} C_{\text {vapor de processo }}=\frac{609 \frac{\mathrm{kJ}}{\mathrm{kg}} \times 3,57.10^{7} \mathrm{~kg} \times 3,63.10^{-5} \frac{\mathrm{R} \$}{\mathrm{~kJ}}}{16329600 \text { segundos }}=4,83.10^{-2} \frac{\mathrm{R} \$}{\mathrm{~s}}$

$\dot{\mathrm{W}}_{\text {ele }}=\frac{30 \frac{\mathrm{kWh}}{\mathrm{TC}} \times 1,05.10^{5} \mathrm{TC}}{16329600 \text { segundos }} \times 3600 \frac{\mathrm{kJ}}{\mathrm{kWh}}=694,44 \frac{\mathrm{kJ}}{\mathrm{s}}$

Analisando que o produto da turbina é a energia este deve arcar com os custos, então:

$\mathrm{C}_{\mathrm{VA}(67)}=\mathrm{C}_{\mathrm{vapor} \text { de processo }}=\mathrm{C}_{\mathrm{VA}(21)}$

Logo,

$\dot{I}+\dot{I}_{0 \& M}+\dot{B}_{V A(67)} \cdot C_{V A(67)}=\dot{B}_{\text {vapor de processo }} \cdot C_{\text {vapor de processo }}+\dot{B}_{V A(21)} \cdot C_{V A(21)}+\dot{W}_{\text {ele }} \cdot C_{\text {eleU a }}$

$\frac{\dot{I}_{+} \dot{I}_{0 \& M}+\dot{B}_{V A(67)} \cdot C_{V A(67)}-\dot{B}_{\text {vapor de processo } \cdot C_{\text {vapor de processo }}-\dot{B}_{V A(21)} \cdot C_{V A(21)}}}{\dot{W}_{\text {ele }} .}=C_{\text {eleUa }}$

$\mathrm{C}_{\text {eleV } \mathrm{a}}=\frac{01,07.10^{-2} \frac{\mathrm{R} \$}{\mathrm{~s}}+7,60 \cdot 10^{-2} \frac{\mathrm{R} \$}{\mathrm{~s}}+1,62 \cdot 10^{-1} \frac{\mathrm{R} \$}{\mathrm{~s}}-4,83 \cdot 10^{-2}-3,85 \cdot 10^{-2} \frac{\mathrm{R} \$}{\mathrm{~s}}}{694,44 \frac{\mathrm{kJ}}{\mathrm{s}}}=1,35 \cdot 10^{-4} \frac{\mathrm{R} \$}{\mathrm{~kJ}}$

$\mathrm{C}_{\text {eleUa }}=1,35.10^{-4} \frac{\mathrm{R} \$}{\mathrm{~kJ}} \times 3600 \frac{\mathrm{kJ}}{\mathrm{kWh}}=4,84 \cdot 10^{-1} \frac{\mathrm{R} \$}{\mathrm{kWh}} \times 1000 \frac{\mathrm{kWh}}{\mathrm{MWh}}=484 \frac{\mathrm{R} \$}{\mathrm{MWh}}$

$\mathrm{C}_{\text {vapor de processo }}=3,62.10^{-5} \frac{\mathrm{R} \$}{\mathrm{~kJ}}$

$\mathrm{C}_{\text {vapor de processo }}=3,62 \cdot 10^{-5} \frac{\mathrm{R} \$}{\mathrm{~kJ}} \times 609 \frac{\mathrm{kJ}}{\mathrm{kg}}=2,21 \cdot 10^{-2} \frac{\mathrm{R} \$}{\mathrm{~kg}}$

$C_{V A(21)}=3,63 \cdot 10^{-5} \frac{R \$}{k J}$

$C_{V A(21)}=3,63.10^{-5} \frac{\mathrm{R} \$}{\mathrm{~kJ}} \times 1304 \frac{\mathrm{kJ}}{\mathrm{kg}}=3,75.10^{-2} \frac{\mathrm{R} \$}{\mathrm{~kg}}$ 
Tabela B-12. Cálculos da análise termoeconômica da Cogeração A 67 bar pelo critério da igualdade, da Tabela 15.

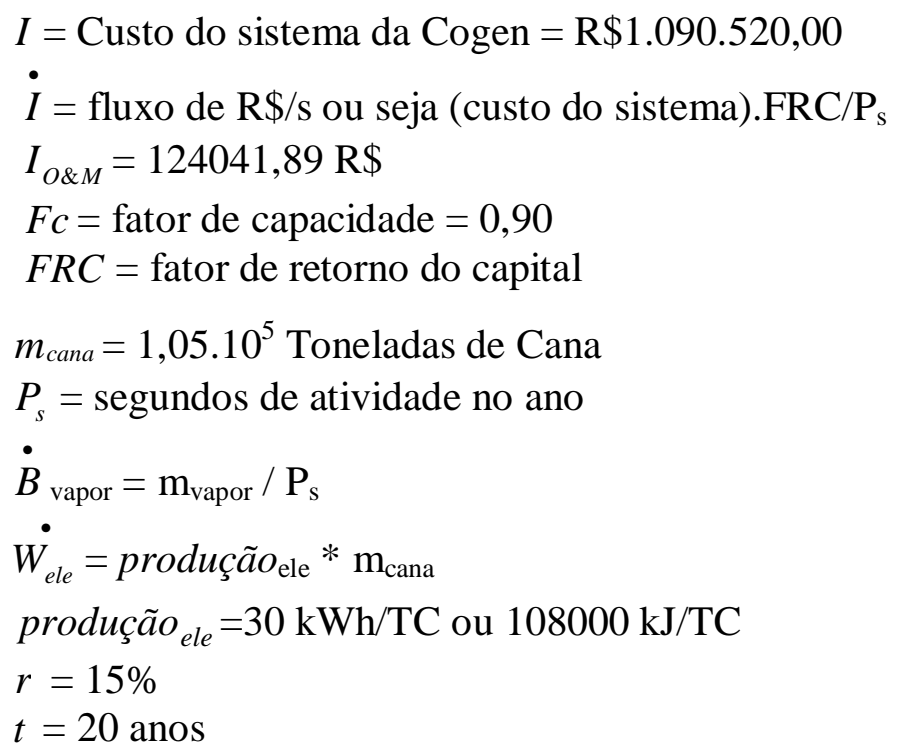

$F R C=\frac{r}{\left(1-(1+r)^{-t}\right)}$
$F R C=\frac{0,15}{\left(1-(1+0,15)^{-20}\right)}=0,1597615$

$P_{s}=24 \frac{\text { horas }}{\text { dia }} \times 210$ dias $\times$ FC $\times 3600 \frac{\text { segundos }}{\text { hora }}=16.329 .600$ segundos

$i=\frac{R \$ 1541030,00 \times 0,1597615}{16329600 \text { segundos }}=1,07.10^{-2} \frac{R \$}{\mathrm{~s}}$

$\dot{i}_{0 \& M}=\frac{R \$ 124041,89}{16329600 \text { segundos }}=7,60.10^{-3} \frac{R \$}{\mathrm{~s}}$

$\dot{B}_{V A(67)} \cdot C_{V A(67)}=\frac{1389 \frac{\mathrm{kJ}}{\mathrm{kg}} \times 5,25.10^{7} \mathrm{~kg} \times 3,55 \cdot 10^{-6} \frac{\mathrm{R} \$}{\mathrm{~kJ}}}{16329600 \text { segundos }}=1,58.10^{-2} \frac{\mathrm{R} \$}{\mathrm{~s}}$

$\dot{\mathrm{B}}_{\mathrm{VA}(21)}=\frac{1034 \frac{\mathrm{kJ}}{\mathrm{kg}} \times 1,68.10^{7} \mathrm{~kg} \times}{16329600 \text { segundos }}=1063,34 \frac{\mathrm{R} \$}{\mathrm{~s}}$ 
$\dot{\mathrm{B}}_{\text {vapor de processo. }}=\frac{609 \frac{\mathrm{kJ}}{\mathrm{kg}} \times 3,57.10^{7} \mathrm{~kg}}{16329600 \text { segundos }}=1331,45 \frac{\mathrm{R} \$}{\mathrm{~s}}$

$\dot{W}_{\text {ele }}=\frac{30 \frac{\mathrm{kWh}}{\mathrm{TC}} \times 1,05 \cdot 10^{5} \mathrm{TC}}{16329600 \text { segundos }} \times 3600 \frac{\mathrm{kJ}}{\mathrm{kWh}}=694,44 \frac{\mathrm{kJ}}{\mathrm{s}}$

Analisando pelo método da igualdade:

$\mathrm{C}_{\text {eleU }}=\mathrm{C}_{\text {vaporde processo }}=\mathrm{C}_{\mathrm{VA}(21)}$

Logo,

$\dot{I}+\dot{I}_{0 \& M}+\dot{B}_{V A(67)} \cdot C_{V A(67)}=\dot{B}_{\text {vapor de processo }} \cdot C_{\text {vapor de processo }}+\dot{B}_{V A(21)} \cdot C_{V A(21)}+\dot{W}_{\text {ele }} \cdot C_{\text {eleVa }}$

$\frac{\dot{I}+\dot{I}_{0 \& M}+\dot{B}_{V A(67)} \cdot C_{V A(67)}}{\dot{W}_{\text {ele }}+\dot{B}_{\text {vapor de processo }}+\dot{B}_{V A(21)}}=C_{\text {eleV }}$

$\mathrm{C}_{\text {eleU a }}=\frac{1,07.10^{-2} \frac{\mathrm{R} \$}{\mathrm{~s}}+7,60.10^{-3} \frac{\mathrm{R} \$}{\mathrm{~s}}+1,58 \cdot 10^{-2} \frac{\mathrm{R} \$}{\mathrm{~s}}}{694,44 \frac{\mathrm{kJ}}{\mathrm{s}}+1331,45 \frac{\mathrm{kJ}}{\mathrm{s}}+1063,34 \frac{\mathrm{kJ}}{\mathrm{s}}}=1.10 .10^{-5} \frac{\mathrm{R} \$}{\mathrm{~kJ}}$

$\mathrm{C}_{\text {eleU a }}=1,10.10^{-5} \frac{\mathrm{R} \$}{\mathrm{~kJ}} \times 3600 \frac{\mathrm{kJ}}{\mathrm{kWh}}=3,97.10^{-2} \frac{\mathrm{R} \$}{\mathrm{kWh}} \times 1000 \frac{\mathrm{kWh}}{\mathrm{MWh}}=39,70 \frac{\mathrm{R} \$}{\mathrm{MWh}}$

$\mathrm{C}_{\text {vapor de processo }}=1,10.10^{-5} \frac{\mathrm{R} \$}{\mathrm{~kJ}} \times 609 \frac{\mathrm{kJ}}{\mathrm{kg}}=6,72.10^{-3} \frac{\mathrm{R} \$}{\mathrm{~kg}}$

$C_{V A(21)}=1,10.10^{-5} \frac{R \$}{\mathrm{~kJ}} \times 1034 \frac{\mathrm{kJ}}{\mathrm{kg}}=1,14.10^{-2} \frac{\mathrm{R} \$}{\mathrm{~kg}}$ 
Tabela B-13. Cálculos da análise termoeconômica da Cogeração B 21 bar pelo critério da extração, da Tabela 16.

$\mathrm{I}=$ Custo do sistema da Cogen $=\mathrm{R} \$ 450.510,00$

$i=$ fluxo de $\mathrm{R} \$ / \mathrm{s}$ ou seja (custo do sistema).FRC/ $\mathrm{P}_{\mathrm{s}}$

$\mathrm{FC}=$ fator de capacidade $=0,90$

$\mathrm{FRC}=$ fator de retorno do capital

$\mathrm{m}_{\text {bagaço }}=0,25^{*} \mathrm{~m}_{\text {cana }}$

$\mathrm{m}_{\text {cana }}=1,05 \cdot 10^{5}$ Toneladas de Cana

$P_{s}=$ segundos de atividade no ano

$\dot{\mathrm{B}}_{\text {vapor }}=\mathrm{m}_{\text {vapor }} / \mathrm{P}_{\mathrm{s}}$

$\mathrm{W}_{\text {ele }}=\mathrm{P}_{\text {ele }} * \mathrm{~m}_{\text {cana }}$

$\mathrm{P}_{\text {ele }}=10 \mathrm{kWh} / \mathrm{TC}$ ou $36000 \mathrm{~kJ} / \mathrm{TC}$

$r=15 \%$

$\mathrm{t}=20$ anos

$F R C=\frac{r}{\left(1-(1+r)^{-t}\right)}$
$F R C=\frac{0,15}{\left(1-(1+0,15)^{-20}\right)}=0,1597615$

$P_{s}=24 \frac{\text { horas }}{\text { dia }} \times 2$ 210dias $\times$ FC $\times 3600 \frac{\text { segundos }}{\text { hora }}=16.329 .600$ segundos

$i=\frac{R \$ 450510,00 \times 0,1597615}{16329600 \text { segundos }}=4,41.10^{-3} \frac{R \$}{\mathrm{~s}}$

$i_{0 \& M}=\frac{R \$ 51243,55}{16329600 \text { segundos }}=3,14 \cdot 10^{-3} \frac{R \$}{\mathrm{~s}}$

$\dot{B}_{V A(21) r} \cdot C_{V A(621)}=\frac{1034 \frac{\mathrm{kJ}}{\mathrm{kg}} \times 1,68 \cdot 10^{7} \mathrm{~kg} \times 3,63 \cdot 10^{-5} \frac{\mathrm{R} \$}{\mathrm{~kJ}}}{16329600 \text { segundos }}=3,86.10^{-2} \frac{\mathrm{R} \$}{\mathrm{~s}}$

$\dot{\mathrm{B}}_{\text {condensado }} \mathrm{C}_{\text {condensado }}=\frac{45 \frac{\mathrm{kJ}}{\mathrm{kg}} \times 1,68.10^{7} \mathrm{~kg} \times 3,63.10^{-5} \frac{\mathrm{R} \$}{\mathrm{~kJ}}}{16329600 \text { segundos }}=1,68.10^{-3} \frac{\mathrm{R} \$}{\mathrm{~s}}$ 
$\dot{\mathrm{W}}_{\text {ele }}=\frac{10 \frac{\mathrm{kWh}}{\mathrm{TC}} \times 1,05.10^{5} \mathrm{TC}}{16329600 \mathrm{segundos}} \times 3600 \frac{\mathrm{kJ}}{\mathrm{kWh}}=231,48 \frac{\mathrm{kJ}}{\mathrm{s}}$

Analisando que o produto da turbina é a energia este deve arcar com os custos, então:

$\mathrm{C}_{\mathrm{VA}(21)}=\mathrm{C}_{\text {condensado }}$

Logo,

$$
\begin{aligned}
& \dot{I}+\dot{I}_{0 \& M}+\dot{B}_{V A(21)} \cdot C_{V A(21)}=\dot{B}_{\text {condensado }} \cdot C_{\text {condensado }}+\dot{W}_{\text {ele }} \cdot C_{\text {eleUb }} \\
& \frac{\dot{I}_{+} \dot{I}_{0 \& M}+\dot{B}_{V A(21)} \cdot C_{V A(21)}-\dot{B}_{\text {condensado } \text { vapor_condensado }_{\text {ele }}}}{\dot{W}_{\text {ele }}}=C_{\text {eleU b }} \\
& C_{\text {eleUb }}=\frac{4,41.10^{-3} \frac{R \$}{\mathrm{~s}}+3,14 \cdot 10^{-3} \frac{\mathrm{R} \$}{\mathrm{~s}}+3,86 \cdot 10^{-1} \frac{\mathrm{R} \$}{\mathrm{~s}}-1,68 \cdot 10^{-3}}{231,48 \frac{\mathrm{kJ}}{\mathrm{s}}}=1,92 \cdot 10^{-4} \frac{\mathrm{R} \$}{\mathrm{~kJ}} \\
& C_{\text {eleUb }}=1,92 \cdot 10^{-4} \frac{\mathrm{R} \$}{\mathrm{~kJ}} \times 3600 \frac{\mathrm{kJ}}{\mathrm{kWh}}=6,91 \cdot 10^{-1} \frac{\mathrm{R} \$}{\mathrm{kWh}} \times 1000 \frac{\mathrm{MWh}}{\mathrm{kWh}}=691 \frac{\mathrm{R} \$}{\mathrm{MWh}} \\
& \mathrm{C}_{\text {condensado }}=3,63 \cdot 10^{-5} \frac{\mathrm{R} \$}{\mathrm{~kJ}} \\
& \mathrm{C}_{\text {condensado }}=3,63 \cdot 10^{-5} \frac{\mathrm{R} \$}{\mathrm{~kJ}} \times 45 \frac{\mathrm{kJ}}{\mathrm{kg}}=1,63 \cdot 10^{-3} \frac{\mathrm{R} \$}{\mathrm{~kg}}
\end{aligned}
$$


Tabela B-14. Cálculos da análise termoeconômica da Cogeração B 21 bar pelo critério da igualdade, da Tabela 16.

$\mathrm{I}=$ Custo do sistema da Cogen $=\mathrm{R} \$ 450.510,00$

$\mathrm{i}$ = fluxo de $\mathrm{R} \$ /$ s ou seja (custo do sistema).FRC/Ps

$i_{\text {o\&M }}=\mathrm{R} \$ 51.243,45$

$\mathrm{FC}=$ fator de capacidade $=0,90$

$\mathrm{FRC}=$ fator de retorno do capital

$\mathrm{m}_{\text {bagaço }}=0,25^{*} \mathrm{~m}_{\text {cana }}$

$\mathrm{m}_{\text {cana }}=1,05 \cdot 10^{5}$ Toneladas de Cana

$\mathrm{P}_{\mathrm{s}}=$ segundos de atividade no ano

$\dot{\mathrm{B}}_{\text {vapor }}=\mathrm{m}_{\text {vapor }} / \mathrm{P}_{\mathrm{s}}$

$\mathrm{W}_{\text {ele }}=\mathrm{P}_{\text {ele }} * \mathrm{~m}_{\text {cana }}$

$\mathrm{P}_{\mathrm{ele}}=10 \mathrm{kWh} / \mathrm{TC}$ ou $36000 \mathrm{~kJ} / \mathrm{TC}$

$r=15 \%$

$\mathrm{t}=20$ anos

$F R C=\frac{r}{\left(1-(1+r)^{-t}\right)}$
$F R C=\frac{0,15}{\left(1-(1+0,15)^{-20}\right)}=0,1597615$

$P_{s}=24 \frac{\text { horas }}{\text { dia }} \times 210$ dias $\times F C \times 3600 \frac{\text { segundos }}{\text { hora }}=16.329 .600$ segundos

$i=\frac{R \$ 450510,00 \times 0,1597615}{16329600 \text { segundos }}=4,41.10^{-3} \frac{R \$}{\mathrm{~s}}$

$i_{0 \& M}=\frac{R \$ 51243,55}{16329600 \text { segundos }}=3,14 \cdot 10^{-3} \frac{R \$}{\mathrm{~s}}$

$\dot{B}_{\text {VA (21) }} \cdot C_{V A(621)}=\frac{1034 \frac{\mathrm{kJ}}{\mathrm{kg}} \times 1,68.10^{7} \mathrm{~kg} \times 1,10.10^{-5} \frac{\mathrm{R} \$}{\mathrm{~kJ}}}{16329600 \text { segundos }}=1,17.10^{-2} \frac{\mathrm{R} \$}{\mathrm{~s}}$

$\dot{B}_{\text {condensado }}=\frac{45 \frac{\mathrm{kJ}}{\mathrm{kg}} \times 1,68.10^{7} \mathrm{~kg}}{16329600 \text { segundos }}=46,28 \frac{\mathrm{kJ}}{\mathrm{s}}$ 
$\dot{\mathrm{W}}_{\text {ele }}=\frac{10 \frac{\mathrm{kWh}}{\mathrm{TC}} \times 1,05.10^{5} \mathrm{TC}}{16329600 \mathrm{segundos}} \times 3600 \frac{\mathrm{kJ}}{\mathrm{kWh}}=231,48 \frac{\mathrm{kJ}}{\mathrm{s}}$

Analisando pelo critério da igualdade:

$\mathrm{C}_{\text {eleub }}=\mathrm{C}_{\text {condensado }}$

Logo,

$$
\begin{aligned}
& \dot{I}+\dot{I}_{0 \& M}+\dot{B}_{V A(21)} \cdot C_{V A(21)}=\dot{B}_{\text {condensado } \cdot C_{\text {condensado }}+\dot{W}_{\text {ele }} \cdot C_{\text {eleU b }}} \\
& \frac{\dot{I}+\dot{I}_{0 \& M}+\dot{B}_{V A(21)} \cdot C_{V A(21)}}{\dot{B}_{\text {condensado }}+\dot{W}_{\text {ele }}}=C_{\text {eleU b }} \\
& C_{\text {eleU b }}=\frac{4,41 \cdot 10^{-3} \frac{R \$}{\mathrm{~s}}+3,14 \cdot 10^{-3} \frac{R \$}{\mathrm{~s}}+1,17 \cdot 10^{-2} \frac{R \$}{\mathrm{~s}}}{46,28 \frac{\mathrm{kJ}}{\mathrm{s}}+231,48 \frac{\mathrm{kJ}}{\mathrm{s}}}=6,94 \cdot 10^{-5} \frac{\mathrm{R} \$}{\mathrm{~kJ}} \\
& \mathrm{C}_{\text {eleUb }}=6,94 \cdot 10^{-5} \frac{\mathrm{R} \$}{\mathrm{~kJ}} \times 3600 \frac{\mathrm{kJ}}{\mathrm{kWh}}=2,50 \cdot 10^{-1} \frac{\mathrm{R} \$}{\mathrm{kWh}} \times 1000 \frac{\mathrm{kWh}}{\mathrm{MWh}}=250 \frac{\mathrm{R} \$}{\mathrm{MWh}} \\
& \mathrm{C}_{\text {condensado }}=6,94 \cdot 10^{-5} \frac{\mathrm{R} \$}{\mathrm{~kJ}} \\
& \mathrm{C}_{\text {condensado }}=6,94 \cdot 10^{-5} \frac{\mathrm{R} \$}{\mathrm{~kJ}} \times 45 \frac{\mathrm{kJ}}{\mathrm{kg}}=3,12 \cdot 10^{-3} \frac{\mathrm{R} \$}{\mathrm{~kg}}
\end{aligned}
$$


Tabela B-15. Cálculos do custo médio ponderado da eletricidade gerada, da Tabela 17.

Custo médio da energia gerada pelo critério da extração

$\mathrm{C}_{\text {elet }}=\frac{484,10^{-1} \frac{\mathrm{R} \$}{\mathrm{kWh}} \times 3,15 \cdot 10^{6} \mathrm{kWh}+6,91 \cdot 10^{-1} \frac{\mathrm{R} \$}{\mathrm{kWh}} \times 1,05 \cdot 10^{6} \mathrm{kWh}+4,95 \cdot 10^{-2} \frac{\mathrm{R} \$}{\mathrm{kWh}} \times 2,97 \cdot 10^{6} \mathrm{kWh}}{3,15 \cdot 10^{6} \mathrm{kWh}+1,05 \cdot 10^{6} \mathrm{kWh}+2,97 \cdot 10^{6} \mathrm{kWh}}=3,35 \cdot 10^{-2} \frac{\mathrm{R} \$}{\mathrm{kWh}}=335 \frac{\mathrm{R} \$}{\mathrm{MWh}}$

Custo médio da energia gerada pelo critério da igualdade

$C_{\text {eleT }}=\frac{3,97 \cdot 10^{-2} \frac{\mathrm{R} \$}{\mathrm{kWh}} \times 3,15 \cdot 10^{6} \mathrm{kWh}+2,50 \cdot 10^{-1} \frac{\mathrm{R} \$}{\mathrm{kWh}} \times 1,05 \cdot 10^{6} \mathrm{kWh}+2,65 \cdot 10^{-2} \frac{\mathrm{R} \$}{\mathrm{kWh}} \times 2,97 \cdot 10^{6} \mathrm{kWh}}{1,80 \cdot 10^{6} \mathrm{kWh}+1,05 \cdot 10^{6} \mathrm{kWh}+4,33 \cdot 10^{6} \mathrm{kWh}}=6,50 \cdot 10^{-2} \frac{\mathrm{R} \$}{\mathrm{kWh}}=65,00 \frac{\mathrm{R} \$}{\mathrm{MWh}}$ 
Tabela B-16. Cálculos da análise termoeconômica do Biodigestor da criação de gado (apresentam o mesmo resultado pelos dois critérios), da Tabela 18.

Termoeconomia do Biodigestor do gado Operação 365 dias no ano $P_{s}=(365 * 24 * 3600)=31536000$ segundos $\mathrm{I}=$ Custo do Biodigestor $=45000 \mathrm{R} \$$ $\mathrm{I}_{0 \& \mathrm{M}}=$ Custo da O\&M $=11050,00 \mathrm{R} \$$ $\mathrm{C}_{\text {dejeto }}=$ Custo da dejeto bovino $=0 \mathrm{R} \$ / \mathrm{kg}$ $\mathrm{m}_{\text {dejeto }}=$ Massa de dejeto $=1,25 \cdot 10^{7} \mathrm{~kg}$ Conversão $=0,27 \mathrm{~m}^{3}$ de biogás $/ \mathrm{kg}$ de dejeto saída $=3,39 \cdot 10^{6} \mathrm{~m}^{3}$ de biogás

$$
\dot{I}+\dot{I}_{0 \& M}+\dot{\mathrm{m}}_{\text {dejeto }} \cdot C_{\text {dejeto }}=\dot{\mathrm{B}}_{\text {biogás }} \cdot C_{\text {biogás }}
$$

$$
\begin{aligned}
& \dot{i}=\frac{45000 R \$ \times 0,1597615}{31536000 \text { segundos }}=2,28 \cdot 10^{-4} \frac{R \$}{\mathrm{~s}} \\
& \dot{I}_{0 \& M}=\frac{11050,00 R \$}{31536000 \text { segundos }}=3,50 \cdot 10^{-4} \frac{R \$}{\mathrm{~s}}
\end{aligned}
$$$$
\dot{B}_{\text {biogás }}=\frac{3,39.10^{6} \mathrm{~m}^{3} \times 14873 \frac{\mathrm{kJ}}{\mathrm{m}^{3}}}{31536000 \text { segundos }}=1597,92 \frac{\mathrm{kJ}}{\mathrm{s}}
$$$$
2,28 \cdot 10^{-4} \frac{R \$}{s}+3,50 \cdot 10^{-4} \frac{R \$}{s}+0,0 \frac{R \$}{s}=1597,92 \frac{k J}{s} C_{\text {biogás }}
$$$$
C_{\text {biogás }}=\frac{2,28 \cdot 10^{-4} \frac{R \$}{\mathrm{~s}}+3,50 \cdot 10^{-4} \frac{\mathrm{R} \$}{\mathrm{~s}}+0,0 \frac{\mathrm{R} \$}{\mathrm{~s}}}{1597,92 \frac{\mathrm{kJ}}{\mathrm{s}}}
$$$$
C_{\text {biogás }}=3,62 \cdot 10^{-7} \frac{\mathrm{R} \$}{\mathrm{~kJ}}
$$$$
C_{\text {biogás }}=3,62 \cdot 10^{-7} \frac{\mathrm{R} \$}{\mathrm{~kJ}} \times 14873 \frac{\mathrm{kJ}}{\mathrm{m}^{3}}=5,38 \cdot 10^{-3} \frac{\mathrm{R} \$}{\mathrm{~m}^{3}}
$$ 
Tabela B-17. Cálculos da análise termoeconômica do Motor-gerador da criação de gado (apresentam o mesmo resultado pelos dois critérios), da Tabela 19.

Custo do sistema $($ motor $)=329.700,00 \mathrm{r} \$$

$\dot{i}=$ fluxo de $\mathrm{R} \$ /$ s ou seja (custo do sistema).FRC/P $\mathrm{P}_{\mathrm{s}}$

$I_{0 \& M}=R \$ 15.550,00$

$i_{0 \& M}=$ fluxo de $\mathrm{R} \$ / \mathrm{s}$ ou seja (custo de $\left.\mathrm{O} \& \mathrm{M}\right) / \mathrm{P}_{\mathrm{s}}$

$F R C=$ fator de retorno do capital

$m_{\text {biogás }}=3,39 \cdot 10^{7} \mathrm{~m}^{3}$

$\mathrm{C}_{\text {biogás }}=5,38 \cdot 10^{-3} \mathrm{R} \$ / \mathrm{m}^{3}$

$\dot{\mathrm{W}}_{\text {ele }}=\left(\right.$ consumo $\left._{\text {biogás }} * \mathrm{~m}_{\text {biogás }}\right) / \mathrm{P}_{\mathrm{s}}$

$\mathrm{P}_{\mathrm{s}}=$ segundos de atividade no ano

$r=15 \%$

$\mathrm{t}=20$ anos

$F R C=\frac{r}{\left(1-(1+r)^{-t}\right)}$

$\mathrm{FRC}=\frac{0,15}{\left(1-(1+0,15)^{-20}\right)}=0,1597615$

$P_{s}=24 \frac{\text { horas }}{\text { dia }} \times 365$ dias $\times 3600 \frac{\text { segundos }}{\text { hora }}=31.536 .000$ segundos

$i=\frac{R \$ 329700,00 \times 0,1597615}{31536000 \text { segundos }}=1,05.10^{-2} \frac{R \$}{S}$

$i_{0 \& M}=\frac{R \$ 15550,00}{31536000 \text { segundos }}=4,93 \cdot 10^{-4} \frac{R \$}{S}$ 


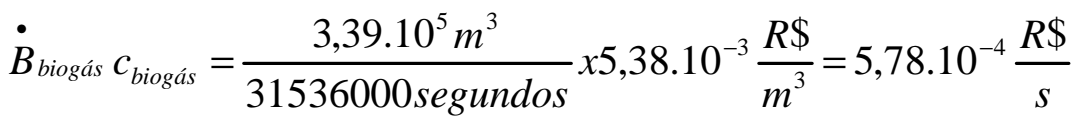

$\dot{\mathrm{W}}_{\text {ele }}=\frac{\left.\mathrm{m}^{3} \text { (biogás }\right) \times \mathrm{kW}(\text { potência })}{\frac{\mathrm{m}^{3}}{\mathrm{~h}}(\text { consumo }) \times \text { segundos }\left(\mathrm{P}_{\mathrm{s}}\right)} 3600 \frac{\mathrm{kJ}}{\mathrm{kWh}}=\frac{\mathrm{kJ}}{\mathrm{s}}($ fluxo de energia $)$

$\dot{\mathrm{W}}_{\text {ele }}=\frac{3,39.10^{6} \mathrm{~m}^{3} \mathrm{x} 1475 \mathrm{~kW}}{423,5 \frac{\mathrm{m}^{3}}{\mathrm{~h}}} \cdot \frac{3600}{31536000 \text { segundos }} \frac{\mathrm{kJ}}{\mathrm{kWh}}=1347 \frac{\mathrm{kWh}}{\mathrm{s}}$

$=$

Logo,

$\dot{I}+\dot{I}_{0 \& M}+\dot{B}_{\text {biogás }} \cdot C_{\text {biogás }}=\dot{W}_{\text {ele }} \cdot C_{\text {eleB }}$

$1,05.10^{-2} \frac{\mathrm{R} \$}{\mathrm{~s}}+4.93 \cdot 10^{-4} \frac{\mathrm{R} \$}{\mathrm{~s}}+5,78 \cdot 10^{-4} \frac{\mathrm{R} \$}{\mathrm{~s}}=\mathrm{C}_{\text {eleB }}\left(1347 \frac{\mathrm{kJ}}{\mathrm{s}}\right)$

$\mathrm{C}_{\text {eleB }}=\frac{1,05 \cdot 10^{-2} \frac{\mathrm{R} \$}{\mathrm{~s}}+4.93 \cdot 10^{-4} \frac{\mathrm{R} \$}{\mathrm{~s}}+5,78 \cdot 10^{-4} \frac{\mathrm{R} \$}{\mathrm{~s}}}{1347 \frac{\mathrm{kJ}}{\mathrm{s}}}=8,56 \cdot 10^{-6} \frac{\mathrm{R} \$}{\mathrm{~kJ}}$

$\mathrm{C}_{\text {eleB }}=8,56.10^{-6} \frac{\mathrm{R} \$}{\mathrm{~kJ}} \times 3600 \frac{\mathrm{kJ}}{\mathrm{kWh}}=3,08.10^{-2} \frac{\mathrm{R} \$}{\mathrm{kWh}} \times 1000 \frac{\mathrm{kWh}}{\mathrm{MWh}}=30,80 \frac{\mathrm{R} \$}{\mathrm{MWh}}$ 
Tabela B-18. Cálculos do custo médio ponderado da eletricidade gerada, da Tabela 20.

Custo médio da energia gerada pelo critério da extração

$\mathrm{C}_{\text {eleT }}=\frac{4,84.10^{-1} \frac{\mathrm{R} \$}{\mathrm{kWh}} \times 3,15.10^{6} \mathrm{kWh}+6,91.10^{-1} \frac{\mathrm{R} \$}{\mathrm{kWh}} \times 1,05.10^{6} \mathrm{kWh}+4,95.10^{-2} \frac{\mathrm{R} \$}{\mathrm{kWh}} \times 2,97.10^{6} \mathrm{kWh}+3,08.10^{-2} \frac{\mathrm{R} \$}{\mathrm{kWh}} \times 1,18.10^{7} \mathrm{kWh}}{3,15.10^{6} \mathrm{kWh}+1,05.10^{6} \mathrm{kWh}+2,97.10^{6} \mathrm{kWh}+1,18.10^{7} \mathrm{kWh}}$

$\mathrm{C}_{\text {elet }}=1,46.10^{-2} \frac{\mathrm{R} \$}{\mathrm{kWh}}=146 \frac{\mathrm{R} \$}{\mathrm{MWh}}$

Custo médio da energia gerada pelo critério da igualdade

$\mathrm{C}_{\text {elet }}=\frac{3,97.10^{-2} \frac{\mathrm{R} \$}{\mathrm{kWh}} \times 3,15.10^{6} \mathrm{kWh}+2,50.10^{-1} \frac{\mathrm{R} \$}{\mathrm{kWh}} \times 1,05.10^{6} \mathrm{kWh}+2,65.10^{-2} \frac{\mathrm{R} \$}{\mathrm{kWh}} \times 2,97.10^{6} \mathrm{kWh}+3,08.10^{-2} \frac{\mathrm{R} \$}{\mathrm{kWh}} \times 1,18.10^{7} \mathrm{kWh}}{3,15 \cdot 10^{6} \mathrm{kWh}+1,05.10^{6} \mathrm{kWh}+2,97.10^{6} \mathrm{kWh}+1,18.10^{7} \mathrm{kWh}}$
$\mathrm{C}_{\text {elet }}=4,37.10^{-2} \frac{\mathrm{R} \$}{\mathrm{kWh}}=43,70 \frac{\mathrm{R} \$}{\mathrm{MWh}}$ 
Tabela B-19. Cálculos da análise termoeconômica do Biodigestor da criação de suínos (apresentam o mesmo resultado pelos dois critérios), da Tabela 21.

Operação 365 dias no ano

$P_{s}=(365 * 24 * 3600)=31536000$ segundos

$\mathrm{I}=$ Custo do Biodigestor $=0 \mathrm{R} \$$

$\mathrm{I}_{0 \& \mathrm{M}}=$ Custo da O\&M = 331500,00 R $\$$

$\mathrm{C}_{\text {dejeto }}$ Custo do dejeto suino $=0 \mathrm{R} \$ / \mathrm{kg}$

$\mathrm{m}_{\text {dejeto }}$ Massa de dejeto $=4.43 .10^{6} \mathrm{~kg}$ bovinos e

Conversão $=0,56 \mathrm{~m}^{3}$ de biogás $/ \mathrm{kg}$ de dejeto

saída $=2,48 \cdot 10^{6} \mathrm{~m}^{3}$ de biogás

$\dot{I}+\dot{I}_{0 \& M}+\dot{m}_{\text {dejeto }} \cdot C_{\text {dejeto }}=\dot{B}_{\text {biogás }} \cdot C_{\text {biogás }}$

$i=\frac{0 R \$ x 0,1597615}{31536000 \text { segundos }}=0 \frac{R \$}{s}$

$\dot{I}_{0 \& M}=\frac{331500,00 R \$}{31536000 \text { segundos }}=1,0510^{-2} \frac{R \$}{\mathrm{~s}}$

$\dot{\mathrm{B}}_{\text {biogás }}=\frac{2,48.10^{6} \mathrm{~m}^{3} \times 14873 \frac{\mathrm{kJ}}{\mathrm{m}^{3}}}{31536000 \text { segundos }}=1171,25 \frac{\mathrm{kJ}}{\mathrm{s}}$

$0 \frac{\mathrm{R} \$}{\mathrm{~s}}+1,05.10^{-2} \frac{\mathrm{R} \$}{\mathrm{~s}}+0 \frac{\mathrm{R} \$}{\mathrm{~s}}=1171,25 \frac{\mathrm{kJ}}{\mathrm{s}} \mathrm{C}_{\text {biogás }}$

$C_{\text {biogás }}=\frac{0 \frac{R \$}{\mathrm{~s}}+1,05.10^{-2} \frac{\mathrm{R} \$}{\mathrm{~s}}+0 \frac{\mathrm{R} \$}{\mathrm{~s}}}{1171,25 \frac{\mathrm{kJ}}{\mathrm{s}}}$

$\mathrm{C}_{\text {biogás }}=8,97 \cdot 10^{-6} \frac{\mathrm{R} \$}{\mathrm{~kJ}}$

$C_{\text {biogás }}=8,97 \cdot 10^{-7} \frac{\mathrm{R} \$}{\mathrm{~kJ}} \times 14873 \frac{\mathrm{kJ}}{\mathrm{m}^{3}}=1,33 \cdot 10^{-1} \frac{\mathrm{R} \$}{\mathrm{~m}^{3}}$ 
Tabela B-20. Cálculos da análise termoeconômica do Motorgerado para o biogás dos dejetos de gado e suíno (apresentam o mesmo resultado pelos dois critérios), da Tabela 23

Custo do sistema $($ motor $)=329.700,00 \mathrm{R} \$$

$\dot{i}$ = fluxo de R $\$ /$ s ou seja (custo do sistema).FRC/P $\mathrm{P}_{\mathrm{s}}$

$\mathrm{I}_{0 \& M}=\mathrm{R} \$ 15.550,00$

$\dot{I}_{0 \& M}=$ fluxo de $\mathrm{R} \$ / \mathrm{s}$ ou seja (custo de $\left.\mathrm{O} \& \mathrm{M}\right) / \mathrm{P}_{\mathrm{s}}$

$\mathrm{FRC}=$ fator de retorno do capital

$\mathrm{C}_{\text {biogás }}=5,96.10^{-2} \mathrm{R} \$ / \mathrm{m}^{3}$

$\dot{\mathrm{W}}_{\text {ele }}=\left(\right.$ consumo $\left._{\text {biogás }} * \mathrm{~m}_{\text {biogás }}\right) / \mathrm{P}_{\mathrm{s}}$

$\mathrm{P}_{\mathrm{s}}=$ segundos de atividade no ano

$r=15 \%$

$\mathrm{t}=20$ anos

$F R C=\frac{r}{\left(1-(1+r)^{-t}\right)}$

$\mathrm{FRC}=\frac{0,15}{\left(1-(1+0,15)^{-20}\right)}=0,1597615$

$P_{s}=24 \frac{\text { horas }}{\text { dia }} \times 365$ dias $\times 3600 \frac{\text { segundos }}{\text { hora }}=31.536 .000$ segundos

$\dot{i}=\frac{\mathrm{R} \$ 329700,00 \times 0,1597615}{31536000 \text { segundos }}=1,05.10^{-2} \frac{\mathrm{R} \$}{\mathrm{~S}}$

$\dot{i}_{0 \& M}=\frac{R \$ 15550,00}{31536000 \text { segundos }}=4,93 \cdot 10^{-4} \frac{R \$}{\mathrm{~s}}$

$\dot{B}_{\text {biogás }} C_{\text {biogás }}=\frac{5,87 \cdot 10^{6} \mathrm{~m}^{3}}{31536000 \text { segundos }} \times 5,96 \cdot 10^{-2} \frac{\mathrm{R} \$}{\mathrm{~m}^{3}}=1,11.10^{-2} \frac{\mathrm{R} \$}{\mathrm{~s}}$

$\dot{W}_{\text {ele }}=\frac{\left.\mathrm{m}^{3} \text { (biogás }\right) \times \mathrm{kW}(\text { potência })}{\frac{\mathrm{m}^{3}}{\mathrm{~h}}(\text { consumo }) \times \operatorname{segundos}\left(\mathrm{P}_{\mathrm{s}}\right)} 3600 \frac{\mathrm{kJ}}{\mathrm{kWh}}=\frac{\mathrm{kJ}}{\mathrm{s}}($ fluxo de energia $)$

$\dot{\mathrm{W}}_{\text {ele }}=\frac{5,87 \cdot 10^{6} \mathrm{~m}^{3} \times 1475 \mathrm{~kW}}{423,5 \frac{\mathrm{m}^{3}}{\mathrm{~h}}} \cdot \frac{3600}{31536000 \text { segundos }} \frac{\mathrm{kJ}}{\mathrm{kWh}}=2334,48 \frac{\mathrm{kJ}}{\mathrm{s}}$ 
Logo,

$$
\begin{aligned}
& \dot{I}+\dot{I}_{0 \& M}+\dot{B}_{\text {biogás } . C_{\text {biogás }}=\dot{W}_{\text {ele }} C_{\text {eleB }}} \\
& 1,05 \cdot 10^{-2} \frac{\mathrm{R} \$}{\mathrm{~s}}+4,93 \cdot 10^{-4} \frac{\mathrm{R} \$}{\mathrm{~s}}+1,11 \cdot 10^{-2} \frac{\mathrm{R} \$}{\mathrm{~s}}=\mathrm{C}_{\text {eleB }}\left(2334,48 \frac{\mathrm{kJ}}{\mathrm{s}}\right) \\
& \mathrm{C}_{\text {eleB }}=\frac{1,05 \cdot 10^{-2} \frac{\mathrm{R} \$}{\mathrm{~s}}+4,93 \cdot 10^{-4} \frac{\mathrm{R} \$}{\mathrm{~s}}+1,11 \cdot 10^{-2} \frac{\mathrm{R} \$}{\mathrm{~s}}}{2334,48 \frac{\mathrm{kJ}}{\mathrm{s}}}=9,44 \cdot 10^{-6} \frac{\mathrm{R} \$}{\mathrm{~kJ}} \\
& C_{\text {eleB }}=9,44 \cdot 10^{-6} \frac{\mathrm{R} \$}{\mathrm{~kJ}} \times 3600 \frac{\mathrm{kJ}}{\mathrm{kWh}}=3,40 \cdot 10^{-2} \frac{\mathrm{R} \$}{\mathrm{kWh}} \times 1000 \frac{\mathrm{MWh}}{\mathrm{kWh}}=34,00 \frac{\mathrm{R} \$}{\mathrm{MWh}}
\end{aligned}
$$


Tabela B-21. Cálculos do custo médio ponderado da eletricidade gerada, da Tabela 24.

Custo médio da energia gerada pelo critério da extração

$c_{\text {eleT }}=\frac{4,84.10^{-1} \frac{\mathrm{R} \$}{\mathrm{kWh}} \times 3,15.10^{6} \mathrm{kWh}+6,91 \cdot 10^{-1} \frac{\mathrm{R} \$}{\mathrm{kWh}} \times 1,05.10^{6} \mathrm{kWh}+4,95.10^{-2} \frac{\mathrm{R} \$}{\mathrm{kWh}} \times 2,97.10^{6} \mathrm{kWh}+3,40.10^{-2} \frac{\mathrm{R} \$}{\mathrm{kWh}} \times 2,05.10^{7} \mathrm{kWh}}{3,15.10^{6} \mathrm{kWh}+1,05.10^{6} \mathrm{kWh}+2,97.10^{6} \mathrm{kWh}+2,05.10^{7} \mathrm{kWh}}$
$c_{\text {eleT }}=1,12.10^{-2} \frac{\mathrm{R} \$}{\mathrm{kWh}}=112 \frac{\mathrm{R} \$}{\mathrm{MWh}}$

Custo médio da energia gerada pelo critério da igualdade

$$
\begin{aligned}
& C_{\text {elet }}=\frac{3,97.10^{-2} \frac{\mathrm{R} \$}{\mathrm{kWh}} \times 3,15.10^{6} \mathrm{kWh}+2,50.10^{-1} \frac{\mathrm{R} \$}{\mathrm{kWh}} \times 1,05.10^{6} \mathrm{kWh}+2,65.10^{-2} \frac{\mathrm{R} \$}{\mathrm{kWh}} \times 2,97.10^{6} \mathrm{kWh}+3,40.10^{-2} \frac{\mathrm{R} \$}{\mathrm{kWh}} \times 2,05.10^{7} \mathrm{kWh}}{3,15.10^{6} \mathrm{kWh}+1,05.10^{6} \mathrm{kWh}+2,97.10^{6} \mathrm{kWh}+2,05.10^{7} \mathrm{kWh}} \\
& \mathrm{C}_{\text {elet }}=4,20.10^{-2} \frac{\mathrm{R} \$}{\mathrm{kWh}}=42,00 \frac{\mathrm{R} \$}{\mathrm{MWh}}
\end{aligned}
$$


Tabela B-22 - Cálculos das Exergias utilizadas neste trabalho

$$
\begin{aligned}
& E x=\left(h-h_{0}\right)-(T+273) x\left(S-S_{0}\right) \\
& \mathrm{Ex}_{\text {condensado }}=(2308,80-104,87)-(25+273) \times(7,6121-0,3673)=44,98 \frac{\mathrm{kJ}}{\mathrm{kg}} \\
& E_{\text {vapor de processo }}=(2713,5-104,87)-(25+273) \times(7,0774-0,3673)=609,02 \frac{\mathrm{kJ}}{\mathrm{kg}} \\
& E x_{V A(21)}=(3008,80-104,87)-(25+273) \times(6,6437-0,3673)=1033,56 \frac{\mathrm{kJ}}{\mathrm{kg}} \\
& E X_{V A(67)}=(3410,3-104,87)-(25+273) \times(6,7974-0,3673)=1389,26 \frac{\mathrm{kJ}}{\mathrm{kg}} \\
& \mathrm{Ex}_{\text {vinhaça }}=\text { Exergia química }+ \text { Exergia física } \\
& \text { Ex }_{\text {vinhaça }}=50 \frac{\mathrm{kJ}}{\mathrm{kg}}+(419,02-104,87)-(25+273) \cdot(1,3068-0,3673)=84,18 \frac{\mathrm{kJ}}{\mathrm{kg}}
\end{aligned}
$$

Os valores de Entalpia e Entropia foram extraídos de Sonntag et al, 2003. 
ANEXO C

C-1. Planilha de cálculo para biossistema da usina autônoma da Tabela 25

\begin{tabular}{|c|c|c|c|c|c|c|}
\hline \multicolumn{3}{|c|}{ TABELA PARA CÁLCULO DA TIR E VPL } & & \multicolumn{3}{|c|}{ USINA AUTÔNOMA } \\
\hline $\mathrm{A}$ & \multicolumn{2}{|r|}{$B$} & & \multicolumn{2}{|c|}{$\begin{array}{l}\text { Recepção e estocagem } \\
\text { Prep. e Alim. da cana }\end{array}$} & 647467 \\
\hline Fluxo Livre & \multicolumn{2}{|r|}{ Descrição } & & \multicolumn{2}{|c|}{ Moagem } & 1904525 \\
\hline $15 \%$ & \multicolumn{2}{|c|}{ A taxa de desconto anual } & & \multicolumn{2}{|c|}{ Tratamento do caldo } & 104572 \\
\hline-11.956 .503 & \multicolumn{2}{|c|}{$\mathrm{O}$ custo inicial } & & \multicolumn{2}{|l|}{ Fermentação } & 693543 \\
\hline 2.949 .295 & \multicolumn{2}{|c|}{ O retorno do 1 ano } & & \multicolumn{2}{|l|}{ Destilação } & 1576408 \\
\hline 2.949 .295 & \multicolumn{2}{|c|}{ O retorno do 2 ano } & & \multicolumn{2}{|c|}{ Armaz. da produção } & 317827 \\
\hline 2.949 .295 & \multicolumn{2}{|c|}{ O retorno do 3 ano } & & \multicolumn{2}{|c|}{ Água, trat. e usina } & 250510 \\
\hline 2.949 .295 & \multicolumn{2}{|c|}{ O retorno do 4 ano } & & \multicolumn{2}{|c|}{ Resfriamento da água } & 80010 \\
\hline 2.949 .295 & \multicolumn{2}{|c|}{ O retorno do 5 ano } & & & 932510 \\
\hline 2.949 .295 & \multicolumn{2}{|c|}{ O retorno do 6 ano } & & \multicolumn{2}{|c|}{ Geraçao de energia } & 450510 \\
\hline 2.949 .295 & \multicolumn{2}{|c|}{ O retorno do 7 ano } & & & 560000 \\
\hline 2.949 .295 & \multicolumn{2}{|c|}{ O retorno do 8 ano } & & \multicolumn{2}{|c|}{ Laboratório Industrial } & 94500 \\
\hline 2.949 .295 & O retorno & do 9 ano & & Laboratório ATR & & 375000 \\
\hline 2.949 .295 & $\mathrm{O}$ retorno & do 10 ano & & Construção civil & & 1146961 \\
\hline 2.949 .295 & O retorno & do 11 ano & & Informatização & & 99698 \\
\hline 2.949 .295 & O retorno & do 12 ano & & Complementos di & ersos & 1008754 \\
\hline 2.949 .295 & O retorno & do 13 ano & & Biodigestor UASE & & 80000 \\
\hline 2.949 .295 & $\mathrm{O}$ retorno & do 14 ano & & Motor-gerador & & 329700 \\
\hline 2.949 .295 & O retorno & do 15 ano & & Geração de vapor & & 450510 \\
\hline 2.949 .295 & $\mathrm{O}$ retorno & do 16 ano & & TOTAL & & 11956503 \\
\hline 2.949 .295 & O retorno & do 17 ano & & & & \\
\hline 2.949 .295 & O retorno & do 18 ano & & & & \\
\hline 2.949 .295 & O retorno & do 19 ano & & & & \\
\hline 2.949 .295 & O retorno & do 20 ano & & & & \\
\hline VPL & & $R \$ 5.655 .746,86$ & & & & \\
\hline TIR & & $24,4 \%$ & & & & \\
\hline & & FATUR & MENTO & & & \\
\hline ITEM & & QUANTIDADE & UNIDADE & PERÍODO & VALOR & TOTAL \\
\hline $\begin{array}{l}\text { VENDA DIÁRIA D } \\
\text { ÁLCOOL }\end{array}$ & & 40000 & L/dia & 210 & 0,6821 & 5729640 \\
\hline $\begin{array}{l}\text { VENDA ANUAL D } \\
\text { ENERGIA }\end{array}$ & & $7,17 \mathrm{E}+03$ & MWh/ano & 1 & 138,85 & 995554,5 \\
\hline VENDA TOTAL & & & & & & 6725194,5 \\
\hline & & CUSTC & ANUAL & & & \\
\hline ITEM & & QUANTIDADE & UNIDADE & PERÍODO & VALOR & TOTAL \\
\hline MANUTENÇÃO & & 1 & ANUAL & 1 & 109000 & 109000 \\
\hline CUSTO DE FUNCIC & NÁRIOS & 11 & FUN/MÊS & 13 & 3500 & 500500 \\
\hline CUSTO DE FUNCIC & NÁRIOS & 68 & FUN/MÊS & 13 & 850 & 751400 \\
\hline CUSTO DA CANA & & $1,05 \mathrm{E}+05$ & $\mathrm{TC}$ & 1 & 23 & 2415000 \\
\hline TOTAL & & & & & & 3775900,00 \\
\hline
\end{tabular}


C-2. Planilha de cálculo para biossistema da usina com dejeto de gado da Tabela 25

\begin{tabular}{|c|c|c|c|c|c|}
\hline \multicolumn{2}{|c|}{$\begin{array}{c}\text { TABELA PARA CÁLCULO DA TIR E } \\
\text { VPL }\end{array}$} & & \multicolumn{3}{|c|}{ USINA + DEJETO DE GADO } \\
\hline A & $\mathrm{B}$ & & \multicolumn{2}{|c|}{$\begin{array}{l}\text { Recepção e estocagem } \\
\text { Prep. e Alim. da cana }\end{array}$} & 647467 \\
\hline Fluxo Livre & Descrição & & \multicolumn{2}{|c|}{ Moagem } & 1904525 \\
\hline $15 \%$ & $\begin{array}{l}\text { A taxa de desconto } \\
\text { anual }\end{array}$ & & \multicolumn{2}{|c|}{ Tratamento do caldo } & 104572 \\
\hline-12.331 .203 & O custo inicial & & \multicolumn{2}{|c|}{ Fermentação } & 693543 \\
\hline 4.565 .290 & O retorno do 1 ano & & \multicolumn{2}{|l|}{ Destilação } & 1576408 \\
\hline 4.565 .290 & O retorno do 2 ano & & & 317827 \\
\hline 4.565 .290 & O retorno do 3 ano & & \multicolumn{2}{|c|}{ Água, trat. e usina } & 250510 \\
\hline 4.565 .290 & O retorno do 4 ano & & & 80010 \\
\hline 4.565 .290 & O retorno do 5 ano & & \multicolumn{2}{|c|}{ Geração de vapor A } & 932510 \\
\hline 4.565 .290 & O retorno do 6 ano & & \multicolumn{2}{|c|}{ Geraçao de energia } & 450510 \\
\hline 4.565 .290 & O retorno do 7 ano & & \multicolumn{2}{|c|}{ Parte elétrica } & 560000 \\
\hline 4.565 .290 & O retorno do 8 ano & & \multicolumn{2}{|c|}{ Laboratório Industrial } & 94500 \\
\hline 4.565 .290 & O retorno do 9 ano & & \multicolumn{2}{|c|}{ Laboratório ATR } & 375000 \\
\hline 4.565 .290 & O retorno do 10 ano & & \multicolumn{2}{|l|}{ Construção civil } & 1146961 \\
\hline 4.565 .290 & O retorno do 11 ano & & \multirow{2}{*}{\multicolumn{2}{|c|}{$\begin{array}{l}\text { Informatização } \\
\text { Complementos diversos }\end{array}$}} & 99698 \\
\hline 4.565 .290 & O retorno do 12 ano & & & & 1008754 \\
\hline 4.565 .290 & O retorno do 13 ano & & & 80000 \\
\hline 4.565 .290 & O retorno do 14 ano & & \multicolumn{2}{|c|}{ Motor-gerador } & 329700 \\
\hline 4.565 .290 & O retorno do 15 ano & & \multirow{2}{*}{\multicolumn{2}{|c|}{$\begin{array}{l}\text { Geração de vapor B } \\
\text { blodigestor canadense }\end{array}$}} & 450510 \\
\hline 4.565 .290 & O retorno do 16 ano & & & dense & 45000 \\
\hline 4.565 .290 & O retorno do 17 ano & & \multicolumn{2}{|c|}{ Motor-gerador } & 329700 \\
\hline 4.565 .290 & O retorno do 18 ano & & \multirow{3}{*}{\multicolumn{2}{|c|}{ TOTAL }} & 12331203 \\
\hline 4.565 .290 & O retorno do 19 ano & & & & \\
\hline 4.565 .290 & O retorno do 20 ano & & & & \\
\hline VPL & \multicolumn{5}{|l|}{ R \$14.125.617,72 } \\
\hline TIR & \multicolumn{2}{|l|}{$36,95 \%$} & & & \\
\hline \multicolumn{6}{|c|}{ FATURAMENTO } \\
\hline ITEM & QUANTIDADE & UNIDADE & PERÍODO & VALOR & TOTAL \\
\hline $\begin{array}{l}\text { VENDA ANUAL DE } \\
\text { ALCOOL }\end{array}$ & 40000 & L/dia & 210 & 0,6821 & 5729640 \\
\hline $\begin{array}{l}\text { VENDA ANUAL DE } \\
\text { ENERGIA }\end{array}$ & $1,90 \mathrm{E}+04$ & MWh/ano & 1 & 138,85 & 2638150 \\
\hline VENDA TOTAL & & & & & 8367790 \\
\hline \multicolumn{6}{|c|}{ CUSTO ANUAL } \\
\hline ITEM & QUANTIDADE & UNIDADE & PERÍODO & VALOR & TOTAL \\
\hline \multirow[t]{2}{*}{ MANUTENÇÃO } & 113500 & ANUAL & 1 & 1 & 113500 \\
\hline & 11 & FUN/MÊS & 13 & 3500 & 500500 \\
\hline $\begin{array}{l}\text { CUSTO DE } \\
\text { FUNCIONÁRIOS }\end{array}$ & 70 & FUN/MÊS & 13 & 850 & 773500 \\
\hline CUSTO DA CANA & $1,05 \mathrm{E}+05$ & $\mathrm{TC}$ & 1 & 23 & 2415000 \\
\hline TOTAL & & & & & 3802500 \\
\hline
\end{tabular}


C-3. Planilha de cálculo para biossistema da usina com dejetos de gado e suíno da Tabela 25

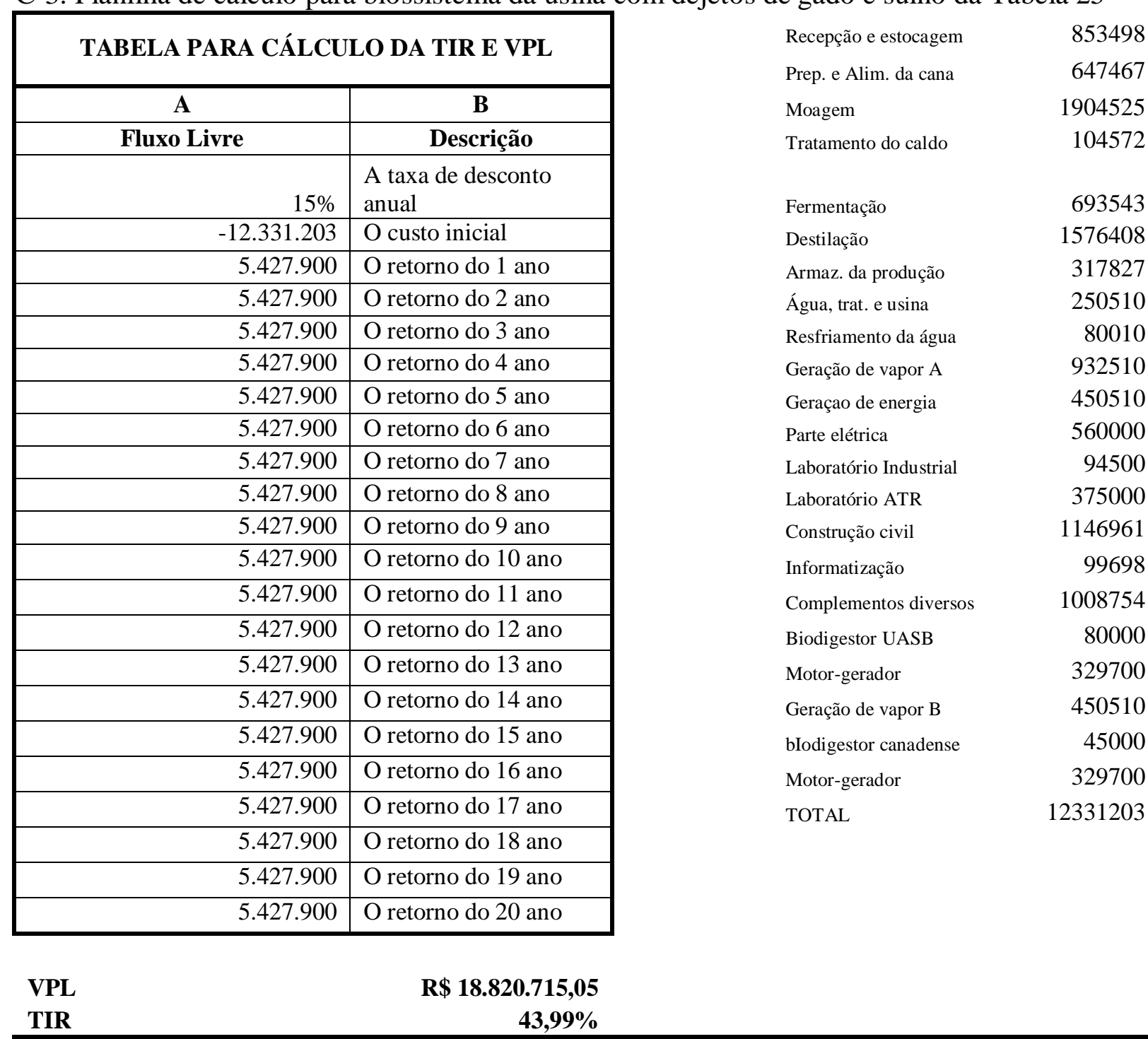

FATURAMENTO

\begin{tabular}{|c|c|c|c|c|c|}
\hline ITEM & QUANTIDADE & UNIDADE & PERÍODO & VALOR & TOTAL \\
\hline $\begin{array}{l}\text { VENDA ANUAL DE } \\
\text { ALCOOL }\end{array}$ & 40000 & L/dia & 210 & 0,6821 & 5729640 \\
\hline $\begin{array}{l}\text { VENDA ANUAL DE } \\
\text { ENERGIA }\end{array}$ & $2,76 \mathrm{E}+04$ & MWh/ano & 1 & 138,85 & 3832260 \\
\hline VENDA TOTAL & & & & & 9561900 \\
\hline \multicolumn{6}{|c|}{ CUSTO ANUAL } \\
\hline ITEM & QUANTIDADE & UNIDADE & PERÍODO & VALOR & TOTAL \\
\hline MANUTENÇÃO & 113500 & ANUAL & 1 & 1 & 113500 \\
\hline CUSTO DE FUNCIONÁRIOS & 11 & FUN/MÊS & 13 & 3500 & 500500 \\
\hline CUSTO DE FUNCIONÁRIOS & 100 & FUN/MÊS & 13 & 850 & 1105000 \\
\hline CANA DE AÇUCAR & $1,05 \mathrm{E}+05$ & $\mathrm{R} \$$ & 1 & 23 & 2415000 \\
\hline TOTAL & & & & & 4134000 \\
\hline
\end{tabular}


C-4. Planilha de cálculo para biossistema da usina autônoma da Tabela 26.

\begin{tabular}{|l|c|r|}
\hline \multicolumn{3}{|c|}{ CUSTO DE IM PLANTA ÇÃO } \\
\hline ITEM & QUANTIDADE & TOTAL \\
\hline COGEN A 30 kWh $\$)$ \\
\hline COGEN B 10 kWh & 1 & 1090520 \\
\hline BIODIGESTOR UASB & 1 & 450510 \\
\hline MOTOR-GERADOR & 1 & 80000 \\
\hline TOTAL & 1 & 329700 \\
\hline
\end{tabular}

\begin{tabular}{|l|c|c|r|}
\hline \multicolumn{4}{|c|}{ CUSTO ANUAL } \\
\hline ITEM & \% DA USINA & CUSTO (R\$) & TOTAL \\
\hline O\&M $\$)$ \\
\hline TOTAL & $16,32 \%$ & 1360000 & 221887,02 \\
\hline
\end{tabular}

\begin{tabular}{|l|r|r|r|c|}
\hline \multicolumn{5}{|c|}{ CUSTO ANUAL } \\
\hline ITEM & QUANTIDADE & TAXA & FRC & $\begin{array}{c}\text { VALOR } \\
\text { (R\$) }\end{array}$ \\
\hline CUSTO DE IMPLANTAÇÃO & 1950730 & $15 \%$ & 0,16 & 311651,49 \\
\hline O\&M & 221887,02 & & & 221887,02 \\
\hline CUSTO ANUAL TOTAL & & & & 533538,51 \\
\hline
\end{tabular}

CUST O DO M Wh gerado ( $\$ / M W h)$

\begin{tabular}{|l|r|l|r|}
\hline ITEM & QUANTIDADE & UNIDADE & \multicolumn{1}{c|}{ TOTAL } \\
\hline CUSTO ANUAL & 533538,51 & $\mathrm{R} \$$ & 533538,51 \\
\hline PRODUÇÃO ANUAL DE ELETRICIDADE & $7,17 \mathrm{E}+03$ & $\mathrm{MWh} / \mathrm{ano}$ & $7,17 \mathrm{E}+03$ \\
\hline CUSTO P/ MWh & & $\mathrm{R} \$ \mathrm{MWh}$ & 74,41 \\
\hline
\end{tabular}


C-5. Planilha de cálculo para biossistema da usina com dejetos de gado da Tabela 26.

\begin{tabular}{|l|c|r|}
\hline \multicolumn{3}{|c|}{ CUSTO DE IM PL ANTAÇÃO } \\
\hline ITEM & QUANTIDADE & VALOR \\
\hline COGEN A 30kWh & 1 & 1090520 \\
\hline COGEN B 10kWh & 1 & 450510 \\
\hline BIODIGESTOR UASB & 1 & 80000 \\
\hline MOTOR-GERADOR & 1 & 329700 \\
\hline BIODIGESTOR CANADENSE & 1 & 45000 \\
\hline MOTOR-GERADOR & 1 & 329700 \\
\hline TOTAL & & 2325430 \\
\hline
\end{tabular}

\begin{tabular}{|c|c|c|c|}
\hline \multicolumn{4}{|c|}{ CUSTO ANUAL } \\
\hline ITEM & $\%$ DA USINA & CUSTO (R\$) & $\begin{array}{c}\text { VALOR } \\
(\mathrm{R} \$)\end{array}$ \\
\hline O\&M & $16,32 \%$ & 1360000 & 221887,02 \\
\hline O\&M biodigestor gado & & 22100 & 22100 \\
\hline O\&M motor-gerador gado & & 15550 & 15550 \\
\hline TOTAL & & & 259537,02 \\
\hline
\end{tabular}

\begin{tabular}{|l|r|r|r|c|}
\hline \multicolumn{7}{|l|}{ CUSTO ANUAL } \\
\hline ITEM & QUANTIDADE & TAXA & FRC & $\begin{array}{c}\text { VALOR } \\
\text { (R \$) }\end{array}$ \\
\hline CUSTO DE IMPLANTAÇÃO & 2325430 & $15 \%$ & 0,16 & 371514,12 \\
\hline O\&M & 259537,02 & R\$ & & 259537,02 \\
\hline CUSTO ANUAL TOTAL & & & & 631051,13 \\
\hline
\end{tabular}

CUSTO DO M Wh gerado ( $\$$ \$/M Wh)

\begin{tabular}{|l|r|l|r|}
\hline ITEM & QUANTIDADE & UNIDADE & VALOR \\
\hline CUSTO ANUAL & 631051,13 & $\mathrm{R} \$$ & 631051,13 \\
\hline PRODUÇÃO ANUAL DE ELETRICIDADE & $1,90 \mathrm{E}+04$ & $\mathrm{MWh} / \mathrm{ano}$ & \\
\hline CUSTO P/ MWh & & $\mathrm{R} \$ / \mathrm{MWh}$ & 33,21 \\
\hline
\end{tabular}


C-6. Planilha de cálculo para biossistema da usina com dejetos de gado e suíno da Tabela 26.

\begin{tabular}{|l|c|r|}
\hline \multicolumn{3}{|c|}{ CUSTO DE IM PL ANTAÇÃO } \\
\hline ITEM & QUANTIDADE & VALOR \\
\hline COGEN A 30kWh & 1 & 1090520 \\
\hline COGEN B 10kWh & 1 & 450510 \\
\hline BIODIGESTOR UASB & 1 & 80000 \\
\hline MOTOR-GERADOR & 1 & 329700 \\
\hline BIODIGESTOR CANADENSE & 1 & 45000 \\
\hline MOTOR-GERADOR & 1 & 329700 \\
\hline TOTAL & & 2325430 \\
\hline
\end{tabular}

\begin{tabular}{|l|r|r|r|}
\hline \multicolumn{4}{|c|}{ CUSTO ANUAL } \\
\hline ITEM & \% DA USINA & \multicolumn{1}{c|}{ CUSTO (R\$) } & \multicolumn{1}{c|}{$\begin{array}{c}\text { VALOR } \\
\text { (R) }\end{array}$} \\
\hline O\&M & $16,32 \%$ & 1360000 & 221887,02 \\
\hline O\&M biodigestor dejeto do gado & & 22100 & 22100 \\
\hline O\&M motor-gerador biogás dej. Gado & & 15550 & 15550 \\
\hline O\&M biodigestor dejeto do suíno & & 221000 & 221000 \\
\hline TOTAL & & & 480537,02 \\
\hline
\end{tabular}

\section{CUSTO ANUAL}

\begin{tabular}{|l|r|r|r|l|}
\hline ITEM & QUANTIDADE & TAXA & FRC & VALOR \\
\hline CUSTO DE IMPLANTAÇÃO & 2325430 & $15 \%$ & 0,16 & 371514,12 \\
\hline O\&M & 480537,02 & R $\$$ & & 480537,02 \\
\hline CUSTO ANUAL TOTAL & & & & 852051,13 \\
\hline
\end{tabular}

CUSTO DO MWh gerado ( $\mathrm{R} \$ \mathrm{MWh}$ )

\begin{tabular}{|l|r|l|r|}
\hline ITEM & QUANTIDADE & UNIDADE & \multicolumn{1}{c|}{ TOTAL } \\
\hline CUSTO ANUAL & 852051,13 & R $\$$ & 852051,13 \\
\hline PRODUÇÃO ANUAL DE ELETRICIDADE & $2,76 E+04$ & MWh/ano & \\
\hline CUSTO P/ MWh & & & 30,87 \\
\hline
\end{tabular}

